Recoverability and Vulnerability of Desert Ecosystems

\title{
Monitoring Ecosystem Quality and Function in Arid Settings of the Mojave Desert
}

Scientific Investigation Report 2008-5064

U.S. Department of the Interior

U.S. Geological Survey 
This page intentionally left blank 


\section{Monitoring Ecosystem Quality and Function in Arid Settings of the Mojave Desert}

By Jayne Belnap, Robert H. Webb, Mark E. Miller, David M. Miller, Lesley A.

DeFalco, Philip A. Medica, Matthew L. Brooks, Todd C. Esque, and Dave Bedford

Recoverability and Vulnerability of Desert Ecosystems

Scientific Investigations Report 2008-5064 


\section{U.S. Department of the Interior DIRK KEMPTHORNE, Secretary}

\section{U.S. Geological Survey \\ Mark D. Myers, Director}

\section{U.S. Geological Survey, Reston, Virginia: 2008}

This report and any updates to it are available at:

http://pubs.usgs.gov/sir/2008/5064

For product and ordering information:

World Wide Web: http://www.usgs.gov/pubprod

Telephone: 1-888-ASK-USGS

For more information on the USGS--the Federal source for science about the Earth, its natural and living resources, natural hazards, and the environment:

World Wide Web: http://www.usgs.gov

Telephone: 1-888-ASK-USGS

Any use of trade, product, or firm names is for descriptive purposes only and does not imply endorsement by the U.S. Government.

Although this report is in the public domain, permission must be secured from the individual copyright owners to reproduce any copyrighted materials contained within this report.

All photographs were taken by U.S. Geological Survey employees, unless otherwise noted.

Suggested citation:

Belnap, Jayne, Webb, R.H., Miller, D.M., Miller, M.E., DeFalco, L.A., Medica, P.A., Brooks, M.L., Esque, T.C., and Bedford, D.R., 2008, Monitoring ecosystem quality and function in arid settings of the Mojave Desert: U.S. Geological Survey Scientific Investigations Report 2008-5064, 119 p.

Produced in the Western Region, Menlo Park, California

Manuscript approved for publication, April 28, 2008. 


\section{Contents}

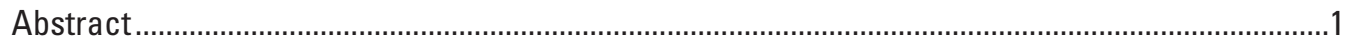

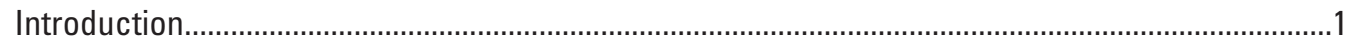

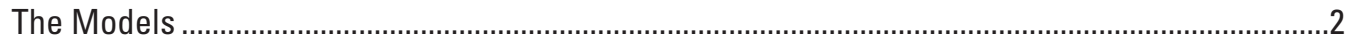

The Underpinnings of Ecosystem Sustainability: The Jenny-Chapin Model .............................2

The Mojave Desert General Conceptual Dryland Model..........................................................2

Connectivity of Components and Process................................................................................2

Regional Climate and Atmospheric Conditions .......................................................................2

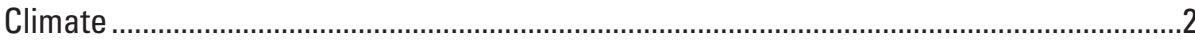

The Physical Template: Geology, Geomorphology, and Soils........................................................6

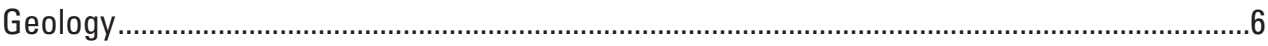

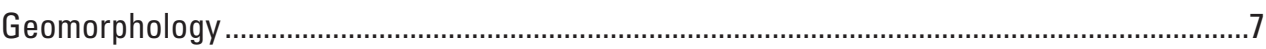

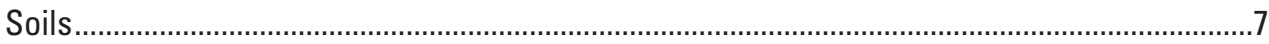

Eolian Processes and Dustfall .....................................................................................12

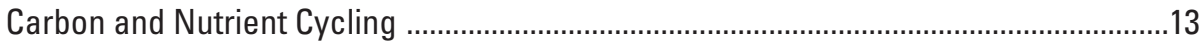

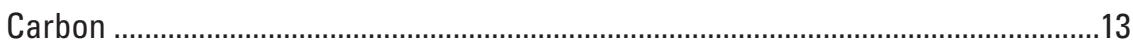

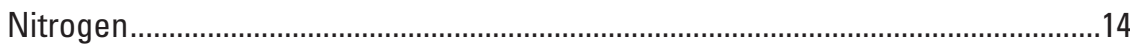

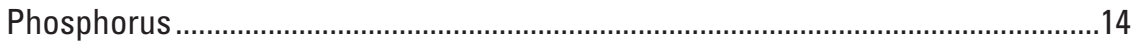

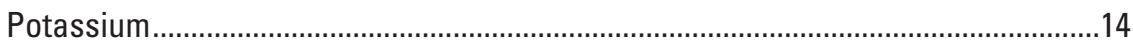

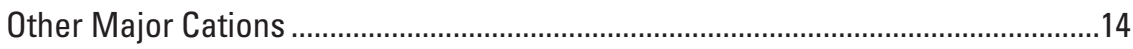

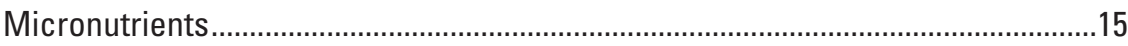

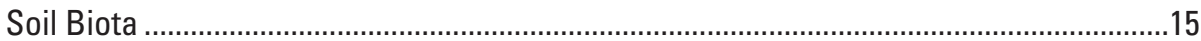

Soil Surface Biota: Biological Soil Crusts.............................................................. 15

Subsurface Soil Biota ..................................................................................... 16

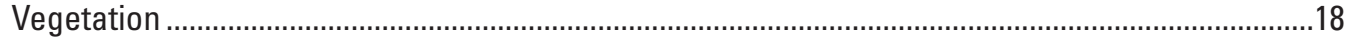

Annual Plants and Climatic Variability ...............................................................................19

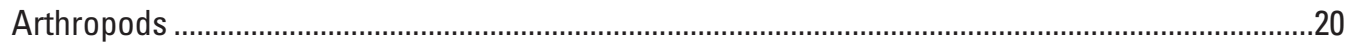

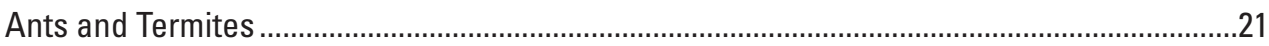

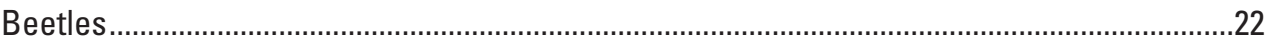

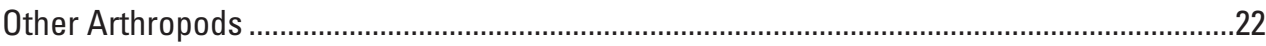

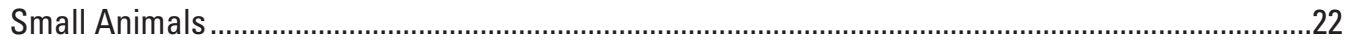

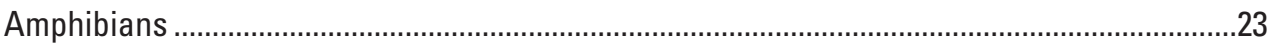

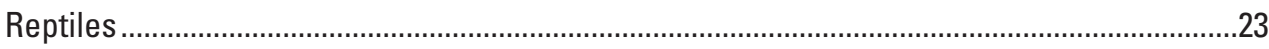

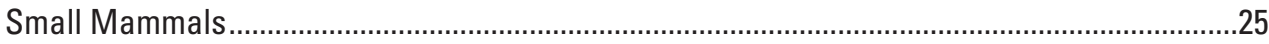

Natural and Anthropogenic Disturbances in the Mojave Desert...................................................26

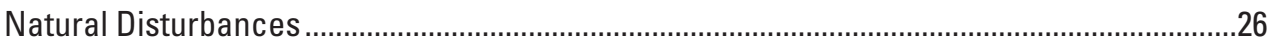

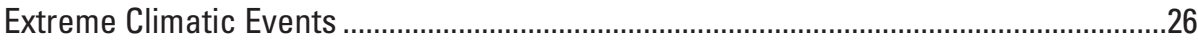

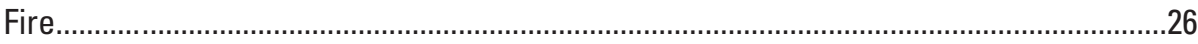

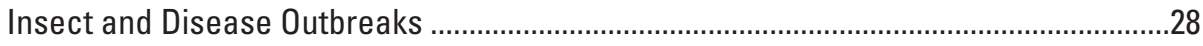

Herbivory and Trampling by Wildlife..........................................................................29

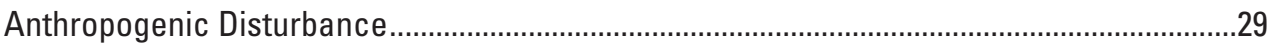

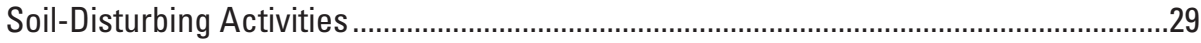

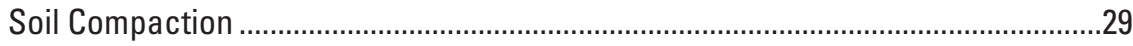


Soil Stability, Nutrient Availability, and Vegetation .....................................................31

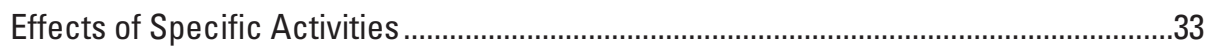

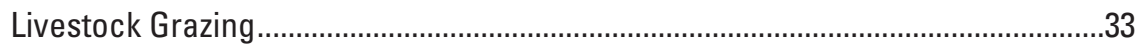

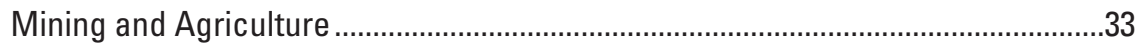

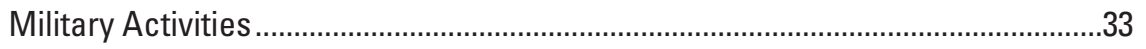

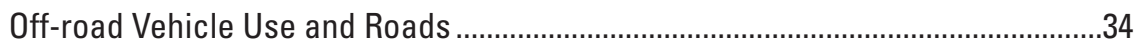

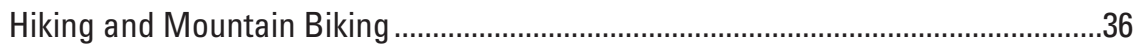

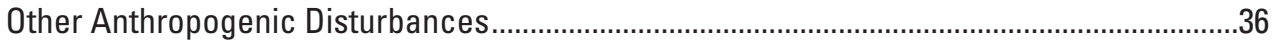

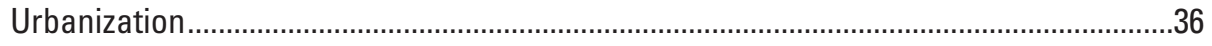

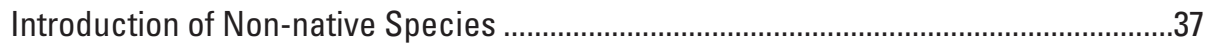

Atmospheric Changes................................................................................................

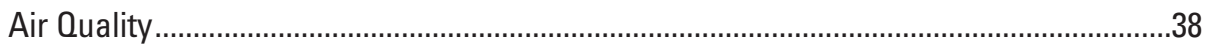

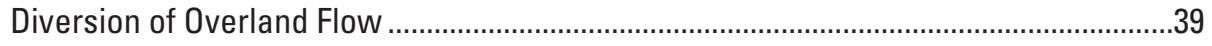

Philosophies and Strategies for Monitoring in the Mojave Desert................................................39

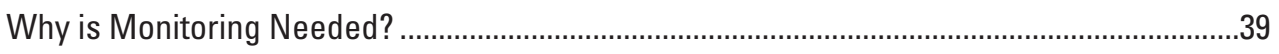

Monitoring Ecosystem Attributes and Processes ……........................................................39

"Vital Signs," or Indicator, Approach ..........................................................................

Measurement and Site Selection ................................................................................... 42

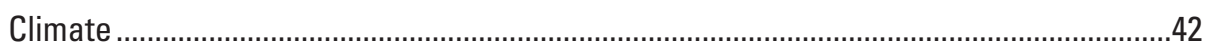

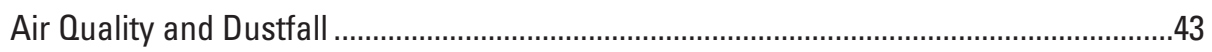

Soils

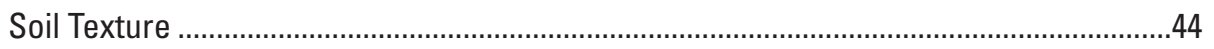

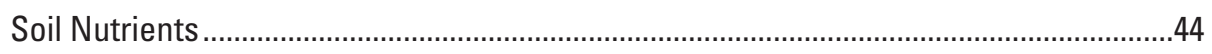

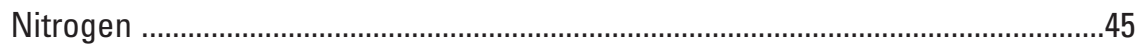

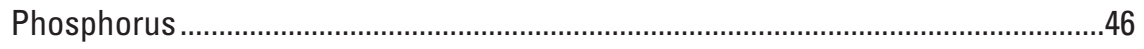

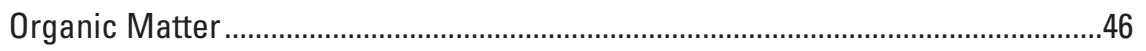

Cations and Micronutrients ...............................................................................46

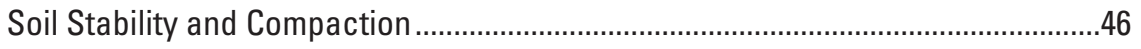

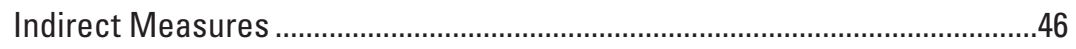

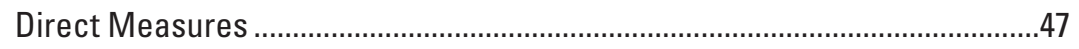

Wind Erosion ...................................................................................

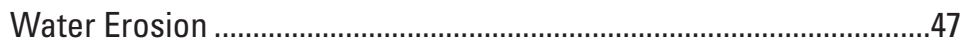

Philosophies and Strategies for Monitoring in the Mojave Desert...............................................54

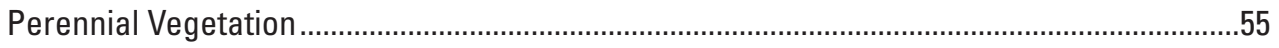

Perennial Vegetation Types in the Mojave Desert......................................................55

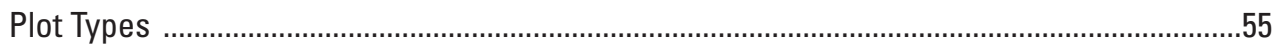

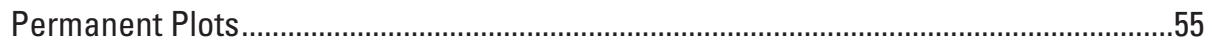

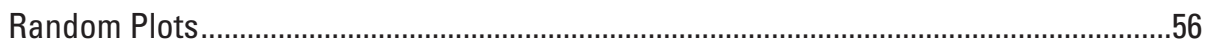

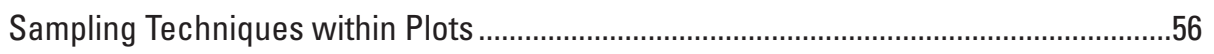

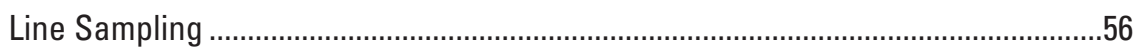

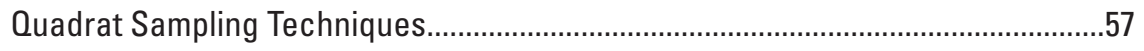

Mapping Techniques................................................................................................

Monitoring of Invasive Plants ................................................................................57

Spatial and Temporal Variability and Sampling Intervals ..............................................58

Measurement Techniques for Perennial Vegetation .......................................................58 
Phytoecological Measures ...................................................................................

Biomass Estimation: Direct and Indirect ............................................................58

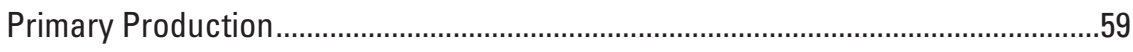

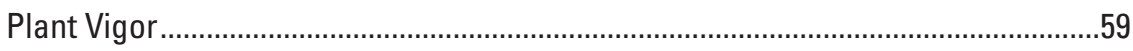

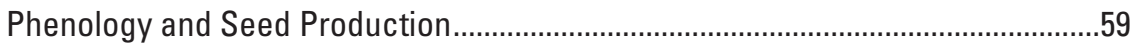

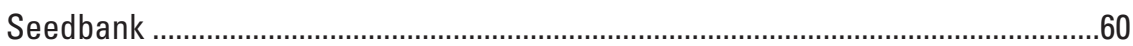

Measurement Techniques for Desert Annuals ..........................................................60

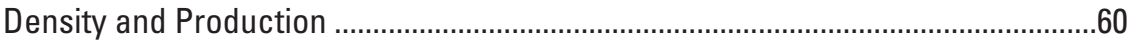

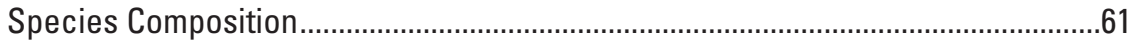

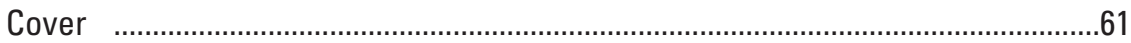

Measurement Techniques for Ground Cover (Including Biological Soil Crusts) ...........61

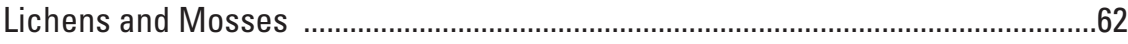

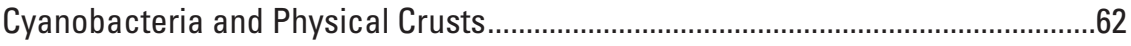

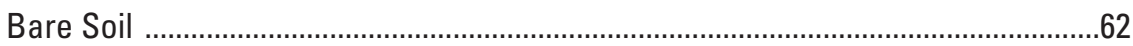

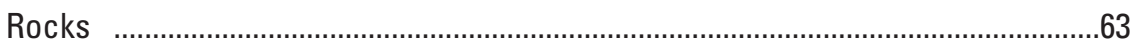

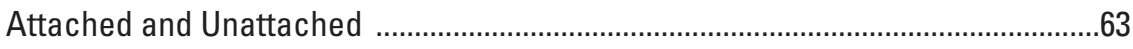

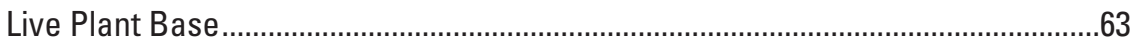

Measurement of Cyanobacterial Biomass and UV-protective Pigments .......................63

Subsurface Soil Bacteria, Fungi, Protozoa, and Fauna ...................................................63

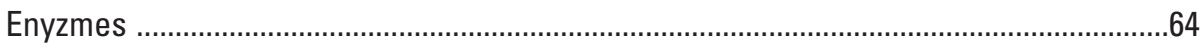

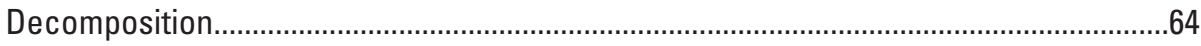

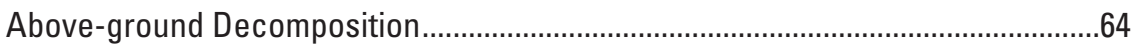

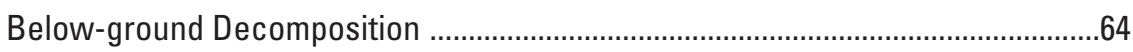

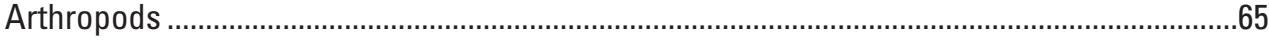

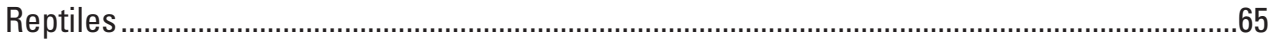

Techniques for Monitoring Reptiles.........................................................................65

Night-driving Surveys .....................................................................................6

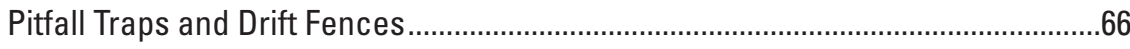

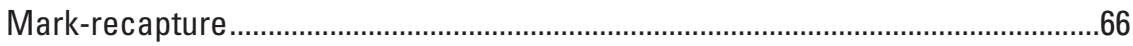

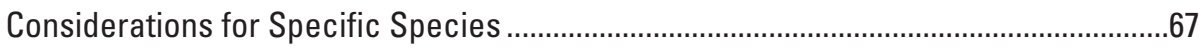

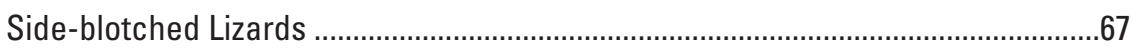

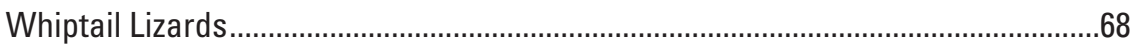

Leopard and Horned Lizards .................................................................................68

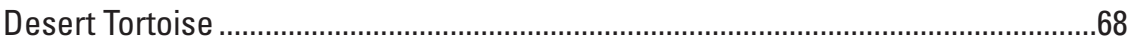

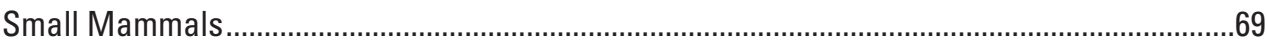

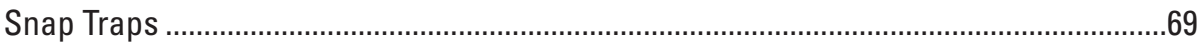

Live Traps for Nocturnal Small Mammals....................................................................69

Handling and Marking Small Mammals ………………..............................................

Special Considerations for Diurnal Species ..............................................................70

Ground Squirrels and Antelope Squirrels ……………….................................70

Jackrabbits and Desert Cottontail Sampling ..........................................................70

Landscape and Regional Scale Monitoring .......................................................................

Repeat Ground-based Oblique Photography ……….................................................

Methods and Equipment Used for Repeat Photography..........................................71

Sources of Historical Photography............................................................................. 


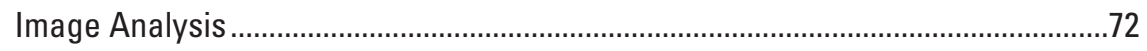

Airborne Remote Sensing .........................................................................................

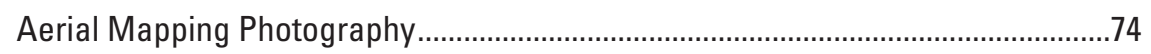

Aircraft-borne Multispectral Scanners ………………………………...........75

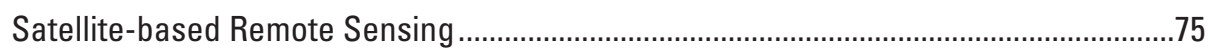

Comparison of Landscape-scale Monitoring Techniques .................................................77

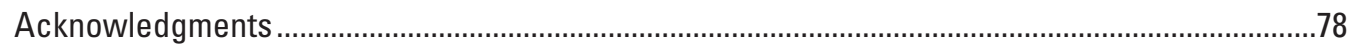

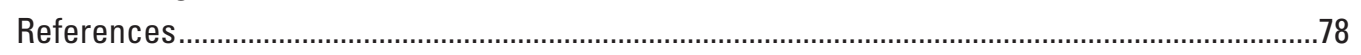

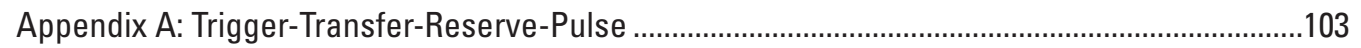

Example of the Trigger-Transfer-Reserve-Pulse Model at the Local and Hillslope Scale,

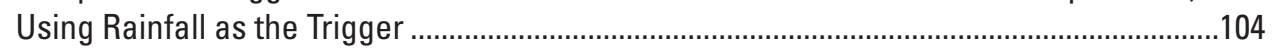

Example of Reserves: Plant Interspaces, Plant Islands, and Hillslopes........................104

Example of Resource Transfer: Horizontal and Vertical Movement of Water, Sediments, and

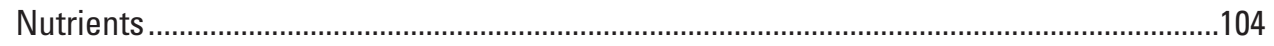

Example of a Pulse Response to the Trigger: Carbon and Nitrogen Dynamics......................105

Example Feedbacks between Transfers, Reserves, and Pulses.............................................105

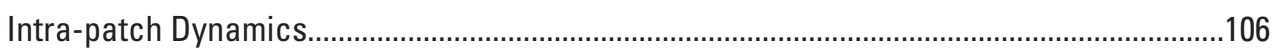

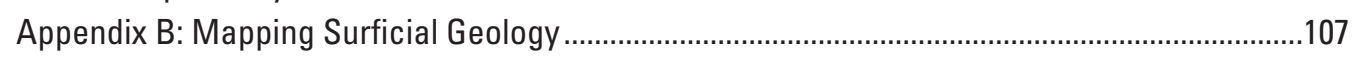

Map Units Used to Describe Geomorphic Surfaces in the Mojave Desert ..........................107

Appendix C: Regression Relations For Perennial Plants..............................................................110

Appendix D: Additional Resources .........................................................................................116

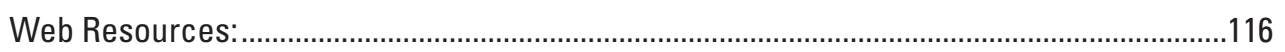

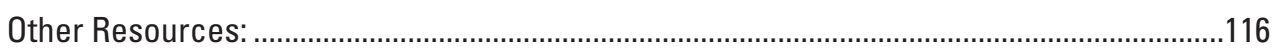

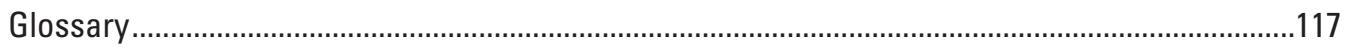




\section{Figures}

1. The Mojave Desert ecosystem...................................................................................

2. The Jenny-Chapin model and the stressors affecting the Mojave Desert.........................3

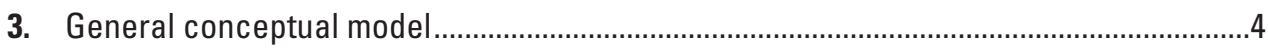

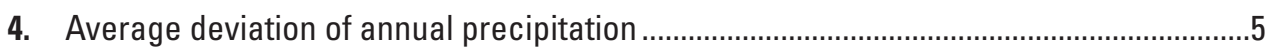

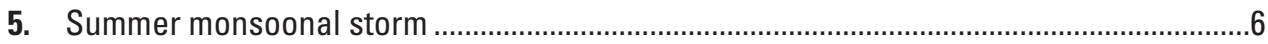

6. Processes operating on an elevation gradient...............................................................

7. Photographs illustrating differences among ages of surficial deposits ............................9

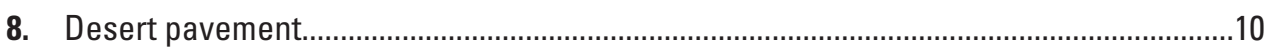

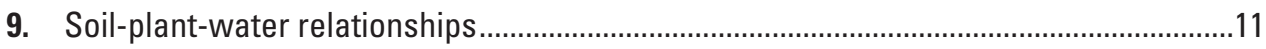

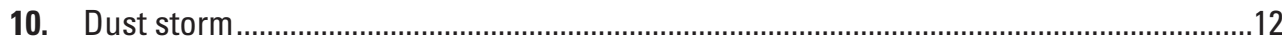

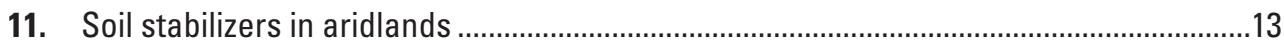

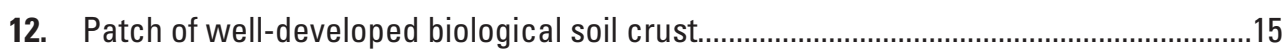

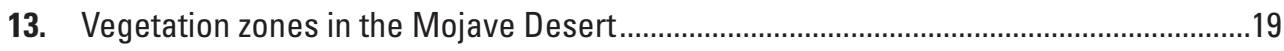

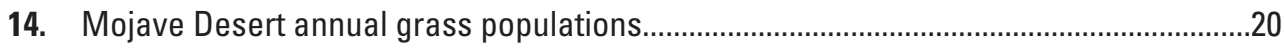

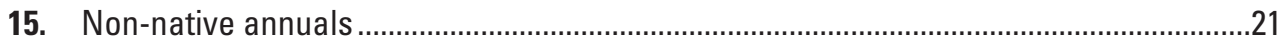

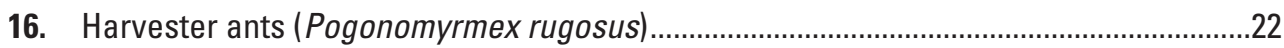

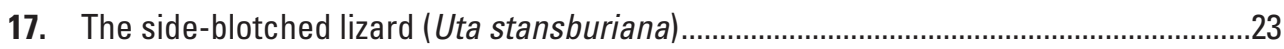

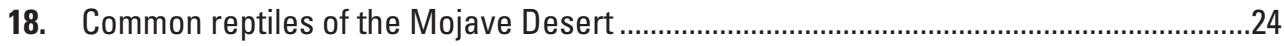

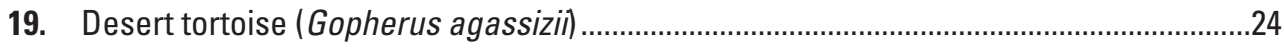

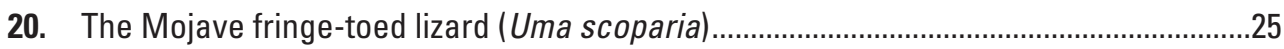

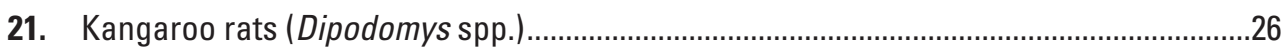

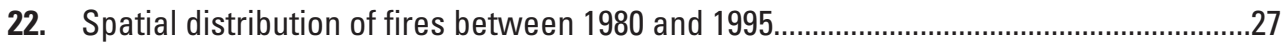

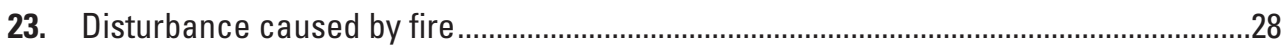

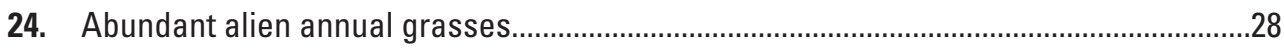

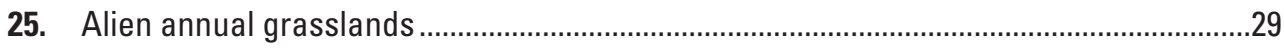

26. Military training exercises during World War II.........................................................

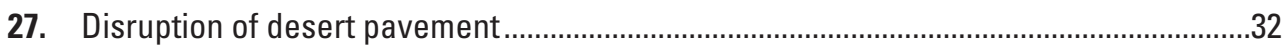

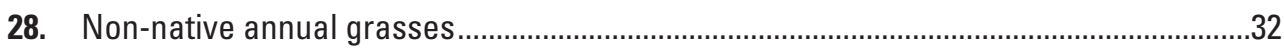

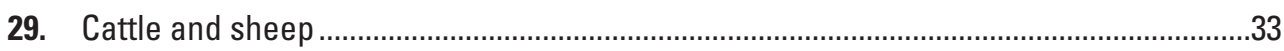

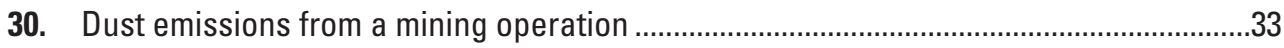

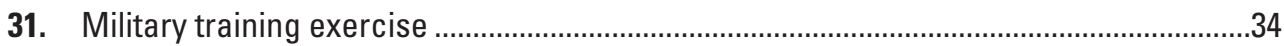

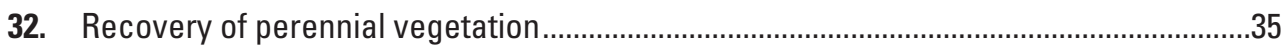

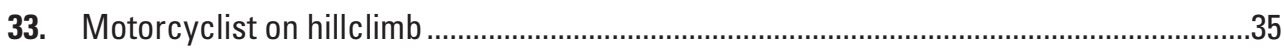

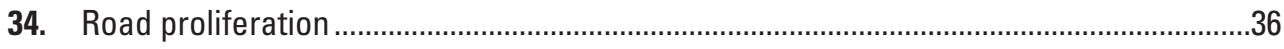

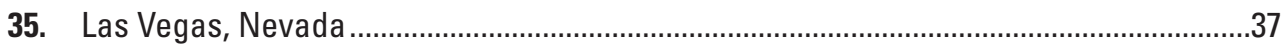

37. Non-native annual vegetation ...............................................................................

38. A climate station in the Mojave Desert.....................................................................4

39. Dustfall traps in the Mojave Desert.........................................................................

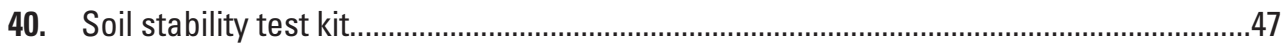

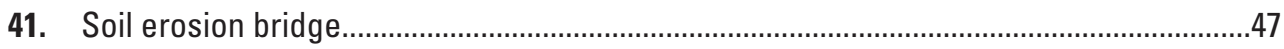

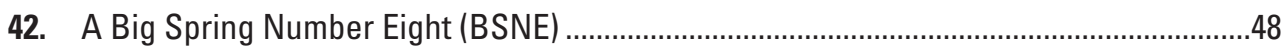

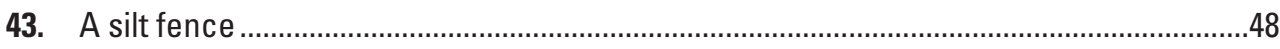

44. A jewelry chain is used to measure soil roughness...................................................48 
45. A box with moveable pins is used to measure soil surface roughness..........................49

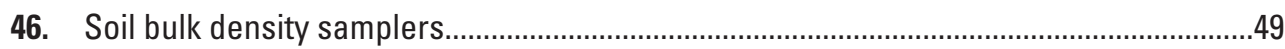

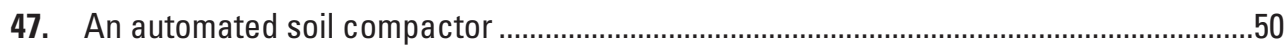

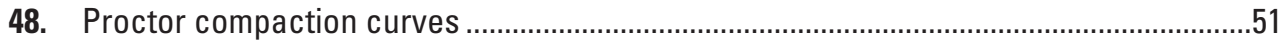

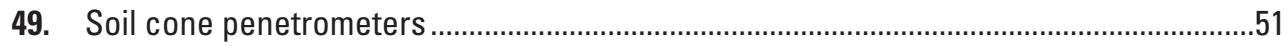

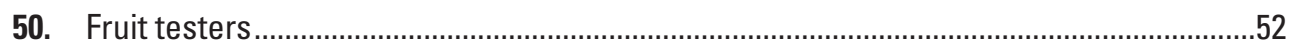

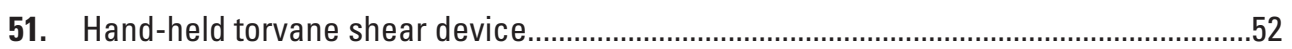

52. The relation between moisture content and matric potential ......................................53

53. Double-ring infiltrometer ....................................................................................

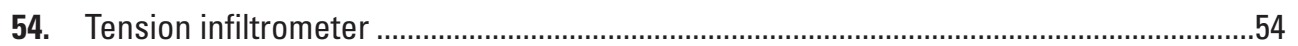

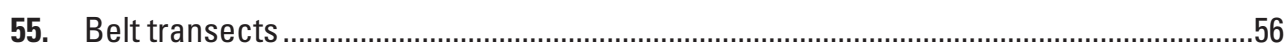

56. Removable frame for sampling cover of biological soil crusts......................................62

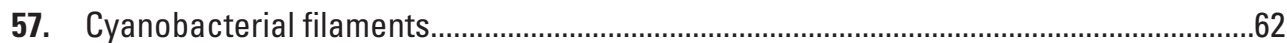

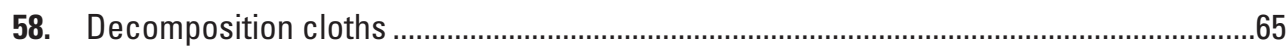

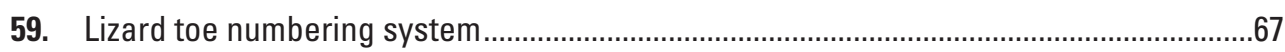

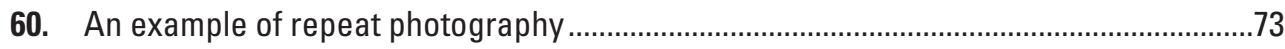

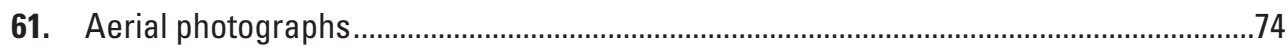

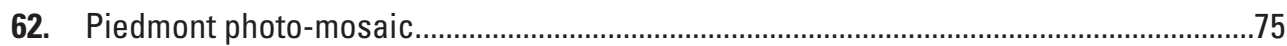

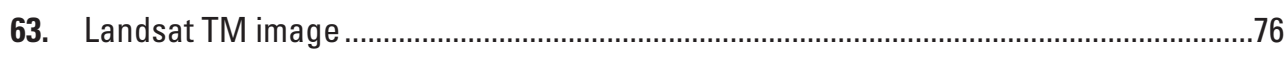

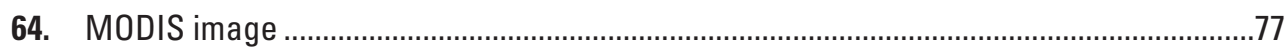

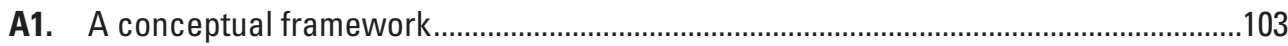

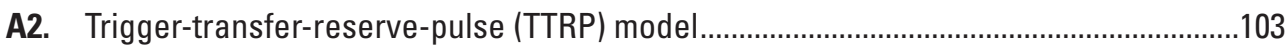

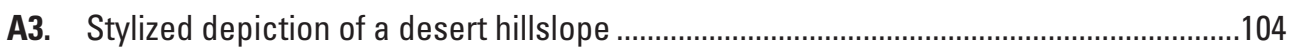

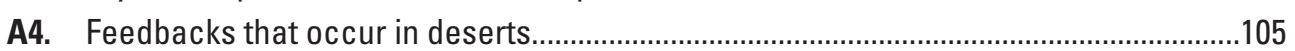

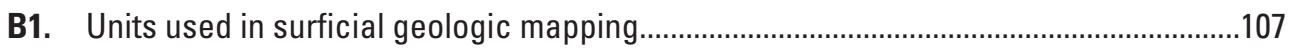

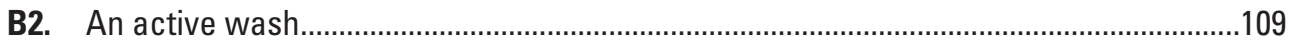

B3. Ambrosia dumosa (white bursage) and Larrea tridentata (creosote bush) .................109

B4. Desert pavement on a Ooa deposit ............................................................................109 


\section{Tables}

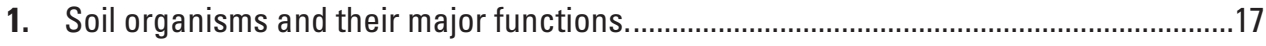

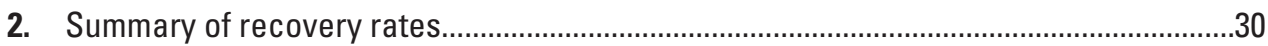

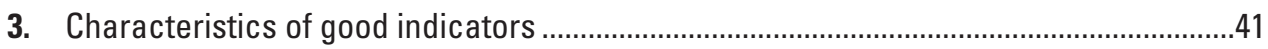

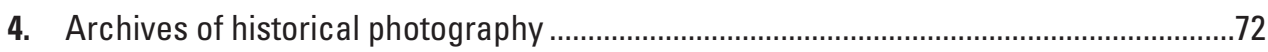

B1. Summary of alluvial fan deposit characteristics.......................................................108

C1. Regression equation producing a dry-weight biomass $(\mathrm{kg})$.........................................110

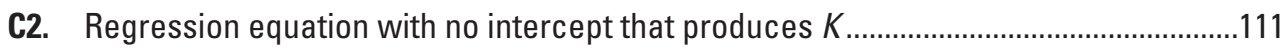

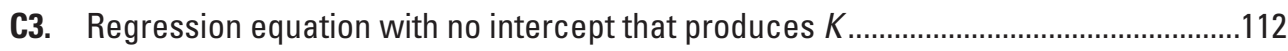

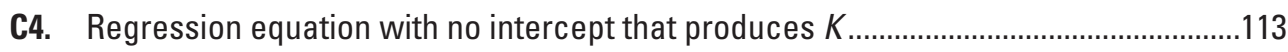

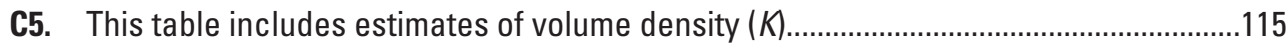




\section{Conversion Factors}

Inch/Pound to SI

\begin{tabular}{lll}
\hline Multiply & By & To obtain \\
\hline Length & & \\
centimeter $(\mathrm{cm})$ & 0.3937 & inch (in.) \\
millimeter $(\mathrm{mm})$ & 0.03937 & inch (in.) \\
meter $(\mathrm{m})$ & 3.281 & foot (ft) \\
kilometer $(\mathrm{km})$ & 0.6214 & mile (mi) \\
kilometer $(\mathrm{km})$ & 0.5400 & mile, nautical (nmi) \\
meter (m) & 1.094 & yard (yd) \\
\hline Area & & \\
\hline square meter $(\mathrm{m} 2)$ & 0.0002471 & acre \\
hectare (ha) & 2.471 & acre \\
square kilometer $(\mathrm{km} 2)$ & 247.1 & acre \\
square centimeter $(\mathrm{cm} 2)$ & 0.001076 & square foot (ft2) \\
square meter $(\mathrm{m} 2)$ & 10.76 & square foot (ft2) \\
square centimeter (cm2) & 0.1550 & square inch (ft2) \\
hectare (ha) & 0.003861 & square mile (mi2) \\
square kilometer (km2) & 0.3861 & square mile (mi2) \\
\hline
\end{tabular}

Temperature in degrees Fahrenheit $\left({ }^{\circ} \mathrm{F}\right)$ may be converted to degrees Celsius $\left({ }^{\circ} \mathrm{C}\right)$ as follows:

${ }^{\circ} \mathrm{C}=\left({ }^{\circ} \mathrm{F}-32\right) / 1.8$

\section{Units and Nomenclature}

In this report, we use metric units to describe all aspects of ecosystem attributes and function. Although we acknowledge that the common names of plants and animals vary considerably among lay persons and scientific observers, we use a consistent set of common names familiar to the authors and cite the appropriate Latin name for plants and animals on first mention in the text. Because the commonly used Latin names for plants and animals vary across the region and among scientists, we use the nomenclature presented in Hickman (1993) for plant species and the naming conventions in Banks and others (1987) for reptiles and small mammals. 


\title{
Monitoring Ecosystem Quality and Function in Arid Settings of the Mojave Desert
}

\author{
Jayne Belnap, Robert H. Webb, Mark E. Miller, David M. Miller, Lesley A. DeFalco, Philip A. Medica, Matthew \\ L. Brooks, Todd C. Esque, and Dave Bedford
}

\begin{abstract}
Monitoring ecosystem quality and function in the Mojave Desert is both a requirement of state and Federal government agencies and a means for determining potential long-term changes induced by climatic fluctuations and land use. Because it is not feasible to measure every attribute and process in the desert ecosystem, the choice of what to measure and where to measure it is the most important starting point of any monitoring program. In the Mojave Desert, ecosystem function is strongly influenced by both abiotic and biotic factors, and an understanding of the temporal and spatial variability induced by climate and landform development is needed to determine where site-specific measurements should be made. We review a wide variety of techniques for sampling, assessing, and measuring climatic variables, desert soils, biological soil crusts, annual and perennial vegetation, reptiles, and small mammals. The complete array of ecosystem attributes and processes that we describe are unlikely to be measured or monitored at any given location, but the array of possibilities allows for the development of specific monitoring protocols, which can be tailored to suit the needs of land-management agencies.
\end{abstract}

\section{Introduction}

The Mojave Desert covers $152,500 \mathrm{~km}^{2}$ of the Basin and Range physiographic province of eastern California, southern Nevada, southwestern Utah, and northwest Arizona (fig.1). Resource managers in this diverse region are challenged with maintaining the integrity of a complex and varied ecosystem under the demands of resource extraction and multiple land uses. In particular, the pressures of off-highway vehicle recreation, military training, livestock grazing, and urban expansion have created a mosaic of intensive uses adjacent to relatively undisturbed landscapes. In addition, this ecosystem faces the additional stresses of increasing fire, invasion by non-native species, atmospheric deposition of pollutants, and fluctuations in temperature and precipitation. Monitoring of ecosystem quality and function is a requirement of state and Federal agencies-particularly the Bureau of Land Management,

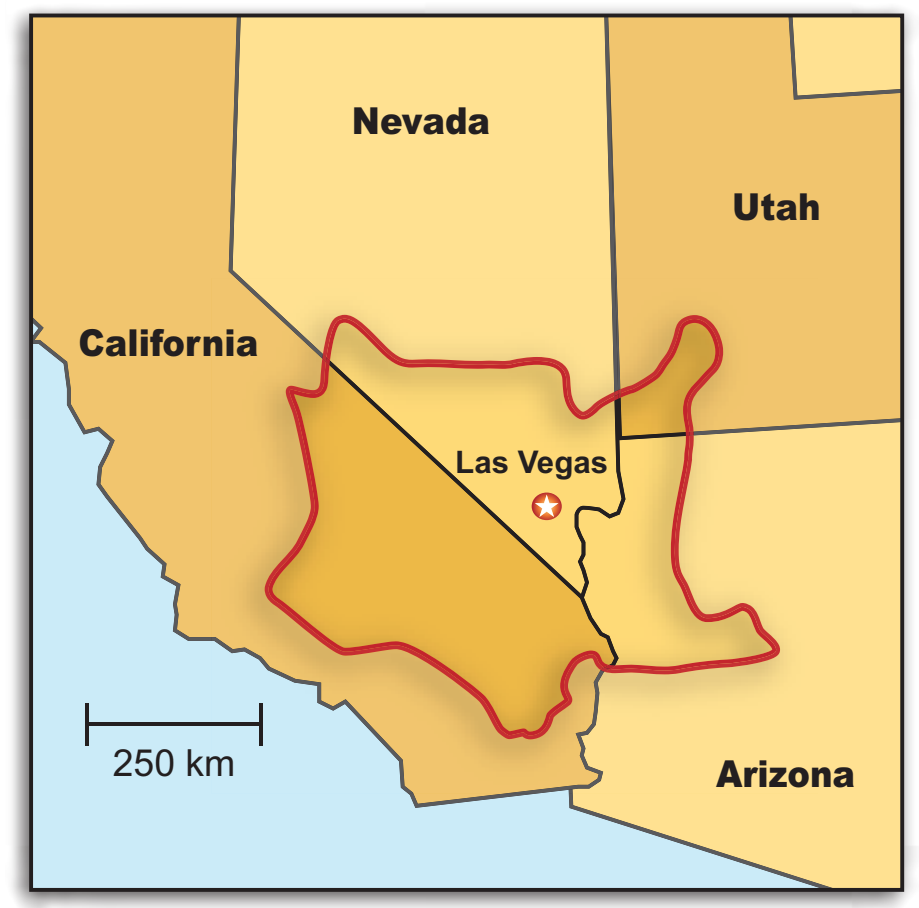

Figure 1. The Mojave Desert ecosystem occurs in southeastern California, western Arizona, southern Nevada, and the extreme southwestern corner of Utah. (Brown outline shows approximate area of the Mojave Desert.)

the National Park Service, and the U.S. Forest Service-as well as a means of determining potential long-term changes. Application of certain Federal laws, such as the Endangered Species Act, requires ecosystem monitoring as an integral part of recovery plans, and agencies with a mandate for ecosystem protection or sustainable use depend on monitoring protocols to assess the success of their mission.

This report presents conceptual ecological models that describe the structure and function of low-elevation, dryland ecosystems of the Mojave Desert. These models identify individual critical components of the ecosystem, their linkages to other components of the model, and how both natural and anthropogenic drivers affect these components and linkages. Such models are of great value in facilitating discussion among scientists, managers, and the public about how eco- 
systems function and how ecosystem condition can best be monitored. We then discuss techniques for designing and conducting programs for monitoring these components and their linkages. We emphasize that the spatial variability induced by climate and landform development is critical to understanding ecosystem function, and these factors need to be considered when designing a site-specific monitoring program. Indeed, climatic variability is the single most important factor to be measured in any monitoring program, and the effect of geomorphic surface on ecosystem function is of sufficient magnitude to affect the interpretations that may be obtained from site-specific measurements. In addition, because there are far more components and processes to monitor than is financially feasible, we favor monitoring processes rather than attributes, with the knowledge that important, rare, or endangered species are likely to be specifically examined for long-term changes wherever these species occur.

The authors call on more than two centuries of collective experience to describe what has worked in the past, what the current recommendations are, and what might be available in the future to measure this unique and threatened desert. We cover what we consider to be the fundamental properties of the Mojave ecosystem that can be used to assess its status or to warn of impending problems, particularly emphasizing atmospheric and soil processes, vegetation productivity and quality, and small animal populations. Although we recognize the legal and scientific importance of endangered species, we do not focus on these and their often unique problems, choosing instead to discuss the habitat framework that encompasses them.

\section{The Models}

\section{The Underpinnings of Ecosystem Sustainability: The Jenny-Chapin Model}

In 1941, Hans Jenny proposed that five state factors-climate, organisms, relief (topography), parent material, and time since disturbance-determine soil and ecosystem processes. This model was later modified by Jenny (1980) and then expanded by Chapin and others (1996) to include four interactive controls that define ecosystem sustainability: climate, soilresource supply, major functional groups of organisms, and disturbance regime. The state factors constrain the interactive controls and determine the "constraints of place" (Dale and others, 2000). For the purposes of this manual, we are using a modified version of this model adapted by Miller (2005; fig. 2).

An underlying assumption of the Jenny-Chapin model is that the maintenance of ecosystem health and integrity requires that the four interactive controls be conserved, as any large changes in them will result in a new ecosystem. For example, changes in the fire cycle or changes in the timing of rainfall can result in different plant species dominating a site. This, in turn, alters both below- and above-ground biota and most of the ecosystem processes associated with the biota. The resultant ecosystem, therefore, will have a different structure and function than the one preceding it.

\section{The Mojave Desert General Conceptual Dryland Model}

Our general Mojave Desert dryland conceptual model is presented in figure 3 . This model is based on the concepts of the Jenny-Chapin model and then expanded to include the specifics of the Mojave Desert following the approach of Miller (2005). In this section, we discuss the main components of the Mojave Desert ecosystem, as outlined in the model.

\section{Connectivity of Components and Process}

Because arid systems are highly heterogeneous, they are often conceptualized as a mosaic of interconnected patches (Peters and Havstad, 2006). Patchiness can occur at all scales, from sub-millimeter patches (for example, soil aggregates versus pore space) to centimeter-sized patches (for example, root versus non-root areas) to meter-sized patches (for example, plant versus interspace) to the hillslope scale, landscape scale, and regional scale (figs. 2 and 3). As pattern and process are inherently linked in desert ecosystems, understanding the processes that form patterns and how patterns influence processes is needed to quantitatively and predictably understand and model ecosystems (Wu and Levin, 1994). As a healthy ecosystem can be defined as one in which the retention of soil, water, and nutrients is within the natural range of variation, and soil-resource patterning controls this retention, soilresource patterning can be a useful indicator for monitoring programs (Herrick and Whitford, 1995; Ludwig and others, 1997; Havstad and others, 2000). This can be as simple as recording the size of spaces between plants, or as sophisticated as mapping the plants, interspace covers, and microtopography that can influence how materials (for example, water, plant litter, soil, seeds) move across the surface. For further discussion on this topic, see appendix A.

\section{Regional Climate and Atmospheric Conditions}

\section{Climate}

The diverse topography of the Mojave Desert was created by complex and active tectonics interacting with a wide variety of geologic formations (fig. 3). This topographic diversity strongly affects the climate of the region. On its west and southwest margins, the Mojave Desert is bounded by the Sierra Nevada, San Gabriel, and San Bernardino Mountains, all of which are fault-bounded margins of the Basin and Range physiographic province. These imposing mountains alter the prevailing westerly winds and intercept moisture derived from the Pacific Ocean, resulting in a rain shadow that creates the arid conditions on the lee side of the ranges. The Mojave 
A

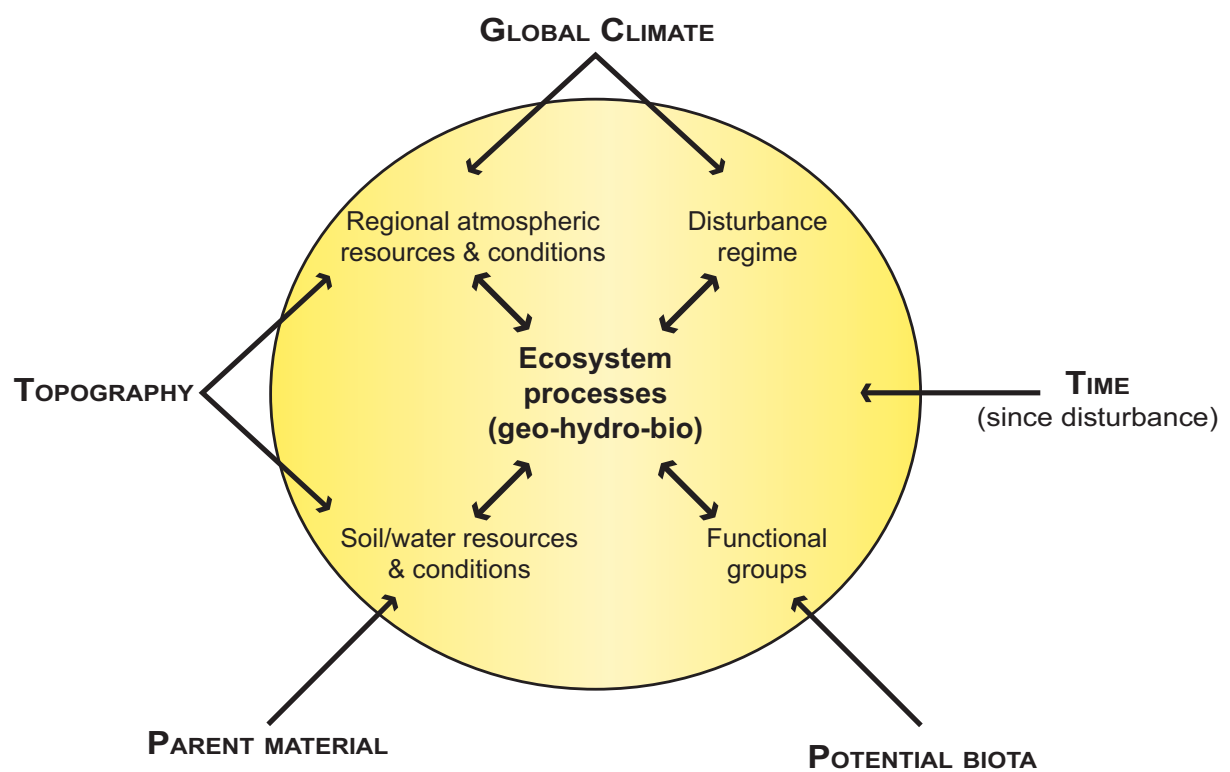

B

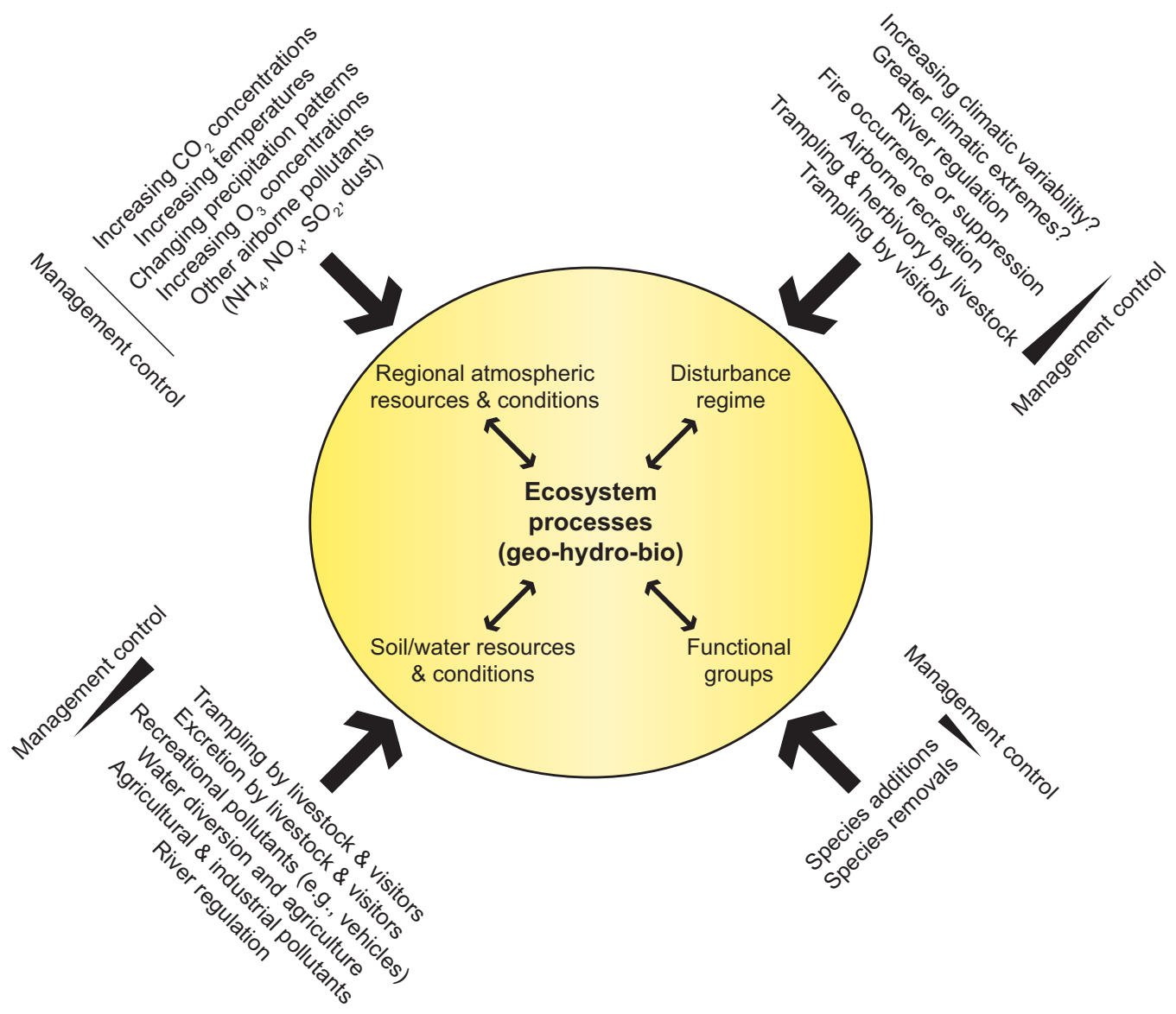

Figure 2. Modified version $A$, of the Jenny-Chapin model that serves as a general ecosystem model for the Mojave Desert (redrawn with permission from The American Naturalist and The University of Chicago Press; Chapin and others, 1996) and B, the array of stressors affecting Mojave Desert ecosystems arranged in the model in relation to their first-order effects. Complex, higher order effects occur as the four major controls interact through ecosystem processes. The circle represents the boundary of the ecosystem. 


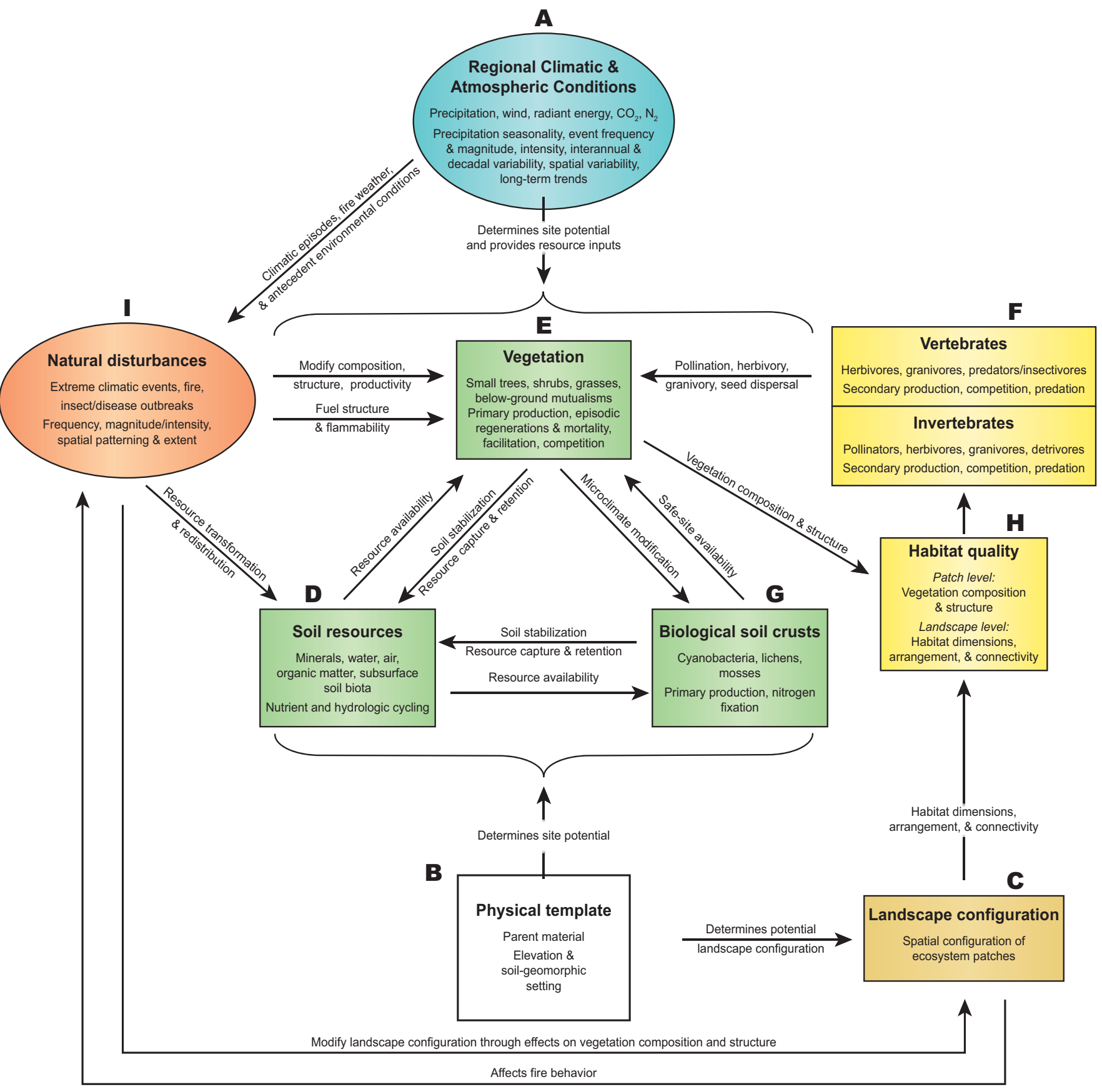

Figure 3. General conceptual model depicting the structure and functioning of dryland ecosystems. Ovals indicate major drivers of ecosystem change and temporal variability, as well as important attributes of drivers. Rectangles indicate major structural components and important processes. Arrows indicate functional relationships among components. Colored areas indicate drivers and dynamic ecosystem components that are subject to monitoring. The model is constrained by global climatic and atmospheric conditions, topography, parent material, potential biota, and time. 
Desert is bounded on the northeast by the Colorado Plateau, which is a broad, mostly semiarid region rising above the general elevation of the southwestern deserts. The northern and southern boundaries of the Mojave Desert are transitional and largely caused by elevation changes. To the south the Mojave Desert grades into the Colorado Desert, to the southeast it grades into the Sonoran Desert, and to the north it transitions into the Great Basin Desert.

Most attributes and processes of dryland ecosystems, such as the Mojave Desert, are driven by the availability of water. Therefore, precipitation characteristics are critical in determining ecosystem function. The main characteristics of interest are event size, timing, reliability, intensity, and the total annual amount. The size of a given precipitation event determines the biotic response to the event. Most events in deserts are very small, with more than 85 percent of events less than $5 \mathrm{~mm}$ (Sala and Lauenroth, 1982). Whereas events of this size may stimulate microbial activity and nutrient transformation at the soil surface, larger events are required for a plant response or recharge of soil moisture at depth.

The timing, reliability, and intensity of precipitation are critical for determining how long soils stay moist, how long surface water is available, and what organisms will be active and able to utilize the moisture when it occurs. Throughout the desert, rainfall during May and June is very low; it is consistently less than 5 percent of the annual precipitation (Hereford and others, 2004). During the rest of the year, the timing of rainfall varies throughout the Mojave Desert. In the regions west of the $117^{\text {th }}$ meridian of longitude, 70 percent of the climate stations record 82 percent of total precipitation falling during winter (October-April; Hereford and others, 2004, 2006). East of the $117^{\text {th }}$ meridian, however, 90 percent of the climate stations document that summer-fall (July-September) precipitation accounts for 29 percent of the annual total, while winter precipitation accounts for only 66 percent of the annual total. Precipitation events during the winter months tend to be widespread, of relatively low intensity, and of relatively long duration. In addition, cool air temperatures result in low evaporation rates. Summer-fall precipitation generally results from either isolated or regional convective thunderstorms resulting from tropical cyclones and hurricanes that originate in the eastern North Pacific Ocean (Smith, 1986). These storms are typically accompanied by severe, localized, and unpredictable flash flooding. Although they constitute a large portion of the annual total for a given site, on average, many summers are totally dry. This is in contrast to deserts to the southeast of the Mojave (for example, the Sonoran and Chihuahuan), where summer-fall rainfall events are dependable. Summerfall rainfall events occur when air temperatures are high, and thus the resultant soil moisture evaporates much more quickly compared to the same-sized events that occur in winter when air temperatures are lower.

Climate is also locally influenced by topography. Winter precipitation is strongly orographic (that is, related to changes in elevation due to mountains), increasing from approximately 100 $\mathrm{mm}$ at lower elevation sites to more than $500 \mathrm{~mm}$ near the tops of some Mojave Desert mountain ranges. Average temperature decreases approximately $6^{\circ} \mathrm{C}$ for every 1,000 -m increase in elevation (Ricklefs, 1990). Thus, topography directly influences the amount and timing of precipitation across large spatial gradients (basins and ranges) and more proximal elevation gradients (for example, on a single mountainside). The variation in temperature, combined with topography, results in high variability of potential evapotranspiration. Only a few studies have directly addressed the magnitude of climate variability over time in the Mojave Desert (fig. 4; Hereford and others, 2004; Hereford, in press). Huning (1978) found an overall decrease in precipitation from the 1940s - a period dominated by El Niño events-compared with the early 1970s. Average annual (calendar year) precipitation calculated from 52 climate stations in the region shows a range of $47-587 \mathrm{~mm} / \mathrm{yr}$, with a regional average of $149 \mathrm{~mm} / \mathrm{yr}$ (Hereford and others, 2004). Regionally, the driest year was 1953, whereas 1941 and 1983 were two of the wettest years. Long-term annual precipitation varied substantially during the $20^{\text {th }}$ century, with five precipitation regimes: 1893-1904 (early $20^{\text {th }}$ century drought), 1905-1941 (above average), 1942-1975 (mid-century drought), 19761998 (above average), and 1998-2004 (early $21^{\text {st }}$ century drought; Hereford, in press). The choice of limiting dates for these periods is subjective; for example, the mid-century dry

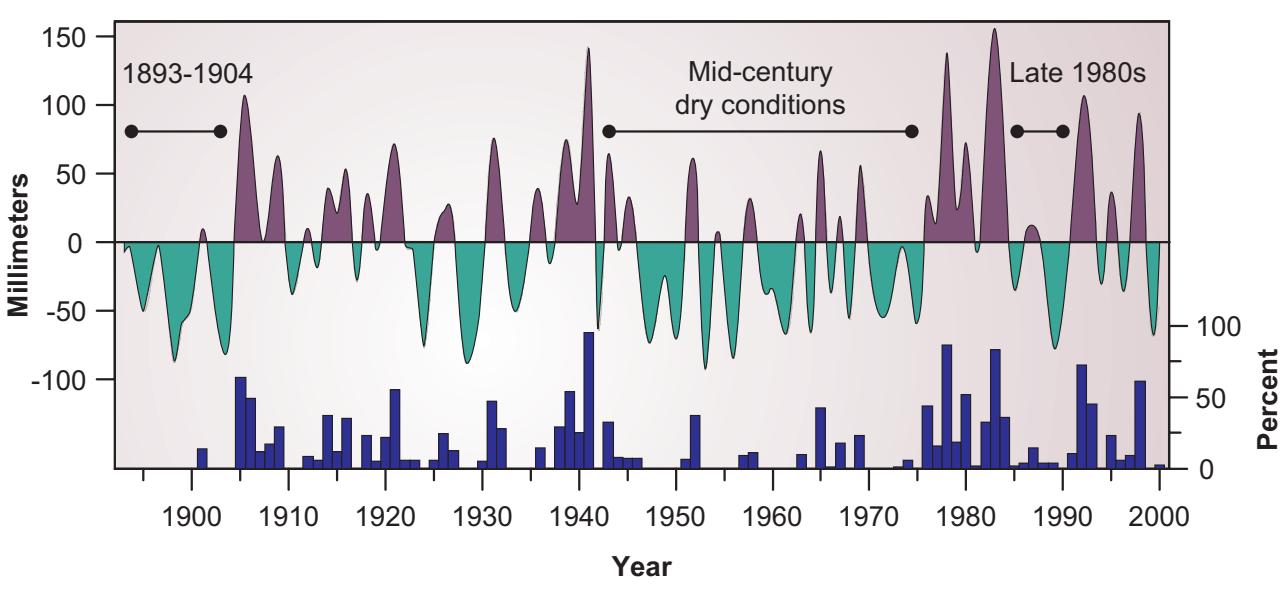

Figure 4. Average deviation of annual precipitation (that is, the average deviation from the mean of the reporting stations) and bar graph showing percent of stations having precipitation more than 68 percent of normal (modified from Hereford and others, 2004). 
regime may have begun as late as 1946 and ended as early as the mid-1960s. Regardless of the exact dates, the mid-century drought intervenes between two wet periods, the latter of which was exceptional in terms of its effects on the Mojave Desert. The period from 1976 through 1998 was the wettest of the $20^{\text {th }}$ century, broken only by a relatively brief, intense drought from 1989 through 1991 (Flint and Davies, 1997).

Climatic variability creates a complex framework for understanding past, current, and future features in the desert, such as plant viability, plant-animal interactions, soil moisture availability, and persistence of ephemeral and perennial streams. Superimposed on top of the background of climate variability are the short- and long-term effects of climate change. Based on past analogs and regional climate models that include increased atmospheric carbon dioxide $\left(\mathrm{CO}_{2}\right)$, scientists predict that drier conditions will prevail during the next few decades. The Pacific Decadal Oscillation (PDO) recently appeared to change phase (see http://topex-www.jpl. nasa.gov/science/pdo.html). The previous similar phase of the PDO occurred during the middle of the $20^{\text {th }}$ century and was accompanied by prolonged dry conditions in the Southwest. By extrapolation, some climatologists predict future drought in the Southwest (Cole and others, 2002; Swetnam and Betancourt, 1998). Frequency of flooding, particularly in larger river systems, may decrease, and eolian activity in the Southwest may increase (Schmidt and Webb, 2001). Predictions for future climate include more intense, more frequent, and longer heat waves (Meehl and Tebaldi, 2004); increased temperature and decreased rainfall in both summer and winter (Thompson and others, 1998; Giorgi and others, 2001; Christensen and others, 2007); and winter warming, reduced snowpack, and more extreme winter storms (Leung and others, 2004). Although future climate trends are imperfectly predicted because climate

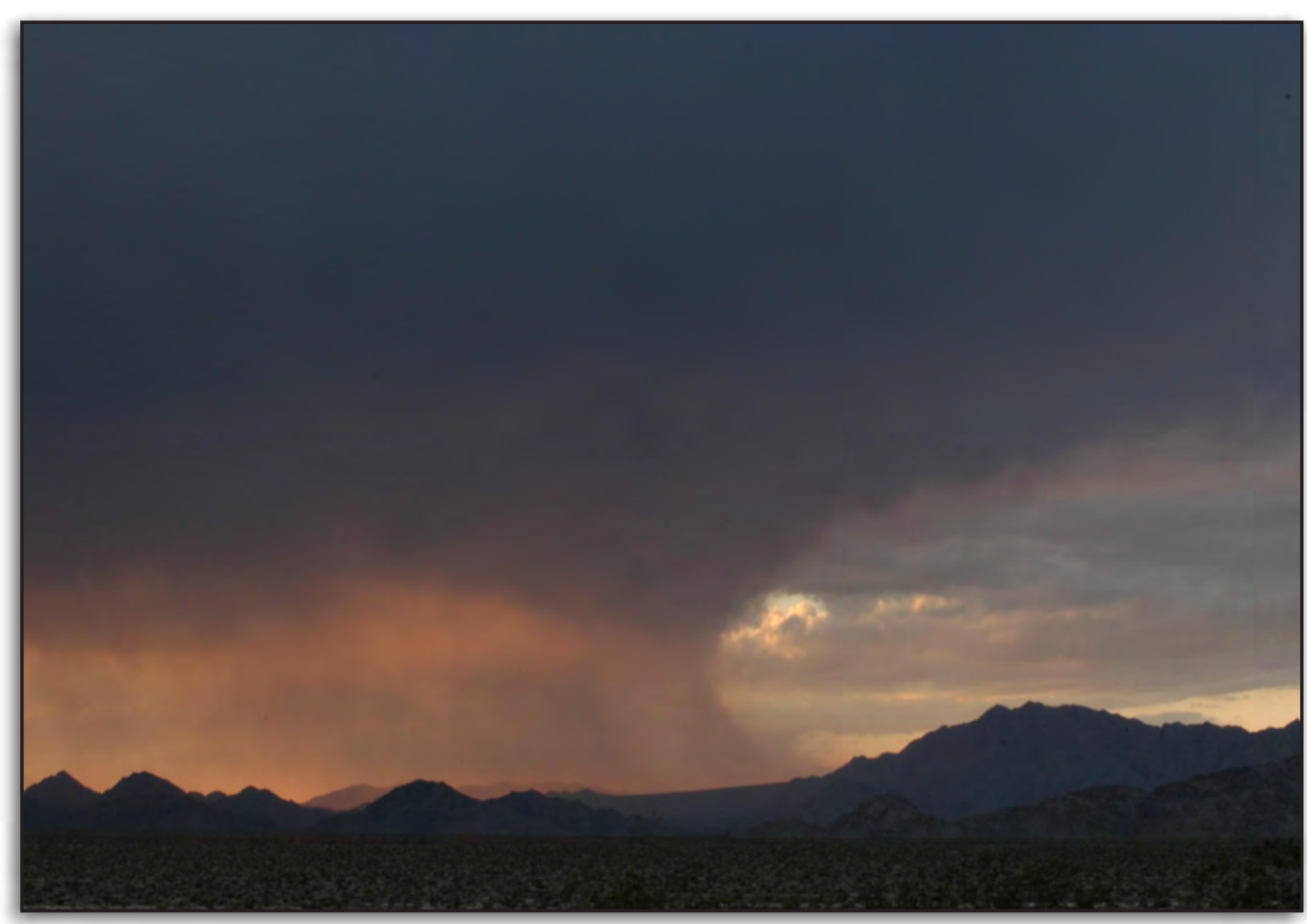

systems are exceedingly complex, most studies agree that in 50 years it will be warmer and probably drier, accompanied by increased storm intensity. Isolating the effects of climate change from climate variability is an essential, but daunting, requirement in the management of desert ecosystems.

Data describing the temporal and spatial variability in climate are needed by resource managers for the purposes of interpreting temporal variations in resource conditions and assessing the spatial variation in ecosystem sensitivity to climatic episodes, natural disturbances, and land use practices. Despite the need for high-resolution data, climate monitoring is conducted only at a small number of point locations in the Mojave Desert. This is especially problematic in this region, as rainfall events, particularly summer thunderstorms, can be extremely localized (fig. 5). Because we will never obtain complete coverage, climate modeling will be an important tool in estimating the spatial and temporal variations in water and energy balances across landscapes. Coarse-scale climate extrapolations are readily available for this ecoregion. For example, Michaelson (in Thomas and others, 2004) provided a gridded climate extrapolation at 1-km spacing for the entire Mojave Desert.

\section{The Physical Template: Geology, Geomorphology, and Soils}

\section{Geology}

Parent material (fig. 3B) strongly influences the characteristics of the landscapes (fig. 3C) and soil (fig. 3D) derived from it and, consequently, patterns of plant distribution (fig.

3E) and animal distribution (fig. 3F). The most important effects are: (1) weathering rates, (2) chemical composition, and (3) texture (McDonald and others, 1995).

Weathering is the progressive fracturing of rocks by physical and chemical processes. This produces finer grained products with time, with the resultant particle size distribution, or soil texture, dependent on the original rock type. Parent materials

Figure 5. Summer monsoonal storms are more unpredictable than winter rainfall and typically deliver moisture in the Mojave Desert in small, isolated patches (U.S Geological Survey photograph by David M. Miller). 
that are fine grained and/or composed of relatively reactive rock fragments, such as glassy volcanic rocks, weather most quickly to form clayey products in soils. In general, granitic rocks and some sedimentary rocks, such as shale and siltstone, weather faster than many other rocks but less fast than volcanic rocks. Sandstones weather to form a coarse-textured soil.

The chemical composition of the weathered rock particles is the primary control on the chemical composition of the resultant soil. Along with dust and weathering products, the mineralogy of the particles creates the starting materials for plants and soil biota to interact with. Limestone tends to create more fertile soils, for instance, whereas quartzite and sandstone create relatively sterile soils. In general, rocks with greater calcium, iron, and magnesium create more fertile soils. These rocks include limestone, marble, basalt, andesite, and mafic granitoids, such as diorite, gabbro, monzodiorite, and quartz diorite.

As soil texture and chemistry exert a strong control on local hydrology, plants, and animals, the rock type from which soils are derived can exert a strong control on community structure. A prime example is the alluvial material shed from granitic rocks that break down into grus (grain-bygrain disintegration). Soils composed of grus tend to exhibit weakly developed soil profiles because they are less stable than rockier soils and because pedogenic silt penetrates deeply into the profile. In general, these characteristics promote soil moisture conditions that are favorable for many plants and for biological soil crusts. In contrast, badlands composed of finegrained, weakly consolidated materials erode so rapidly as to be practically devoid of plants.

\section{Geomorphology}

Geomorphic surfaces can be thought of as the surface characteristics of landforms in the desert, whether sand dunes, alluvial fans, or bajadas, and the surficial deposits are the nearsurface interval of materials associated with those landforms (figs. 3B and $\mathrm{C}$ and 6; for information on mapping surficial geology, see appendix B). Of the many geomorphic environments in the desert, mountains and piedmonts cover the greatest area. Mountains are highly variable environments, as slope, aspect, and curvature, driven by both substrate materials and topography, can vary widely. Mountains have relatively high near-surface moisture stored locally in thin colluvial and alluvial sediment deposits that are underlain by eroded rock. They may also contain extensive water in the bedrock that flows downward toward the valley floors. At lower elevations, depositional surfaces are found that include alluvial fans, coalesced fans (termed bajadas), and various other landforms that, collectively, can be termed the piedmont. These are primarily depositional areas, where sediment eroded from the mountains accumulates over long time periods. Farther from the mountain front are other types of piedmont systems that are quite variable through the region and include such features as sand dunes, sand sheets, intermixed eolian sand and alluvial fans, and even wetlands (for example, Ash Meadows near
Death Valley). Playas, stream systems, or, more rarely, perennial lakes generally occupy the valley floor.

Plant communities are highly variable on piedmonts in response to elevation gradients and to characteristics of geologic deposits. Surficial geologic deposits vary in soil texture (grain size distribution and packing), bulk density, and other factors. The grain size of deposits generally decreases from mountain front downward to distal piedmont, as do topographical features, such as channel incision and slope (Blair and McPherson, 1994). Superimposed on these textural and topographic patterns is the depositional history of a specific area, with features ranging from remnant fragments of very old piedmont deposits to actively depositing segments (fig. 7). The resulting patterns are crucial to ecosystems because they influence where, how much, and what type of soil is formed (McFadden and Knuepfer, 1990; McDonald and others, 1995).

\section{Soils}

Soils (fig. 3D) provide the basic foundation for most terrestrial life, because they provide structure and determine the availability of water and nutrients to soil biota (figs. 3D, F, and G) and plants (fig. 3E), which in turn, provide habitat and food (fig. $3 \mathrm{H}$ ) for larger animals. The influence of soils on soil biota and plants is determined by the physical, chemical, biological, and depth characteristics of the soil. Even small differences in these characteristics can have relatively large effects on water and nutrient bio-availability, and thus biota (Comstock and Ehleringer, 1992; McAuliffe, 2003).

Soil formation, or pedogenesis, creates vertical variation on the landscape. Soils are mostly formed by the weathering of sediments within deposits. Because of the low rates of weathering and soil-forming processes in regions with low precipitation, the relative importance of parent material in determining soil properties increases with aridity (Jenny, 1941). In addition to this process, the accumulation of chemical deposition and the infiltration of eolian, fine-grained materials also contribute to pedogenesis (Pavich and Chadwick, 2003). Thus, the nature of the resultant soil depends on the physical and chemical properties of the bedrock from which the soil has weathered as well as the proximity to dust sources. The particle size distribution of the soil determines the quantity of nutrients and water and how tightly they are held in soil layers. For instance, sandy soils have large pore spaces and large particles that bear little electrical charge, which allows the rapid leaching of nutrients and water deeper into subsurface soils. In contrast, finer-grained soils, with higher silt and clay content, generally have small pore-size distributions and contain charged particles, enabling soil particles to bind nutrients and hold water higher in the soil profile.

Downward translocation of soil particles and nutrients occurs in more stable settings (for example, above the geomorphically active zones, such as washes) and results in a layered soil, with layers (horizons) varying in hydrologic and other properties. Thus, older deposits generally exhibit more 


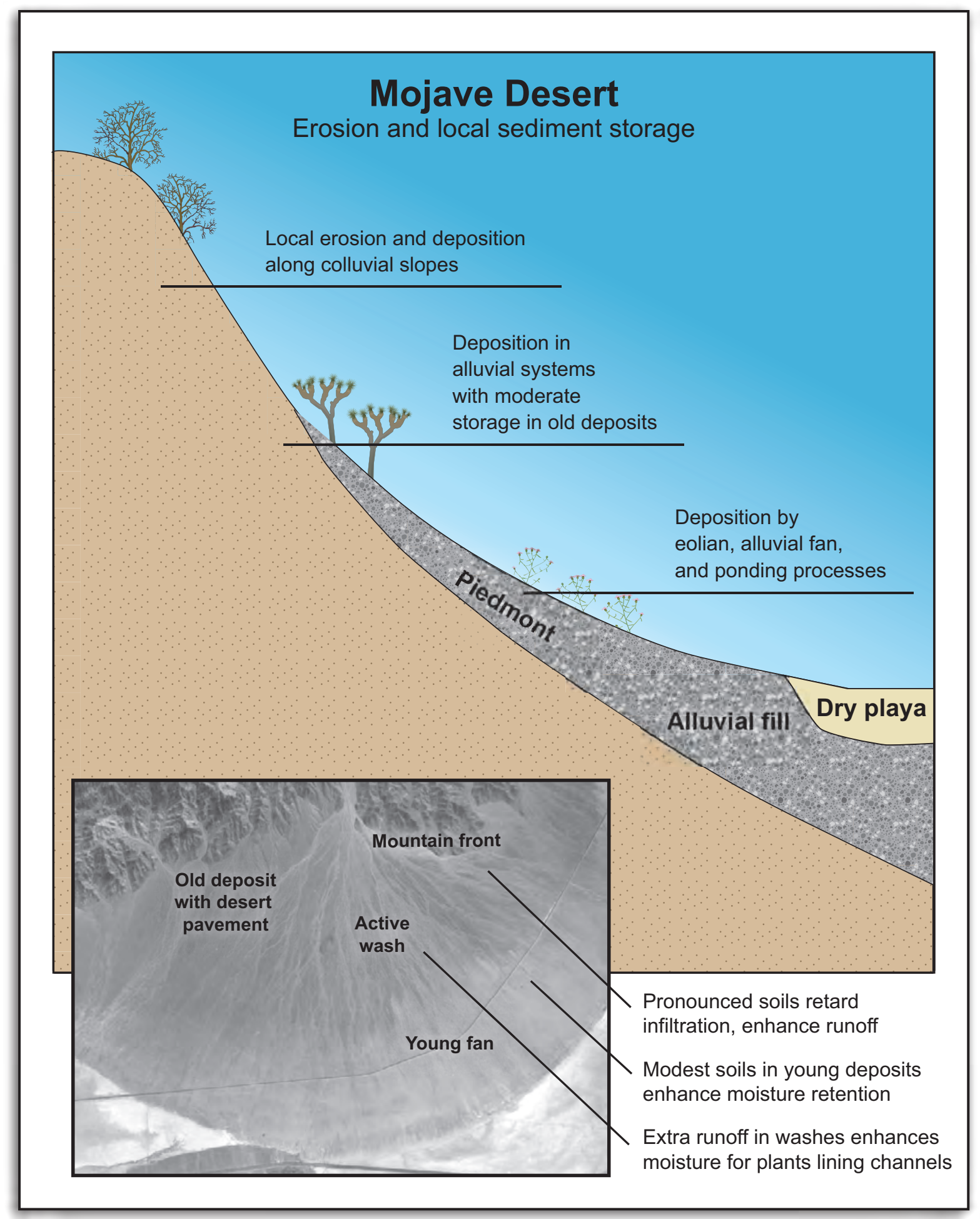

Figure 6. Processes operating on an elevation gradient representing desert mountain and alluvial systems in the Mojave Desert. The processes are partly related to elevation and climate, partly related to slope, and partly related to substrate; all of these factors have feedback loops to plants, animals, and moisture availability. 

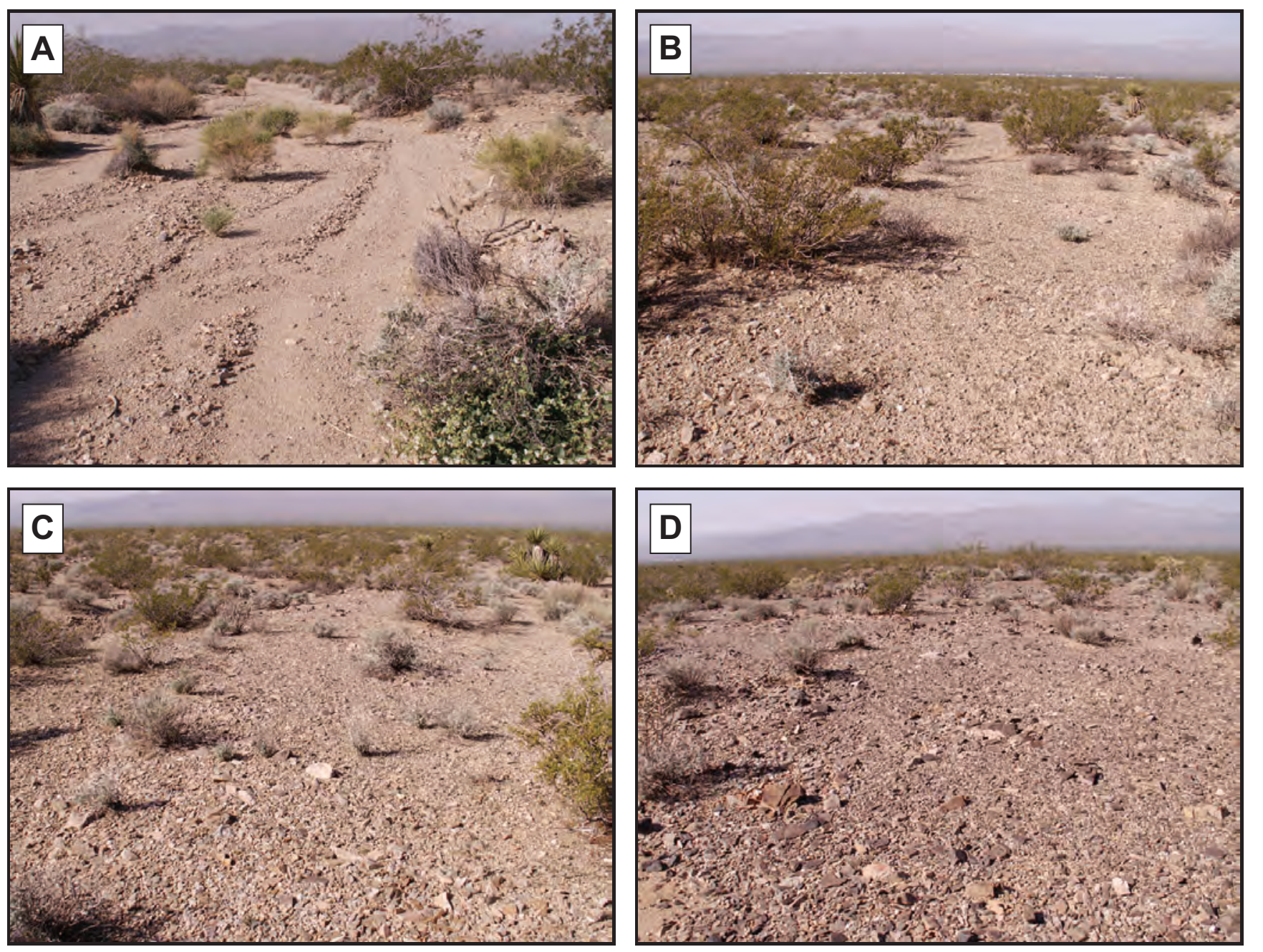

Figure 7. Photographs illustrating differences among ages of surficial deposits in the Mojave Desert. All photos from alluvial fans at about $900 \mathrm{~m}$ elevation, adjacent to the Providence Mountains. A, Active wash (Oya1) showing high albedo of frequently reworked channel surface, and Hymenoclea salsola (common cheesebush). Note the flowering Encelia farinosa (brittlebush) in middle distance and large Larrea tridentata (creosote bush) and Yucca schidigera (Mojave yucca) along the banks. B, Middle Holocene deposit (0ya3) showing darker surface with biotic soil crusts and tiny annual plants. A very weak pavement and Ambrosia dumosa (white bursage) and creosote bush are typical of this deposit. C, Early Holocene deposit (Qya4) showing weak pavement and desert varnish. Plants are similar to the mid-Holocene deposit, but slightly more sparse. D, Pleistocene deposit (Qia3) showing stronger varnish and pavement, and only rare annual plants. White bursage and creosote bush are sparse, and Senna covesii (desert senna), Opuntia acanthocarpa (staghorn cholla), and Mojave yucca are present (U.S. Geological Survey photographs by David M. Miller). 
intense soil horizonation than younger surfaces (fig. 8). These older deposits are often capped with a silt layer filled with bubbles called a vesicular layer. As the vesicular layer is part of the surface, or A horizon, it is referred to as an Av horizon. Vesicular horizons restrict water infiltration, and as they get thicker through time, infiltration rates decrease.

The Av horizon is underlain by argillic (clay-rich) and calcic (calcium-carbonate cemented) horizons that can restrict water penetration and root growth due to their increased cohesion and high strength properties. Although this potentially decreases the amount of soil volume that can be explored by plant roots for water and nutrients, this layer also often perches and holds water, thus keeping it available to plant roots (Shreve, 1917; McAuliffe, 1994, 2003). Salts can accumulate in older soils in certain landscape settings, thus changing soil properties to favor plants with higher tolerances of soil salinity. Because of restricted water infiltration and salt accumulation, plant cover generally decreases with age of deposit within a given geologic setting (Hamerlynck and others, 2002). An exception is the low plant cover evident in many active washes, where unstable substrate and abrasion during floods reduce plant establishment and persistence. Unlike older geomorphic surfaces, young surfaces have little soil structure to restrict root elongation, have high infiltration rates, and generally are low in salinity. As a result of the progressive development of pedogenic soils, and the presence of deposits of varying ages in the piedmonts, the piedmont environment is a complex mosaic of areas with varying soil properties (fig. 9).

Concentrations of elements and carbon in soils is important in determining plant distribution and productivity.
The soil elements essential for plant growth include nitrogen, phosphorus, potassium, magnesium, sodium, calcium and the micronutrients zinc, manganese, copper, and iron (Titus and others, 2002). The availability of a given nutrient is a function of many factors, including soil $\mathrm{pH}$, the amount of acidic exudates from roots and other organisms in the soil, the concentrations of other nutrients in the soil, and soil temperature and moisture. Many studies have shown that, although water is generally the limiting factor for plant productivity, nutrients can quickly become limiting in wet years (Romney and others, 1973; Whitford, 2002). Some authors have suggested that nutrients and water are co-limiting in deserts (Hooper and Johnson, 1999). In addition, elevated levels or altered ratios of nutrients, particularly sodium, potassium, and phosphorus, may cause shifts in the species composition of annual and perennial species that can inhabit a particular geomorphic surface (Belnap and Phillips, 2001; Miller and others, 2001). Organic matter is also important in ecosystem processes, as soil food web organisms depend on soil organic matter for energy. Soils also contain enzymes excreted by microbes during decomposition (Sinsabaugh and others, 2002), and they can be used to measure the "health" of the decomposition cycle. Enzyme activity is also thought to be correlated with the relative availability of soil carbon and nitrogen.

There are other soil variables that also influence plants and soil biota. Soil depth is an important property, as it determines the volume of soil through which plant roots can extend to obtain water and nutrients. In addition, water in very shallow soils will evaporate more quickly than in deeper soils. Many desert fauna prefer specific soil depths at which they reside or burrow (Hafner, 1977; Whitford, 2002); if soils are

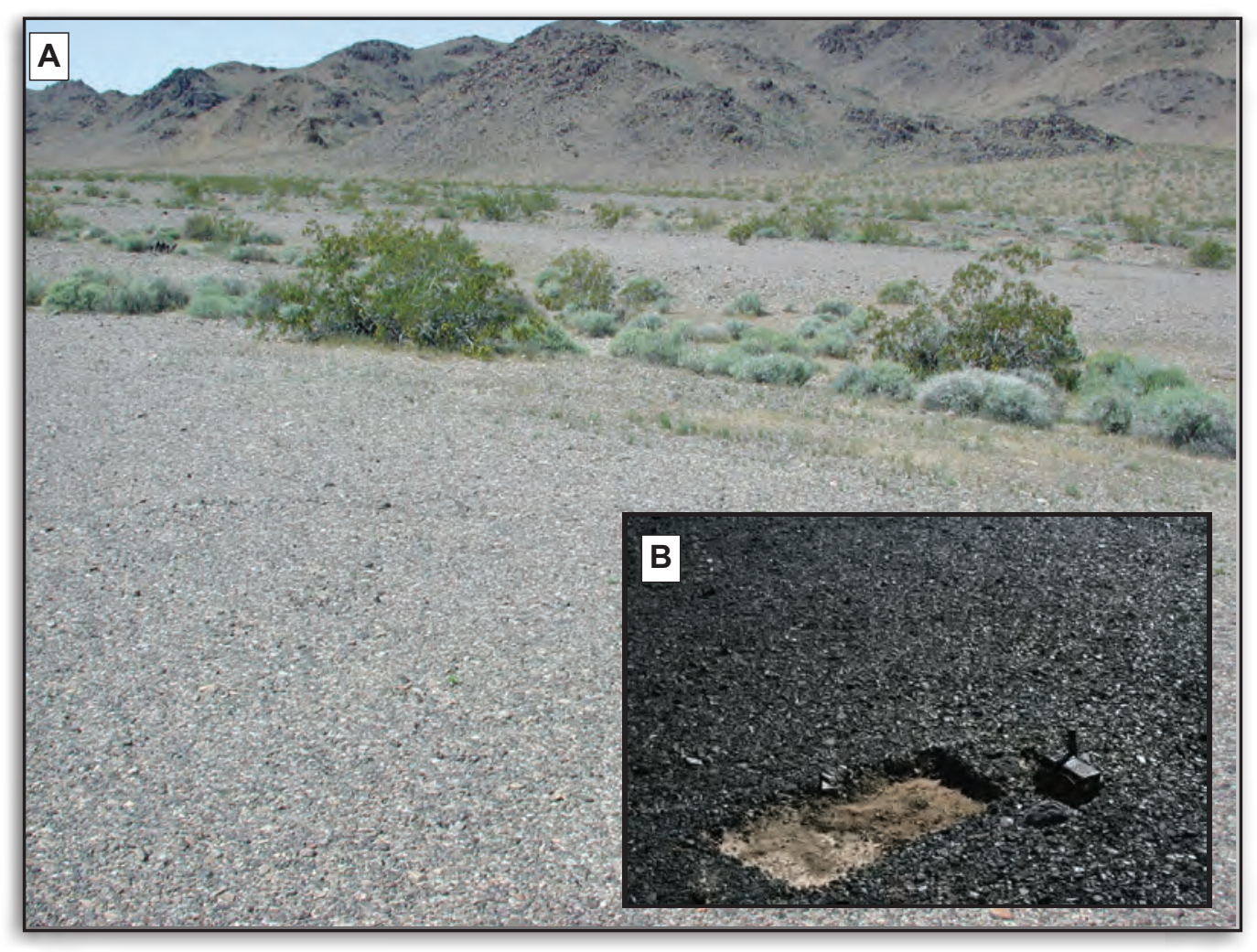

Figure 8. Photographs of desert pavements in the Mojave Desert. A, Desert pavement on a deposit with old soils, which is devoid of perennial plants except in dissected gullies, where soil horizons are disrupted. B, Welldeveloped desert pavement on a surface of late Pleistocene age. The lighter tan layer is the middle of the vesicular layer, or Av horizon, and the darker reddish unit underneath is the top of the argillic B horizon (U.S. Geological Survey photographs by David M. Miller). 

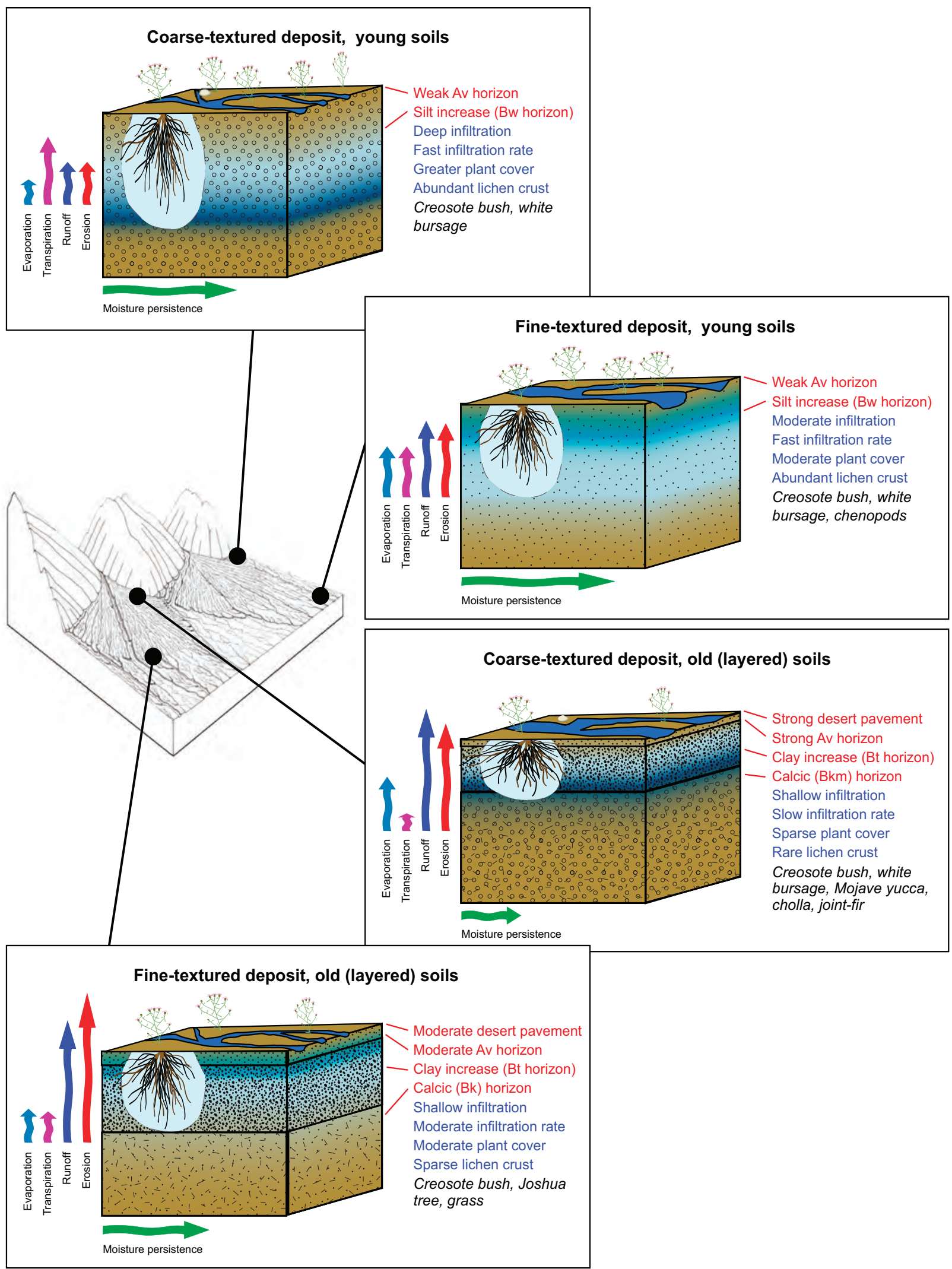

Figure 9. Soil-plant-water relationships for Mojave Desert piedmonts showing major processes and relative amounts and locations of soil moisture, overland flow, nutrient cycling, and functional vegetation. Varying soil properties exert strong control on surface and soil-water dynamics. Vegetation typical of a moderate-elevation bajada is given in italics. The size of the arrows indicates the relative rate or amount of the process indicated. 
too shallow, those species will not be found at that site. Mineral crusts, also termed physical crusts, are present on many desert soils and help reduce wind erosion. However, they also decrease infiltration rates and dissolve when wet, thus offering little protection from water erosion. In addition, they generally form a smooth surface that makes lodging of wind-transported seeds more difficult, and their strength properties may inhibit plant seedling establishment (Sumner and Stewart, 1992).

Surface roughness can determine the capture and retention of nutrient-rich dust particles and organic matter and affect local nutrient status.

Soil aggregate stability and structure are also important in determining soil function, as they influence soil stability, water infiltration, and nutrient cycling (Seybold and others, 1999). Most microbial activity occurs on the surface of soil aggregates, and thus it is where most nutrient transformations occur as well. Soil structure is also essential in conserving the pore space through which gases, water, and organisms move. Water infiltrates into the soil at different rates, depending on the pore space and moisture status of the soil. When rainfall intensity exceeds the ability of the soil to absorb the rainfall, or when a subsurface impediment to flow slows surface infiltration, runoff occurs. Although water moves downwards due to gravity, it can also move up or down through the root systems of plants and return to the soil at another depth, a process termed hydraulic redistribution (Ryel and others, 2003). Water can also move upwards in the soil due to vapor transport or capillary force when the soil is near saturation.

Soils provide habitat for animal burrows, and through their burrowing activities, animals alter soil texture, organic matter content, mineral availability, and soil moisture content, thus enhancing plant growth (Mielke, 1977; Inouye and others, 1997; Reichman and Seabloom, 2002; Titus and others, 2002; Wagner and others, 2004). Coppice mounds beneath Larrea tridentata (creosote bush) are common sites for rodent burrows (Titus and others, 2002), which are excavated into a generally finergrained substrate created by the combination of bioturbation and eolian accumulation. Mounds associated with harvester ant colonies are a mix of surface and subsurface soil, in addition to large amounts of organic matter collected by the ants. Desert tortoises, larger mammals, lizards, and snakes all utilize burrows, and thus can also affect soil texture and chemistry.

\section{Eolian Processes and Dustfall}

Movement of soil particles (sand, silt and/or clay) by wind (fig. 10) is one of the dominant processes in dryland environments (Breshears and others, 2003). Soil movement affects ecosystem function through its effects on soil texture, depth, and chemistry. Such changes in soil characteristics can alter the plant species assemblage, density, and/or size in a given area. Inputs of sand onto existing soil surfaces increase water infiltration, dilute nutrient concentrations, reduce soil surface stability, and restrict the ability of the soils to hold nutrients and water in the soil profile (Breshears and others, 2003). Sand deposition causes plant burial, either partially or completely, favoring those plant species with the ability to adapt to rapid changes in the surrounding substrate. In addition, sand inputs can increase or decrease the ability of specific animal species to effectively burrow into the soil. The deposition of fine particles (silt and clay), which are generally rich in nutrients, can alter soil fertility, and thus plant community composition (Reynolds and others, 2001), including invasion patterns of non-native annual grasses (Miller and others, 2006). This input can also increase the water-holding capacity of soils, although if it is incorporated into an Av horizon, water infiltration can be restricted (as described above). As airborne dust collects and accumulates on leaves and stems of desert plants, a reduction in physiological performance may eventually reduce plant growth (Sharifi and others, 1997, 1999) and seedling establishment (D.R. Sandquist, oral commun.).

Many natural factors interact to determine rates of soil loss through eolian processes. Armoring of the soil surface is provided by rocks, physical and biological soil crusts, plants, and plant litter (van Donk and others, 2003; fig. 11). Wellarmored soils are generally very stable. Soil texture is also very important in soil erodibility. Sand grains are large, and thus difficult to move, often blowing only short distances, whereas silt and clay particles can become entrained in the atmosphere and travel around the globe. Surfaces containing only silt and clay particles (for example, playas) are generally very stable, as physical crusting can rapidly armor the surface. However, input of sand particles, either as substrates are exposed or newly deposited by wind, will reduce the effectiveness of the armoring, as their high impact velocity can easily break through most physical crusting, dislodging the fine particles and allowing them to leave the site. Contrary to common belief, most desert surfaces are very stable and in the absence of disturbance, produce little sediment (Marticorena and others, 1997), although there are a few surface types (for example, playa margins, dry wash bottoms) that are inherently unstable. Because winds can more easily move silt and clay

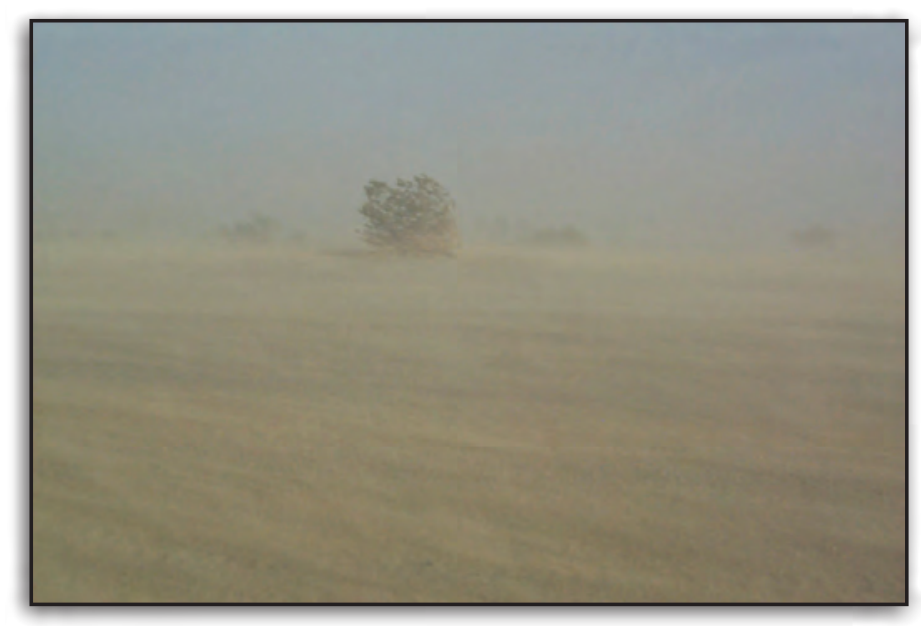

Figure 10. Dust storm at U.S. Army National Training Center, Fort Irwin, California, illustrates the extremely large transport of topsoil in severely disturbed environments (U.S. Geological Survey photograph by Jayne Blenap). 
than sand particles, loss of soil through wind erosion leaves behind a coarser textured soil with lower fertility and waterholding capacity.

\section{Carbon and Nutrient Cycling}

\section{Carbon}

In desert soils, there are two main sources of carbon: carbonate deposits and organic matter. Most carbonate deposits are formed when salt-bearing precipitation percolates down through the soil and the water evaporates, and the salts precipitate as carbonates. Carbonates are not considered a readily available form of carbon to either soil biota or plants; organic matter, on the other hand, is a readily available source of carbon. Most soil organic matter is derived from dead above- and below-ground plant material. Many models of above-ground plant materials assume that decomposition rates are mostly dependent on the quality of the litter (that is, how attractive is the litter to microorganisms and how easily can they decompose it). However, in desert ecosystems, there is little demonstrated relation between the quality of the litter and decomposition (Whitford, 2002), decomposition rates are often independent of temperature, and decomposition can occur in the absence of all biota (MacKay and others, 1994). Therefore, it is likely that most decomposition of above-ground litter is abiotically driven in deserts (Moorhead and Reynolds, 1989; Whitford, 2002). In contrast, decomposition of below-ground materials (such as plant roots) is biotically driven and highly dependent on the number and type of soil organisms present (Whitford, 2002). The activity, type, and abundance of these organisms are, in turn, affected by soil texture, chemistry, and structure, as well as climate and the quality of the litter available.

When soils are wetted, some soil carbon is lost due to abiotically driven outgassing. However, most carbon is lost from the soil through respiration by plant roots and surface and subsurface soil biota. Respiration rates are dependent on temperature, moisture, and on how much biomass is present to respire. Res-
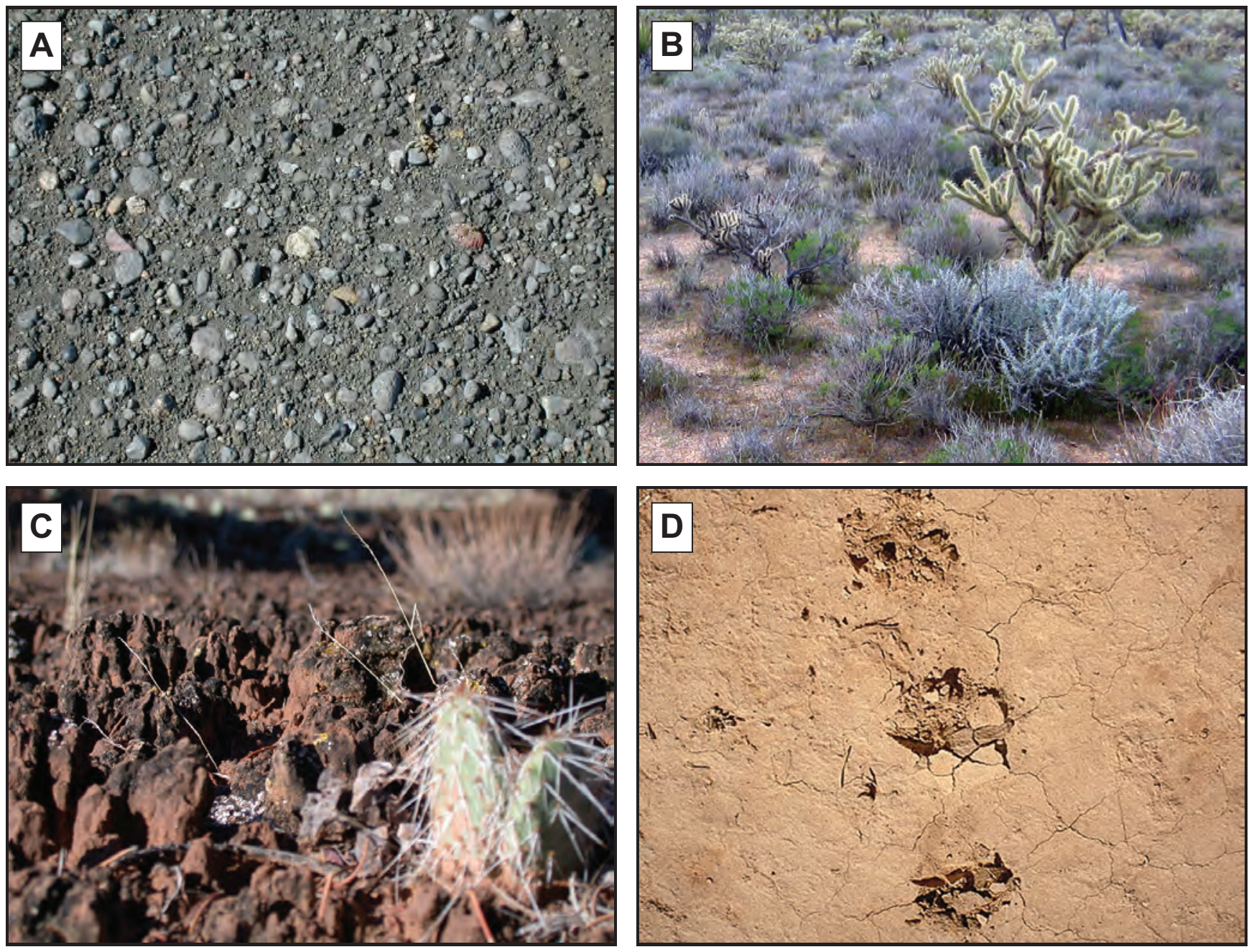

Figure 11. Soil stabilizers in aridlands include A, rocks, B, plants and plant litter, C, biological soil crusts, and D, physical and chemical crusts (U.S. Geological Survey photographs by Jayne Belnap). 
piration rates in plants and soil biota increase with increasing temperature. While plants are always respiring, soil moisture is required for any measurable respiration from soil biota.

\section{Nitrogen}

Nitrogen, as it occurs in the atmosphere, is in a form not usable by vascular plants or other eukaryotic organisms. It must first be reduced or "fixed" by either lightning or prokaryotic organisms (for example, eubacteria and cyanobacteria). As rainstorms with lightning are infrequent in this region, lightning provides only a small amount of nitrogen to this system. Thus, the dominant source of nitrogen in the Mojave Desert is prokaryotes, and the dominant prokaryote is the cyanobacterium Nostoc. Nostoc occurs as a free-living organism or as part of the soil lichens Collema and Peltula. Heterotrophic bacteria, which occur in the root zones of plants, can also fix nitrogen, but reported values of nitrogen fixed by these organisms are extremely low. Some desert plants also have root nodules containing nitrogen -fixing bacteria (Rhizobium spp. or Bradyrhizobium spp.; Farnsworth and others, 1976; Whitford, 2002). However, the abundance of such plants is low in the Mojave Desert, and thus their contribution of nitrogen is limited.

Cyanobacteria and bacteria are physiologically active only when wet. Consequently, nitrogen fixation is primarily controlled by moisture, with temperature the next limiting factor (Belnap, 2003c). The nitrogen fixed by these organisms is often released into surrounding soils, where it is available for uptake by plants, other microbes, or to be reabsorbed by the fixing organism. Once nitrogen is fixed as ammonium $\left(\mathrm{NH}_{4}^{+}\right)$, it goes through several transformations mediated by soil microbes, producing multiple forms of nitrogen $\left(\mathrm{NO}, \mathrm{N}_{2} \mathrm{O}\right.$, and $\mathrm{N}_{2}$ ). During each transformation, nitrogen-containing gases are released back into the atmosphere, and thus nitrogen is lost from the soil. The primary control on each step is the availability of the substrate to be converted and secondary controls are moisture and temperature. Therefore, nitrogen transformation rates are affected by soil disturbance and climate. Loss of nitrogen also occurs through ammonia $\left(\mathrm{NH}_{3}\right)$ volatilization, by leaching (Walvoord and others, 2003), or during rainstorms, where it is carried away in both runoff water and the sediment suspended in the water (Barger and others, 2006).

\section{Phosphorus}

Phosphorus can limit plant production in deserts (DeLucia and others, 1989; Schlesinger and others, 1989; Parker, 1995). The primary source of phosphorus is the weathering of primary minerals, such as apatite. Phosphorus inputs from the atmosphere (either as wet or dry deposition) are very low (Reheis, 1999).

In high-pH desert soils, phosphorus is relatively insoluble due to reactions with carbonates (for example, $\mathrm{CaCO}_{3}$ ), iron oxide, or other compounds (Barber, 1995; Lajtha and Harrison, 1995). As a consequence, it is relatively unavailable for uptake by soil biota and plants (Barber, 1995; Marschner, 1995). Exudates of bacteria, fungi, cyanobacteria, and plant roots can increase phosphorus availability and uptake by dissolving some of these compounds (Lajtha and Harrison, 1995; Barrow and Osuna, 2002). For example, the emission of respiratory carbon dioxide $\left(\mathrm{CO}_{2}\right)$ by roots and soil biota results in the formation of carbonic acid $\left(\mathrm{H}_{2} \mathrm{CO}_{3}\right)$ when $\mathrm{CO}_{2}$ dissolves in water (Knight and others, 1989). The effectiveness of this mechanism for acidification and the enhancement of phosphorus availability is greater in cool moist soils than in warm dry soils because $\mathrm{CO}_{2}$ solubility in water increases with decreasing temperatures above freezing (Krauskopf and Bird, 1995).

\section{Potassium}

Potassium is an essential nutrient for plants. Plants often require more potassium than is available in soils (Troeh and Thompson, 2005). Potassium is not easily leached from soils, even over long periods of time; thus potassium is fairly evenly distributed throughout the soil profile, especially in dryland regions where precipitation, and thus leaching potential, is limited (Troeh and Thompson, 2005).

\section{Other Major Cations}

Calcium concentrations in dryland soils are generally sufficiently high to not limit plant productivity. The high levels of calcium can have a profound influence on the availability of other nutrients. In addition to raising the $\mathrm{pH}$ of soils, excess calcium precipitates as calcium carbonate at the soil depth to which most precipitation infiltrates; this can create a solid layer (called caliche or calcrete) that impedes plant roots and water flow. Calcium compounds also react with other soil nutrients, such as phosphorus, magnesium, and micronutrients, reducing their solubility and bio-availability (Troeh and Thompson, 2005). Therefore, the ratio of calcium to other cations can influence plant productivity (Barber, 1995). Because carbon dioxide solubility in water (thus potential carbonic acid $\left[\mathrm{H}_{2} \mathrm{CO}_{3}\right]$ formation) and calcium carbonate $\left(\mathrm{CaCO}_{3}\right)$ solubility both increase with decreasing temperatures (Krauskopf and Bird, 1995), adverse effects of calcium compounds on the bio-availability of other nutrients may decrease when soils are cold and wet.

Magnesium tends to be relatively easily weathered, and thus soils are depleted of magnesium faster than potassium or calcium. Magnesium interacts strongly with other cations, especially the monovalent potassium and sodium, due to the preferential adsorption of the polyvalent magnesium ion. Therefore, the ratio of magnesium, like the polyvalent calcium, to other cations can influence plant productivity (see Potassium section).

Sodium is considered a non-essential element, but it is beneficial in small amounts. Sodium levels in desert soils are almost always sufficient for plant growth. Sodium is the most easily leached cation. In deserts, salts (mostly sodium chloride $[\mathrm{NaCl}]$ ) move upwards in soils due to capillary action when the soil surface is drier than underlying layers and form a white crust on the surface (Troeh and Thompson, 2005). Thus, much of the alkalinity of dryland soils is due to the presence of sodium. Many dryland plants have active mechanisms to handle excess soil sodium levels, such as extruding salt onto 
the leaf surface or storing ions in cell vacuoles to prevent interference with processes in the cytoplasm (Whitford, 2002).

\section{Micronutrients}

Copper, iron, zinc, and manganese are all important to plants as well. However, coarse soils with high $\mathrm{pH}$, which are typical in the Mojave Desert, have inherently low concentrations of bio-available micronutrients (Alloway and Tills, 1984). In addition, micronutrients often react with carbonate compounds in desert soils, resulting in low solubility and bio-availability similar to phosphorus. Interactions among the micronutrients themselves can also reduce their bio-availability (Day and Ludeke, 1993).

Low availability of the micronutrients can impact plant communities. Jarrell and Virginia (1989) postulated that copper may limit plant productivity in dryland regions. Copper deficiency has been linked to suppression of nitrogen fixation in vascular plant-Rhizobium associations (Cartwright and Hallsworth, 1970). Iron deficiencies are common in dryland regions and may limit plant productivity (Hunter and others, 1980; Wallace, 1989). Cramer and Nowak (1992) report that the addition of manganese stimulates growth in annual grasses, and others have noted that manganese deficiencies may limit plant productivity in drylands (Jaurequi and Reisenauer, 1982; Marschner, 1995). Bowker and others (2006) reported that manganese deficiency controls the distribution of the common nitrogen-fixing lichen Collema tenax in western North America. Zinc deficiency is also common throughout dryland regions of the globe and also can limit plant productivity (Jaurequi and Reisenauer, 1982; Jarrell and Virginia, 1989; Killingbeck, 1989; Marschner, 1995; Hacisalihoglu and Kochian, 2003).

\section{Soil Biota}

Soil biota (figs. 3D, F, and G) play a critical part in most ecosystem processes, including soil stabilization, nutrient cycling, and local hydrology. Because soil biota influence so many parts of the desert ecosystem, they are considered part of each of the four components of our general ecosystem conceptual model (fig. 3): soil resources (D), vegetation (E), biological soil crusts $(\mathrm{G})$, and invertebrates (F). Most of the species diversity of any ecosystem occurs in the soils, but the species composition is poorly understood and difficult to elucidate. Functioning of soil processes depends on the soil biota present; the type and amount of inputs from above-ground biota; and soil structure, aeration, temperature, and moisture.

\section{Soil Surface Biota: Biological Soil Crusts}

Biological soil crusts (BSCs) are biotic communities composed of cyanobacteria, algae, microfungi, mosses, and lichens that occur on and within the upper few millimeters of the soil surface (Belnap and Lange, 2003; figs. 3G and 12). These diverse communities are characteristic of ecosystems where conditions limit the development of closed-canopy vas- cular plant communities or the development of thick layers of plant litter (Belnap and Lange, 2003). Almost all soil surfaces in the Mojave Desert are covered by a layer of cyanobacteria, with the dominant species being the large filamentous Microcoleus vaginatus. On more stable surfaces with finer-textured soils, the smaller cyanobacteria (for example, Nostoc commune) are common as well. In addition, more stable surfaces and soils at higher elevations also support lichens (for example, Collema tenax, Placidium lachneum, Peltula richardsii) and mosses (for example, Syntrichia caninervis, S. ruralis). In many areas, these crusts represent over 70 percent of the living ground cover (Belnap, 1997).

In addition to their major contributions to biological diversity, BSCs perform many other functions in dryland ecosystems. The presence and physiological activity of BSC organisms aggregate soil particles, thereby increasing soil stability and reducing the susceptibility of soil to erosion by wind and water (Williams and others, $1995 \mathrm{a}, \mathrm{b}$ ). They roughen the soil surface, thus facilitating the capture and retention of wind-blown dust, which can be a significant source of mineral nutrients in dryland ecosystems (Belnap and Lange, 2003; Reynolds and others, 2001). BSCs similarly can enhance retention of windborne and waterborne organic matter and seeds (Belnap and Lange, 2003).

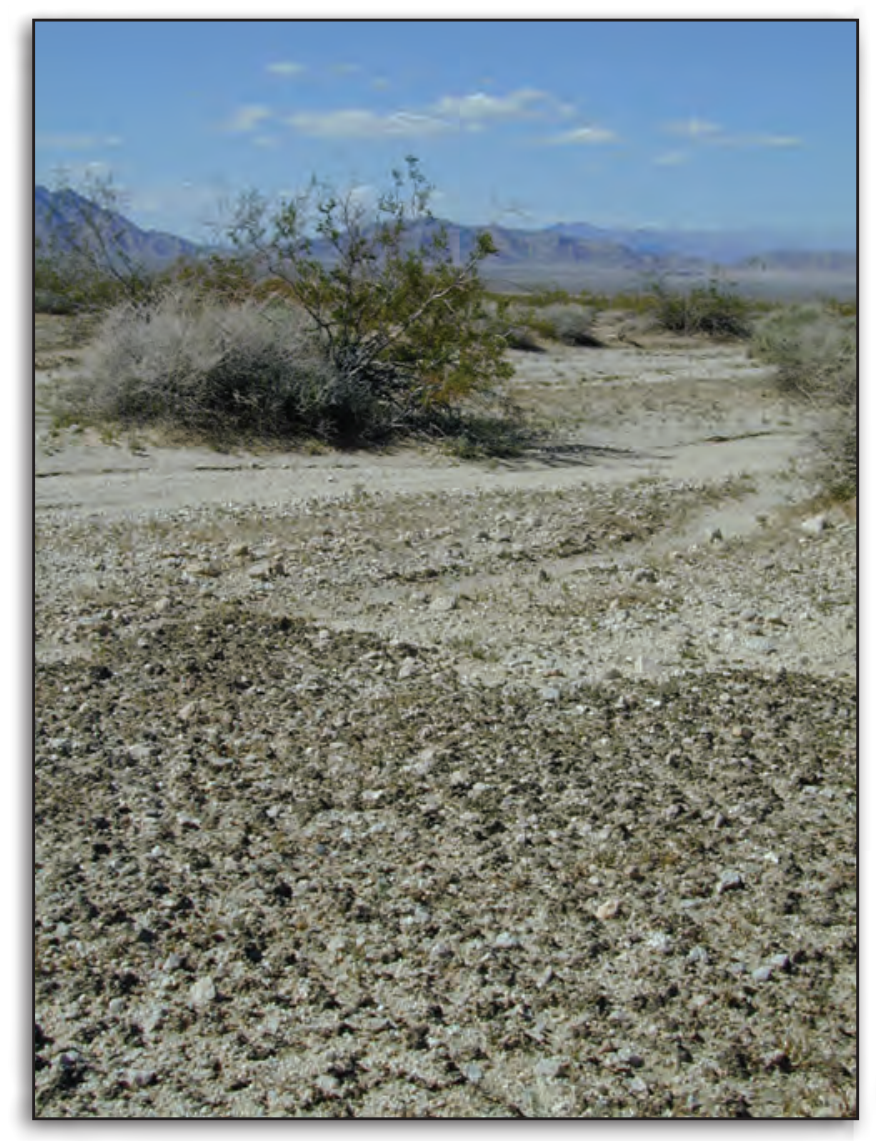

Figure 12. Patch of well-developed biological soil crust typical of the Mojave Desert (U.S. Geological Survey photograph by David M. Miller). 
The hydrologic effects of BSCs are complex, as their effects on infiltration and runoff are very site specific. Regardless of crust or soil type, the presence of BSCs stabilizes soils and reduces water erosion. This stabilization is due to the above-ground structures of BSCs reducing raindrop impact and detachment of soil particles. In this function, cyanobacteria and algae are less effective than mosses and lichens. However, BSC organisms also can clog soil pores and inhibit infiltration. At higher elevations, soils frost heave, and the presence of BSCs roughens the soil surface. At these locations, the inhibition of infiltration from the presence of BSC organisms is more than offset by increased residence time of the water due to soil roughness, which increases infiltration. At low-elevation sites, however, BSCs do not always substantially increase soil surface roughness, and in these situations the presence of a well-developed soil crust can either decrease or increase infiltration, depending on specific site characteristics (Belnap, 2003a). Organic carbon produced by BSC organisms can contribute to the formation of stable soil aggregates that increase the ratio of macropores to micropores, and thus enhance infiltration. Strong soil features, such as the presence of a thick Av horizon or heavy shrink-swell clays, will override any effect of BSCs in terms of local hydrology.

In addition to enhancing soil stability and nutrient retention, BSCs also contribute to soil fertility. Mosses, cyanobacteria, green algae, and lichens are photosynthetic, and thus can be significant sources of carbon in dryland ecosystems, particularly in interspaces among vascular plants where soil crusts can attain 100 percent cover (Lange, 2003). Most cyanobacteria (for example, Nostoc and Scytonema) and cyanolichens (for example, Collema) are also capable of fixing atmospheric nitrogen into a mineral form that can be used by vascular plants (Evans and Lange, 2003). Consequently, BSCs can be the dominant source of nitrogen in many dryland regions (Evans and Ehleringer, 1993; Belnap, 2002). Soil organisms are significant sources of carbon for other soil biota, and they are more abundant and diverse under BSCs than under bare soils (Belnap, 2003b). BSCs also increase nutrient cycling rates of soil food webs through their effects on near-surface moisture availability, soil structure, soil aeration, and soil temperature, thus increasing soil nutrient availability (Belnap, 2003b).

BSCs also influence vascular plants. Where they roughen the soil surface, as when lichens and mosses are present or where soils frost heave, they increase the retention of seeds. Conversely, where they smooth the soil surface, as in very low elevations, they can increase the movement of seeds from the interspace to the nearest obstruction, such as a plant or rock. The effect of BSCs on plant germination is very species and site specific; research has shown them to suppress germination in some species and enhance germination in other species. They seem to consistently suppress the germination of large-seeded, non-native, annual grasses, such as Bromus tectorum (Belnap and Lange, 2003). Relative to plants growing in soils without BSCs, plants growing in association with BSCs consistently have greater biomass and greater nitrogen concentrations in tissues and usually have higher concentra- tions of the plant-essential nutrients potassium, magnesium, copper, and zinc (Harper and Belnap, 2001). In contrast, plants growing in soils with BSCs commonly have lower concentrations of phosphorus and iron than plants growing in soils without BSCs, suggesting that plants and BSCs may compete for these elements. Nutritional differences between plants grown in soils with and without BSCs are greatest in shallowrooted herbaceous species, probably because they are rooted in near-surface soils that are most directly influenced by BSCs (Harper and Belnap, 2001). However, there are species-specific exceptions to these patterns (DeFalco and others, 2001). In addition, plants growing in crusted soils have a higher mycorrhizal infection rate than those growing in non-crusted soils, and thus have greater access to water and nutrients (see below; Pendleton and others, 1989).

\section{Subsurface Soil Biota}

Many thousands of tiny organisms, including bacteria, fungi, protozoa, nematodes, and microarthropods, comprise the subsurface soil biota (figs. 3D, F, and G; table 1). As these organisms are not photosynthetic, they depend for energy on the carbon contributed by biological soil crust organisms and plant litter or on predation on other soil biota. These organisms are critical in the breakdown of plant litter and roots in the soil and making the nutrients contained within these materials available to plants and other biota (Adl, 2003).

Because bacteria and fungi are very tolerant of harsh conditions, they are often the most important component for decomposition in deserts (Whitford, 2002). Bacteria thrive on readily decomposed substrates, such as fresh plant litter, fine roots, and compounds found near living roots. The species composition and abundance of bacteria vary with plant community composition. Because they are very small $(1 \mu \mathrm{m})$, they cannot extend through the soil to find nutrients sufficient for their survival. Instead, those nutrients need to be in one small microregion. In addition, some nitrogen-fixing bacteria can colonize nodules that occur on the roots of particular plant species. These plants benefit by being able to directly absorb the fixed nitrogen.

Fungi, in contrast, tend to grow in threads that can be meters long, and thus nutrients found in one zone can be transported to another zone. Fungi can utilize recalcitrant litter, such as wood or large roots. Soil fungi also include mycorrhizal fungi, which colonize the roots of most desert plant species. These fungi can be very important in obtaining water, nitrogen, phosphorus, and zinc for plants due to their ability to expand into the soil zones beyond the reach of roots, and thus increase the soil volume being explored for water and nutrients. These fungi are especially important under adverse conditions. In addition, the presence of fungal hyphae winding through the soils also contributes to soil stability.

Larger soil microfauna include protozoa (ciliates, amoebae, and flagellates), nematodes, mites, and other microarthropods. They perform many important ecosystem functions, such as shredding large pieces of organic matter into smaller pieces, 
Table 1. Soil organisms and their major functions.

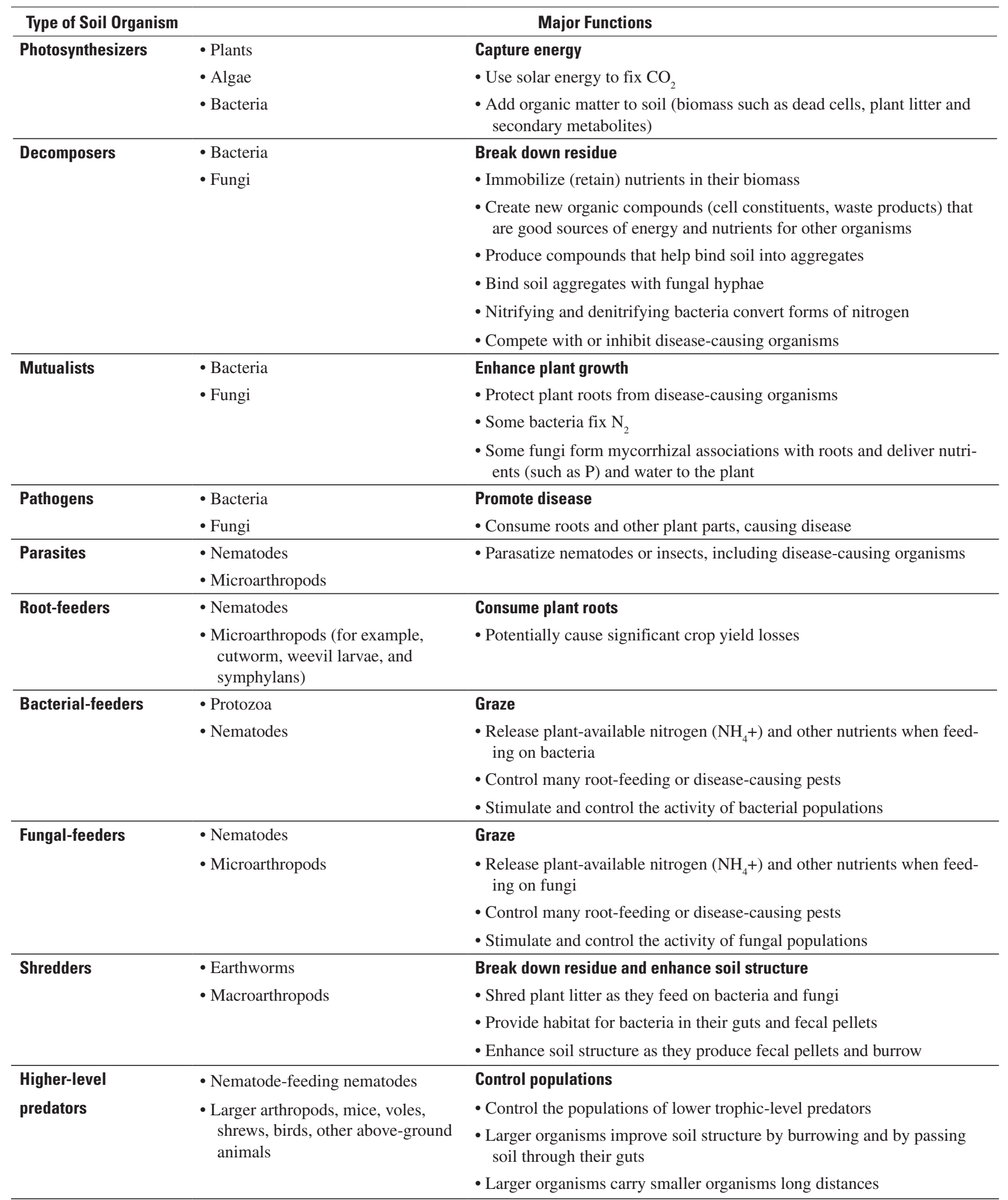


making it more easily decomposed by bacteria and fungi. They stimulate microbial activity by grazing on them. They enhance soil aggregation through their fecal matter, while their burrows enhance penetration of water and gas into the soil. They stimulate species succession in the soil biota, and they can control plant pests (or be plant pests). All microarthropods prey on soil bacteria and fungi, as well as each other. Nematodes prey on bacteria, fungi, protozoa, microarthropods, plant roots, and other nematodes. When these animals eat each other, nutrients such as nitrogen are released into the surrounding soil. Soil microarthropods, especially nematodes and mites, have been shown to be sensitive indicators of ecosystem health in other arid ecosystems (Kay and others, 1999).

\section{Vegetation}

In terrestrial ecosystems, vegetation is the dominant functional type, as vegetation defines the productivity, habitat structure, and ecological processes within an ecosystem (fig. 3E). Plants convert carbon dioxide from the atmosphere into shoots, leaves and roots, and upon their decomposition, contribute carbon to soils (fig. 3D). Plant canopies and roots protect soils from erosion and mediate microhabitat conditions. They also provide fuels for fire and habitat for aboveand below-ground fauna (figs. 3F, $\mathrm{H}$, and I). The cover of native perennials, particularly the most common species, such as Larrea tridentata (creosote bush), Ambrosia dumosa (white bursage), and Coleogyne ramosissima (blackbrush), represents one of the most important signs of ecosystem health in the Mojave Desert. Plants are also effective indicators of biodiversity in arid ecosystems (de Soyza and others, 1998, 2000; Landsberg and Crowley, 2004).

The composition of Mojave Desert plant communities is influenced by the flora of the Sonoran and Colorado Deserts to the south and southeast and the flora of the Great Basin Desert to the north (Johnson, 1976; Rowlands, 1995). At the regional level, a high abundance of succulent plants that rely on summer precipitation (cacti, ocotillo, and members of the genera Yucca, Agave, and Nolina) can be found in the small portion of the Mojave (east and south) east of the $117^{\text {th }}$ meridian, where summer rainfall is dependable (Rowlands, 1995). About 15 percent of these plants utilize the water-use-efficient $\mathrm{C}_{4}$ or Crassulacean Acid Metabolism (CAM) photosynthetic pathways (Johnson, 1976). However, most of the Mojave Desert is dominated by winter rainfall, and consequently, 85 percent of the vascular flora utilize the $\mathrm{C}_{3}$ photosynthetic pathway (Johnson, 1976) and have maximum growth during the spring months following winter rainfall. The most common perennial grasses in this desert also use the $\mathrm{C}_{3}$ pathway, with the notable exception of the $\mathrm{C}_{4}$ Pleuraphis rigida (big galleta grass). At the local scale, rainfall patterns interact with the soils and geomorphy to determine the distribution of plants, which, ultimately, governs the distribution and abundance of biota in desert systems (Juhren and others, 1956; Beatley, 1969, 1976; Schwinning and Sala, 2004).
Several classification systems for Mojave Desert perennial plant assemblages were developed in the mid $20^{\text {th }}$ century (Johnson, 1976). Beatley (1976) proposed the first detailed classification system, describing 16 vegetation assemblages for the Nevada Test Site and vicinity in the northeastern Mojave and transition Great Basin deserts. She determined her assemblages based on almost a decade of work collected on 68 permanent vegetation plots. Ostler and others (2000), working in the same area as Beatley, defined 10 vegetation alliances and 20 associations using multivariate analyses of 1,508 observation points on the Nevada Test Site. In contrast, Sawyer and Keeler-Wolf (1995), in a manual of California vegetation, listed 26 assemblages that included either L. tridentata or $C$. ramosissima. Finally, Thomas and others (2004) defined 101 alliances in the Mojave Desert, ranging from those in riparian zones to those in arid settings, and provided a key to determining the alliance type from field-collected data. The concept of vegetation association and alliance has considerable elasticity, and a large amount of variation in species composition occurs within these vegetation units. The units described by Thomas and others (2004) are large, with low-resolution boundaries. Some of their units have explicit or implicit disturbance histories that drive the species composition (for example, wash assemblages).

The Mojave Desert is predominantly a shrubland with a large annual plant component and scattered, highly localized patches of perennial grasses and endemic plants. In general, the distribution of Yucca brevifolia (Joshua tree) and $Y$. schidigera (Mojave yucca) defines the broader extent of the Mojave Desert. The lowest elevations in the Mojave Desert have wet playas (salt flats) that support sparse vascular perennial vegetation (fig. 13). At the edges of the barren wet playas are salt scrub plant communities represented by Distichlis spp. (saltgrass), Tessaria sericea (arrowweed), and Allenrolfea occidentalis (pickle weed). Prosopis glandulosa (mesquite) stands occur near the margins of wet playas and the base of dune complexes, where they seasonally take advantage of both deep and shallow water tables.

Just above the lowest elevations are found the two most common species in the Mojave Desert: L. tridentata and A. dumosa. These species are shared with the southerly deserts and can be found in the medial piedmonts which cover much of the Mojave Desert. These two shrubs are often interspersed with a variety of cacti, such as Echinocactus polycephalus (cottontop cactus); semi-succulents, such as Encelia farinosa (brittlebush) and Lycium andersonii (wolfberry); as well as Yucca schidigera (Mojave yucca). The various saltbushes (Atriplex canescens, A. confertifolia), Grayia spinosa (spiny hopsage), Krascheninnikovia lanata (winterfat) and Sarcobatus vermiculatus (greasewood), shared with the Great Basin Desert, occur on gravelly soils at the base of piedmonts and sometimes the margins of dry playas at lower and middle elevations. The most common desert scrub community at intermediate elevations is dominated by $C$. ramosissima and Artemisia tridentata (big sagebrush) and provides an important transition with the Great Basin Desert. C. ramosissima can form near-monospecific stands on old deposits with 
strongly developed soils. Although previously viewed as a species-depauperate vegetation type, recent studies indicate that blackbrush-dominated communities are as speciose as other desert scrub alliances (Brooks and others, 2004). Near the upper piedmonts, desert scrub alliances may border savannah grassland represented by perennial bunch grasses (for example, Pleuraphis rigida, P. jamesii, Achnatherum hymenoides) and scattered shrubs including $C$. ramosissima and $Y$. brevifolia. Above the blackbrush and sagebrush level, at the upper piedmont and the lower slopes of mountain ranges, is a sclerophyllus woodland characterized by the evergreen Pinus spp. (pinyon pine) and Juniperus spp. (juniper). These trees are interspersed with shrubs, such as Purshia glandulosa (bitterbrush) and Cercocarpus montanus (mountain mahogany). These woodlands occur at elevations above about 1,500 $\mathrm{m}$ and are transitional to the vegetation of the Basin and Range mountains, as well as to the Transverse Ranges and Sierra Nevada to the west. At higher elevations, the montane slopes are dominated by forests consisting of several different conifer species, such as Abies concolor (white fir), Pinus flexilis (limber pine), and Picea englemannii (spruce). These forests are highly variable in species composition.

Mojave Desert annual plants have been studied for decades, and research has focused on a broad diversity of topics, including soil seed reserves (Nelson and Chew, 1977; Guo and others, 1998, 1999), germination requirements (Went, 1948, 1949; Juhren and others, 1956; Beatley, 1974), microsite associations and environmental gradient (Nelson and Chew, 1977; Samson, 1986; Lichvar and others, 1998), population fluctuations in response to climatic variability (Beatley, 1974; Bowers, 1987; Webb and others, in press), physiology, growth and development (Went and Westergaard, 1949; Mooney and others, 1976), resource use and allocation (Williams and Bell, 1981; Bell

Figure 13. Vegetation zones in the Mojave Desert. As latitude increases, vegetation zones descend in elevation due to decreasing temperature and increasing available moisture. Plant cover is, in general, more dense northward and upward, except at very high elevations. and others, 1979; DeFalco and others, 2001, 2003), native versus non-native species compositions and interactions (Beatley, 1966; Brown and Minnich, 1986; Hunter, 1991; Brooks, 1999a, 1999b, in press), and competition and competitive abilities (DeFalco and others, 2003, 2007; Brooks, 2000). Desert annuals have also been integral to studies on the diet and foraging habits of the many herbivores that rely on them, such as heteromyid rodents (Beatley, 1969) and the desert tortoise (Esque, 1994; DeFalco, 1995). The timing and abundance of rainfall are enormously variable in the Mojave Desert, challenging our ability to predict annual plant productivity and species composition from year to year (fig. 14). Understanding variability by collecting data in multiple years of contrasting rainfall at sites that span a range of soil types is paramount to distinguishing natural fluctuations in native and non-native annual plant responses from those that signal a need for management action.

\section{Annual Plants and Climatic Variability}

The abundance and diversity of desert annuals are intimately tied to rain that falls from late autumn through early spring (Beatley, 1974), especially that occurring from late Sep-

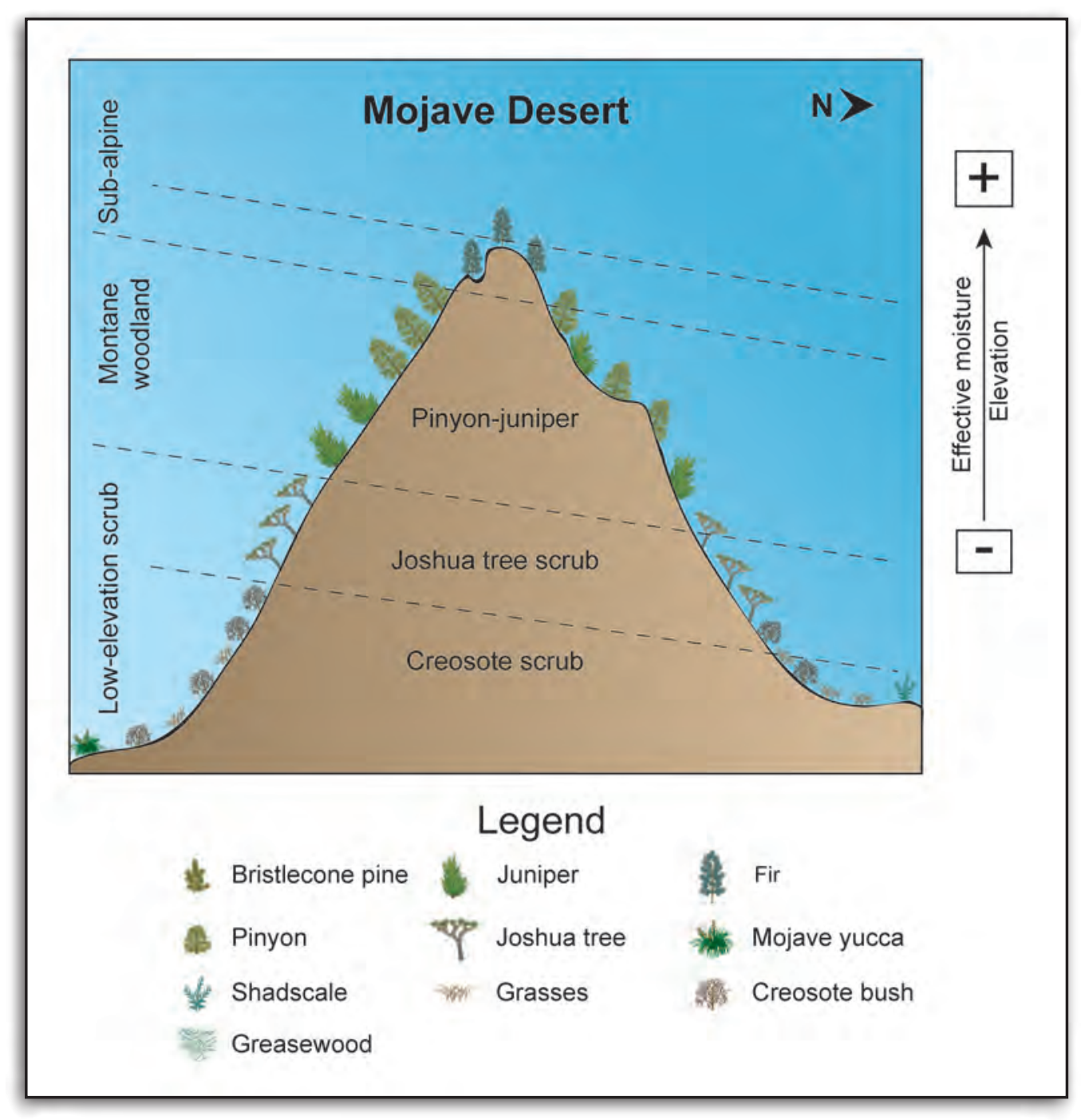


tember through December, which is needed to break seed dormancy and stimulate germination (Went, 1948; Beatley, 1967, 1969, 1974; Bowers, 1987; Hunter, 1991). On a regional scale, the above-average rainfall which generally occurs during an El Niño year stimulates the greatest amount of winter annual production in the Mojave Desert (Bowers, 2005a). Although most winter annual species senesce by late spring and early summer, occasional heavy monsoonal storms during July and August, which increase in importance to the east and south (Rowlands and others, 1982), can also stimulate a unique flora of summer annuals. Non-native Bromus madritensis ssp. rubens (red brome), an increasingly dominant species in annual plant communities (Brown and Minnich, 1986; Hunter, 1991), responds positively during wet rainfall years and has low numbers or is completely absent during drought periods (figs. 14 and 15). Revisitation of the undisturbed Beatley plot 3 in Rock Valley (DeFalco and others, unpub. data), censused from 1963 to 1975,1987 to 1995 , and 2000 to 2006, indicates that $B$. madritensis ssp. rubens has been continuously present. However, while $B$. madritensis ssp. rubens has the traits that allow it to outcompete native winter annual species (DeFalco and others, 2003), native population densities are not often negatively correlated with $B$. madritensis ssp. rubens densities (Beatley, 1966; Hunter, 1991). Thus, all annual species respond in complex ways to the timing, distribution, and amounts of winter precipitation.

Wet winters, such as the El Niño winter of 1997-1998, generally result in high densities of native and non-native annuals (Smith and others, 2000), leading to storage of propagules in seedbanks. Seeds of native desert species can remain dormant in the soil for years, which allows them to delay emergence when germination conditions are unfavorable (Cohen, 1966); the optimal conditions for breaking seed dormancy, germination, and plant growth vary among species and do not occur every year (Baskin and Baskin, 1998). Therefore, only a small number of the native seeds present in the soil may germinate and mature into adult plants each season, and the species composition of these standing annual plants can differ by more than 50 percent compared to the soil seedbank (M.L. Brooks, unpub. data). In contrast, $B$. madritensis ssp. rubens does not have seed dormancy (DeFalco and others, 2003), which makes it susceptible to extended periods of belowaverage rainfall that can result in dramatic seedling mortality. Seeds of natives and non-natives are also distributed unevenly across the landscape and the variable microsite conditions they experience introduce additional variability in germination and establishment success (Halvorson and Patten, 1975; Young and others, 1976; Reichman and Oberstein, 1977; Reichman, 1984; Price and Reichman, 1987; Price and Joyner, 1997;

Guo, 1998; Esque, 2004). Consequently, seedbanks should be monitored in addition to above-ground plants and their productivity; not doing so underestimates the potential and true composition of the plant community.

\section{Arthropods}

Arthropods influence a diversity of trophic levels represented in the Mojave Desert through their role as pollinators, herbivores, predators, prey, vectors of disease, hosts and parasites, and decomposers (figs. 3D, F, and G). Macroinvertebrates are, by far, the most speciose animal group, with ants, termites, bees, and flies playing roles in pollination, seed predation, facilitation, decomposition, and bioturbation (MacMahon and others, 2000; Esque, 2004; Wagner and Jones, 2006). Arthropods that occur in soils and on the soil surface, such as ants, termites, and beetles, are critical in nutrient cycles. These organisms move large amounts of plant matter found on the soil surface into subsurface soils, accelerating the cycling of this plant material. In addition, nutrients released

Figure 14. Mojave Desert annual grass populations fluctuate interannually as demonstrated across nearly three decades of censusing of the non-native annual grass Bromus madritensis ssp. rubens (red brome) and native species (adapted from Hunter, 1991). Census did not occur 1977 through 1982. Note the $\log 10$ scale of annual density: no individuals of $B$. madritensis occurred in 1972, no natives occurred in 1990, and no species germinated in the exceptionally dry year of 1989 . 
from plant material are less likely to be lost to the atmosphere through gaseous emissions, as temperatures at depth are less variable and gaseous exchange rates with the atmosphere are reduced. All burrowing arthropods also create macropores in the soil, increasing the infiltration of rain water (Whitford, 2002). Arthropods are concentrated around shrubs, as they are probably responding to higher levels of soil organic matter (Rundel and Gibson, 1996).

\section{Ants and Termites}

Probably the most well known of the arthropods are ants and termites. Termites are exclusively decomposers, feeding on wood, leaves, and soil organic matter and nesting 2 to $3 \mathrm{~m}$ below the soil surface. Thus, they are important in nutrient cycling and making nutrients available to vascular plants. In addition, building and maintenance of their nests require churning of the soil, which brings nutrient-rich soil to the surface and increases water infiltration, which stimulates other soil fauna. This creates nutrient-rich patches throughout the desert. However, termite numbers are low in the Mojave Desert, unlike many other deserts, and thus they are of only low or moderate ecological significance (Rundel and Gibson, 1996). In addition, they are relatively insensitive to vegetation change, making them less suitable than other soil variables as indicators of ecosystem health (Whitford, 2002).

Ants, on the other hand, are common throughout the Mojave Desert and are among the most abundant arthropods in deserts of the world. Ants are very flexible foragers, as they can be herbivores, granivores, farmers of fungi, or predators. They live in many diverse vegetation types and diverse places within those habitats, including soil and plants. They range widely and their prodigious numbers promote their success in deserts.
They are highly socialized and together they function as a large organism, regulating temperature, humidity, and gases within the nest, reproducing and providing food to all parts of the "organism." This has required evolution of fairly sophisticated communication and the ability to transport materials from afar in a coordinated way. The females are the workers: they build the nest, collect the food, lay the eggs, and guard the nest. The males merely feed themselves and provide sperm; thus, they have lost the ability to evolve socially (Brian, 1978). Because ants can only travel a limited distance, the nest must occur in areas where resources are accessible, reliable, and sufficient. As ants collect materials and concentrate them at the nest, they also create fertile patches in the desert landscape, increasing organic matter, nitrogen, phosphorus and potassium in the vicinity of the nest (Wagner and others, 2004; Wagner and Jones, 2006).

Among the many ant species, harvester ants (for example, Pogonomyrmex rugosus; fig. 16) are the most studied, as they can have a large impact on vegetation dynamics. Observations on the distribution of ant colonies in time and space, and across thermal gradients, indicate that competition may shape ant community composition (Bernstein, 1974; Whitford, 1978; Davidson, 1980). Harvester ants regularly include seeds in their diets (MacMahon and others, 2000; Hölldobler and Wilson, 1994), and so their population size is greatest when seed drop occurs (Whitford, 2002). Seeds of specific species are often favored (Stradling, 1978), and harvester ants have been observed to collect from 33 to 100 percent of the seeds from these plant species and 9 to 26 percent of all available seeds (Crist and MacMahon, 1992). Seed harvesting by these ants can increase the diversity of seedbanks and plant production because ants consume the most common seeds and release rare plant species from competition (Brown and others, 1979). Although seed predation by ants has been emphasized in the literature, harvester ants are not always seed predators;
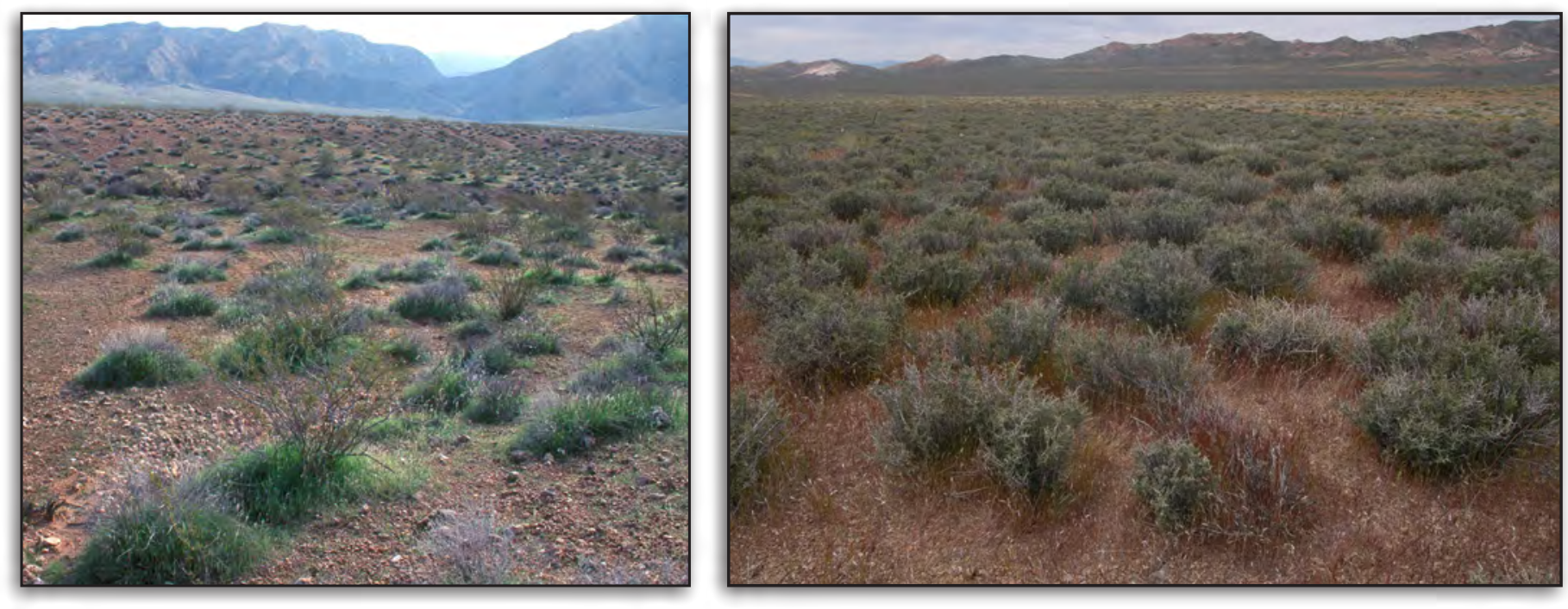

Figure 15. Non-native annuals, primarily Bromus madritensis ssp. rubens (red brome), in creosote bush-white bursage assemblages in the Mojave Desert are often restricted below shrub canopies in most years when average winter rainfall occurs (left). When aboveaverage winter rainfall occurs, distribution of red brome can extend into the shrub interspaces such as in this blackbrush shrubland at the Nevada Test Site in southern Nevada (right) (U.S. Geological Survey photographs by Todd C. Esque). 
worker ants sometimes disperse seeds by carrying seeds to the nest but not consuming them (Hölldobler and Wilson, 1994). Foraging can occur during the day and the night, depending on the species. Soil surface temperature, saturation deficits, and forage availability strongly affect foraging activity of harvester ants (Whitford, 2002). The main predators of ants are lizards, snakes, birds, and small mammals.

While Mojave Desert ants are likely to be good indicators of ecosystem health (Oliver and Beattie, 1996), much work is needed toward understanding the relations ants share with other taxa and whether they respond to environmental change similarly to other taxa. Nash and others (2004) did not consider ants to be good indicators of rangeland status in the Mojave Desert because it was not possible to discern a difference in the response of ant communities found in rangeland study sites that were ranked "fair" and "good." However, they were able to distinguish between "poor" and "fair" study sites. In contrast, ants in arid regions of Australia are routinely used as ecologi-

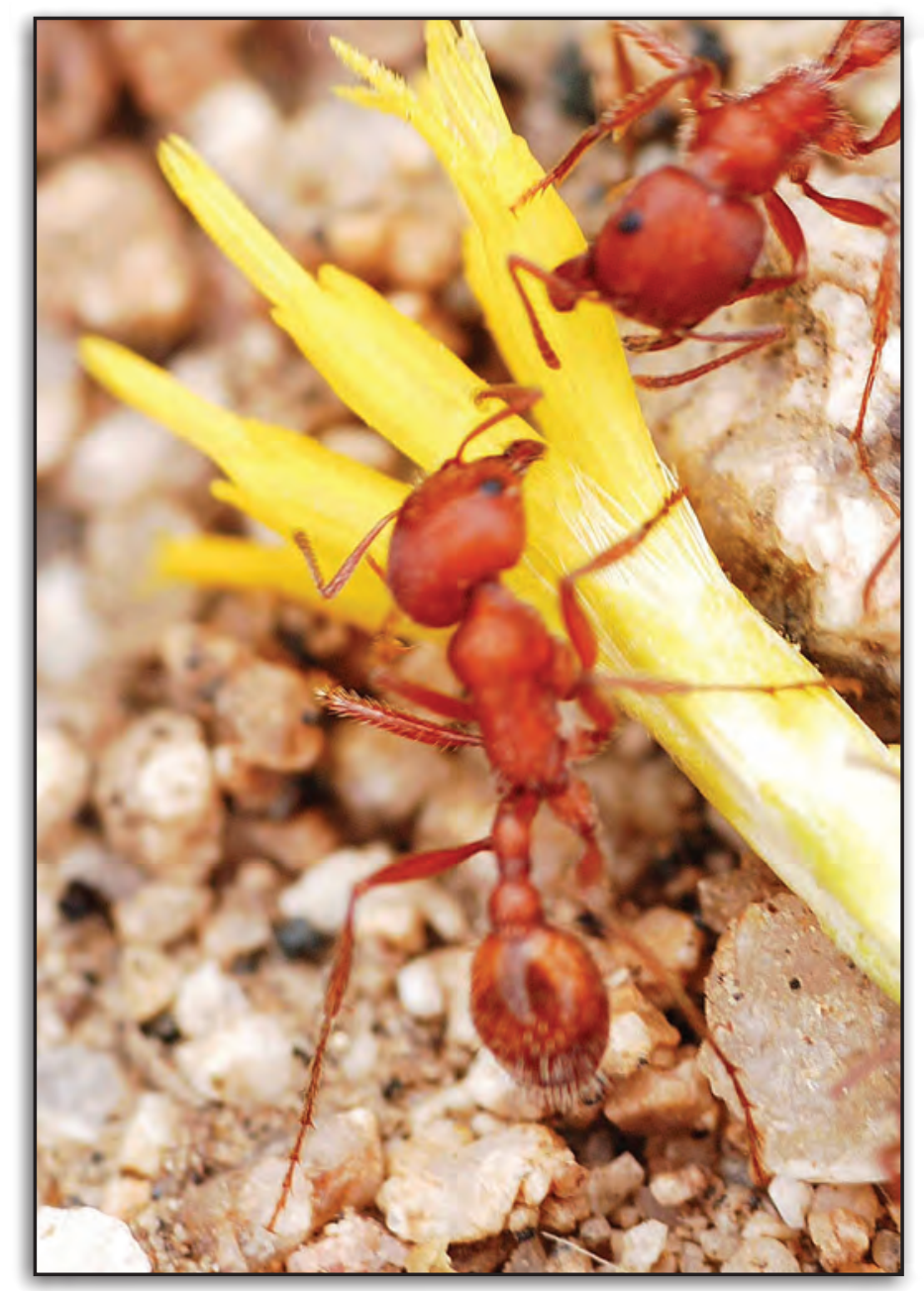

Figure 16. Harvester ants (Pogonomyrmex rugosus) collect the fruits of many species of annual and perennial plants. Ants transfer fruits below ground where the seeds are usually removed, and the empty caryopses are discarded above ground near the nest entrance (U.S. Geological Survey photograph by Todd C. Esque). cal indicators associated with diverse land uses (Andersen and Majer, 2004). It remains to be seen whether or not ants can be used as bioindicators in Mojave Desert communities.

\section{Beetles}

Darkling beetles (family Tenebrionidae) are very abundant in the Mojave Desert. There are about 50 species in this region, with Eleodes obscura generally the most abundant (Rundel and Gibson, 1996). Abundance of this beetle varies with habitat type, with the highest numbers found in LarreaAmbrosia and Grayia-Lycium communities (Allred and others, 1963). Specific species prefer specific soil types, although overall abundance is higher on sandy soils. This is likely due to the poor conductance of heat through sand, resulting in substantially reduced soil temperatures at the shallow depths where they place their burrows (Crawford, 1988). In addition, the high water infiltrability of sands results in water accumulating below the burrow. Beetle density can be startlingly high, with estimates of 48,000 individuals per ha (Rundel and Gibson, 1996). Darkling beetles are active year round, although most activity occurs March-October, with activity peaking in August and September. Most species feed on plant litter found under plants, captured in small litter dams, or around ant mounds. These habitats also moderate the high heat of the day. The species composition and abundance of these beetles appear to be very similar among disparate deserts of the world (Whitford, 2002).

\section{Other Arthropods}

Many other species of arthropods occur in the Mojave Desert. Soil-dwelling arthropods include Orthoptera, isopods, millipedes, scorpions, solpugida, spiders, phalangida (daddy longlegs), centipedes, and mites, and all are ecologically important. Whereas phytophagous soil arthropods are dominated by weevils, foliage-dwelling arthropods are dominated by three orders: Lepidoptera (moths and butterflies), Coleoptera (weevils and leaf beetles), and Orthoptera (grasshoppers and crickets). Among all the insects, sap-feeders from the Homoptera and Hemiptera (bugs) and Thysanoptera (thrips) are the most abundant. Other insects, including mealybugs, treehoppers, leafhoppers, phyllids, beeflies, wasps, and ticks are also common and are ecologically important. Insects also have predators and parasitoids, including spiders, neropterans, hemipterans, and thrips. However, because of the difficulty of sampling these organisms and the limited background available for interpreting results, we will not include them in our discussion of monitoring.

\section{Small Animals}

Small animals are an important component in the Mojave Desert ecosystem, and they occur from the lowest to highest 
elevations (fig. 3F). Within the northern Mojave Desert, in the vicinity of the Nevada Test Site, there are at least 34 species of reptiles (17 species of snakes, 16 lizards, and 1 tortoise), while the number of small mammal species is somewhat less (approximately 24 species of small mammals, excluding bats and rabbits; Wills and Ostler, 2001). There is a reduction of small mammal species with an increase in elevation and latitude and a similar, but less drastic, reduction in reptilian species. These animals are small individuals (mostly far less than $1 \mathrm{~kg}$ ), but their combined biomass is formidable. Small animals churn (Whitford and Kay, 1999) and aerate soils, increasing water infiltration and bringing nutrient-rich soils to the surface. Daily activity patterns of small animals are varied, with the majority of the snakes and rodents being nocturnal and the majority of the lizards being diurnal. Most small animals reside within or near shrub cover to avoid predation. There is considerable variation in these animals' demographics. Some species of lizards (for example, side-blotched lizard [Uta stansburiana]; fig. 17) and small mammals (for example, Merriam's kangaroo rat [Dipodomys merriami]) exhibit nearly an annual turnover in their populations; their abundance increases after wet winters (Hirsch and others, 2002). Other small animals, such as the desert tortoise, can live multiple decades. Many of these small animals are prey for higher trophic levels of vertebrates.

\section{Amphibians}

Amphibians are unlikely desert dwellers, as they are intolerant of high temperatures and dehydrate quickly. In the Mojave Desert, the dominant amphibian species is the spadefoot (Spea and Scaphiopus spp.). These animals have a large protuberance on their back foot that facilitates digging. Their burrows are deep in the soil, where they can maintain body moisture. They produce only a small amount of urine, instead concentrating solutes and urea in their tissues, thus maintaining a favorable moisture gradient with the surrounding soils. In addition, they have thin, highly vascularized skin where most water uptake occurs (Gordon, 1982). Spadefoots can spend nearly a year buried in the soil, coming to the surface in response to large, intense, summer rainfall events, after which they feed and mate. They then bury themselves again, waiting for the next summer. While buried, their metabolism can drop to one-fifth of normal. However, individuals frequently die during the dormancy period due to insufficient fat stores or soil water. Another amphibian that is fairly widespread in parts of the Mojave Desert is the red-spotted toad (Bufo punctatus), which is a true toad, possessing small round parotid glands and horizontal or round pupils (Stebbins, 2003). Details for sampling amphibian populations is dealt with intensively in Heyer and others (1993), and the marking techniques by Ferner (2007). Many of the same sampling and marking techniques used to study amphibians are discussed in the section pertaining to lizards.

\section{Reptiles}

The number of reptilian species varies considerably between the major deserts of North America; the Mojave Desert has more species than the Great Basin, but fewer than the Sonoran or Chihuahuan Deserts (fig. 18).

The largest Mojave Desert reptile, the desert tortoise (Gopherus agassizii), is distributed throughout much of this desert at elevations below 1,200 m (Bury and others, 1994), with the population north and west of the Colorado River listed in 1990 by the Fish and Wildlife Service as threatened (fig. 19). The habitat selected by tortoises varies considerably between populations. The Sonoran population in Arizona generally inhabits rocky slopes, whereas the Mojave population inhabits primarily valley bottoms and foothills (Germano and others, 1994). The diet of the Mojave desert tortoise is primarily composed of ephemeral vegetation (Nagy and Medica, 1986; Esque, 1994; DeFalco, 1995; Avery, 1998), which is generally produced as a result of rains of $25 \mathrm{~mm}$ or more during the fall and winter (Beatley, 1974). Additionally, tortoises require free water for drinking, and after several continuous years of drought, a high mortality of adults has been observed (P.A. Medica, pers. observation; Longshore and others, 2003).

Figure 17. The side-blotched lizard (Uta stansburiana) is one of the smaller lizards found in the Mojave Desert and is prey for many other animals (U.S. Geological Survey photograph by Todd C. Esque).

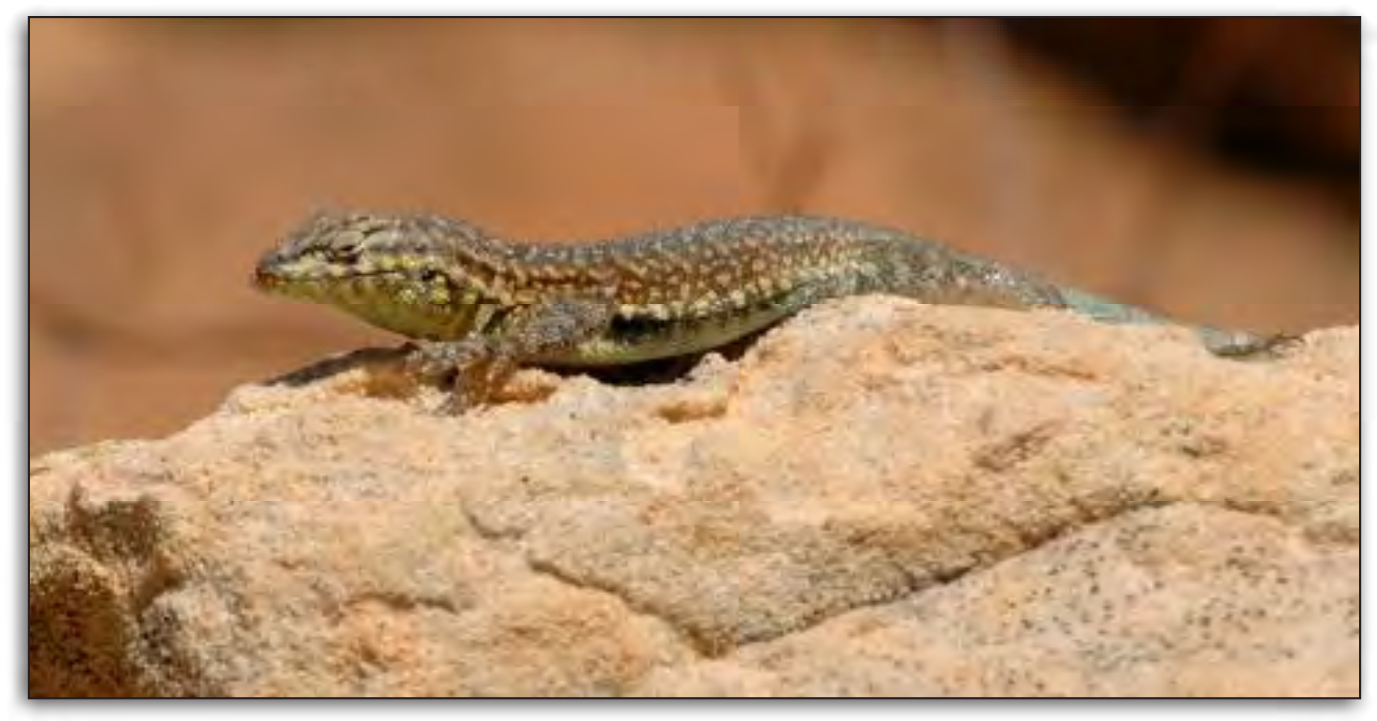


A moderate number of lizard species are common within the Mojave Desert. Diurnal species include the side-blotched lizard (Uta stansburiana), western whiptail lizard (Cnemidophorus $=$ Aspidoscelis tigris), zebra-tailed lizard (Callisarus draconoides), desert horned lizard (Phrynosoma platyrhinos), desert spiny lizard (Sceloporus magister), desert iguana (Dipsosaurus dorsalis), common chuckwalla (Sauromalus ater), Great Basin collared lizard (Crotaphytus bicinctores) and long-nosed leopard lizard (Gambelia wislizenii). There are only two common nocturnal lizards, the western banded gecko (Coleonyx variagatus) and the night lizard (Xantusia vigilis).

The highest species diversity of lizards is generally found in Larrea-Ambrosia communities (11 species). A moderate number of species are found in Coleogyne communities (8 species), Grayia-Lycium communities (7 species), Atriplex-Kochia communities (6 species) and disturbed communities dominated by Salsola (6 species). Only three species are commonly found in pinyon-juniper woodlands (Allred and others, 1963).

Most lizards are insectivores, feeding on larvae of ants, arachnids, termites, and other invertebrates. Some species are specialists, feeding primarily, but not exclusively, on ants (desert horned lizard, Phrynosoma platyrhinos) or termites (western whiptail lizard, Cnemidophorus = Aspidoscelis tigris), whereas others (long-nosed leopard lizard, Gambelia wislizenii and leopard lizards, Crotaphytus wislizenii) are omnivorous and feed on lizards, insects, and even the fruit of Lycium andersonii (wolfberry). The desert iguana (Dipsosaurus dorsalis) and common chuckwalla (Sauromalus ater) are almost exclusively herbivorous, feeding on flowers. The desert iguana feeds on those from Larrea tridentata (creosote bush) and Abronia spp. (sand verbena; P.A. Medica, pers. observation), and the common chuckwalla feeds on those from Sphaeralcea spp. (globe mallow; Sanborn, 1972). Some lizards are habitat specialists, with special adaptations, such as the specialized toes found on the Mojave fringe-toed lizard (Uma scoparia, fig. 20).

The most common and ubiquitous lizard in the Mojave Desert is the side-blotched lizard (Uta stansburiana). This lizard serves as a food item for many predatory species of vertebrates and even arachnids. Side-blotched lizards can occur in very high

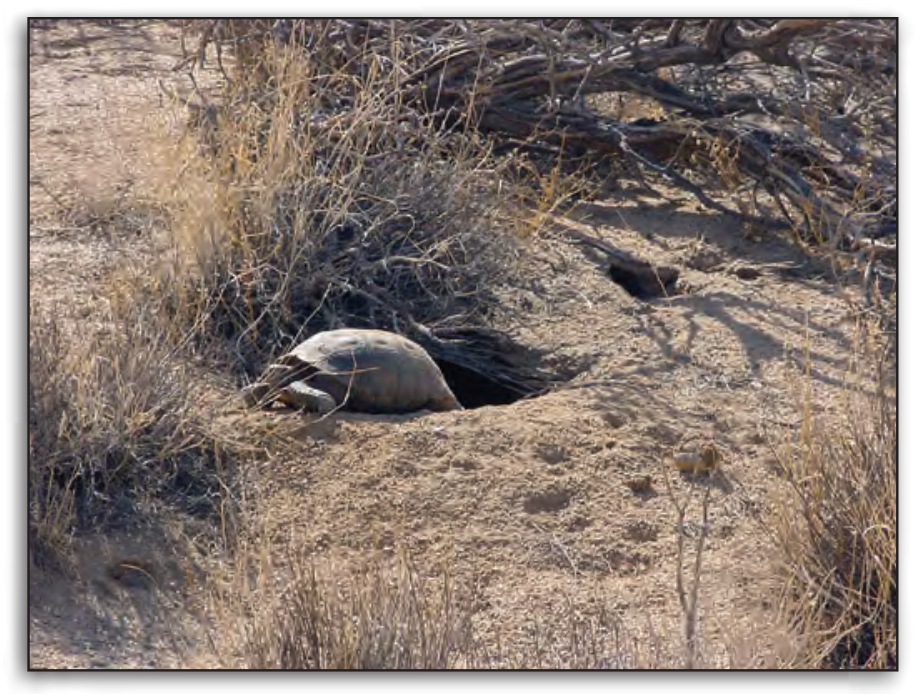

Figure 19. Desert tortoise (Gopherus agassizil) emerging from a burrow at Joshua Tree National Park (U.S. Geological Survey photograph by Todd C. Esque).

densities (80/ha; Turner and others, 1982) and are considered an annual species, as 75 to 80 percent of populations are replaced annually. There is a large amount of interannual co-variation with rainfall (Medica and others, 1994; Woodward, 1994), as high winter precipitation and the concomitant growth of annual vegetation and insect populations strongly increases reproduction in this lizard (Turner and others, 1974). Therefore, their population fluctuations often mirror short-term environmental change.

In contrast, many other lizard species are long-lived. Longnosed leopard lizards (Gambelii wislizenii) live up to 10 years. Desert horned lizards (Phrynosoma platyrhinos) can live up to 6.5 years, the western whiptail lizard (Cnemidophorus tigris) can live up to 7.8 years (Medica and Turner, 1984), and the desert night lizard (Xantusia vigilis) can live up to 6 to 7 years (Zweifel and Lowe, 1966). In general, long-lived species require at least two seasons to become sexually mature. While the number, activity, and reproductive potential of the populations of the longer-lived species can vary greatly from year to year, they have demonstrated potential as indicators of environmen-

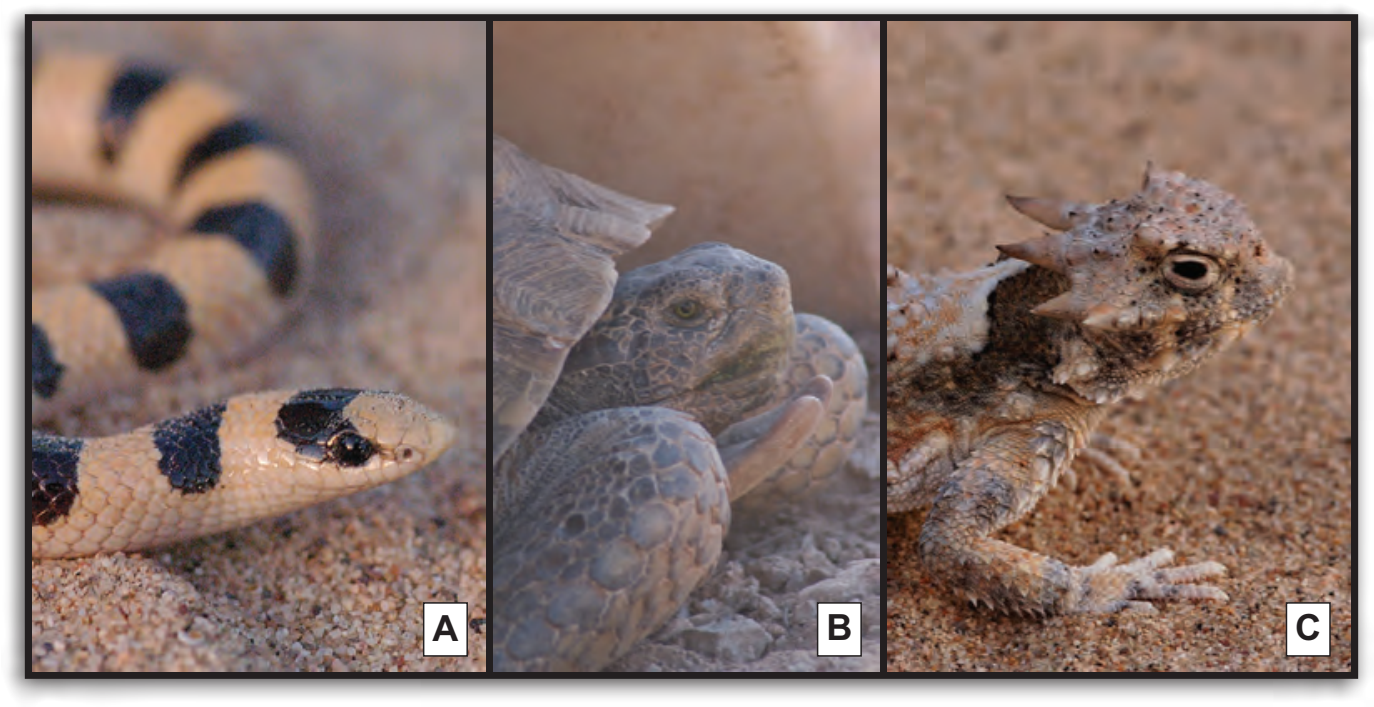

Figure 18. Common reptiles of the Mojave Desert. A, Shovelnosed snake (Chionactis occipitalis occipitalis); $\mathrm{B}$, Desert tortoise. (Gopherus agassizii); C, Horned lizard (Phrynosoma platyrhinos) (U.S. Geological Survey photographs by Todd C. Esque). 
tal stress and disturbance (Medica, 1992; Medica and others, 1994).

There are many species of snakes in the Mojave Desert, and most are nocturnal. Many of these snakes are small and are known to feed on invertebrates and/or small lizards (for example, western blind snake [Leptothyplops humilis], ground snake [Sonora semiannulata], shovel-nosed snake [Chionactis occipitalis], and the night snake [Hypsiglena torquata]). The moderately sized snakes, such as the rattlesnake (Crotalus spp.), long-nosed snake (Rhinocheilus lecontei), and glossy snake (Arizona elegans), feed mainly on rodents and lizards. Other species may specialize in feeding on particular prey: the common king snake (Lampropelus getulus) feeds on snakes and rodents, and the lyre snake (Trimorphodon biscutatus) feeds primarily on lizards, bats and rodents. There are three diurnal species, the coachwhip (Masticophis flagellum), the gopher snake (Pituophis melanolucus) and the less common patch-nosed snake (Salvadora hexelepus), that feed on lizards, small mammals, and birds (Ernst and Ernst, 2003). There are at least two species of snakes that inhabit the southern portions of the Mojave Desert and are not found in the north. They include the rosy boa (Lichanura roseofuscus) and the diamondback rattlesnake (Crotalus atrox). Sampling records indicate that initial snake activity in the spring and early summer is highly dependent upon temperatures, as when daytime temperatures exceed $90^{\circ} \mathrm{F}\left(32^{\circ} \mathrm{C}\right)$ and nocturnal snake activity is greatly increased.

\section{Small Mammals}

A large proportion of the small mammals in the Mojave Desert belong to the family Heteromyidae (kangaroo rats and pocket mice), Cricetinae (white-footed mice, grasshopper mice, and wood rats), and bats. Besides the Heteromyids, the Sciuridae (ground squirrels and gophers) are most common. These small mammals subsist primarily on seeds, vegetation, roots, and insects. Their ability to survive under harsh conditions is tied to their nocturnal habit; their greatest activity times are when temperatures are cool. In addition, many have a variety of adaptations to economize water. Heteromyid rodents are able to survive without free water, and other species may be able to do so as well, but they have not been studied (Schmidt-Neilson, 1964; MacMillan and Hinds, 1983; French, 1993). Population numbers of small mammals vary widely among years as they respond to changes in their immediate environment. Their population numbers are closely tied to precipitation, and green forage is a cue to become reproductively active (Chew and Butterworth, 1964; Beatley, 1969). Differences in the distribution of two species of kangaroo rats along an elevational gradient reflects a dynamic interaction among primary productivity, driven by annual rainfall and the varying metabolic requirements of the two species (Price and others, 2000). Monitoring short-lived species, such as kangaroo rats, along such environmental gradients provide a sensitive indicator of a changing climate in the Mojave Desert.
Small mammals influence ecosystems in many important ways. Recent studies have shown that granivores may interact with seeds and each other in ways that affect multiple trophic levels both directly and indirectly (Mares and Rosenzweig, 1978; Brown and others, 1979; Galindo, 1986; Samson and others, 1992). As with ants and reptiles, they move large amounts of soil, bringing nutrients to the surface and creating macropores that significantly increase the amount of water infiltrating downwards. They are food for mammalian and avian predators. Plant-rodent interactions can be a significant mechanism in plant community change (Niering and others, 1963; Beatley, 1969; Chew and Chew, 1970; Soholt, 1973; Reichman, 1976; Price and Reichman, 1987; Brown and Heske, 1990; Kerley and others, 1997), as they are important in the dispersal and establishment of vascular plants as well as in the removal of seeds from the seedbank (Whitford, 2002; fig. 21). Small mammals are known to select seeds on the basis of size, burial depth, distribution (Reichman and Oberstein, 1977), and nutrient content (Kelrick and McMahon, 1985; Kelrick and others, 1986; Kerley and Erasmus, 1991; Crist and MacMahon, 1992). Heteromyids typically select the largest seeds available (Brown and others, 1979). Granivores may consume as much as 86 percent of seed production in the Chihuahuan Desert (Chew and Chew, 1970), 30 percent of the seeds of some plant species in the Mojave Desert (Soholt, 1973), and less than 1 percent of seeds in desert grasslands (Pulliam and Brand, 1975; Brown and others, 1979). Rodent populations in the Mojave Desert may be food-limited under some situations and, at these times, they may heavily impact seedbanks and vegetation (Soholt, 1973; Reichman, 1976). Unlike seeds buried in shallow caches, seeds that are transported to deep underground burrows are either eaten or forgotten, and thus ultimately removed from the seed pool (Reichman, 1975).

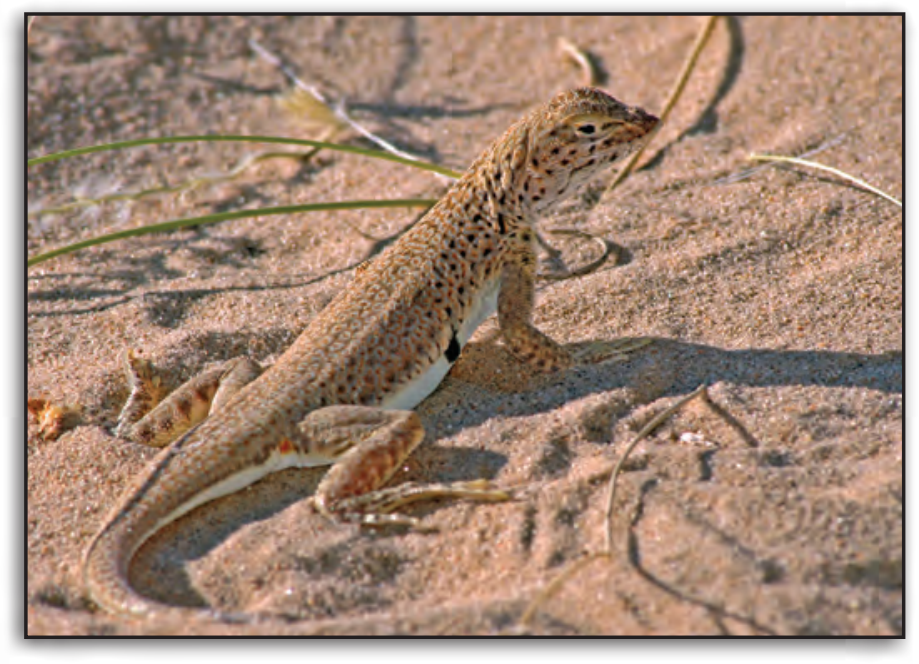

Figure 20. The Mojave fringe-toed lizard (Uma scoparia) is specially adapted for movement in its sand dune habitat at Kelso sand dunes in Mojave National Preserve. Note the fringes along the toe of the rear left leg (U.S. Geological Survey photograph by Todd C. Esque). 
Rodents can also benefit plants (Reynolds and Glendening, 1949; Carroll and Janzen, 1973; McAdoo and others, 1983; McAuliffe, 1990; Vander Wall, 1990; Longland and others, 2001). Rodent manipulation of seeds in preparation for consumption and/or caching can increase viable seed numbers, spatial distributions, and establishment (Brown and Minnich, 1986; Price and Jenkins, 1986). Seeds placed in shallow caches, but not recovered, have higher germination rates than seeds germinating without rodent caching (Reichman, 1976; Vander Wall, 1990; Longland and others, 2001). In experiments, rodents, both diurnal and nocturnal, collected a larger percentage of seeds made available in trays than did ants (Brown and others, 1975). Dispersal of seeds of species, such as Achnatherum hymenoides (Indian ricegrass), Pinus monophylla (single-leaf pinyon pine), Yucca brevifolia (Joshua tree), Coleogyne ramosissima (blackbrush), and Psorathamnus fremontii (indigobush), have been documented for the Mojave Desert (Vander Wall, 1997; Longland and others, 2001; Esque, 2004). Rodents can also promote the establishment and success of the invasive species Erodium cicutarium (redstem filaree) and Bromus madritensis ssp. rubens (red brome) at their burrowing sites, due to continuous disturbance (Schiffman, 1994, 1997). Community relationships among granivores and ants of widely varying taxa can be more important than birds in affecting the abundance of seed resources (Pulliam and Brand, 1975).

\section{Natural and Anthropogenic Disturbances in the Mojave Desert}

Both natural and human disturbances in the Mojave Desert can result in ecosystem disruption (Lovich and Bainbridge, 1999; figs. 2 and 3I). Natural disturbances include extreme cli-

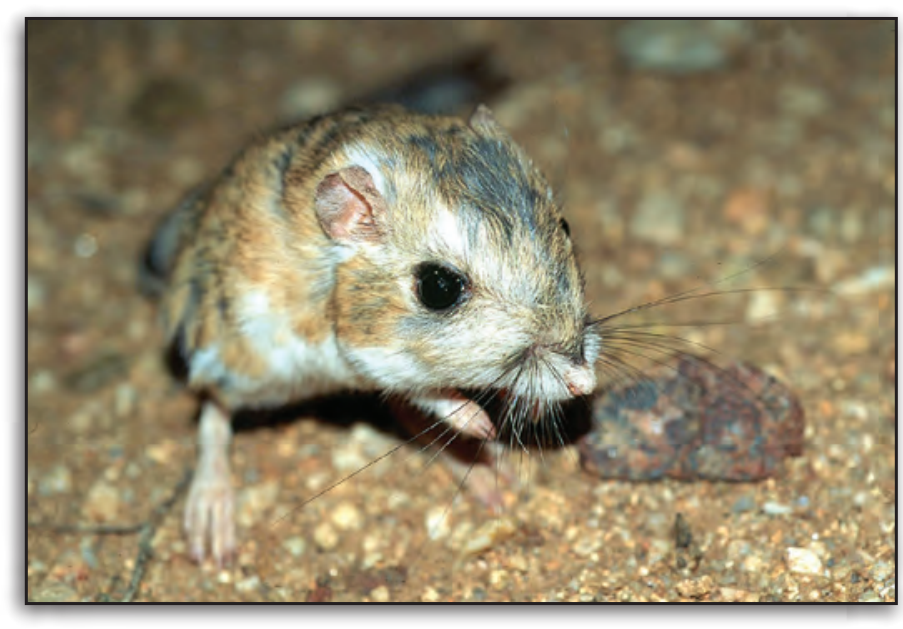

Figure 21. Kangaroo rats (Dipodomys spp.) constantly move large numbers of desert plant seeds across the landscape. Although a portion of stored seeds is consumed as seed availability declines, other seeds are forgotten and germinate when soil moisture and temperature conditions are favorable (U.S. Geological Survey photograph by Todd C. Esque). matic events, fire, insect and disease outbreaks, and herbivory and trampling by wildlife. Human-related disturbance includes military training exercises, non-motorized recreation, offroad vehicle use, livestock grazing, mining, air pollution, and urbanization. Global atmospheric changes, invasive plants, and alterations of fire regimes result from an interaction of natural and human disturbance and will be discussed below.

In addition to understanding the impacts of these disturbances on ecosystem structure and function, it is also critical to know the history of a site in order to understand current conditions. Legislation for homesteading, mining, grazing, and water use enacted more than a century ago has left a legacy in most of the Mojave Desert. The type and placement of infrastructure, such as roads, utility corridors, and water diversions, and all uses associated with public lands have resulted from the complex interplay of human values, social structure, survival, and the ecosystems in which these uses occurred.

\section{Natural Disturbances}

Natural disturbances are those events which occur within the natural range of conditions experienced by an ecosystem over time (fig. 3I). Natural disturbance regimes are important in altering the structure and function of ecosystems, and thus in determining their trajectories through space and time. Different disturbance types often interact with each other or act in sequence, and the synergistic effect can have consequences that are much larger than the consequences of a single event. For instance, wet periods often create high annual-plant biomass on landscapes, and when dried this high biomass can contribute to wildland fires. Interactions can also happen between natural and anthropogenic stressors. For instance, nitrogen deposition can lead to an increase in invasive annual grasses (Brooks, 2003; Allen and others, in press), which, in turn, may promote fire. Episodic, event-driven change is an important feature of many ecosystems (Holling, 1996; Scheffer and others, 2001) and is particularly characteristic of dryland ecosystems (Whitford, 2002).

\section{Extreme Climatic Events}

Severe climatic events have a strong influence on Mojave Desert ecosystems. These include very high or very low precipitation amounts or temperatures, hail and lightning storms and/or high winds. All these events can alter ecosystems in profound ways and set their trajectories for many years through the widespread mortality of plants and animals. An example is the effect of the 1989-91 drought on plant communities in the northern Mojave Desert. Before this period, 8 of the 16 plant communities monitored at the Nevada Test Site were dominated or co-dominated by Grayia spinosa (spiny hopsage). However, after the drought, surveys showed G. spinosa as co-dominant in only one community due to its extensive mortality (Webb and others, 2001). This mortality event will have huge impacts on the structure and function of 
this ecosystem for many years to come. Consecutive extremely wet years can also change community composition and structure, as they often result in high recruitment and establishment of perennial plants and animals. Extremely wet years can also facilitate the invasion of non-native annual grasses. Highly erosive floods or large wind storms may redistribute soil resources and alter site conditions that can fundamentally change plant and animal communities.

\section{Fire}

Fire can have enduring effects on desert ecosystems, with one of the most significant being the alteration of vegetation composition and structure due to the selective injury or elimination of fire-intolerant life forms or age classes (Whelan, 1995). Specific effects of fire on vegetation structure vary in relation to fire-regime characteristics (frequency, intensity, seasonality, and spatial patterning) and the responses of different plant species. Variables that affect the occurrence of fire include elevation, seasonal precipitation, natural vegetation type, fuel flammability, the presence or absence of invasive plants, and proximity to roads (DeBano and others, 1998; fig. 22). When fuels are available in sufficient quantity, structure, and continuity, fire incidence varies with local weather conditions, such as humidity, wind direction and velocity, and air temperatures. Finally, an ignition source, such as "dry" lightning or human activities, is required (Swantek and others, 1999).

Because shrub canopy cover in Mojave Desert plant communities is generally low, large plant-free gaps exist, creating a lack of continuous fuel so that most low-elevation areas went centuries without fire in the past (Humphrey, 1974).
Numerous studies have reported on fire in Mojave Desert plant communities that probably were not subject to fire previously (McLaughlin and Bowers, 1981; Brown and Minnich, 1986; Brooks and Pyke, 2001; Brooks and Esque, 2002; Brooks and Minnich, 2006). However, fire dynamics have changed, and wildfires have become more frequent in the past 30 years (Brooks and Esque, 2002; fig. 23), especially at middle elevations dominated by Larrea tridentata (creosote bush), Yucca brevifolia (Joshua tree), and Coleogyne ramosissima (blackbrush; Brooks and Matchett, 2006). This is partially due to the increased dominance by invasive annual grasses that accompanied the above-average rainfall during this same time period (Brooks, 1999a, 1999b; Brooks and others, 2004; Brooks and Matchett, 2006; Brooks and Minnich, 2006; fig. 24).

Owing to high winter rainfall, native annual plants also have a large role in landscape fuel accumulation that can lead to fires; following the record rainfall of the winter of 2004-05, some fires in the Southwest were fueled primarily by native annuals, such as Plantago spp.

Because of their propensity to increase fires, non-native grasses have caused changes in the composition and physical structure of many Mojave Desert plant communities, as most native plants are not fire-adapted (Young and others, 1969; Jackson, 1985; Mack, 1986; Billings, 1990; D'Antonio and Vitousek, 1992; Brooks, 2002; Brooks and Minnich, 2006). Once an area has burned and reburned, native species diversity and densities decline (Brooks, unpub. data), and thus there is less competition and more nutrients for the non-native grasses. Combined with the abundant seed sources often found in adjacent invaded areas, favorable conditions are created for dominance by alien grasses. As alien grasses become more

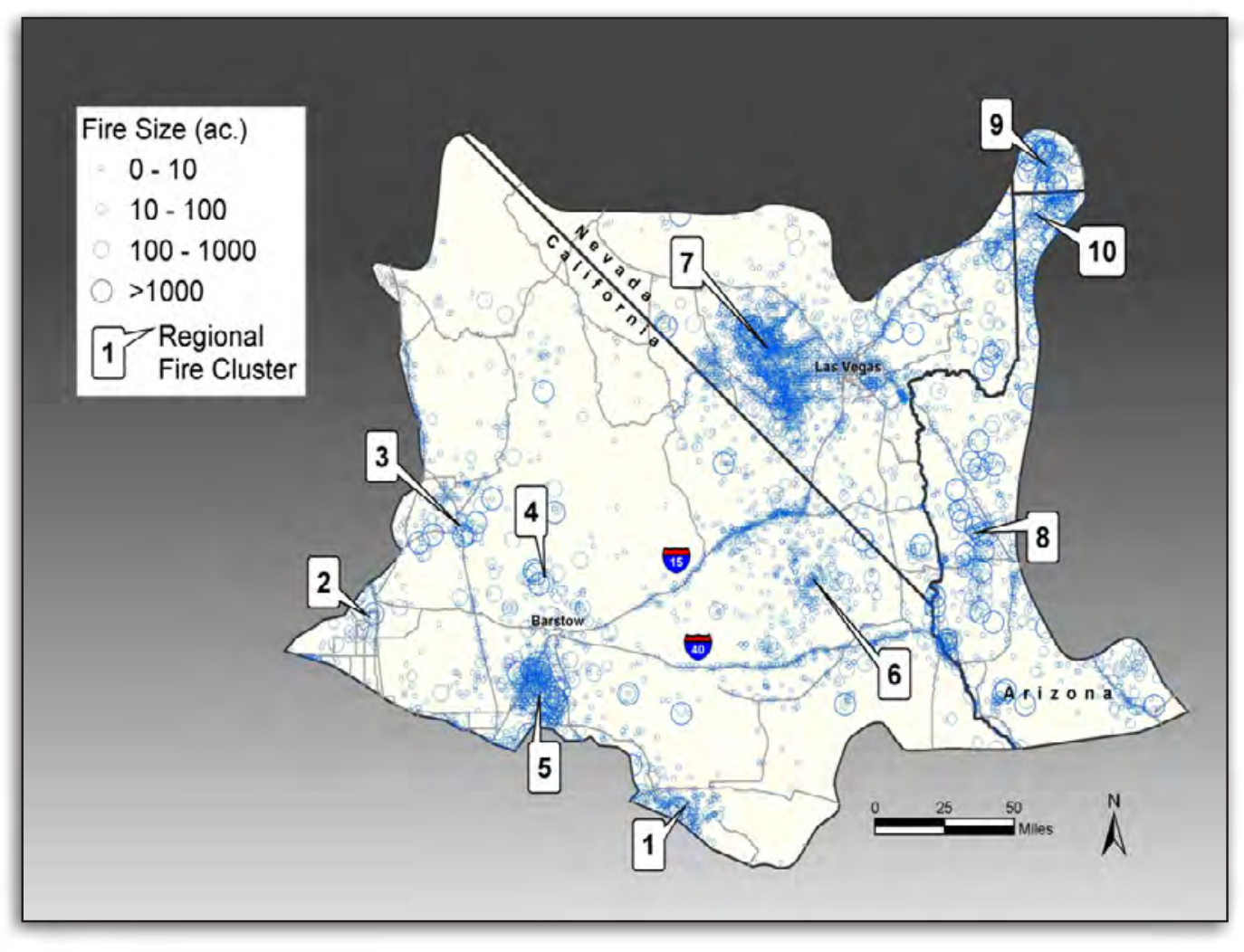

Figure 22. Spatial distribution of fires between 1980 and 1995 in the Bureau of Land Management California Desert District, and clusters of fire activity since the 1970 s across the entire Mojave and Colorado Deserts. Major roads are included as geographic reference points (from Brooks and Esque, 2002). 
abundant, the potential for fire increases, resulting in a positive feedback loop (D’Antonio and Vitousek, 1992).

Because most desert shrubs require extended periods without fire to re-establish, and grow slowly, fire is particularly destructive in shrub-dominated desert systems (Billings, 1990; Esque, 2004; Webb and others, 2003; Brooks and Minnich, 2006). As fire cycles are accelerated, opportunities for shrub establishment decrease. With the loss of perennial vegetation, important microclimates are lost, including those that provide conditions promoting germination and establishment of native plants and provide habitat for native animals. Repeated fire occurrence may be exacerbated by anthropogenic disturbances, such as atmospheric deposition of nutrients, which increases the production of non-native grasses (Brooks, 2003; Allen and others, in press), or an increase in precipitation due to climate change. Seedbanks can also change with fire (Esque, 2004), which impacts wildlife species of special concern (Esque and others, 2003; Brooks and Esque, 2002; Miller, 2005). Fire can create hydrophobic soils (Johansen and others, 2001; Miller, 2005) which, when combined with massive loss of vegetation cover, can allow for large losses of soil, nutrients, and organic matter. Wind erosion is often increased as well (Whicker and others, 2002; Miller, 2005). Soil movement is a risk wherever fires occur, but is a particular problem in habitats where vertebrates and invertebrates depend on free surface water (that is, springs, seeps, and riparian areas), as these features can be completely buried by siltation from burned areas. Fire also affects soil nutrients and nutrient cycling. Effects are variable, depending on the site and fire characteristics. Phosphorus and nitrogen availability can be increased temporarily (Raison, 1979; Blank and others, 1994; Miller, 2005), although this is highly variable from site to site. Nutrient stocks can also be depleted due to volatilization, ash, or soil erosion. Biota living at, or just under, the soil surface are often killed, thus slowing decomposition cycles and reducing soil nutrient availability. Depending on the severity of the fire, soil $\mathrm{pH}$, cation exchange capacity, and infiltration rates can be affected as well.

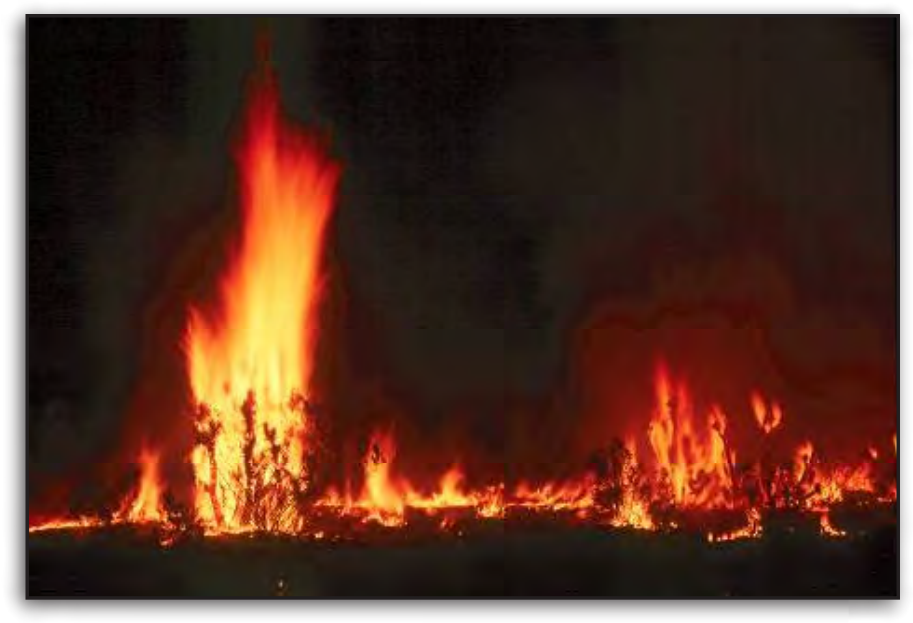

Figure 24. Abundant alien annual grasses can cause high intensity fires, such as the one featured here engulfing an adult Joshua tree. Wildfires fueled by non-native annual grasses can cause catastrophic losses of native plant and animal species in Mojave Desert shrub assemblages (U.S. Geological Survey photograph by Todd C. Esque).

All of these factors change the biophysical environment of burned sites, creating openings for invasive species, suppressing the establishment of native plants, decreasing cover and forage for wildlife, changing nutrient availability and cycling, and, ultimately, changing the disturbance regimes and trajectories of these communities (fig. 25).

\section{Insect and Disease Outbreaks}

There is little information on the impact or role of insect and disease outbreaks in dryland ecosystems, unlike forests, where the effects of insects are a well-studied source of natural disturbance (for example, Veblen and others, 1991). Insect outbreaks are likely associated with drought conditions, which lower the resistance of vegetation to infection and affect the life cycles and dispersal patterns of the insect herbivores,

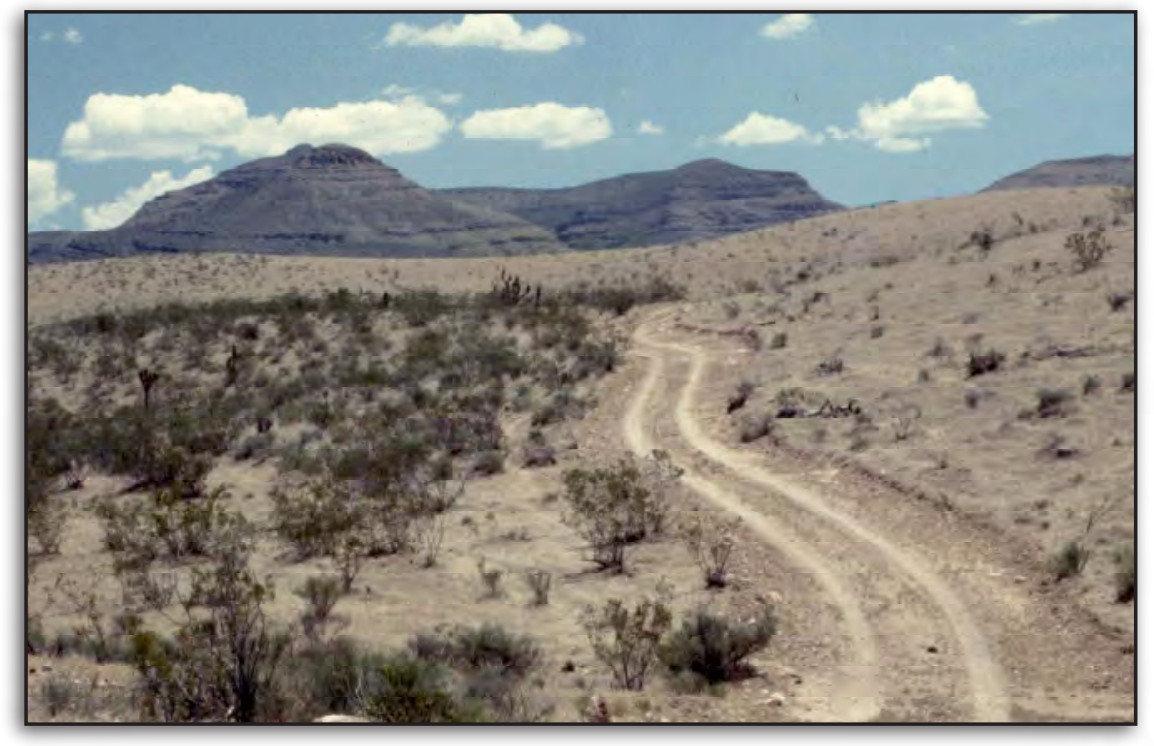

Figure 23. Disturbance caused by a single fire was sufficient to remove most woody perennial plant cover to the right of the road in this desert scrub plant community in Pakoon Basin, Mojave County, Arizona, 1989 (U.S. Geological Survey photograph by Todd C. Esque). 
enabling them to infect plants (Swetnam and Betancourt, 1998; Logan and others, 2003; Miller, 2005). Hundreds of species of defoliating arthropods occur in the Mojave Desert (Rundel and Gibson, 1996), and thus it is likely that, under optimal conditions, they can have large impacts on the vegetation. For example, gelechiid moth larvae (Chrysoesthia sexguttella) consumed 40 to 80 percent of the leaves of Lycium spp. in 1971 in Rock Valley, Nevada, resulting in no fruits maturing on this species. These larvae are also attracted to Ephedra cones (Mormon tea) during pollen production. Outbreaks of the bark beetle pinyon ips (Ips confuses) in pinyon-juniper ecosystems are triggered by drought conditions that weaken host tree populations (Leatherman and Kondratieff, 2003; Miller 2005). Therefore, similar to fire, insect outbreaks can interact with climate to generate long-term changes in vegetation structure (Allen and Breshears, 1998; Miller, 2005). Insect- or pathogen-generated changes in vegetation structure can have multiple ecosystem-level consequences due to vegetation interactions with nutrient cycles, hydrologic processes, and geomorphic processes.

\section{Herbivory and Trampling by Wildlife}

Herbivory and trampling are also part of the natural disturbance regimes in the Mojave Desert. The effects of these disturbances depend on the characteristics of the ecosystem (for example, climatic conditions, soil properties, and vegetation structure and composition) in which they occur. However, given limited surface water and forage (Mack and Thompson, 1982; Grayson, 1994), and hunting by native peoples (Truett, 1996), it is unlikely that native ungulates were ever very abundant in this region. Thus, overall, herbivory and trampling by large ungulates were likely relatively minor disturbances in most dryland ecosystems prior to European settlement. However, herbivory by small mammals, such as gophers (Thomomys spp.), packrats (Neotoma spp.), mice (for example, Peromyscus and Dipodomys spp.), ground squirrels (Ammospermophilis spp., Spermophilus spp.), chipmunks (Tamias spp.), and rabbits (Lepus and Sylvilagus spp.) can be substantial, especially during drought years when they clip vegetation to access plant sap.

\section{Anthropogenic Disturbance}

There are a multitude of human-related disturbance types in the Mojave Desert that have a wide range of impacts on soils and ecosystem processes. In this discussion, we divide these disturbances into soil-disturbing activities, invasive plants, the alterations of fire regimes, urbanization, global atmospheric changes (including air pollutants), and the diversion of overland flow. The major types of disturbance, and recovery rates from these disturbance types, are presented in table 2 .

\section{Soil-Disturbing Activities}

Although many land-use practices create severe disturbances in the Mojave Desert, those that disturb the soil surface (for example, military training, non-motorized recreation, off-road vehicles, livestock grazing, mining) create the largest direct and indirect ecosystem effects. These disturbances have several features in common: all increase soil compaction and vegetation loss while decreasing soil stability, nutrient cycling, and soil biotic activity. In this section, we will first discuss these common effects and then discuss the unique aspects of each disturbance type.

\section{Soil Compaction}

In its simplest sense, soil compaction results from the application of stress to the soil surface (fig. 26). In reality,
Figure 25. In alien annual grasslands, such as this example in Pakoon Basin, Arizona, Bromus madritensis ssp. rubens (red brome) and $B$. tectorum (cheatgrass) dominate the landscape in a former Larrea tridentata (creosote bush) and Ambrosia dumosa (white bursage) community that has burned multiple times in the past three decades (U.S. Geological Survey photograph by Todd C. Esque).

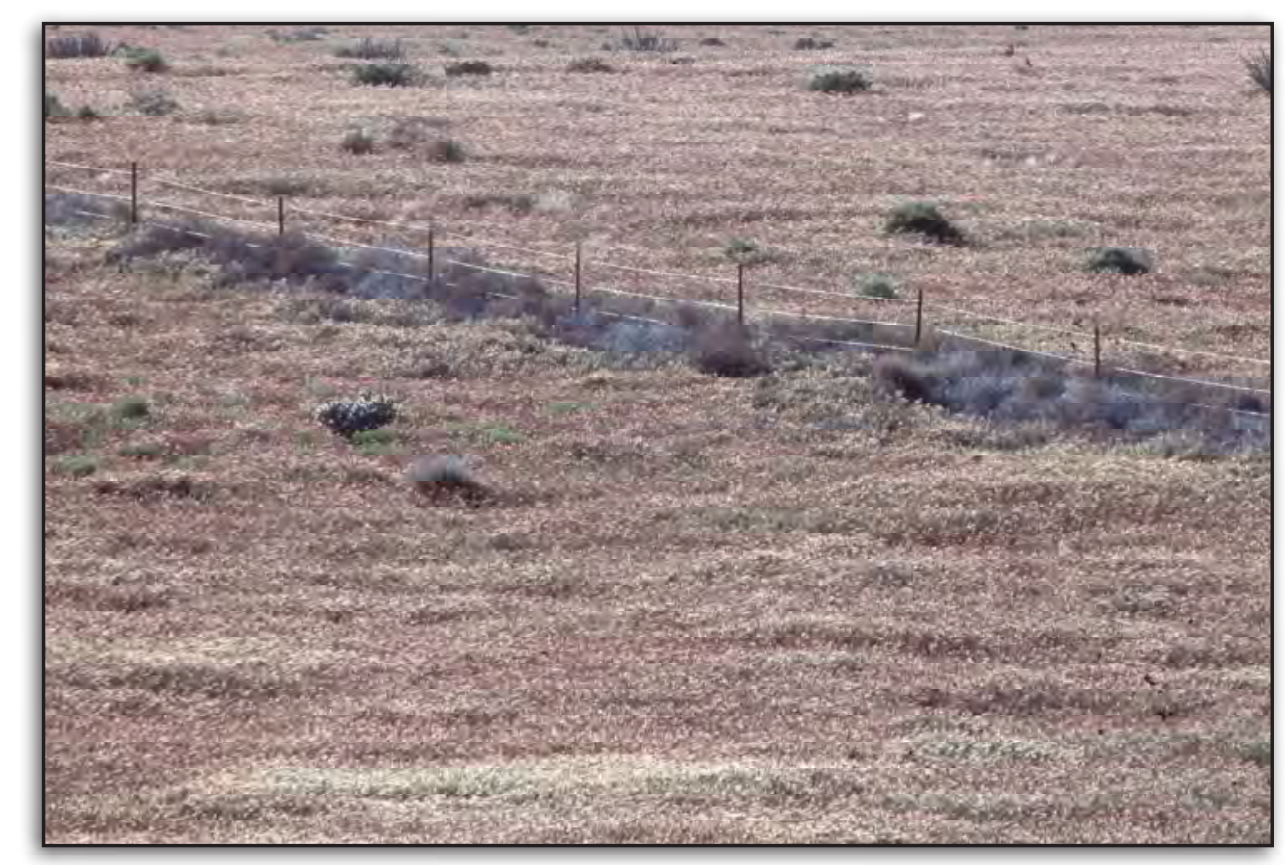


most disturbances impart a complex, three-dimensional stress field on soil, resulting in a normal stress that compacts the soil and a shear stress that dilates the soil (Webb, 1982). Depending upon the magnitude of the normal stress, maximum compaction typically occurs between 0.05 and $0.30 \mathrm{~m}$ depth, with the amount of compaction decreasing at greater depths. The amount of compaction that a soil can undergo is a function of particle size distribution, structure, and water content at the time of compaction (Webb, 1983). Poorly sorted soils (those containing a wide range of particle sizes), such as loamy sands and sandy loams, are compacted more readily than well-sorted soils (those with fairly uniform particle sizes), such as eolian sand or playas.

The amelioration of soil compaction is a complex process. Several factors affect recovery rates, especially the amount that bulk density increases with depth. Soil loosening occurs with freeze-thaw cycles, frost heaving, bioturbation, and the expansion and shrinking of clay minerals during wetting and drying (Webb, 2002). Therefore, loosening rates are heavily dependent on the clay content and mineralogy of the soil, the depth of water penetration, the frequency of wetting and drying cycles, and the depth of the compaction. Akram and Kemper (1979) applied both wetting and drying and freeze-thaw cycles to compacted soils and found that most of the change in infiltration rate, which is indicative of soil compaction, occurred during the first three cycles. Multiple freeze-thaw cycles reduce compaction in regions where severe freezing occurs (Orr, 1975; Brady and Weil, 1996), although such sites are rare in the Mojave Desert, and the loosening

Table 2. Summary of recovery rates for several metrics of ecosystem recovery on low-slope xerophytic sites in the Mojave Desert (from Webb and others, in press).

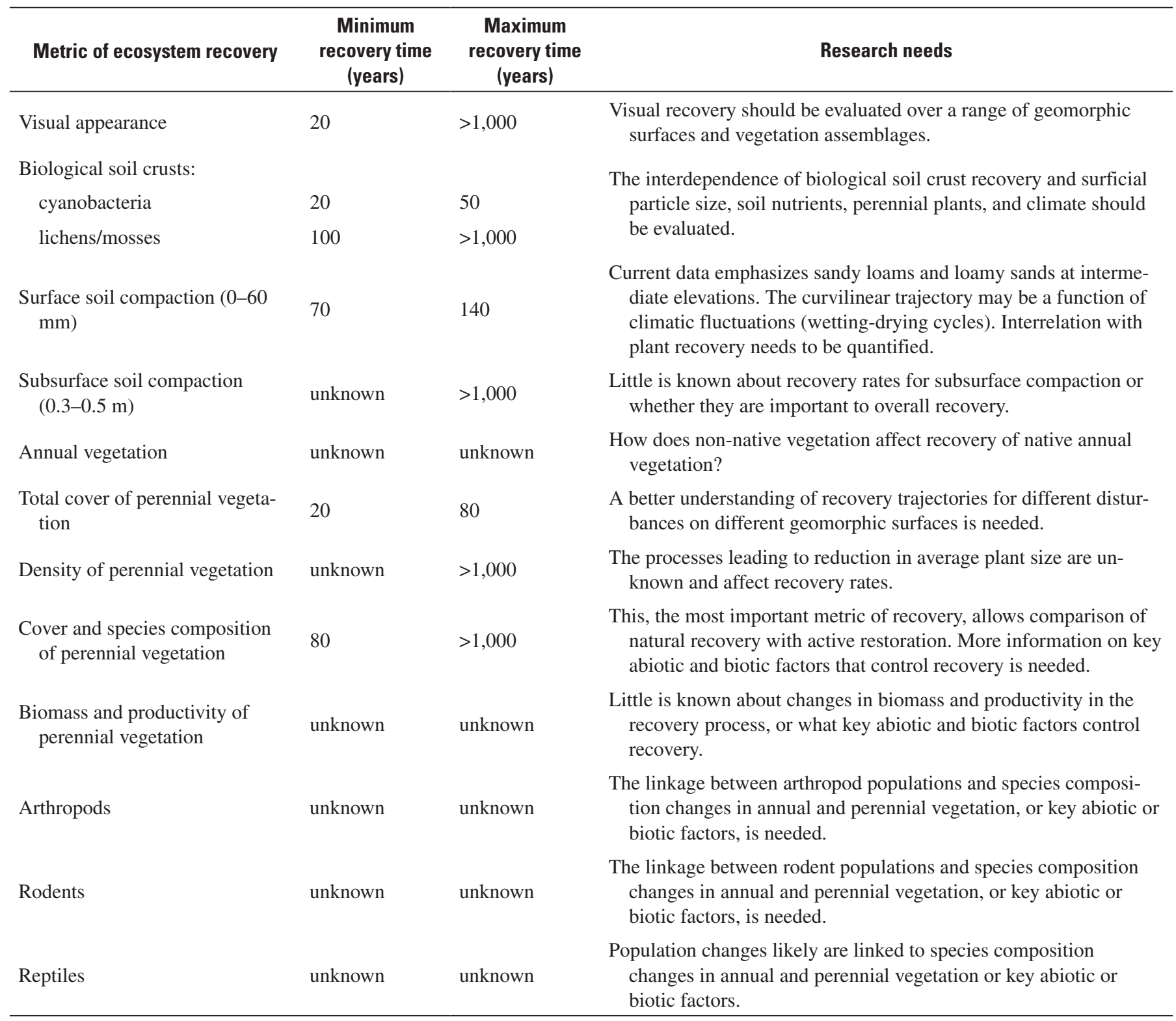


may occur only above $0.2 \mathrm{~m}$ (Blake and others, 1976; Larson and Allmaras, 1971; van Ouwerkerk, 1968). The effectiveness of freeze-thaw loosening depends on soil water content, texture, rate of frost penetration, and depth of compaction.

Bioturbation, ranging from roots penetrating the soil subsurface to insects or rodents burrowing, may be more important than physical processes in loosening compacted soil, especially in coarse-grained desert soils where clay content is low. The role of arthropods, particularly ants, in the dilation of compacted soils has not been studied. Observations indicate that rodent activity may increase in disturbed areas, particularly during or following overgrazing, but no work has been done to evaluate whether animals play a large role in the amelioration of compaction.

In the Mojave Desert, estimates of recovery time for compaction range from 80 to 130 years (Webb and Wilshire, 1980; Webb and others, 1986; Knapp, 1992; Webb, 2002; Webb and Thomas, 2003). A limited number of studies suggest that recovery below a depth of $0.3 \mathrm{~m}$ may be much slower than at shallower depths (Prose and Wilshire, 2000; Webb and others, in press) and may be so slow as to not be measurable. Bolling and Walker (2000) did not report any significant compaction recovery on roads that had been abandoned 5-88 years ago. However, they concluded that spatial heterogeneity among the roads they studied may have obscured any significant recovery trends, as they grouped measurements over a complicated array of geomorphic surfaces that likely respond differently to both the initial disturbance and subsequent recovery. Most general studies have assumed that a linear recovery model is an appropriate way to describe compaction recovery and have concluded that compaction amelioration is faster at higher-elevation sites, where freeze-thaw and wetting-and-drying cycles are more frequent than at lower elevation sites. However, as discussed above, the level of recovery needed for plant success is not known.

\section{Soil Stability, Nutrient Availability, and Vegetation}

Soil surface disturbance often compromises the stability of surface soils. The fibers in biological soil crusts that confer tensile strength to soil surfaces cannot withstand the shear stresses placed on them by trampling or vehicular traffic (Belnap and Eldridge, 2003). Other soil stabilizers are damaged or removed from the soil surface as well, including plants, plant litter, and rocks. Damage or complete destruction of these soil stabilizers leaves soil surfaces highly susceptible to erosion by wind and water (fig. 27). In addition, surface disturbances often kill plants, resulting in larger spaces between the plants. This allows more wind and water to reach the soil surface at a greater velocity, which, combined with greater water runoff due to soil compaction, increases the loss of soils. A decrease in soil fine particles (silts, clays) can be an indication that soil erosion is taking place. An increase in sand, especially the fine and medium fraction, can indicate deposition from a nearby area. Vegetation loss also alters the abundance, spacing, and species composition of the plant community. This, in turn, alters food and habitat availability for animals.

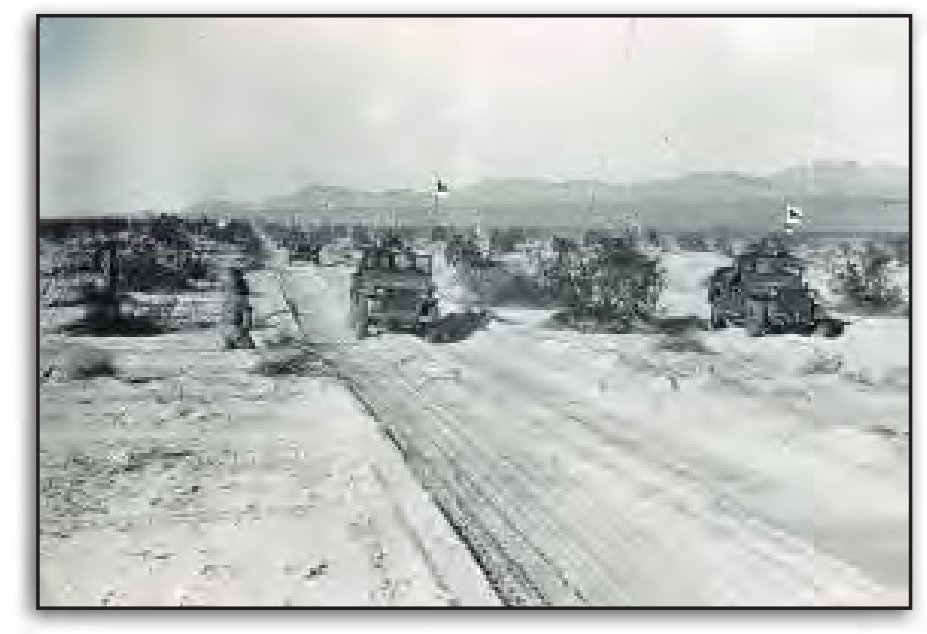

Figure 26. Soil compaction caused by military training exercises in the eastern Mojave Desert during World War II (U.S. National Archives photograph).

Loss of plants and biological soil crust organisms decreases the contribution of nitrogen and organic matter to soils. Loss of pore space in the compacted soils restricts the amount of water and gases that can enter the soil, lowering the abundance, activity, mobility, and survival of soil biota (Brady and Weil, 1996). Combined, these factors all lead to less decomposition and nutrient transformations in disturbed soils. Thus, surface disturbance often leads to a reduction in soil fertility.

Recovery times of soil stability and fertility are dependent on the recovery time of plants, biological soil crusts, subsurface soil biota, and soil structure. These factors are dependent on dispersal rates of the organisms and climatic conditions. Soil biota are especially sensitive to climatic fluctuations. Soil organisms are metabolically active only when wet, and thus recovery time for them is almost completely dependent on the length of time the soil is sufficiently wet for activity. Recovery times also increase as the severity and size of the disturbed areas increase (Belnap and Eldridge, 2003), as much of the recolonization of soil biota must occur from the edges of the disturbance. Smaller organisms, such as cyanobacteria, bacteria, and fungi, colonize first, followed by other larger organisms, such as burrowing arthropods. In severely impacted areas in the very dry and hot regions of the Mojave Desert, full recovery of soil biota can take hundreds of years (Belnap and Warren, 2002).

More is known about recovery of perennial vegetation. Complete recovery of plant cover (irrespective of species composition) in the low elevations of the Mojave Desert is relatively slow (Vasek, 1980; Webb and Wilshire, 1980; Webb and others, 1988; Lovich and Bainbridge, 1999), but significant recovery in cover can occur in a few decades at some sites (Webb and others, 1988). Combined data from 127 sites show that, while road recovery follows a linear trajectory, recovery from other disturbance types follows a curvilinear relation, with 60 to 80 percent recovery in total perennial cover occurring in about 30 years (Webb and others, in press). However, the course of recovery is strongly affected by the species 
present at a site, as well as disturbance type, soil properties, and climate. Short-lived species, such as Encilia farinosa, $E$. virginensis, and E. frutescens (various brittle bushes), Gutierrezia spp. (snakeweed), Atriplex spp. (salt bushes), and perennial grasses, including Achnatherum hymenoides (Indian ricegrass), Pleuraphis rigida (big galleta grass), and Achnatherum speciosum (needle-and-thread grass), are the first to establish in disturbed sites (Webb and Wilshire, 1980; Lathrop, 1983; Prose and others, 1987; Webb and others, 1988; Angerer and others, 1994; Lei, 1999). These species are eventually replaced by longer-lived species. It is not known if the classic concept of succession applies to the recovery of desert vegetation, as many of the changes in desert perennial plant communities are abiotically, not biotically, driven.

Plant community composition, on the other hand, recovers much more slowly than total cover. Because climatic variability results in large fluctuations in community composition and cover of undisturbed vegetation (Hereford and others, 2006; Webb and others, in press), recovery goals for perennial vegetation need to be based on a comparison with nearby undisturbed vegetation, rather than on the exact conditions

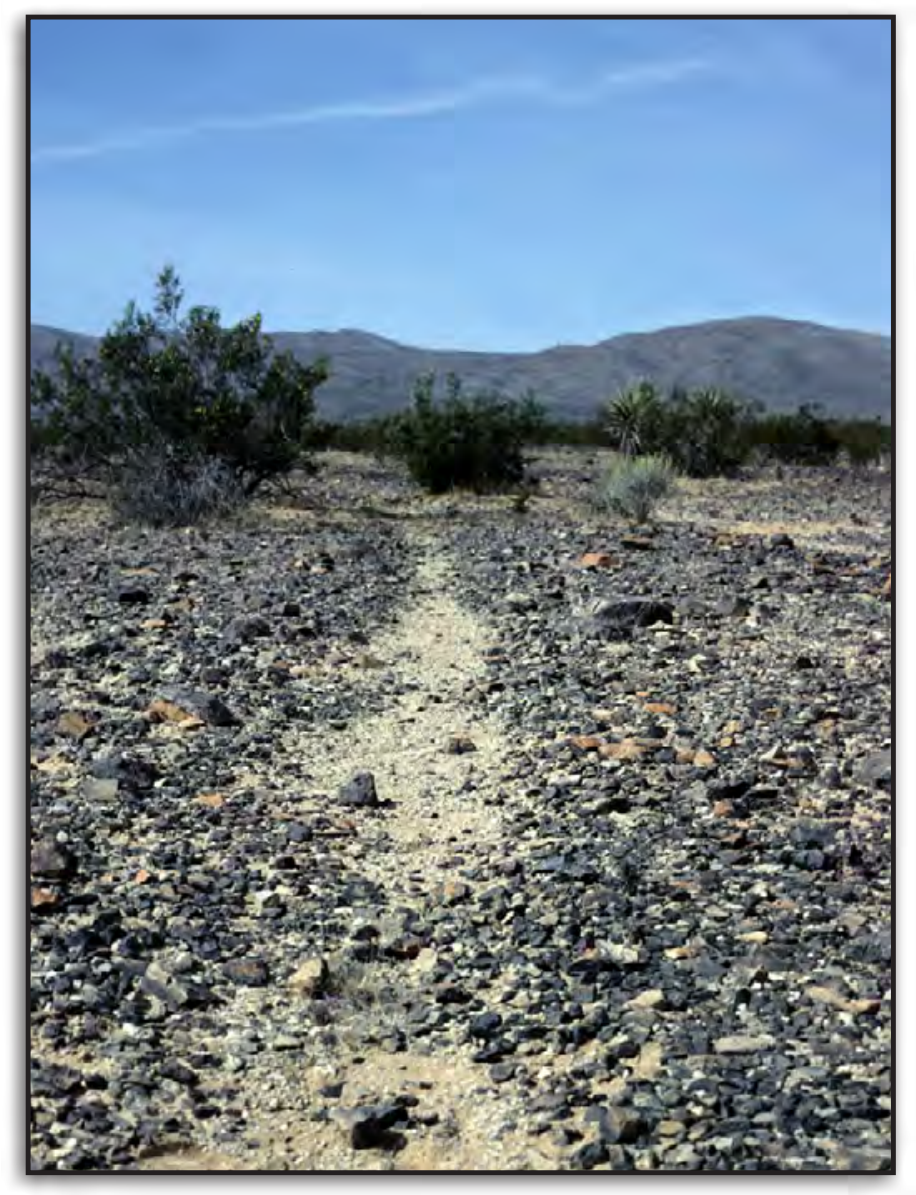

Figure 27. Disruption of desert pavement in a motorcycle trail near Barstow, California. The contrast in surface color is due to removal of desert pavement and exposure of the underlying, finer-grained vesicular layer, or Av horizon (U.S. Geological Survey photograph by David M. Milller). . before the beginning of disturbance (Webb and others, 1988). The presence of non-native annuals may reduce recovery rates of native plants due to competition (Brooks and others, 2004; DeFalco and others, 2007). The severity of soil disruption is also important to the course of vascular plant recovery. If resource patches that occur under shrubs are left intact, recovery of total cover is often accelerated (Wallace and others, 1980). If desert pavements are removed and the Av horizon is disrupted, the disturbed area may support higher plant biomass than undisturbed pavements (Gilewitch, 2004).

Soil compaction levels at the time of abandonment likely affect the reestablishment of plants (Webb and others, 1988). Although high levels of compaction appear to retard the establishment of native perennial desert plants (Adams and others, 1982; Prose and others, 1987; Webb and others, 1988; Prose and Wilshire, 2000), both native and non-native annuals are initially more numerous than in nearby undisturbed areas and recover much more quickly than the perennial vegetation (Hunter, 1995). Non-native annual grasses appear to have the greatest ability to grow on compacted soils, as they are usually the first to colonize such soils (Lathrop and Rowlands, 1983; Prose and Wilshire, 2000; fig. 28). That said, compaction can decrease the cover of native annuals; however, it can also increase their density (Adams and others, 1982).

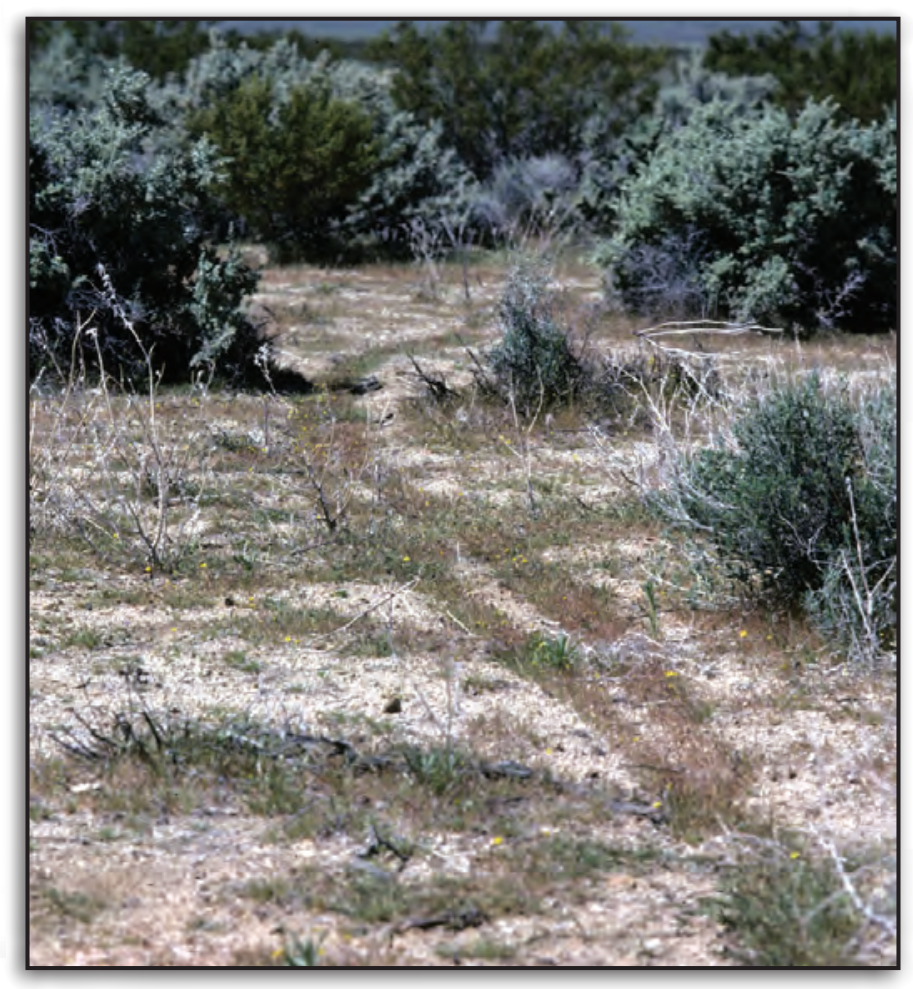

Figure 28. In the Mojave Desert, non-native annual grasses often heavily colonize disturbed areas, especially where soils are somewhat compacted and a depression that collects water is formed (U.S. Geological Survey photograph by David M. Miller). 


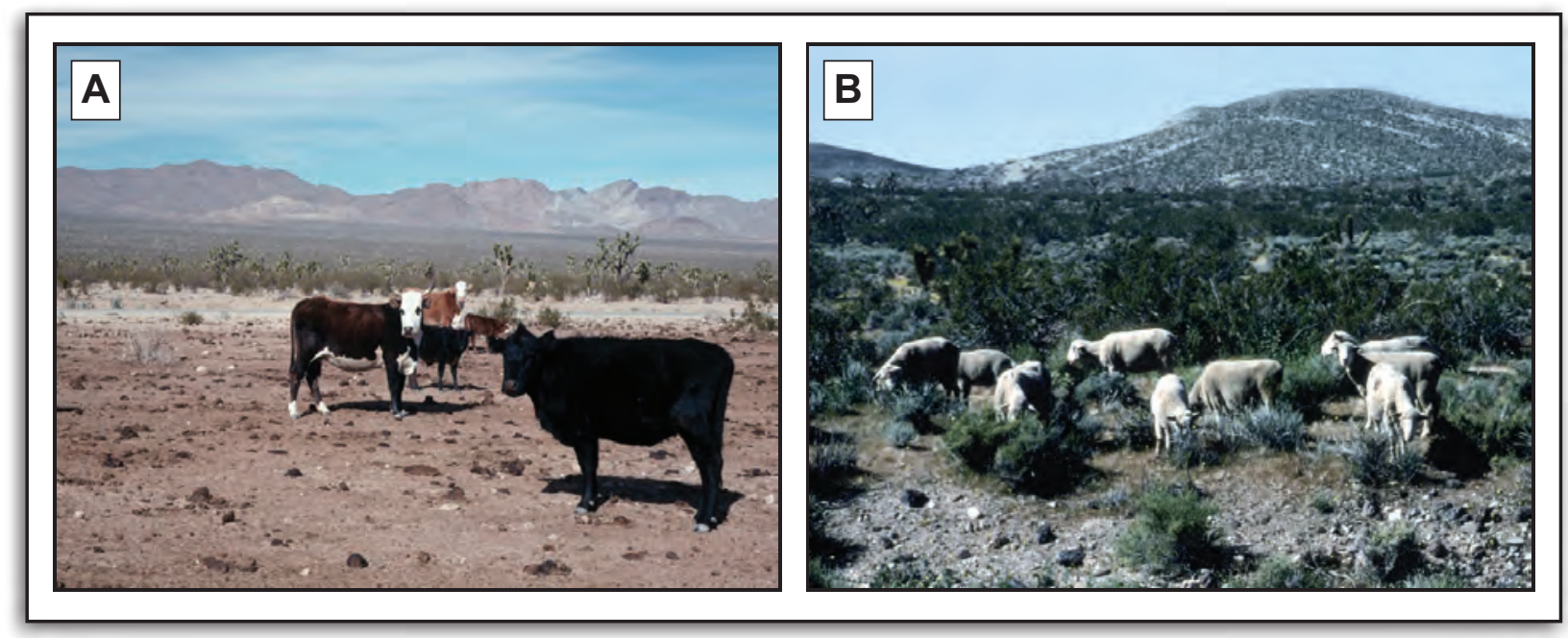

Figure 29. A, Cattle in the Ivanpah Valley of the Mojave Desert. B, Sheep near Ridgecrest in the western Mojave Desert (U.S. Geological Survey photographs by David M. Miller).

\section{Effects of Specific Activities}

\section{Livestock Grazing}

Livestock grazing is the most pervasive land use in the western United States (Fleischner, 1994), and, in general, grazing is thought to change ecosystem characteristics and create numerous disruptions of ecosystem function (fig. 29). In the Mojave Desert, soil compaction by domestic livestock can be especially high near watering areas (Webb and Stielstra, 1979; Avery, 1998; Brooks and others, 2006). As with all surface-disturbing activity, livestock grazing crushes biological soil crusts, reduces soil stability, and reduces nutrient inputs, while increasing the loss of soil, carbon, and nutrients from the ecosystems (Neff and others, 2005).

Livestock also consume plants, and often shift plant community species composition by decreasing the density of perennial grasses and the diversity of winter annuals, while increasing cover of unpalatable forbs and shrubs, such as Larrea tridentata (creosote bush; Avery, 1998). Livestock also disrupt the integrity of the soil surface, which often results in the invasion of non-native annual grasses. In addition, they damage plants as they seek shade. There is very little information on how grazing affects wildlife populations in the Mojave Desert.

\section{Mining and Agriculture}

Mining activities and agriculture have large impacts in the Mojave Desert, although in somewhat different parts of the landscape. Hard-rock mining usually impacts mountain ranges and their foothills, although deposition of tailings piles may bury vegetation on nearby alluvial fans and produce copious amounts of dust (fig. 30). Placer and gravel mining impact alluvial fans, typically in coarse-grained soils. In contrast, agricultural activities generally occur in low-relief areas with finer-grained soils. Mine spoils erode easily, and wind and water erosion can transport potentially toxic substances many miles from the source. We have no information on how mining activities affect wildlife populations.

In contrast, dust production from agricultural areas is a significant component of overall dust emissions in the Mojave Desert (Reynolds and others, 2003) and results in a loss of soil fertility from the source region. Native plants can take many decades to re-colonize abandoned fields, and if nitrogen was added to the soil as fertilizer, or if nitrogen-fixing plants (for example, alfalfa) were planted, non-native annual plants ( $\mathrm{Sal}$ sola tragus [tumbleweed], Brassica spp. [mustards], Bromus spp. [brome grasses], Schismus spp. [schismus grasses], and Erodium cicutarium [redstem filaree]) can outcompete native vegetation for many years and prevent their reestablishment (Carpenter, 1983; Carpenter and others, 1986).

\section{Military Activities}

Military training and testing exercises often involve extensive use of vehicles or troops on the ground, resulting in soil churning and compaction, removal of soil surface protectors, loss of perennial vegetation, and disruption of wildlife populations. Although these ecological impacts are similar to

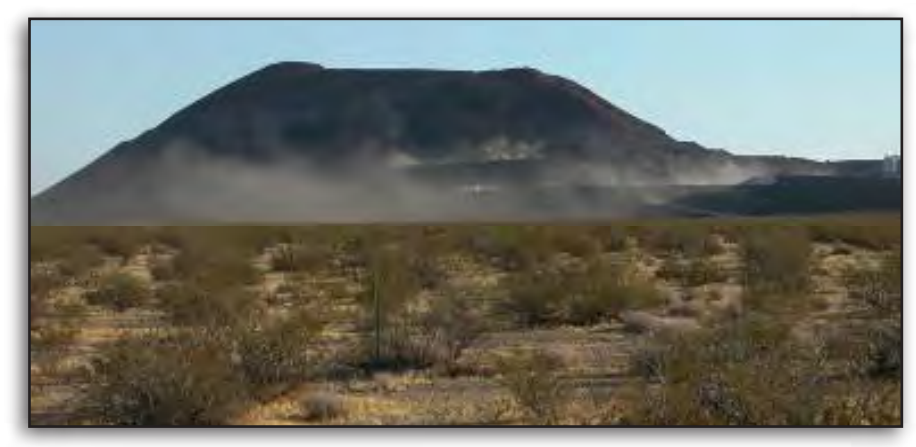

Figure 30. Dust emissions from a mining operation in the Mojave Desert of southern Nevada (U.S. Geological Survey photograph by David M. Miller). 
other land uses, military training may involve very large areas, such as whole valley bottoms, and occur over longer time periods. Moreover, military training exercises may involve more extensive mechanical manipulation, such as blading, than other land uses in the Mojave Desert. Removal of surface soils, in particular, is one potential effect that could significantly slow recovery of abandoned military sites (Steiger and Webb, 2000; Kade and Warren, 2002). Use of the Mojave Desert for military training and testing exercises is increasing, particularly as greater emphasis is being placed on training in desert regions (fig. 31).

The Mojave Desert has a long legacy of use for military training, beginning with General George S. Patton and the need to train for the North African campaign in World War II (Howard, 1985; Bischoff, 2000). Military camps were constructed throughout the desert and then abandoned. Tanks and other vehicles left many miles of tracks. The effects of these military exercises during World War II and in 1964 are still evident in the central Mojave Desert (Prose, 1985; Prose and Metzger, 1985; Prose and others, 1987; Steiger and Webb, 2000; Prose and Wilshire, 2000; Belnap and Warren, 2002). Some areas have recovered, whereas others have not, providing an opportunity to document which site factors affect recovery rates of soils, crusts, and perennial vegetation (Wells, 1961; Webb and Wilshire, 1980; Webb and others, 1988; Webb and Thomas, 2003).

Disruption of desert pavement is still apparent 55 years after these exercises, and total biomass of biological soil crusts has only recovered 46 to 65 percent in tank tracks, even when the tank made only a few passes (Belnap and Warren, 2002). Disruption of desert wash systems is another effect of military training and requires significant time for recovery (Nichols and Bierman, 2001). Total recovery of perennial vegetation cover (without considering species composition) occurs about 80 years following these disturbances (fig. 32). Recovery of species composition ranges from less than a century for assemblages on young geomorphic surfaces to thousands of years in blackbrush assemblages that occur on older geomorphic surfaces. The trajectory of recovery may depend on the history of climate following disturbance. Rates of change are expected to be higher during wet periods than during drought periods, although severe droughts may cause high mortality in ruderal species, allowing longer-lived species to assume dominance.

\section{Off-road Vehicle Use and Roads}

Off-road vehicle use, particularly in open areas, causes significant environmental degradation (fig. 33). Soil compaction increases as a function of the number of passes, with the largest changes occurring during the initial passes (Davidson and Fox, 1974; Wilshire and Nakata, 1976; Webb, 1982, 1983; Lei, 2004). Hillclimbs, a favorite use of motorcycles and four-wheel drive vehicles, cause compaction and soil disruption on steep slopes, and water erosion on slopes can be 10-20 times greater than on disturbed, level ground (Iverson, 1980; Iverson and others, 1981). The increased runoff and sediment yield that result from these activities can have significant

Figure 31. A, Tank involved in a military training exercise in the Mojave Desert, 1964. B, The streets of Camp Iron Mountain, a World War II training facility abandoned in 1944, were still highly visible in this 2001 aerial photograph (copyrighted photographs by D.V. Prose, used with permission).
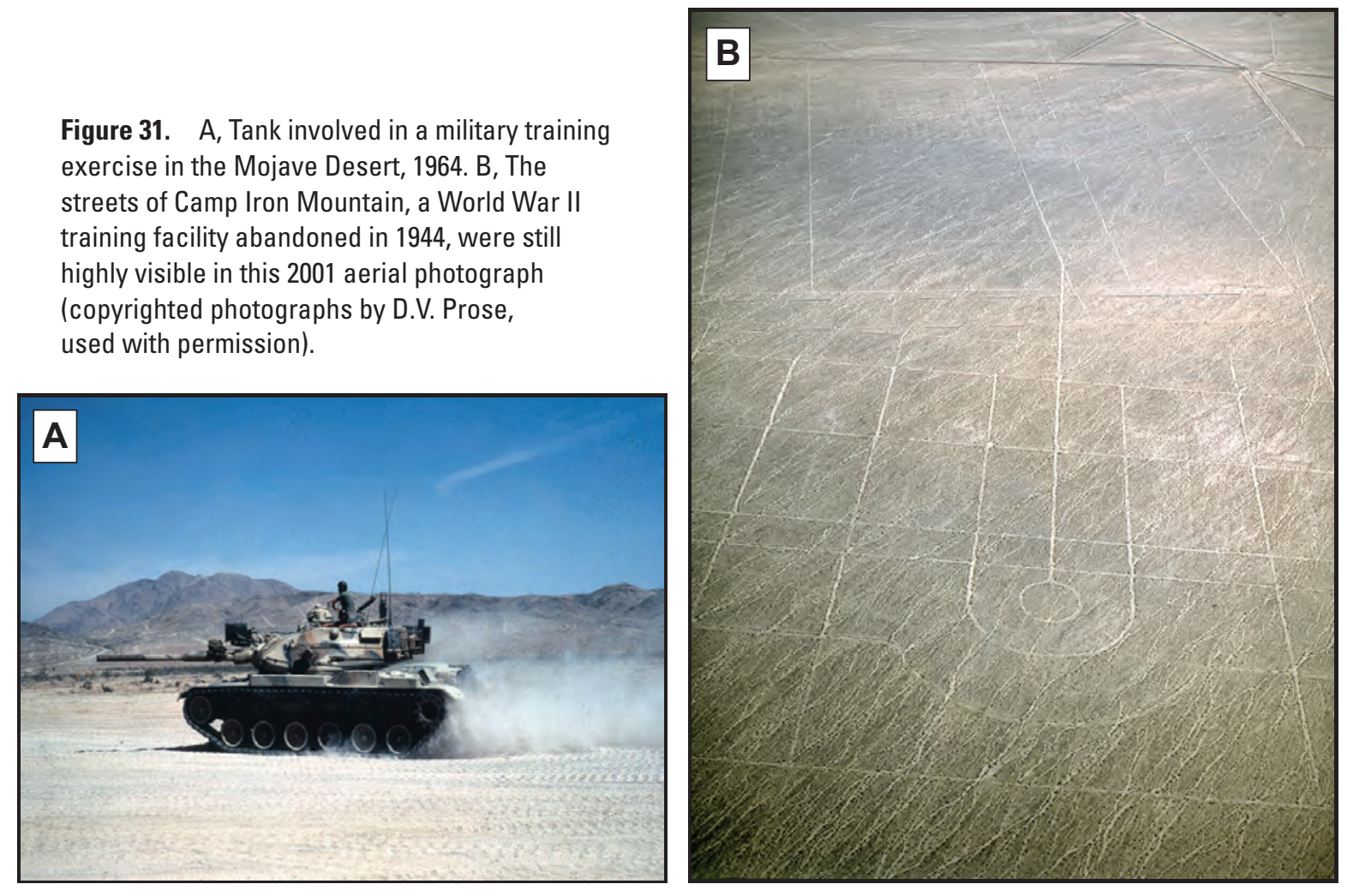


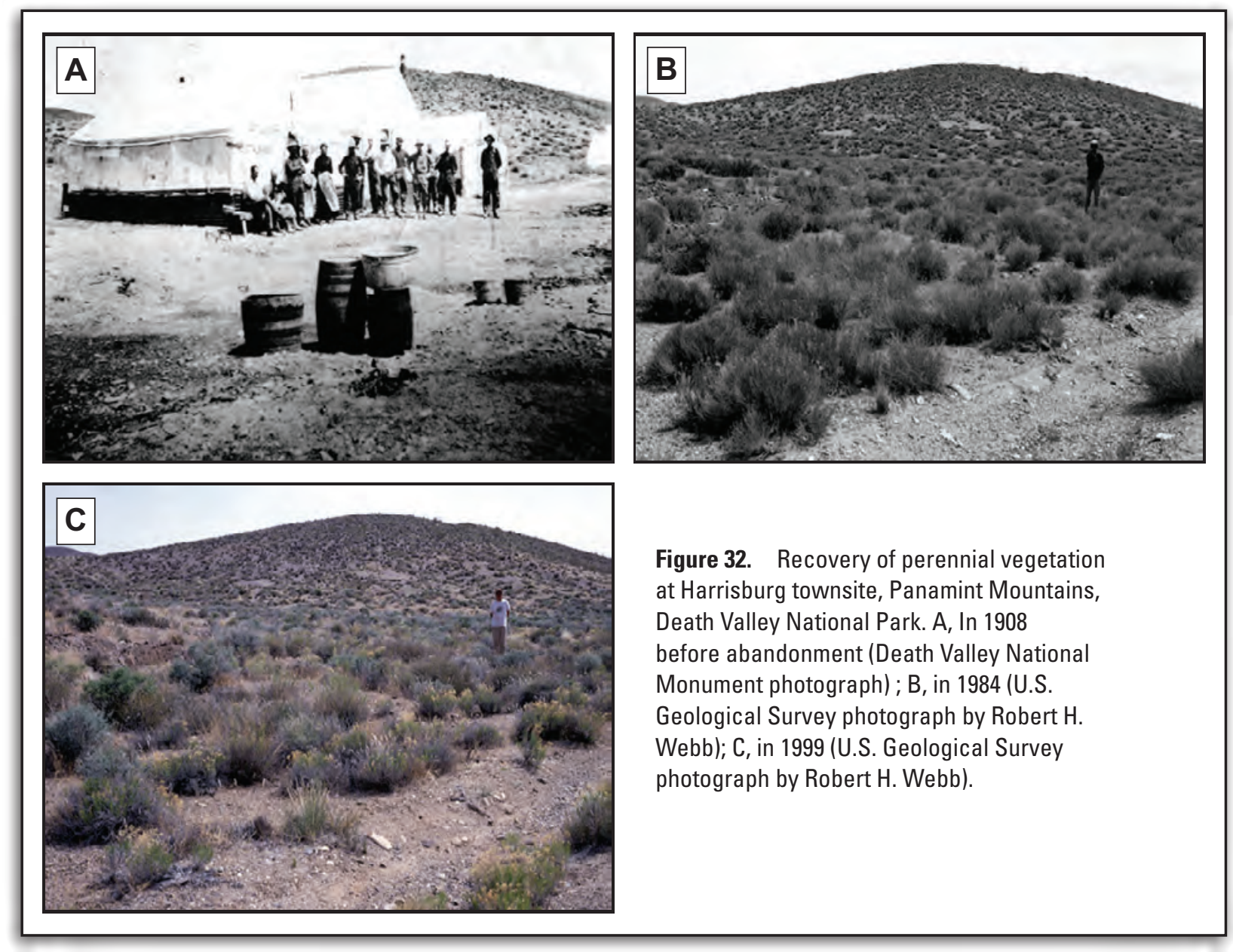

effects downstream, including high dust production. Shrubs are often killed, and late-successional communities replaced by ruderal species, such as Hymenoclea salsola (cheesebush) and Chrysothamnus nauseosus (rabbitbrush; Avery, 1998). Increasing density of off-road vehicle tracks is correlated with decreased cover and diversity of standing vegetation and decreased density and species richness of the soil seedbank (Matchett and others, 2004). One study reported that biomass of an invasive non-native grass (Schismus spp.) was higher within off-road vehicle tracks compared to adjacent untracked areas (Brooks, in press). A dated review of off-road vehicle effects in the Mojave Desert was done by Webb and Wilshire (1983). There is almost no data on how off-road vehicles affect wildlife populations.

Much less is known regarding the effects of roads in the Mojave Desert (Brooks and Lair, in press). The few previous studies that described road effects in this region primarily compared conditions in an actual roadbed with those in a control area located away from the study road. The studies showed that plants (Frenkel, 1970; Johnson and others, 1975; Vasek and others, 1975b), rodents (Garland and Bradley, 1984; Starr, 2002), arthropods (Lightfoot and Whitford, 1991), and tortoises (Nicholson, 1978; Berry and Turner, 1984; Boarman and others, 1997, Berry and others, 2006) are affected by roads. Two studies report that biomass of non-native annual plants is significantly correlated with density of dirt roads (Gelbard and Belnap, 2003; Brooks and Berry, 2006), and another showed that biomass of the invasive Sahara mustard (Brassica tournefortii) was higher along dirt roads than areas away from roads (Brooks, in press). Effects of roads on Mojave Desert bird communities have not been described.

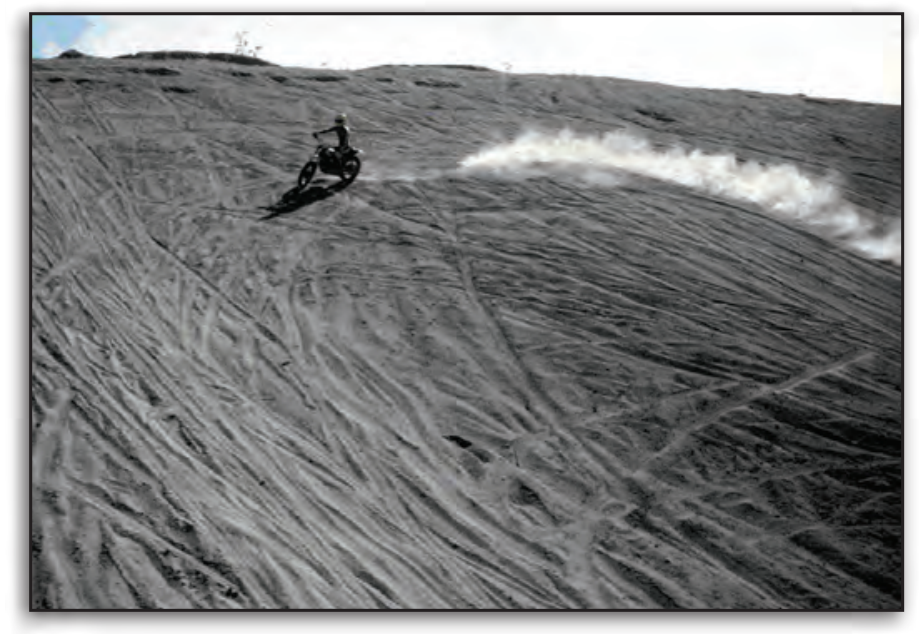

Figure 33. Motorcyclist on hillclimb in Dove Spring Canyon, western Mojave Desert (U.S. Geological Survey photograph by David M. Miller). 


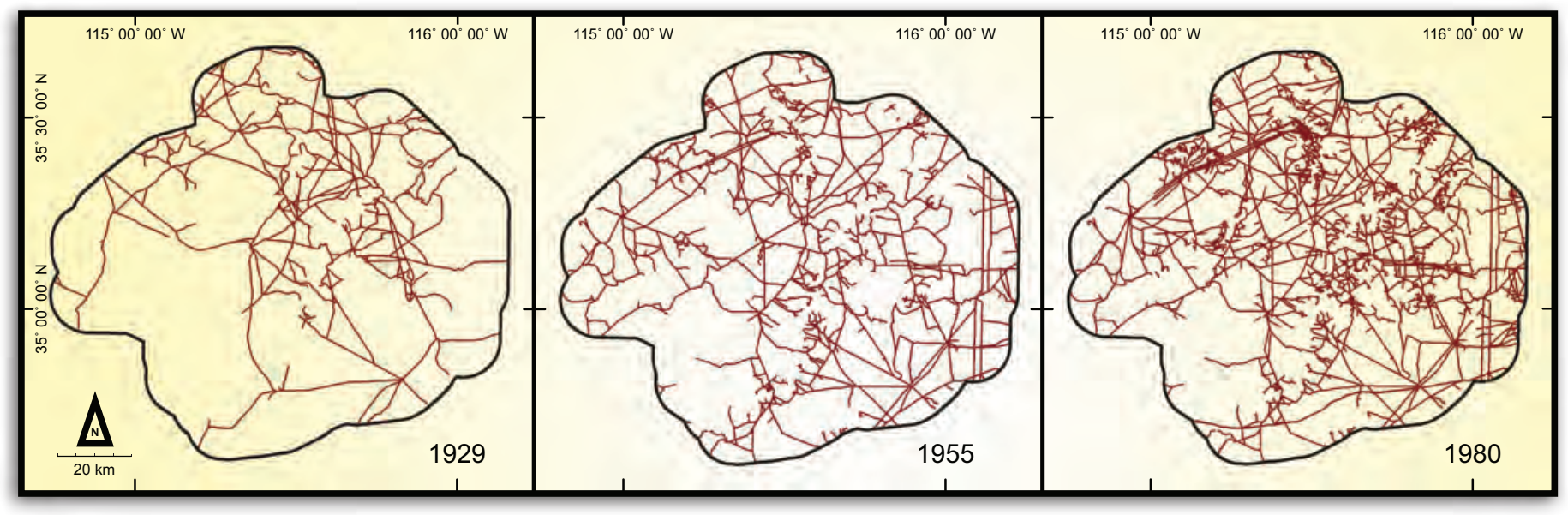

Figure 34. Road proliferation in the Mojave National Preserve from 1929 to 1980 (from Vogel and Hughson, in press).

Fugitive dust from roads has not been studied, despite the fact that it clearly is an issue. Additionally, traffic on main thoroughfares, such as Interstate-15, Interstate-40, and major state highways, create an almost impenetrable barrier for animals attempting to cross, fragmenting their habitat. Although these data indicate that roads can have significant ecological effects, most of these studies only looked at the effect within the roads themselves and in the immediate corridors and did not evaluate gradients of effects away from the road (Brooks and Lair, in press). Therefore, we have almost no data on how widespread road impacts are in the Mojave Desert. The number of roads has increased dramatically in the Mojave Desert (Vogel and Hughson, in press; fig. 34), and there is no data on how this habitat fragmentation has affected animal populations, or on the possible multiplicative effects as road density increases.

Recovery of abandoned roadbeds has been studied by numerous people. It has been primarily these studies and studies of ghost town roads that have been used to estimate recovery of vegetation and compaction in this region. As discussed in the sections above, the time needed for recovery of compacted roadbed soils ranges from 80 to 130 years (Webb and Wilshire, 1980; Webb and others, 1986; Knapp, 1992; Prose and Wilshire, 2000; Webb, 2002; Webb and Thomas, 2003), although Bolling and Walker (2000) did not find any recovery after 88 years. The recovery rate of vegetation is hugely variable, depending on site characteristics and whether total cover or species composition is being measured. We have no information on recovery of animal populations from the impacts of roads.

\section{Hiking and Mountain Biking}

Although long known to contribute to ecosystem damage, the impact of recreational activities, such as hiking and mountain biking, have been little studied in the Mojave Desert. Lei (2004) compared the effects of hiking, mountain biking, motorcycle traffic, and vehicle use on a desert soil in Kyle Canyon of southern Nevada. Two studies (Webb, 1983; Lei, 2004) evaluated the effects of trampling and vehicle use. It was found that one vehicle pass causes the equivalent amount of soil compaction as ten passes by a human on foot (Lei, 2004). Hiking and mountain biking have less effects than motorcycle or vehicle use, but available information suggests that these activities can, with sufficiently heavy use, create the same amount of surficial soil compaction as off-road vehicles. There is no known information on the impact of dispersed hiking and biking on soils, plants, or wildlife populations.

\section{Other Anthropogenic Disturbances}

\section{Urbanization}

Urbanization is perhaps the greatest single threat to the Mojave ecosystem (fig. 35). Roads, paved and unpaved, proliferate around urban areas, fragment wildlife habitat, and cause habitat alteration. Proliferation of vegetation along roads attracts wildlife, leading to high mortality rates when wildlife attempts to cross (T.C. Esque, oral commun.; fig. 36). Unpaved roads are a major source of fugitive dust in desert ecosystems (Campbell, 1972), disrupt surface water flow, and act as a conduit for invasive plants (Gelbard and Belnap, 2003; Brooks and Berry, 2006; Brooks, in press; Brooks and Lair, in press). The abandonment of subdivisions following the initial phase of development may cause many years of elevated dust production. Completed subdivisions extend the urban environment into the desert, introducing dogs and cats as domestic or feral predators of native wildlife, increasing vehicle access to the desert, and increasing noise levels. The increase in dumps and litter is unsightly and has the potential to damage animal populations, either by consumption by wildlife of indigestible material, trapping of rodents in containers, ensnaring of birds in plastic, or the attraction and resource subsidy of predators (for example, ravens), which then increases predation pressure on their prey (for example, baby tortoises). Lights cause the death of millions of desert insects attracted to them. The disturbance associated with urban areas allows for the expansion of non-native plant and animal species into areas where they previously had not become established. 


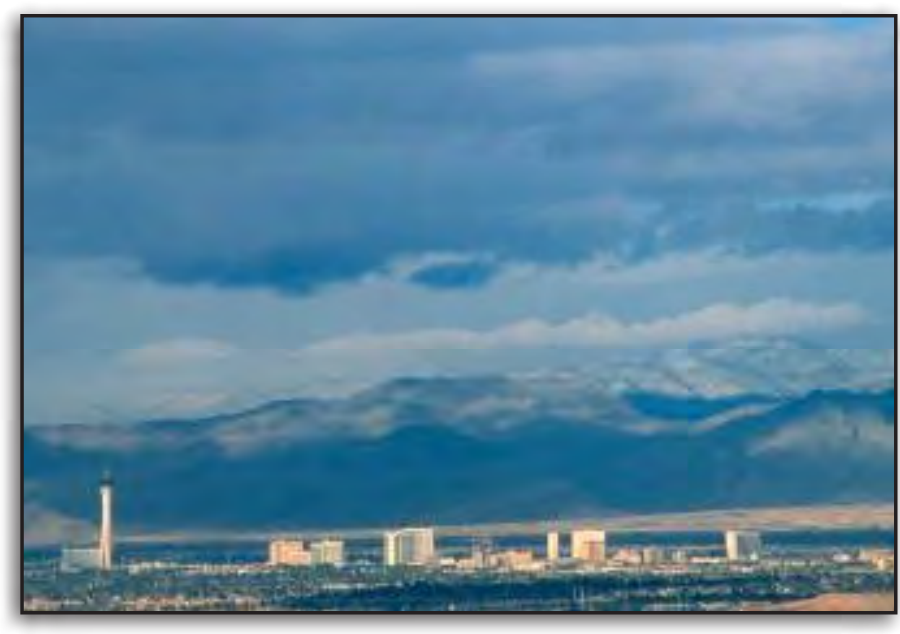

Figure 35. The sprawling nature of cities such as Las Vegas, Nevada, introduce multiple impacts to ecosystem quality and function in the Mojave Desert (U.S. Geological Survey photograph by David M. Miller).

\section{Introduction of Non-native Species}

Although relatively few non-native species have become established in the Mojave Desert compared to other more mesic ecosystems (Brooks and Esque, 2002), their ecological effects have been highly significant (figs. 15 and 37). Bromus madritensis ssp. rubens (red brome), Bromus tectorum (cheatgrass), Schismus spp. (schismus grasses), and Erodium cicutarium (filaree) appear to compete effectively with native annuals for soil nitrogen and moisture in the Mojave Desert (Brooks, 2000, 2003; DeFalco and others, 2003). After germination, these non-native annual plants initiate vegetative growth earlier than most native species (Jennings, 2001), and established seedlings may inhibit the subsequent germination of other annual plant seeds (Inouye, 1980, 1991). B. madritensis ssp. rubens, in particular, can even impact the growth of

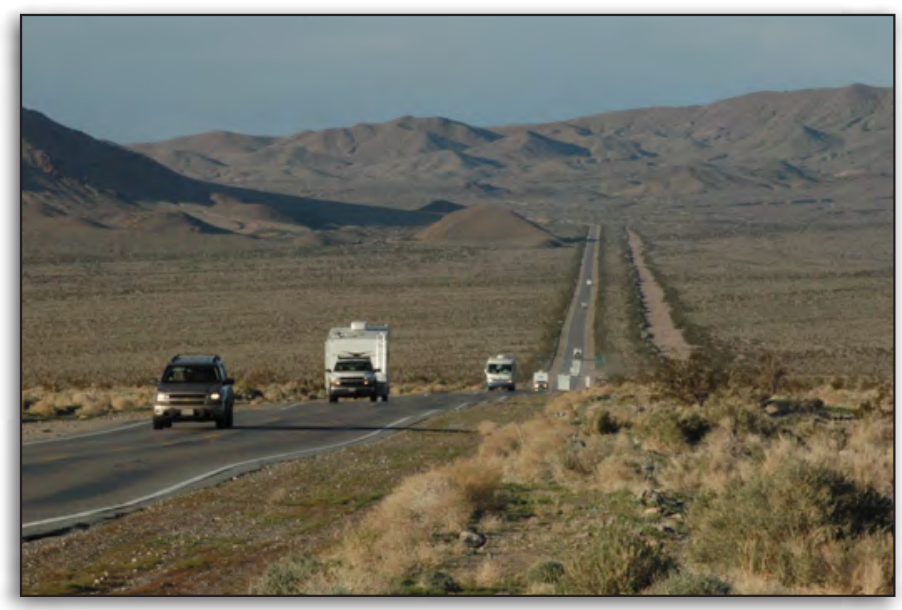

Figure 36. Roadside enhancement of perennial vegetation, mostly Larrea tridentata (creosote bush), along Highway 127 between Baker, California and the Dumont Dunes, eastern Mojave Desert (U.S. Geological Survey photograph by David M. Miller). mature Mojave Desert shrubs, such as Larrea tridentata (creosote bush), and the perennial grasses Pleuraphis rigida (big galleta grass) and Achnatherum hymenoides (Indian ricegrass). The intensity of this impact on perennials depends on the timing of B. madritensis ssp. rubens establishment; earlier winter germination and growth of $B$. madritensis ssp. rubens has a greater impact than those established in spring (DeFalco and others, 2007). These impacts can result in major changes in the composition of plant communities (Bock and others, 1986).

Plant litter created by non-native annual grasses decomposes more slowly than that of native annuals (Brooks, 1999b) due to the higher fiber content in non-native species (DeFalco, 1995), and thus accumulates over successive years. Thick plant litter may impede germination of plant seeds by shading the soil surface, intercepting water that otherwise would infiltrate into the soil, and suspending seeds above and out of contact with soil surfaces (Facelli and Pickett, 1991).

Some have suggested that non-native species, which can occur at high densities, could affect the mobility of desert rodents and reptiles (Cowles, 1977). In addition, sit-and-wait predators, such as lizards, have a difficult time sighting their prey from their observation points under shrubs, as the view is often obscured by non-native annual grasses (T.C. Esque, pers. observation).

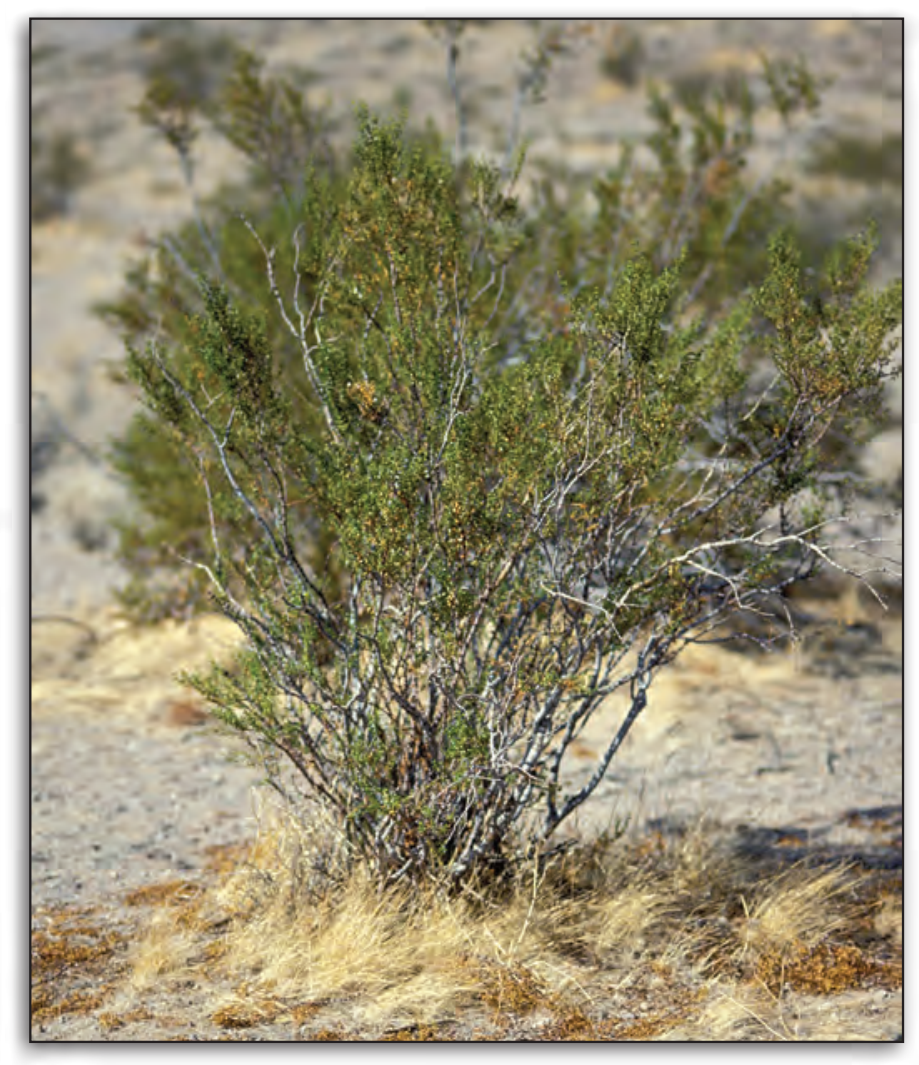

Figure 37. Non-native annual vegetation, primarily Bromus madritensis ssp. rubens (red brome), as an understory to Larrea tridentata (creosote bush). Note the pieces of creosote bush branches on the ground that resulted from pruning by rabbits (U.S. Geological Survey photograph by Jayne Belnap). 
As previously discussed, persistent plant litter contributed by non-native annual grasses has accelerated fire cycles, heavily impacting non-fire-adapted native plants in the Mojave Desert (Brooks, 1999a, 1999b, 1999c; Brooks and Esque, 2002; Brooks and Matchett, 2006; Brooks and Minnich, 2006; Howard, 2006) and elsewhere (D'Antonio and Vitousek, 1992; Brooks and others, 2004). In addition, many invasive plant species possess physiological traits that enable them to benefit from aspects of global change, such as increased atmospheric carbon dioxide and warmer minimum temperatures during winter and at night (Alward and others, 1999; Dukes and Mooney, 1999; Smith and others, 2000).

\section{Atmospheric Changes}

Many aspects of the Earth's atmosphere are expected to change in the near future (Houghton and others, 2001). These include increasing levels of atmospheric carbon dioxide, increasing soil and air temperatures, increasing aridity (Seager and others, 2007), and altered precipitation patterns. In addition, more extreme wind, precipitation, and temperature events than occurred in the past are expected in the future. This will have many impacts on different aspects of Mojave Desert ecosystems. Elevated temperatures and an increase in the frequency of small precipitation events have been shown to kill mosses, lichens, and cyanobacteria (Belnap and others, 2006, 2007). Changes in the global atmosphere are expected to affect the physiological processes and competitive relationships of vascular plants, including enhancement of non-native annual grasses (Alward and others, 1999; Smith and others, 2000) and their competitive effects on native species (DeFalco, 2003), nutrient cycles, hydrologic processes, and disturbance regimes, all of which have the potential to greatly alter the structure and functioning of dryland ecosystems, including the sensitivity of these systems to anthropogenic stressors (for example, Ehleringer and others, 1999; Smith and others, 2000; Weltzin and others, 2003). Despite modeling efforts, there is great uncertainty about how global atmospheric changes will affect precipitation patterns in particular regions, such as the Mojave Desert. Uncertainty regarding how different atmospheric factors will change, and the ecological outcomes of this change, greatly compounds the challenges of managing and monitoring these ecosystems.

\section{Air Quality}

Although the Mojave Desert may appear to be a remote area with superb air quality, much of the region experiences high levels of air pollutants, especially areas downwind of urban zones (for example, the Los Angeles basin and Las Vegas) or fossil-fueled power plants (Allen and others, 1992). The pollutants of particular concern in the Mojave Desert are ozone, sulphur dioxide, nitrogenous compounds, particulates, and various organic compounds (Allen and others, 1992). Acid rain does not appear to be an issue in deserts, as desert soils have a high $\mathrm{pH}$, and thus neutralize raindrop acidity (Bytnerowicz, 2003).

Ozone and sulphur dioxide are generated by the burning of fossil fuels, whether from vehicles or power plants. Both compounds can directly damage vascular plants and other organisms (Thompson and others, 1984; Olszyk and others, 1987; Bytnerowicz and others, 1988; Gonzalez-Coloma and others, 1988; Temple, 1989). In contrast, other major pollutants, such as nitrogenous compounds, can alter many aspects of ecosystem function through the fertilization of soils (Asner and others, 1997; Brooks, 2003; Fenn and others, 2003, Galloway and others, 2003; Allen and others, in press). As desert soils are low in most nutrients, this may be perceived as a benefit. However, fertilization can present a large threat to desert ecosystems. The structure of desert plant communities is often based on the ability of individual plant species to exploit soil nutrients in different ways. As some nutrients are more limiting to the growth of some plants than others, depending on soil and plant characteristics, increases in soil nutrient levels can alter the competitive relationships between plants, and thus change the composition of plant communities (Allen and others, 1992). For instance, annual plants are better able than perennial plants to utilize nitrogen, and thus increased soil nitrogen gives annual plants an advantage (Mun and Whitford, 1998). Because the most problematic non-native desert plants are annuals, additional soil nutrients may exacerbate the problem of invasion (Brooks, 2003; DeFalco and others, 2003; Fenn and others, 2003). Similarly, higher levels of soil nutrients can alter soil biota, and thus decomposition and nutrient transformation rates.

Particulates are another type of air pollution of special concern in deserts. Because plant cover and rainfall are sparse, and soil surface stabilizers (rocks, biological and physical soil crusts) are easily disturbed by vehicles, livestock, and other human activities, levels of airborne particulates can be very high. Dust storms reduce the highly valued clarity of the desert air, often obscuring distant vistas. Drastically reduced visibility on highways can result in severe vehicle accidents. Dust reduces photosynthesis and growth in plants. Dust can scratch the cuticles of insects, leading to their death (Sharifi and others, 1997, 1999). Dust is also a human health hazard, as it carries soil pathogens that can cause diseases, such as Valley Fever (Reynolds and others, 2001), and fine particulates lodge easily in human lungs, potentially leading to lung cancer or other respiratory ailments.

Hundreds of other compounds also pollute the air in this region, including a huge variety of organic compounds released during the application of herbicides or fertilizers, or when fuels, such as wood, coal, and gas, are incompletely burned. Release of metals, such as lead from combustion of leaded gasoline, arsenic, metalloids, and the fallout of humanproduced radioactive elements, such as cesium and plutonium, have an unknown effect on ecosystem and human quality and health; scientists know very little about the effects of these compounds, because they are difficult to sample accurately and expensive to analyze. Some species, such as the desert 
tortoise, may bioaccumulate some or all of these substances, notably metals and metalloids, during their life spans. Thus, it may be helpful to focus resource monitoring protocols on the distribution of these substances, as well as their long-term effects on the environment (Berry and others, 2006).

\section{Diversion of Overland Flow}

Thousands of miles of linear features, such as roads, railroads, and pipelines, crisscross the Mojave Desert. Most of these are located mid-slope or at the toes of alluvial fans, disrupting or blocking water channels and overland flow from reaching the downslope vegetation. As a result, water collects above the feature and flows off the feature, accumulating along its margins, resulting in increased productivity of the vegetation that is directly adjacent to the feature (reviewed by Brooks and Lair, in press). However, vegetation below the feature can be deprived of water and this effect can be seen for $500 \mathrm{~m}$ or more below the diversion (Schlesinger and others, 1989). This deprivation can lead to altered plant community composition and spacing, thus affecting animal habitat and food sources. Soil moisture is decreased, along with the activity times of soil biota. This results in slower nutrient transformations, and thus lower soil fertility.

\section{Philosophies and Strategies for Monitoring in the Mojave Desert}

\section{Why is Monitoring Needed?}

Land management agencies have multiple mandates for managing use in Federal lands in the Mojave Desert. Congressional mandates include the General Mining Act of 1872, the Taylor Grazing Act of 1934 (amended several times), the Endangered Species Act of 1973 (amended in 1988), the Federal Land Policy and Management Act of 1976, the National Environmental Policy Act of 1969, and the California Desert Protection Act of 1994. These laws, combined with the Federal Water Pollution Control Act Amendments of 1972 (as amended in 1977, this became the Clean Water Act), the Clean Air Act of 1990 (amended in 1997), various laws protecting archaeological and cultural resources (especially the National Historic Preservation Act of 1966), and laws protecting Native American lands and resources, provide much of the legal basis for land management in the Mojave Desert. These mandates and the regulations specified for the Department of Defense, Department of Energy, Bureau of Land Management, and National Park Service underscore the responsibility to manage public lands in a fashion that does not threaten basic ecosystem quality or integrity. This goal is becoming ever more difficult to reach as the demands on public lands increase from many different user groups.

Although there are many definitions of ecosystem quality and integrity, all include the idea that soil, water, and nutrients should not be lost or accumulate at an accelerated rate, that species are sustained, that ecosystem processes are balanced and sustained, and that the potential of the landscape be conserved (Noon, 2003). In order to meet their mandates, managers need to understand the condition of their resources, the natural disturbance and climate regimes, the impacts of different stressors and altered disturbance regimes on these resources, and the effectiveness and unintended consequences of corrective management actions. Therefore, monitoring programs generally have one or more of the following goals: (1) determine status and/or trends in the condition of ecosystems and the species contained within them; (2) contribute to the understanding of ecosystem dynamics and response to stressors; (3) provide early warning of undesired changes to the ecosystems and species so as to trigger management action; (4) evaluate the effects of a management effort; and (5) meet legal mandates, such as the Endangered Species Act. A successful monitoring program depends on its goals being well defined from the beginning, as many aspects of the program (for example, sampling design, measured variables) will later be defined in terms of the monitoring goals.

It should be noted that to be most effective for land managers, monitoring programs should provide insight into the cause-and-effect relations between environmental stressors, management actions, and ecosystem response. Without this linkage, there will be little information pertaining to when a management action is required to rectify undesirable conditions. There is also value in incorporating measures that are both retrospective (seeking to understand effects after they occur) and prospective (predictive or stress-oriented to detect effects before they occur or become serious). However, finding prospective measures is difficult, as few cause-effect relations are well understood (National Research Council, 1995).

\section{Monitoring Ecosystem Attributes and Processes}

Although the monitoring of species and/or populations provides one level of information to managers, the monitoring of explicit ecosystem processes provides a very different and valuable perspective. Thus, most monitoring programs generally consist of monitoring both ecosystem components and processes. There are many attributes and processes that are the basis of ecosystems, and their healthy functioning is vital to the conservation and preservation of that ecosystem. A good example of an important ecosystem attribute is total cover of perennial vegetation. An example of an important process is nitrogen cycling or fire frequency. The distinction between attributes and processes may be blurred in many cases; for example, ant populations are an attribute, but they are also integral to the process of bioturbation. Soil compaction is both a process and a state described by soil pore space.

The benefit of attribute monitoring is that biological and physical attributes are combined as indicators of the functional status of rangeland integrity. Thus, the multitude of direct measures of site integrity and status of ecological 
processes, which are difficult or expensive to measure due to the complexity of the processes and their interrelationships, are reduced to a manageable effort. Moreover, the focus is on biotic and abiotic processes that reflect on the functioning of the ecosystem, as opposed to tabulation of a specific component of the ecosystem (for example, bird populations) without cognizance of its trend or the broad array of potential forces for change.

Because the success of most biota depends on the proper functioning of ecosystem processes, such as decomposition, nutrient cycling, and hydrologic cycles, these processes are important to consider when designing a monitoring program (Coleman and Crossley, 1996). In addition, observing dysfunction in a process is often anticipatory of other changes likely to occur. For instance, increased wind erosion or decreased decomposition rates may presage a decrease in soil fertility at a given site before the decline is manifest in the plant community. Monitoring of the physical structure of an ecosystem can also be valuable in understanding and/or predicting changes in species or populations. Physical structure (for example, the height, width, and distribution patterns of plants) has been shown to heavily influence the availability of habitat and food for biota. Although it would be optimal to monitor all species and processes, such an endeavor will never be logistically or monetarily possible. Therefore, in most general monitoring programs, some subset of the measures of species, processes, and physical structures is desirable. In addition, many programs include the monitoring of special species of concern (for example, desert tortoise).

In assessing rangeland status, Pellant and others (2000) developed a guide for interpreting indicators based on three broad ecosystem attributes: (1) soil/site stability, defined as the capacity to limit redistribution and loss of soil resources by wind and water; (2) hydrologic function, defined as the capacity of the site to capture, store, and safely release water from rainfall, run-on, and snowmelt, to resist a reduction in this capacity, and to recover this capacity following degradation; and (3) integrity of the biotic community, defined as the capacity of the site to support characteristic functional and structural communities in the context of normal variability, to resist loss of this function and structure due to disturbance, and to recover following disturbance. This guide is based on the premise that ecological processes functioning within a normal range of variation will support specific plant and animal communities.

\section{"Vital Signs," or Indicator, Approach}

As ecosystems are complicated entities with numerous components and interacting processes, they are difficult and expensive to monitor in their entirety. For this reason, many monitoring programs utilize indicators of ecosystem or population condition, rather than measuring the specific processes or species themselves (National Park Service, undated). Many agencies have developed indicators for their monitoring programs, and there are many lists of potential indicators and the criteria that should be considered for choosing indicators for a specific site when developing a monitoring program. Unfortunately, many indicators address specific and localized impacts, such as those created by campsites and trails. However, the need for monitoring many other aspects of ecosystems or ecosystem condition, including areas of diffuse impact, will require developing new and different indicators. Therefore, it is useful to understand the process of indicator selection and testing so monitoring plans can be tailored to the specific needs of the landscapes to be monitored.

The selection of indicators is a fairly straightforward process. First, the ecosystem to be monitored, its processes, and the real and potential stressors on that ecosystem need to be identified. A list of potential indicators is then constructed using three primary methods: (1) performing a literature search on the ecosystems and stressors of concern, (2) interviewing local experts, and (3) determining what changes occur in an ecosystem of interest when non-impacted areas are compared to areas where the stressors of interest have been applied - those variables that differ between compared sites become potential indicators.

Once a list of potential indicators is compiled, the indicators are entered into a matrix that evaluates the suitability of each indicator (table 3 ). The matrix is constructed by creating a column for each suitability factor and a row for each potential indicator. This matrix includes both required and desirable characteristics of indicators. Indicators are ranked from 1-5 according to how well they meet the characteristics. Required characteristics include: (1) response to the stressors of interest is reliable and measurable, (2) measuring the indicators has no or low impact, (3) measurements are repeatable through time and with different personnel, and (4) indicators have high ecological relevance. Indicators that do not meet all required characteristics are rejected. Those potential indicators that are not rejected are then ranked according to desirable characteristics, which include: (1) a quick response to stressors and management actions taken to mitigate the impacts, so that the efficacy of management actions can be determined in a short time frame; (2) minimal spatial, temporal, and climatic variability, which allows the effects of the stressor to be clearly distinguished from natural variability; (3) ease of sampling; (4) large temporal sampling window to allow flexible scheduling of fewer personnel; (5) cost effectiveness; (6) short training time; (7) availability of baseline data; (8) components that respond over a range of stressor intensity, which allows impacts to be detected while still relatively slight; (9) integrative measures that reflect multiple processes, populations, or gradients; and (10) inclusion of components that anticipate larger, impending changes in the ecosystem. If indicators show no response to impacts until a large decline in resource condition occurs, impacts may be impossible or difficult to repair. The numerical rankings are then added to produce a short list of potential indicators.

After the list of potential indicators is narrowed to a short list, making certain to consider indicators from different scales (for example, plot to landscape), further research is then needed to demonstrate that these indicators truly repre- 
Table 3. Characteristics of good indicators of ecosystem condition. Note that there are those characteristics that are required (left hand side of matrix) and those that are desirable (right hand side of matrix).

\begin{tabular}{|c|c|c|c|c|c|c|c|c|c|c|}
\hline \multirow[b]{2}{*}{ Potential indicators } & \multicolumn{4}{|c|}{ Required characteristics } & \multicolumn{6}{|c|}{ Desired characteristics } \\
\hline & $\begin{array}{c}\text { Reliable, } \\
\text { quick, and } \\
\text { measurable } \\
\text { response } \\
\text { to visitor } \\
\text { impacts and } \\
\text { management } \\
\text { actions }\end{array}$ & $\begin{array}{c}\text { Non- } \\
\text { destructive } \\
\text { to measure }\end{array}$ & $\begin{array}{c}\text { Repeatable } \\
\text { with different } \\
\text { personnel }\end{array}$ & $\begin{array}{l}\text { Ecological } \\
\text { relevancy; } \\
\text { indicative of } \\
\text { significant } \\
\text { adverse ef- } \\
\text { fects }\end{array}$ & $\begin{array}{l}\text { Relatively } \\
\text { quick recov- } \\
\text { ery response } \\
\text { to manage- } \\
\text { ment actions }\end{array}$ & $\begin{array}{l}\text { Independent } \\
\text { as possible } \\
\text { from other } \\
\text { environmen- } \\
\text { tal variables }\end{array}$ & $\begin{array}{l}\text { Ease of } \\
\text { sampling }\end{array}$ & $\begin{array}{l}\text { Ability to be } \\
\text { sampled at } \\
\text { any season }\end{array}$ & $\begin{array}{c}\text { Cost } \\
\text { effectiveness }\end{array}$ & $\begin{array}{c}\text { Short training } \\
\text { time required } \\
\text { for sampling } \\
\text { personnel }\end{array}$ \\
\hline \multicolumn{11}{|l|}{ Soil stability } \\
\hline \multicolumn{11}{|l|}{ Biological soil crusts } \\
\hline \multicolumn{11}{|l|}{ Vegetation cover } \\
\hline
\end{tabular}


sent the ecologically relevant processes or populations they are intended to represent. This step is absolutely essential in choosing indicators and should not be skipped, even though the exercise of definitively linking indicators to their target can be expensive and time-consuming. Once it is established that the indicators meet the intention of the program, protocols are developed for measuring them, these protocols are field tested, and the final monitoring program is designed. An important aspect of indicator selection is maintaining flexibility at all stages of the process. During testing, selected indicators need to be freely added or dropped based on experience gained in the field. During field testing of chosen indicators, measurement methods may be changed several times until they are adequately modified to meet monitoring needs.

Available funding generally dictates the number of indicators used for a given monitoring program, and funding typically is limited. Given this constraint, managers have several choices: (1) monitor more indicators at fewer sites, which limits the geographic area to which the results can be extrapolated; (2) monitor fewer indicators at more sites, which provides less information about each site and increases the risk that subtle shifts with potentially large ecosystem impacts may be missed, but allows results to be extrapolated to a larger area; or (3) monitor using a tiered program in which some indicators are monitored more frequently than others. For instance, factors that change quickly with stress (for example, vegetation cover) could be measured annually, while monitoring factors slow to change (for example, soil compaction) could be monitored every five years. This approach can offer a great deal of flexibility to a monitoring program and facilitate measurements at more sites more often.

Once indicators are chosen, triggers for management action, or standards, need to be defined for each indicator. Standards are based on a combination of data obtained from research, management goals, and professional judgment. Standards should be specific, quantifiable, and generally attainable. Standards define the desired condition of a given resource and so should not necessarily be based on current conditions.

Standards are an important tool for achieving management goals. The level at which they are set is generally based on the importance of a variable to ecosystem functioning and the indicator's resiliency and resistance to disturbance. For example, little deviation from normal may be tolerated in variables that are essential for healthy ecosystem functioning and have very slow recovery times, whereas more tolerance for impacts may be shown for indicators less crucial to the overall system functioning or with short recovery times. Standards also tend to be more lax in areas of high visitation, relative to areas of low visitation, reflecting both the higher use of the area, the higher incidence of impacts, and the reduced ability of management to control such impacts. Because standards reflect the desired future condition of the resource, not necessarily the current condition of the resource, they may be set at levels, such that the areas are currently out of compliance. As a result, immediate management action to correct this condition would be triggered.
It is also important that standards not allow ecosystems to cross a threshold from one stable state to another stable state. Thresholds are defined as the point past which, when the stressors driving change are stopped, the system fails to recover back to its original state. Such a transition is not easily reversed without significant inputs of resources (National Research Council, 1994). For example, in Chihuahuan Desert grasslands, reduction below a threshold value of 20 percent shrub cover heralds the local extinction of banner tailed kangaroo rats (Dipodomys spectabilis; Krogh and others, 2002). In the Mojave Desert, the invasion of annual grasses has pushed many grassland ecosystems over a threshold where accelerated fire cycles prevent the reestablishment of perennial plants. Expensive restoration measures (for example, non-native plant control, soil ripping, or reseeding) may be necessary to restore ecosystems once they have passed a threshold (Pellant and others, 2000). Furthermore, when ecosystem degradation extends beyond specific thresholds, the changes may be irreversible (Whitford and others, 1995).

\section{Measurement and Site Selection}

Criteria for site selection are as varied as the issues being addressed by the monitoring program. Therefore, the intent and goals of the monitoring program must be clearly stated in the design and execution of the program. The most important program decisions are whether (1) to monitor the status of ecosystems, the trends in ecosystems, or both; (2) the program will provide managers with information as to why the observed changes are occurring, as well as when and what management actions are needed; (3) measures will be qualitative, quantitative, or a mixture of both; (4) the program will measure the natural background of change, focusing mostly on undisturbed sites, or will include disturbed sites; and (5) all ecosystems will be targeted or whether the program will be limited to specific ecosystems, such as ones that are dominant, at high risk, and/or of special interest. Together, these decisions dictate what, where, and how often sampling is required.

One of the biggest trade-offs faced by designers of monitoring programs is the vast landscape that is to be monitored in light of the amount of funds that are available. To further exacerbate the trade-offs, climate variability is high and components of the desert ecosystems, whether plants or animals, can have significant lag times between the application of a stressor (for example, drought) and the response. Therefore, if the monitoring program is to document only the status of ecosystems, it may be sufficient to visit sites on a rotating basis (for example, every five years). However, if the documentation of trends is desired or if the program's intent is to explain the cause of the observed trends, sites are best visited annually. This will likely require a tiered sampling program as discussed above.

\section{Climate}

Documenting climatic conditions is basic to most monitoring programs. The placement of climate stations (fig. 38) is 
a decision that should be based on where current stations exist in relationship to the climatic zones where the study plots or other areas of interest reside. At a minimum, each precipitation-temperature zone should be represented by some level of climate monitoring. Data from these stations can then be modeled and extrapolated to represent areas that are not monitored. However, where vegetation or process studies are located, it is strongly suggested that air temperatures and precipitation be monitored on site.

Monitoring of climate should include at least daily maximum and minimum air temperatures and precipitation at multiple locations. However, this information is much more valuable if measurements are taken hourly. Given new advances in technology (for example, Hobo event recorders), this is now feasible for a minimum price. Additional data that is of value, particularly if potential or actual evapotranspiration is wanted, are relative humidity, solar radiation, and wind speed and direction.

\section{Air Quality and Dustfall}

Monitoring of wet and dry deposition is both costly and time consuming, and thus aerosol deposition generally is not monitored by local land managers except as part of a larger network or for specific, short-term research questions. The National Atmospheric Deposition network (http://nadp.sws. uiuc.edu) currently operates stations at many sites across the United States, including two in the Mojave Desert (Joshua Tree and Death Valley National Parks). However, these stations only measure wet deposition, including nitrogen (inorganic, nitrate, ammonium), magnesium, sodium, calcium, potassium, chloride, sulfate, and $\mathrm{pH}$. Unfortunately, this network ignores the large amount of dry deposition that occurs in

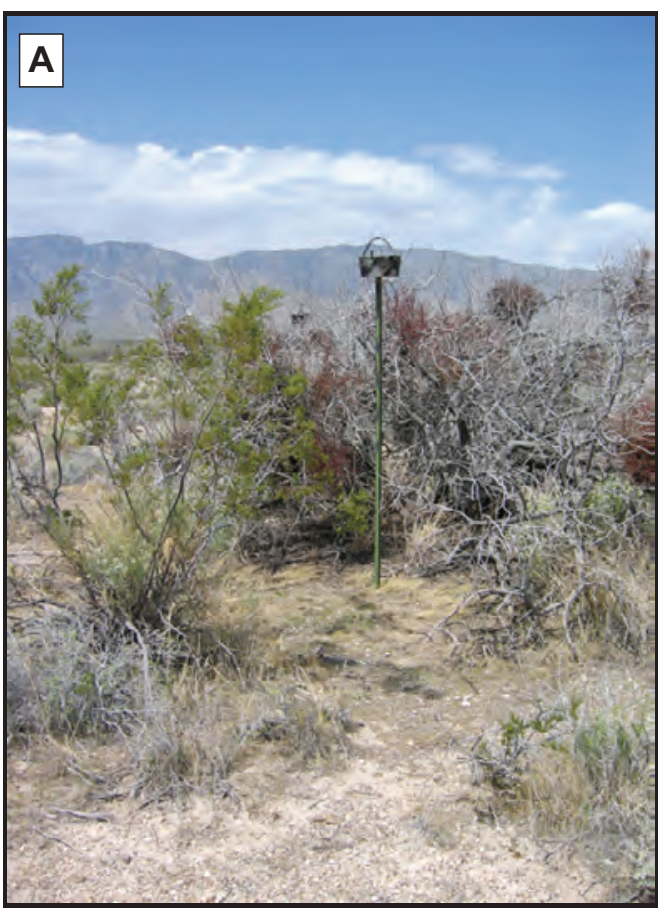
deserts. The National Park Service has a network of sites that measures some aspects of

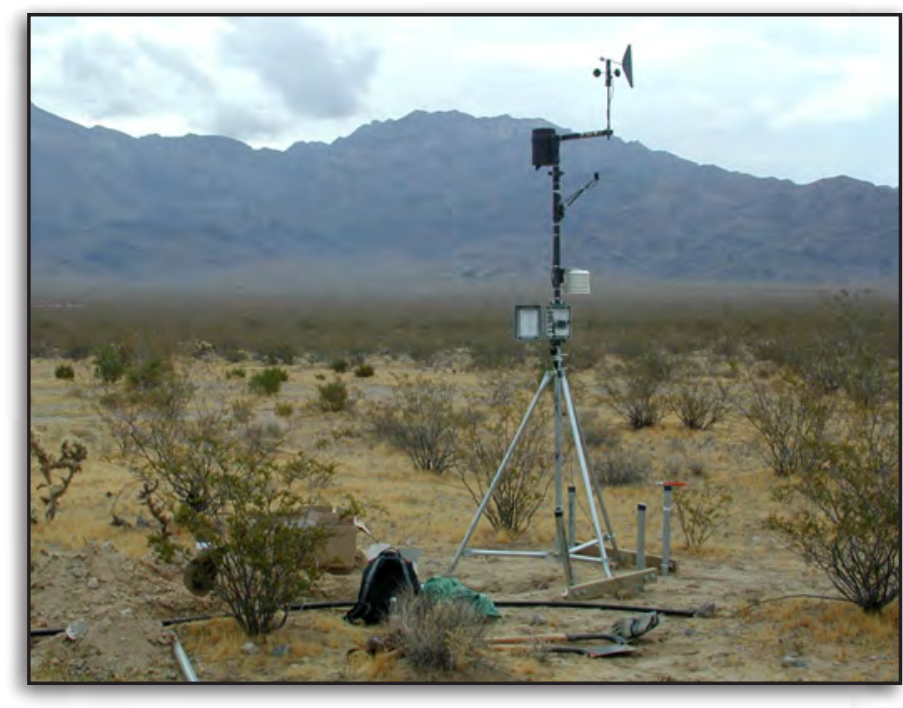

Figure 38. A climate station in the Mojave Desert simultaneously measures multiple meteorological parameters, including rainfall, temperature, wind speed and direction, and solar radiation (U.S. Geological Survey photograph by Richard Reynolds).

dry deposition, including nitrogen, ozone, sulfur, and particulates; Joshua Tree National Park has one of these stations. Data from these stations can be obtained at http://www.nps.gov.

Dust inputs are fairly straightforward to measure (fig. 39; for measuring dust output, see Soil Stability section below). It is best if the collection devices are co-located with climate stations that are recording at least precipitation and, more optimally, wind speed and direction as well. Wind direction and speed are needed if any extrapolation of the data to other areas or modeling of sediment production is desired. The simplest dustfall collectors are angel food cake pans placed $2 \mathrm{~m}$ above the ground and filled with marbles. Their rims are covered with sticky materials to discourage birds from perching on them. Dust sticks to the marbles and is then washed down below the marbles when it rains. (Due to limited rainfall and high evaporation rates, the pans do not fill with water). Pans are emptied every six months by carefully brushing and washing off the marbles and the bottom of the pan. If you want seasonal data, you will need more than one pan, as dust amounts are generally small ( 2 to $3 \mathrm{~g}$ ). The water is evaporated from the samples, which are then weighed. This type of

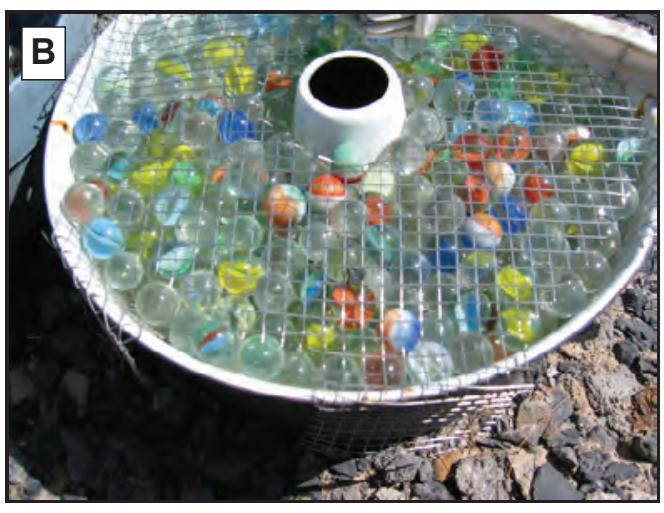

Figure 39. Dustfall traps in the Mojave Desert. A, Dustfall trap installed on the east side of the Sheep Range. B, Close-up of a dustfall trap showing marbles in an angel-food cake pan used to collect dust for analysis (U.S. Geological Survey photographs by Marith Reheis). 
collector, along with extensive data from the Mojave Desert from a network of such collectors, can be seen at http://esp. cr.usgs.gov/info/sw/clim-met/. Data from an extensive dust trap system throughout the Mojave can bee seen at http://pubs. usgs.gov/of/2003/ofr-03-138/ofr_03_138_508.pdf.

\section{Soils}

Soil properties are highly variable across even small distances. Therefore, characterizing soil requires either a high number of replicates ( $\sim$ to 10$)$, or a smaller number of replicates made up of multiple subsamples (for example, 2 to 5 samples, each made up of 30 composite sub-samples). Depth of sample collection depends on the soil property being measured. Because Mojave Desert soils are often rocky and have indurated subsurface horizons, sample depth should be kept as shallow as possible without compromising the goal of the data collection. In general, because most plant roots occur in the top 20 to $30 \mathrm{~cm}$ of soil, sampling for soil nutrients and/ or soil food web activity is most often restricted to the top 10 to $20 \mathrm{~cm}$ of soil. On the other hand, depth profiles for soil texture may be important to determining hydraulic properties and moisture-holding capacities.

Soil depth is an important indicator of a number of ecosystem-related processes, particularly water-holding capacity. Unfortunately, this indicator is not appropriate for either rocky soils, cohesive soils, or soils on old geomorphic surfaces where indurated subsurface horizons will impede insertion of depth probes. If the issue is rocky soils, the only option is to either use a large auger (bigger than the buried rocks) or collect all soils and rock within a given area and estimate the volume of soil per area (see Soil Texture section). Measuring the depth to the caliche layer can be very informative, although where soils are very rocky, again, either a large auger will be needed, or a hole will have to be dug. To measure soil depth in soils without issues such as rocks (for example, sandy soils), a thin, pointed, metal pole that has a handle and has distance from the pointed bottom marked at 1 or $5 \mathrm{~cm}$ intervals is inserted (often pounded) into the soil along a transect. At least 10 randomly spaced probes are inserted around the entire plot. At each measuring point, the probe is pushed straight into the soil until some obstruction prevents the probe from going any deeper. If soil depths are highly variable, the number of sampling points should be increased to at least 30 .

\section{Soil Texture}

Soil texture (the distribution of different particle sizes in the soil) is an important descriptor of surface and subsurface soil properties. Soil particles are classified according to size. Although there are several different classification systems, most scientists use the following diameter categories: particles greater than or equal to $0.002 \mathrm{~mm}(2 \mu \mathrm{m})$ are clay, particles $0.002 \mathrm{~mm}$ to less than $0.063 \mathrm{~mm}$ are considered silt, and particles from $0.063 \mathrm{~mm}$ to less than $2 \mathrm{~mm}$ are considered sand.
Gravel consists of particles greater than or equal to $2 \mathrm{~mm}$, and the terms stones, cobbles, and boulders are used with a variety of size definitions to describe the largest size fractions.

Particles larger than $128 \mathrm{~mm}$ are often measured by one of two techniques: point counts (Wolman, 1954) are done by stretching a tape measure across the soil surface and, at a fixed interval, the size of the intercepted particle is measured and tallied into size classes. The total number of particles measured should range from 100 to 400, depending upon the range in particle size. Each size group is then weighed and a volume for weight transformation used (Kellerhals and Bray, 1971a, 1971b; Rice and Church, 1996). Alternatively, a pit of known volume is excavated, particles are segregated by size into classes, and the groups are weighed. This method requires either an estimation of bulk density or collection of the total weight of all material removed from the pit.

A sieve analysis is used to obtain the particle size distributions of the moderately sized soil particles (0.063-128 mm; Klute, 1986). Sieves with different mesh sizes are commercially available, and soils can be sieved by hand with a mechanical shaker or an ultrasonic vibrator. The initial sample weights and analysis times vary with the method used, the sieve diameter, and the particle-size distribution of the sample. If particles larger than $128 \mathrm{~mm}$ are measured separately, a proportion of this size fraction is required to combine the results from point counts or direct measurement with sieve data. The volume of the soil fraction remaining on the sieve is calculated and used to determine the proportion of the soil volume that the given fraction represents. The fraction passing through the $0.063 \mathrm{~mm}$ sieve (also known as "pan leavings") is further analyzed for silt and clay percentages.

A variety of techniques are used to measure the distribution of silt and clay particles. All of these methods use some variation of measuring the velocity of particles falling through water (Klute, 1986). The simplest method uses a hydrometer to measure changes in fluid density with time. A disaggregated and dispersed soil sample is introduced into a graduated cylinder filled with deionized water, and the change in the fluid density is measured at fixed time intervals corresponding to when the various sizes are expected to have fallen through the water column. The more sophisticated pipette method extracts a sample of the fluid at fixed time intervals for gravimetric measurement. Other methods use gamma rays or optical properties to estimate the amount of silt and clay in suspension as a function of time. As each soil analysis technique is different, it is important to stay with one technique throughout the sampling time.

\section{Soil Nutrients}

Soil nutrients are highly variable, both spatially and temporally, and thus many subsamples are required to adequately characterize a site. Because most plant roots occur in the top 20 to $30 \mathrm{~cm}$ of soil, and because soil nutrients at 20 to $30 \mathrm{~cm}$ are highly correlated with nutrients at 0 to 10 or 0 to $20 \mathrm{~cm}$, most sampling for soil nutrients is done at 0 to 10 or 0 to $20 \mathrm{~cm}$. 
Many soil nutrients are often used for monitoring change or recovery. These usually include nitrogen, phosphorus, and carbon, but may also include major cations (for example, potassium, calcium, magnesium, sodium) and micronutrients. Although cations and micronutrients are very important in understanding the functioning of desert ecosystems, they are seldom used to detect changes in sites, as little is known about what is "normal" for these elements. An exception to this is in burned areas or where subsurface soils have been brought to the surface (for example, due to mining activities), where both cations and micronutrients can change dramatically.

Nutrient analyses are traditionally done on the soil fraction larger than $2 \mathrm{~mm}$, and thus once soils are collected for analysis they are either sieved first or sent directly to a soil analysis lab. Selection of a soil lab must be done with care, as most are equipped to handle agricultural soils with low $\mathrm{pH}$ and high organic matter. Therefore, their extraction techniques need to be modified to handle the high $\mathrm{pH}$ and low organic matter of desert soils. For a complete site characterization, the most important data to collect is soil texture, $\mathrm{pH}$, organic matter, electrical conductivity, total nitrogen, calcium carbonate $\left(\mathrm{CaCO}_{3}\right.$, or an estimate of the buffering capacity of the soil), bio-available phosphorus, exchangeable cations, and bio-available micronutrients. If possible, obtaining data on total concentrations of phosphorus, cations and micronutrients using Inductively Coupled Plasma Emission Spectrometry (ICP-ES) is also valuable, as it indicates the total pool of the nutrients in the soil. If funding is limiting, the minimum analyses should include soil texture, total nitrogen, calcium carbonate, and bioavailable phosphorus and cations. The amount of soil required for analyses is about $100 \mathrm{~g}$ for soil $\mathrm{pH}$ and salinity, and $50 \mathrm{~g}$ for all other types of chemical analyses.

\section{Nitrogen}

There are three types of nitrogen analyses commonly included in monitoring programs: (1) total nitrogen, using the Kjeldahl method of analysis (Bremner, 1960); (2) bio-available nitrogen (nitrate and ammonium), using resin or potassium chloride extractions (Sparks and others, 1996); or (3) actual or potential mineralization (Haney and others, 2004). Total nitrogen measures all nitrogen in the soil, regardless of its form and whether or not it is bio-available. This measure is fairly constant through time. Nitrate and ammonium are the two forms of nitrogen most utilized by biota, and thus their levels indicate how much nitrogen is readily available for uptake. Consequently, it can be a more sensitive measure than total nitrogen. However, transformations between these two nitrogen pools occur continuously. Therefore, they can only be used for monitoring if measured repeatedly and under similar conditions or in comparison with a nearby reference area with similar climate, soil texture, and landscape position. In addition, potassium chloride extraction needs to be done in the field.

The most common nitrogen transformation measure used in monitoring programs is actual or potential nitrogen mineralization. Potential nitrogen mineralization is a labora- tory measure. Soils are analyzed for nitrate and ammonium, incubated under ideal conditions for a set period of time (weeks to months), and then re-analyzed to examine changes in the two pools. Actual mineralization rates are done in the field. Soils are collected, a subset is extracted in the field for ammonium and nitrate concentrations (and analyzed in the lab afterwards), and the rest of the soil is then re-inserted into the soil. After incubation for a set time, the re-inserted soils are collected, extracted in the field, and analyzed again for nitrate and ammonium (Haney and others, 2004). Pre- and post-incubation pool sizes are then compared. Positive numbers indicate net mineralization (an increase in plant-available nitrogen), whereas negative numbers indicate net immobilization due to microbial uptake (a decrease in plant-available nitrogen).

Nitrogen inputs can also be measured as part of a monitoring program, although this is much more difficult than measuring pools of soil nitrogen. Most present-day inputs to Mojave soils are likely from the cyanobacteria and/or lichens in biological soil crusts, although even these inputs are low. Deposition of nitrogen due to human activities can also be significant in some parts of the Mojave. Measuring nitrogen inputs in these ecosystems, therefore, requires assessment of nitrogen fixation by microbes and inputs from atmospheric deposition. Measuring microbial fixation is generally done by incubating the sample under a 10 percent acetylene atmosphere in the light, under known temperature and moisture conditions (in the field or the laboratory), for up to six hours. Subsamples of the gaseous headspace are then injected into a gas chromatograph and the amount of ethylene evolved is measured as a surrogate for nitrogen fixation (this is based on the fact that the nitrogenase enzyme preferentially reduces the acetylene rather than the atmospheric nitrogen gas). Ethylene amounts are then converted to nitrogen units, using a multiplier of three (this number appears accurate for lichens; however, the correct number for soil cyanobacteria is under discussion; Belnap, 2003c).

Atmospheric deposition is measured in several ways. The simplest is a passive collector, which does not require power, but collects only ambient deposition (see dustfall traps in the Air Quality and Dustfall section). This means collected amounts are often low and timing of deposition cannot be determined. More sophisticated collectors can separate wet and dry deposition, collect an enhanced volume of air using a vacuum system, as well as determine the time of deposition.

Nitrogen losses are also difficult to measure. Gaseous losses need to be measured with some form of closed chamber system where gases are collected and analyzed with a gas analyzer (in the laboratory or field). These systems are expensive, are generally restricted to one-point-in-time assessments (although very expensive, continuously monitoring systems are available), and are high maintenance. Leaching losses are also difficult to assess, as there needs to be some sort of collecting device inserted at depth in the soil from which nitrogen-containing water can be collected. Nitrogen losses due to wind erosion are straightforward to measure (see wind erosion in the Eolian Processes and Dustfall section). Losses due to 
water erosion are, again, difficult to measure, as both the water and sediment contained in the water need to be collected and analyzed. Therefore, most measures of nitrogen inputs and losses are not generally part of a monitoring program.

All is not lost, however. In addition to total soil nitrogen, soil nitrogen isotopes can be used as an indicator of the balance between gains and losses of nitrogen from an ecosystem. Therefore, isotopes can be an excellent integrated measure of the disruption or recovery of nitrogen cycles. However, the collection of the samples has to be done carefully, as only areas with the same soil moisture availability can be compared. Therefore, comparisons can only be made among areas of similar climate and soil texture (and thus landscape position, as soil texture can change downslope due to the movement of fine soil particles). If the disturbance is only at the surface, with little subsurface effects, comparisons can be made of the surface (0 to $1 \mathrm{~cm}$ ) and subsurface (4 to $6 \mathrm{~cm}$ ) soils at the same site, assuming soil characteristics do not change with depth. Under these conditions, a reference site is not needed. For isotope analyses, soils are collected as for other nutrients (depth of soil collection will depend on what part of the soil is of interest), and $1 \mathrm{~g}$ is sent to a laboratory for analysis on a mass spectrophotometer.

\section{Phosphorus}

Although total phosphorus is often high in desert soils, its interaction with other soil elements often makes it unavailable to plants and soil organisms (Lajtha and Schlesinger, 1988). Therefore, while total phosphorus (using Inductively Coupled Plasma Emission Spectrometry [ICP-ES]; Sparks and others, 1996) is of interest, it should be combined with other measures, including bio-available phosphorus and either calcium carbonate or the acid-neutralizing capacity (ANP; a combined measure of calcium carbonate $\left[\mathrm{CaCO}_{3}\right]$ and oxides of zinc, manganese, iron, and magnesium, which all buffer soil acidity) of the soil. Bio-available phosphorus is most often determined by extracting soils with sodium bicarbonates or resin strips (Olsen and others, 1954). The ANP of the soil is usually done by measuring the amount of hydrochloric acid required to obtain a neutral $\mathrm{pH}$ of the tested soil (Allison and Moodie, 1965). Calcium carbonate is generally determined gasometrically with a Chittick apparatus and is reported as percent calcium carbonate equivalent (Dreimanis, 1962).

\section{Organic Matter}

Organic matter is generally very low in deserts and can be highly variable across small areas (Whitford, 2002). Soil organic matter occurs in many forms that range in their ease of decomposition. Therefore, there are many levels of precision at which soil organic matter can be measured. For total organic matter, the soil is weighed, heated to combust the organic matter (Sparks and others, 1996), and then reweighed to determine mass loss. Distinguishing the different fractions of organic matter that have different rates of decomposition is more elaborate and is only done in specialized laboratories.

\section{Cations and Micronutrients}

Cations and micronutrients are critical for plant growth. However, we know very little about how these nutrients change with season or disturbance in desert soils. The one exception is sodium. This element can increase dramatically after the invasion of salt-tolerant plants (for example, Tamarix spp.[salt cedar], Atriplex spp. [salt bush], Halogeton glomeratus [salt lover], Distichlis spicata [salt grass]). In general, however, the use of cations or micronutrients in a monitoring program requires the use of reference areas or sampling needs to take place under similar conditions throughout a long time period. When cations are sampled, total concentrations are obtained using Inductively Coupled Plasma Emission Spectrometry (ICP-ES), and exchangeable levels are obtained using extraction with ammonium acetate (Sparks and others, 1996). Available (as opposed to exchangeable) potassium is extracted with sodium bicarbonate (Schoenau and Karamonos, 1993). Although micronutrients can be limiting in deserts (Bowker and others, 2005), these are not often included in a monitoring program, as little is known about their natural abundance or controls on this abundance. Bio-available levels of these nutrients are determined after extraction with diethylenetriaminepentaacetic acid (Leita and others, 1999). It is important to request that all these extractions be done at a $\mathrm{pH}$ similar to that of the soil being tested, as most laboratories generally use a $\mathrm{pH}$ of 7 .

\section{Soil Stability and Compaction}

Soil stability and compaction can be measured using both indirect and direct measures. The most common indirect methods include measurements of protective ground covers, soil aggregate stability, and/or erosion using bridges or pins. Direct measures include collecting and quantifying soils moved by wind and/or water.

\section{Indirect Measures}

Protective ground covers include rocks, plants, plant litter, and biological and physical soil crusts. These parameters are measured using line transects or quadrats, as discussed in the biological crust/ground cover and vascular plant sections below. Another measure of soil stability is aggregate stability, which can be measured either quantitatively in the lab, or qualitatively in the field using a soil stability test kit (Herrick and others, 2001; fig. 40). Quantitative assessments require specialized field collection and laboratory equipment, and thus are seldom included in monitoring programs. In contrast, the soil stability test kit is quick and easy to use in the field. It requires collecting a small $(20 \mathrm{~mm})$ soil surface fragment and placing it into a basket constructed from 25-mm PVC pipe with window screen glued to the bottom. Although 18 samples are usually collected per site, high variability may require more samples. The baskets containing the soil are slowly lowered into a 10 -mm container of distilled water. The time it takes to lose 50 percent of its structure is recorded. If, after five minutes, 
there is no loss of structure, the baskets are slowly raised and lowered three times, and left to soak again. Class ratings are then assigned; fragments which are highly prone to erosion fall into the lower classes, and those less prone to erosion fall into higher classes. These kits can be easily constructed or can be purchased commercially (Herrick and others, 2001).

Another indirect measure of soil erosion is an erosion bridge, which consists of two short posts placed about $15 \mathrm{~cm}$ apart and protruding from the ground by about $5 \mathrm{~cm}$. A line is tautly stretched between the two posts and secured on both ends to a permanently marked position. To measure soil loss or deposition, a ruler is placed between the two posts, and the distance to the ground measured at predetermined intervals, staying away from the posts (fig. 41). An increase in the distance to the ground indicates a loss of soil, whereas a decrease in the distance indicates deposition. This method is heavily used to monitor the impacts of trails, particularly on hillslopes, but its utility on general undisturbed hillslopes is questionable, because it does not readily account for spatial variability. This technique has limited value in areas where soils freeze or in soils with high amounts of shrink-swell clays, as soils can heave upwards during these events.

\section{Direct Measures}

\section{Wind Erosion}

Soil loss due to wind erosion accounts for the greatest amount of soil loss in dryland regions (Breshears and others, 2003). Soil loss by wind is most commonly measured by using Big Spring Number Eight (BSNE) collection boxes (fig. 42). These boxes allow air to flow through them without allowing dust or sand to escape (Fryrear, 1995). They are generally placed 15,50 , and $100 \mathrm{~cm}$ above the ground (although these heights would be different in areas with tall shrubs) on a pole that allows them to swing freely. The buckets have vanes that enable them to face the wind, regardless of direc-

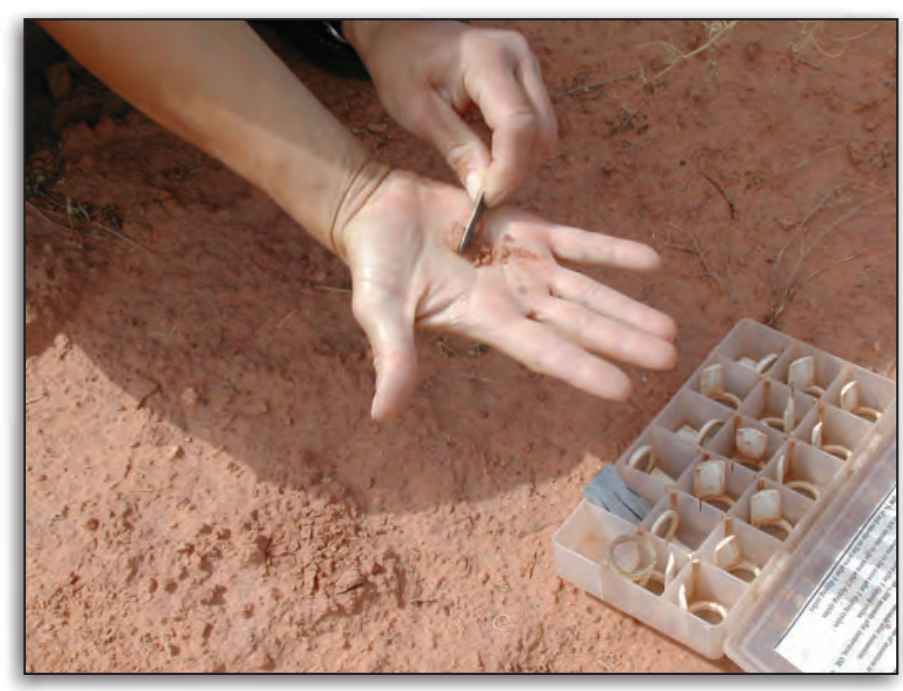

Figure 40. Soil stability test kit (U.S. Geological Survey photograph by Jayne Belnap). tion. These boxes generally need to be emptied every 3 to 6 months, unless the measured surfaces are highly erodible. Collected sediment is weighed. If texture or chemical analyses are desired, the sediment can then be sieved and sent in for analysis.

\section{Water Erosion}

Directly measuring soil loss because of water erosion is much more difficult. There are several qualitative indicators that can be measured, including number of rills, plants on pedestals, gullies, litter dams, and water flow patterns (Pellant and others, 2000). While these are useful indicators of condition, they are mostly qualitative and it is difficult or impossible to compare results from year to year. These features can be measured quantitatively (marking individual spots and carefully delineating where measures are taken), although it is hard to relate changes in these features directly to soil lost through water erosion. There are only two quantitative measures that are generally feasible for monitoring applications. The first is the installation of silt fences (like those used at construction sites) at the bottom of the area of interest (Robichaud, 2002). These fences (fig. 43) retain whatever sediment is moving off the area, which can then be collected and weighed. To install the fences, a $0.15-\mathrm{m}$ deep, $0.30-\mathrm{m}$ wide trench is dug along the bottom edge of the plot. The bottom of the silt fence material (Amoco 2130, about $1 \mathrm{~m}$ wide), is placed in the trench. The lower $0.30 \mathrm{~m}$ of the mesh is used to line the bottom of the trench, the uphill side of the trench, and part of the uphill slope. The bottom of the trench is then refilled. A 305-mm band of aluminum flashing is placed over the filled trench,

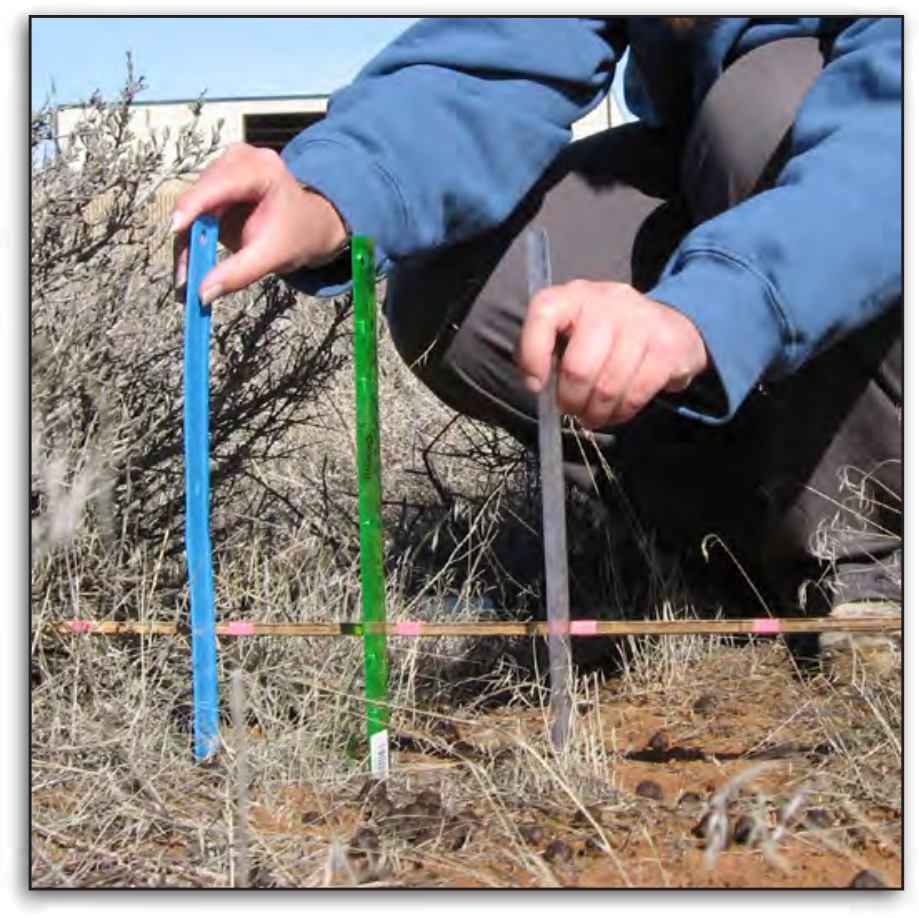

Figure 41. Soil erosion bridge (U.S. Geological Survey photograph by Jayne Belnap). 


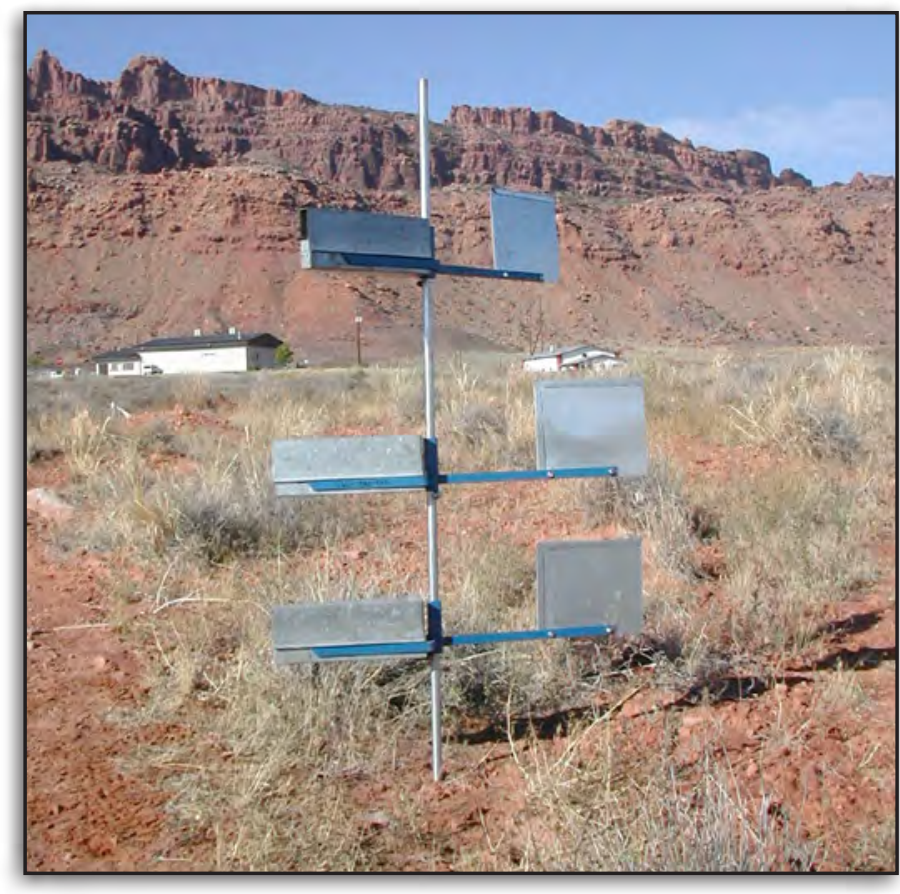

Figure 42. A Big Spring Number Eight (BSNE) measures soil lost due to wind erosion (U.S. Geological Survey photograph by Jayne Belnap).

and the $0.30-\mathrm{m}$ bottom of the silt fencing is then folded back downhill over the flashing. The upper edge of the fencing is then attached to metal T-posts placed at a minimum of $1 \mathrm{~m}$ intervals along the downhill side of the trench. (If placed in a channel, the T-posts are more closely spaced). If the watershed area contributing to the silt fence is not defined by topography, it needs to be defined with some type of edging. For this, a trench is dug to outline the sides and top of the plot, and edging (for example, galvanized steel flashing, plastic

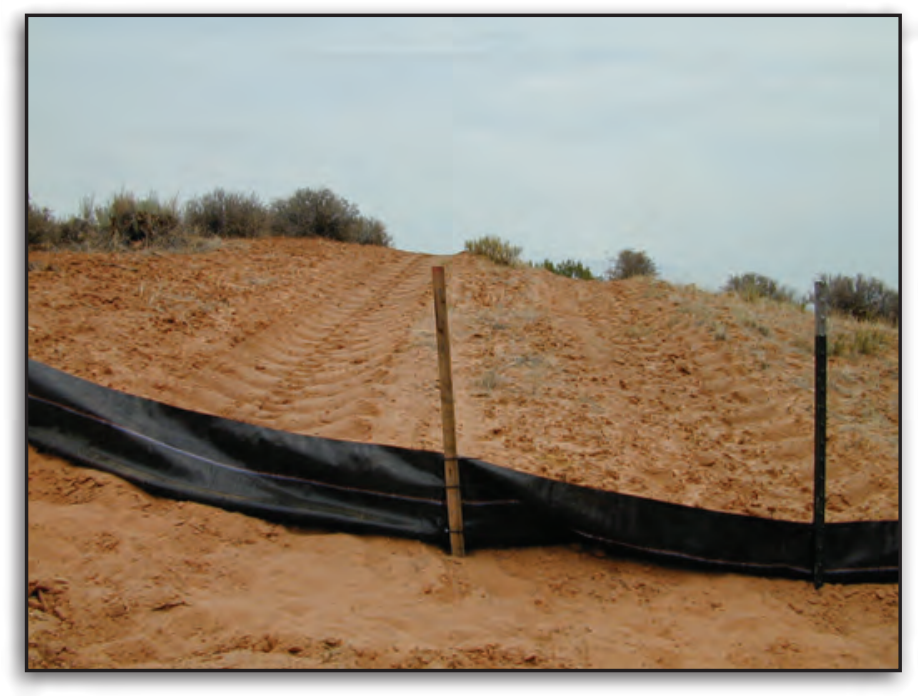

Figure 43. A silt fence is established along linear disturbance features, such as this unpaved road, to collect soil lost by water erosion (U.S. Geological Survey photograph by Jayne Belnap).. garden edging, wood) is placed in the trench. The trench is then backfilled. A tipping rain-gauge bucket and Hobo event recorder should also be installed at the site, so that there is a record of the timing and intensity of rain events to correlate with amounts of soil movement.

\section{Soil Surface Roughness}

Soil surface roughness is created by rocks, biological soil crusts, and plant litter. There are four ways generally used to measure soil roughness. The first uses a chain from the jewelry section at any store (fig. 44). Links need to be small (about $1 \mathrm{~mm}$ or less long) and the chain highly flexible. The chain is laid across the area of interest, with care taken that each link of the chain is in close contact with all the soil irregularities. Soil surface roughness is then defined as the difference between the chain length it takes to cover rough ground versus the length that would be required if the ground was flat.

The second method for measuring soil surface roughness is using a pin box. This is basically a board with holes drilled in it, such that pins hanging downwards are held snugly in place (fig. 45). The board is placed on supports hammered into the surface of interest. The pins are then pushed down to meet, but not penetrate, the soil surface. The standard deviation of the different measures between the pins is used as a measure of roughness. The advantage of these two techniques is that they are cheap and easy. The disadvantage is that they give only a two-dimensional view of surface roughness.

The third method uses a laser that scans back and forth across a small area, while the fourth uses cameras from several angles. These two methods are superior in that they give a threedimensional picture of the soil surface. However, they are expensive, time consuming, and are, at this point, mostly restricted to small surface areas. However, the field is moving rapidly forward and is likely to be extremely useful in the future.

\section{Soil Compaction}

By definition, soil compaction is the decrease in pore volume within a soil mass, resulting in an increase in bulk density (Johnson and Sallberg, 1960). The density increase caused by

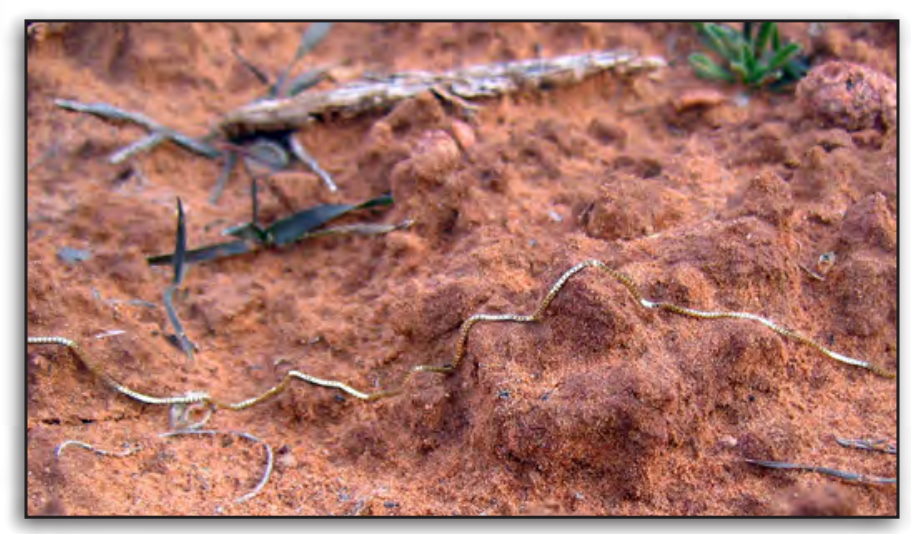

Figure 44. A jewelry chain is used to measure soil roughness (U.S. Geological Survey photograph by Jayne Belnap). 


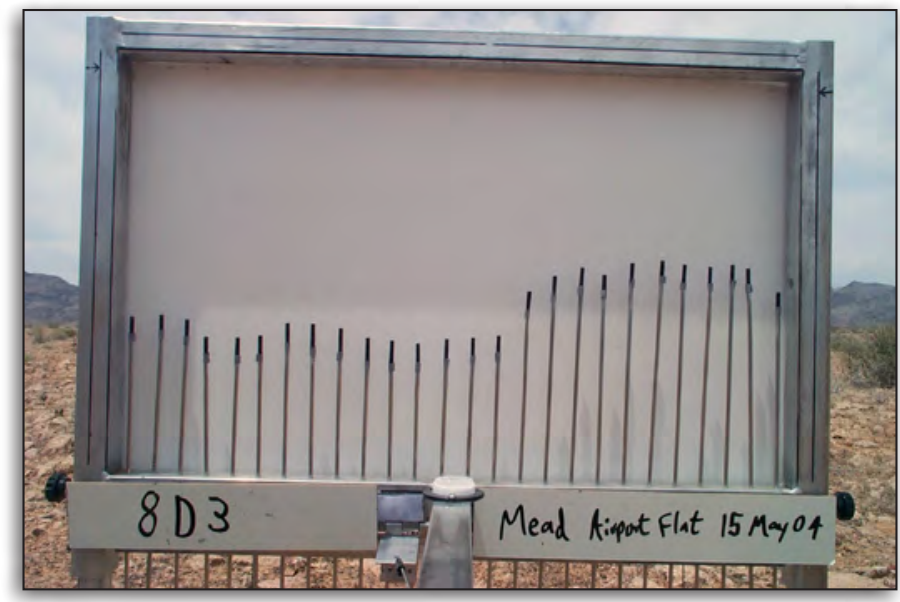

Figure 45. A box with moveable pins is used to measure soil surface roughness (U.S. Geological Survey photograph by Jayne Belnap).

soil compaction changes other soil properties, most notably the size distribution and continuity of pores (thus influencing the infiltration rate of water and gases), and strength characteristics. Numerous methods have been developed for measuring soil compaction and its effects (Freitag, 1971). Here we

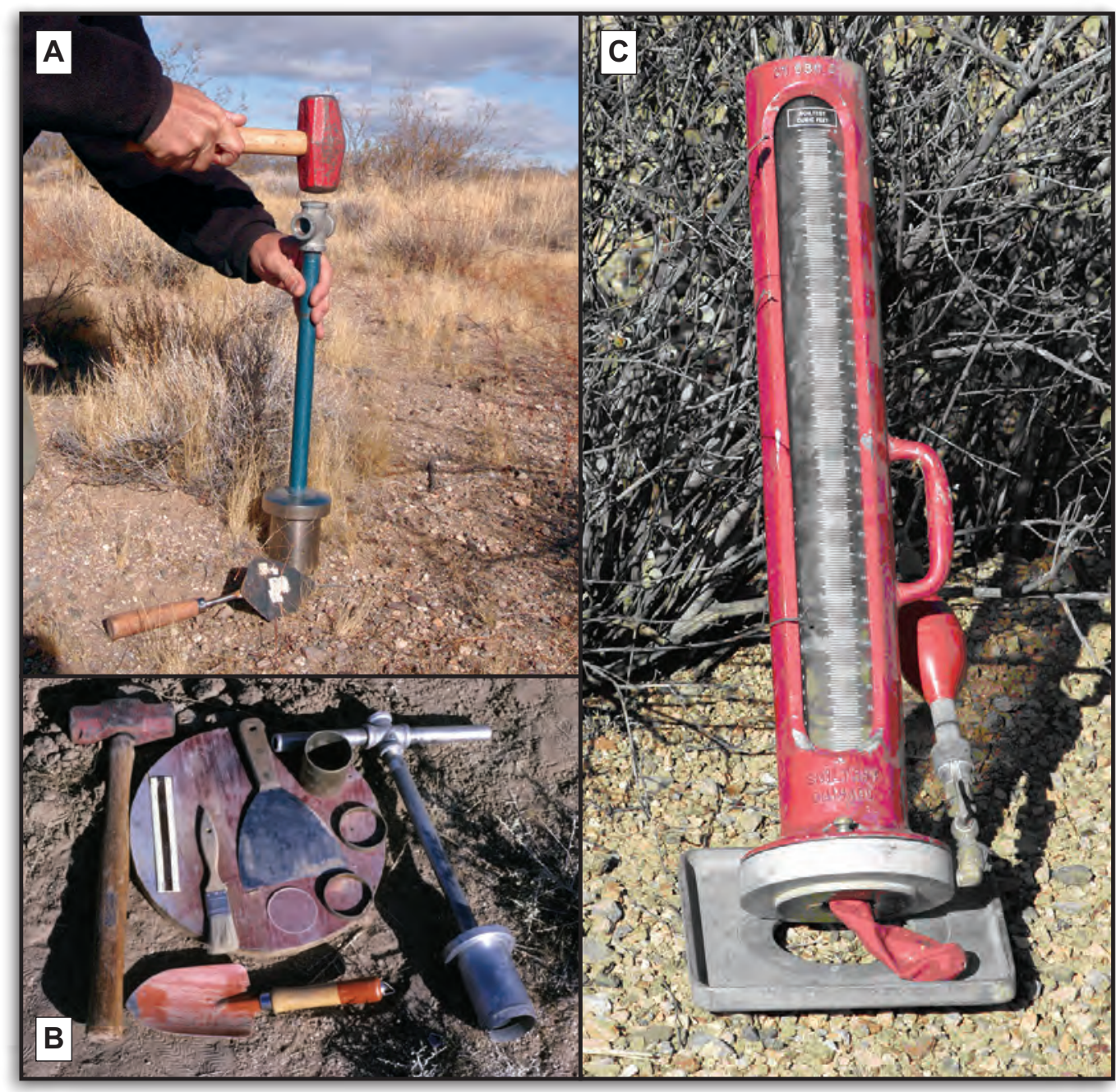

consider soil density and strength properties, and we discuss infiltration properties in the next section.

\section{Bulk Density and Moisture Content}

Soil bulk density is measured using a variety of techniques (Klute, 1986) For fine-grained soils, use of a core sampler is the preferred technique (fig. 46). The most common core sampler (figs. 46A and B) consists of a 57-mm diameter cylinder equipped with a wedge cutting tip and designed to collect intact samples. Narrow-diameter core samplers, which are designed for homogeneous, fine-grained agricultural soils, are more difficult to use in the Mojave Desert. Most samplers collect from the $0-6 \mathrm{~cm}$ depth-with the potential for splitting depth into $3-\mathrm{cm}$ increments $(0-3 \mathrm{~cm}$ and 3-6 cm) - although some core devices sample a slightly deeper depth range of 0-10 cm (Prose and Metzger, 1985). The sampler is carefully inserted into the soil either using a coaxial hammer or a hand-held sledge hammer; this insertion technique, which works best on soils wet at or near field capacity, must be done carefully to avoid soil dilation and inaccurate bulk densities. A minimum of 10 bulk density samples are recommended for each site. Another choice, especially in rocky soils, is to dig a small hole and drive a small object of known volume (for example, a socket) into the soil at the appropriate depth from the side of the hole.

Coarse-grained soils, with gravel content greater than about 15 percent by weight, pose a large problem for measurement of bulk density. The simplest technique involves collection of a sample from a shallow depression, lining the hole with plastic, and measuring the amount of water that fills the excavated volume (fig. 46C). Although this technique is useful for soils with considerable gravel contents, the error is large unless the rim of the depression is perfectly level. Methods are available for measuring the volume of an excavation,

Figure 46. Soil bulk density samplers. A, Soil corer for fine-grained soils and, $B$, the accompanying tools. C, Balloon sampler for coarse-grained soils (U.S. Geological Survey photographs by Robert H. Webb). 
including inflating a water-filled balloon into the depression or filling the depression with a known-volume substance, such as well-sorted sand or other spherical solids (Johnson and Sallberg, 1960). Gravel content affects the representative volume that must be sampled in gravelly soils; at gravel contents greater than 54 percent, that volume must be between 5 and 50 L (Vincent and Chadwick, 1994).

All bulk densities are calculated as dry weight $\left(\mathrm{g} / \mathrm{cm}^{3}\right)$; thus, moisture contents are required on all samples. This is obtained by weighing samples before and after drying. Certain applications of density data, such as estimation of hydraulic properties, may require knowledge of particle size distributions, especially the clay, silt, sand, and gravel fractions, and therefore provision should be made for particle-size analysis, either on bulk density samples or a separately collected sample.

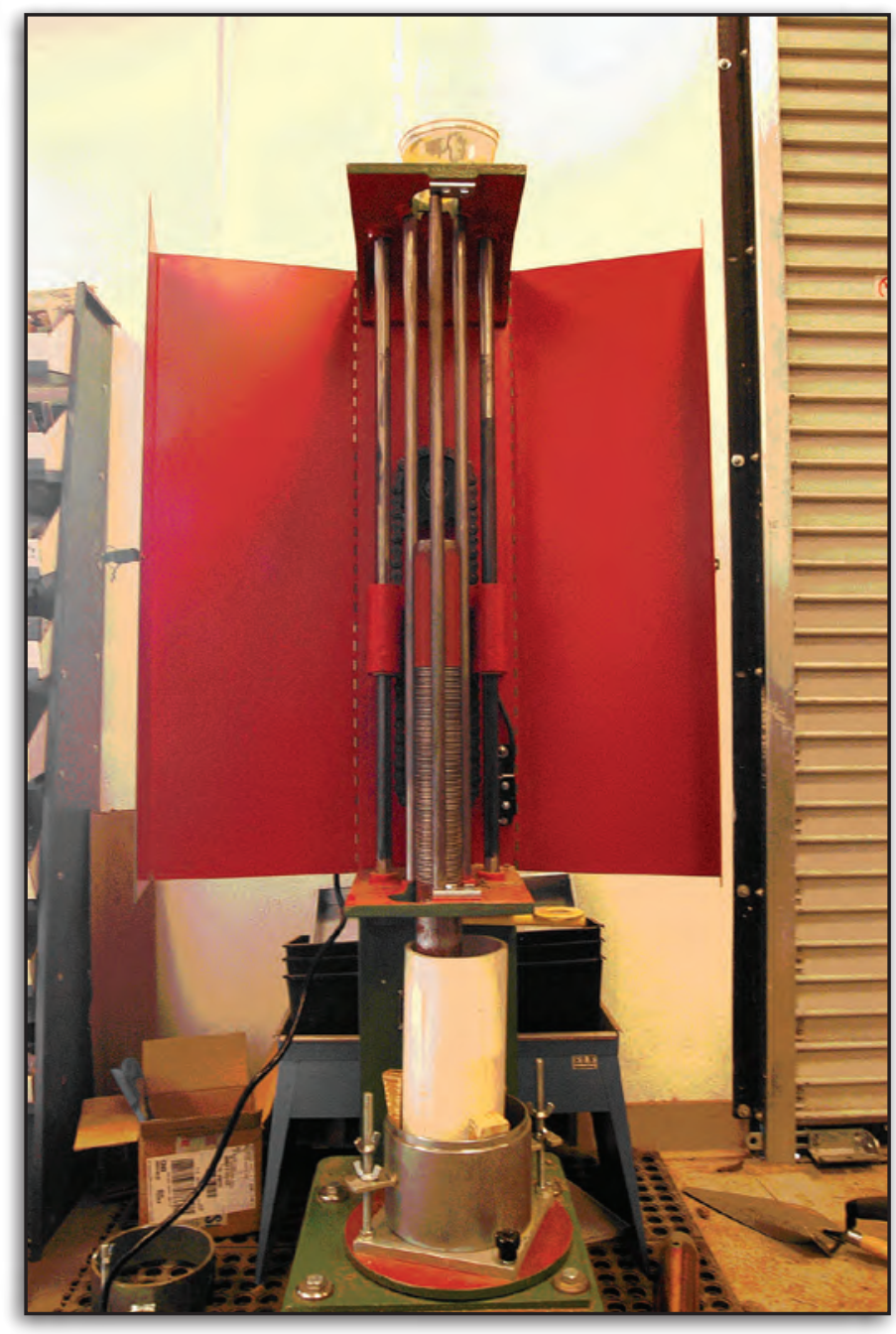

Figure 47. An automated soil compactor is used for compacting soils at specific bulk densities by varying the hammer weight, the number of hammer blows, and the hammer height. A pot that is prepared for a compaction experiment (white PVC pipe) is secured to the rotating table and the hammer (here, in the lowered position) blows are delivered to each soil layer (U.S. Geological Survey photograph by Robert H. Webb).

\section{Proctor Compaction Tests}

The Proctor compaction test is used for analysis of soils to determine the moisture content of engineered fill soil at their maximum density (Klute, 1986). This test is useful for management purposes because it can distinguish whether soils are vulnerable or invulnerable to compaction, and the moisture contents at which soils are most vulnerable (Webb, 1983, 2002).

Proctor tests are conducted in a laboratory using the method specified in the ASTM International standards. The standard test uses a steel or aluminum mold, $102 \mathrm{~mm}$ in diameter, in which the sample is placed. The soil to be tested is sieved to remove particles larger than $19 \mathrm{~mm}$. A sample of known weight and gravimetric moisture content is then placed in the mold and compacted in three layers using either a manual hammer or an automated machine (fig. 47). A total of 25 blows are administered for each layer, moving the hammer head to achieve uniformity of compaction. Bulk density is calculated by measuring the volume of soil after completion of the test.

Typical Proctor compaction curves are shown in figure 48. A "zero voids curve" constrains the possible bulk density to values beneath the curve. A minimum of 4 , and up to 8 , water contents are analyzed per compaction curve. The curve generally has two maxima, one at dry or near-dry conditions, and one that is at, or just below, field capacity (see section on Infiltration Rates). For Mojave Desert soils, the most important point is when soils are dry, because this is typically when soils are most vulnerable to compaction. Other points are empirically distributed between dry and field capacity, and at least one point is wetter than field capacity to constrain the curve. Maximum bulk densities achieved using Proctor compaction tests are greater than field-measured densities, even from roads, because in the field the surface of disturbed soils has generally dilated.

\section{Soil Strength}

Soil strength is measured using a variety of devices that range from rudimentary to sophisticated. In this discussion, we limit soil strength tests to field measurements, although laboratory tests, such as triaxial shear, can be used as well. Soil strength can be measured as an index (penetration depth), as shear-stress resistance, and as penetration resistance. In all cases, a downward pressure is applied, and in the case of shear-stress resistance, a rotational shear stress is applied as well. Soil strength is strongly controlled by soil texture, particularly silt and clay content, and soils are classified as cohesive (silt- and clay-rich) or non-cohesive (sandrich) on the basis of these contents. All measurements of soil strength are sensitive to moisture content (Greacen, 1960), and thus measurements must be reported in conjunction with gravimetric or volumetric water contents.

Penetration depth is the mean depth to which a $30^{\circ}, 920$ $\mathrm{mm}^{2}$ cone penetrometer (known as a "geostick"; fig. 49A) can be pushed into the soil surface (Wilshire and Nakata, 1976). This depth can be used as an index of compaction recovery 


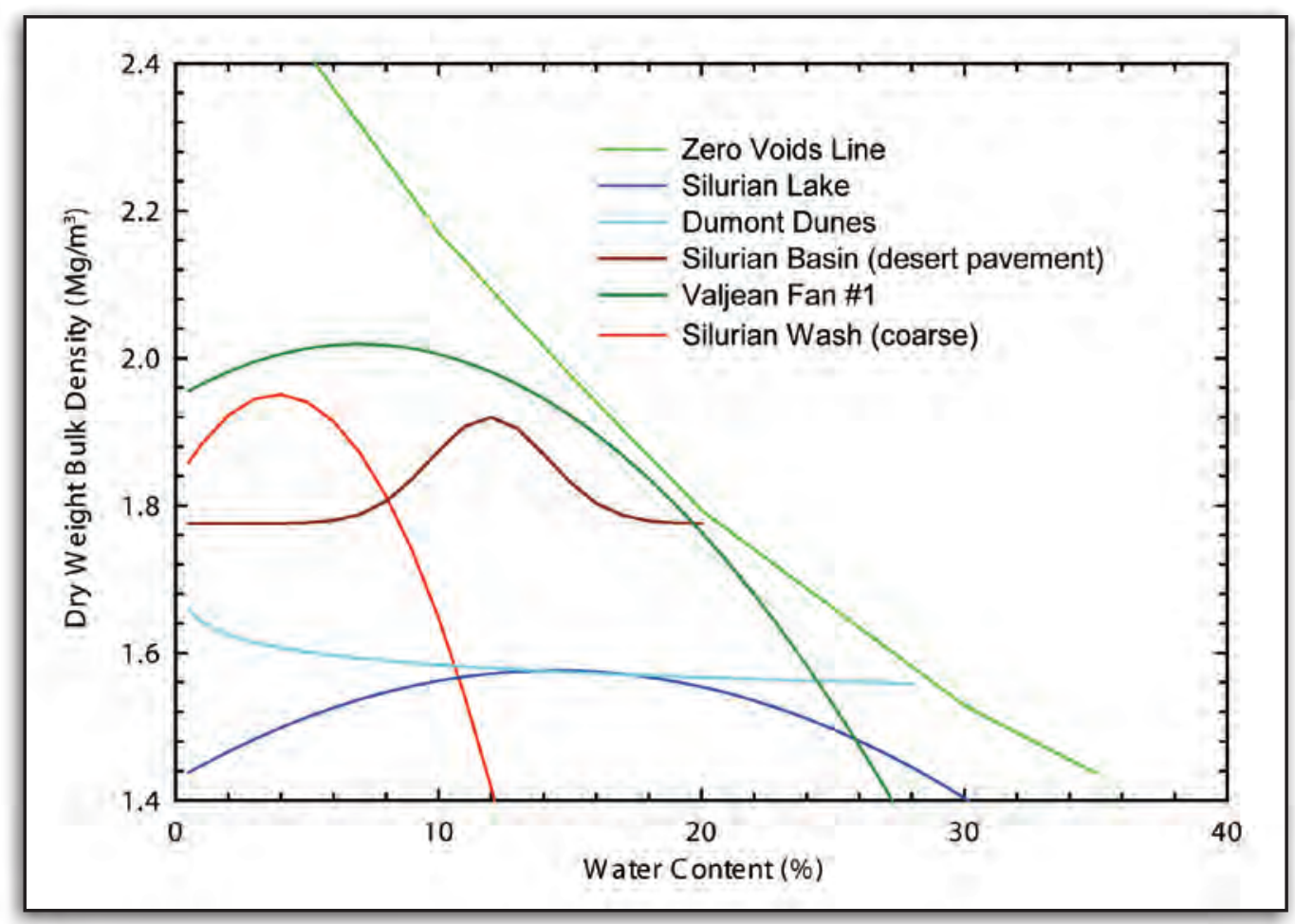

Figure 48. Proctor compaction curves for a variety of Mojave Desert soil types.

(Webb, 2002) or as a monitoring technique (Wilshire and Nakata, 1976). Of the variety of soil strength measurement techniques, penetration depth is least sensitive to soil gravel content, which inhibits measurement of the other, more fundamental, soil properties, such as bulk density (Webb, 1983; Webb and others, 1986). The downward pressure exerted on the penetrometer at insertion is the body weight of the operator, which means that the device is sensitive to operator variability. This, combined with sensitivity to moisture content, strongly suggests that penetration depth should be indexed, either to maximum compaction (for example, a nearby heavily compacted road) and an undisturbed condition, or over a range of soils. We recommend at least 70 penetration depths as the minimum sample for this technique.
Several penetrometers (figs. 49B-D), described as static cone penetrometers (Herrick and Jones, 2002), measure the penetration resistance as a cone is pushed through a soil column. The standard method for penetration resistance involves application of downward pressure at levels just high enough to slowly push the cone downward into the soil at a constant velocity. In practice, these penetrometers are pushed down by an operator. Maintaining a constant velocity is difficult, as subsoils vary in strength. For highly compacted and dry soils, these devices may not be able to penetrate past $3-5 \mathrm{~cm}$ depth. The so-called Corps of Engineers penetrometer (figs. 49B and 49C) measures only the maximum pressure required to penetrate to a fixed depth (Karafiath and Nowatzki, 1978). Other devices record the penetration resistance as a function of

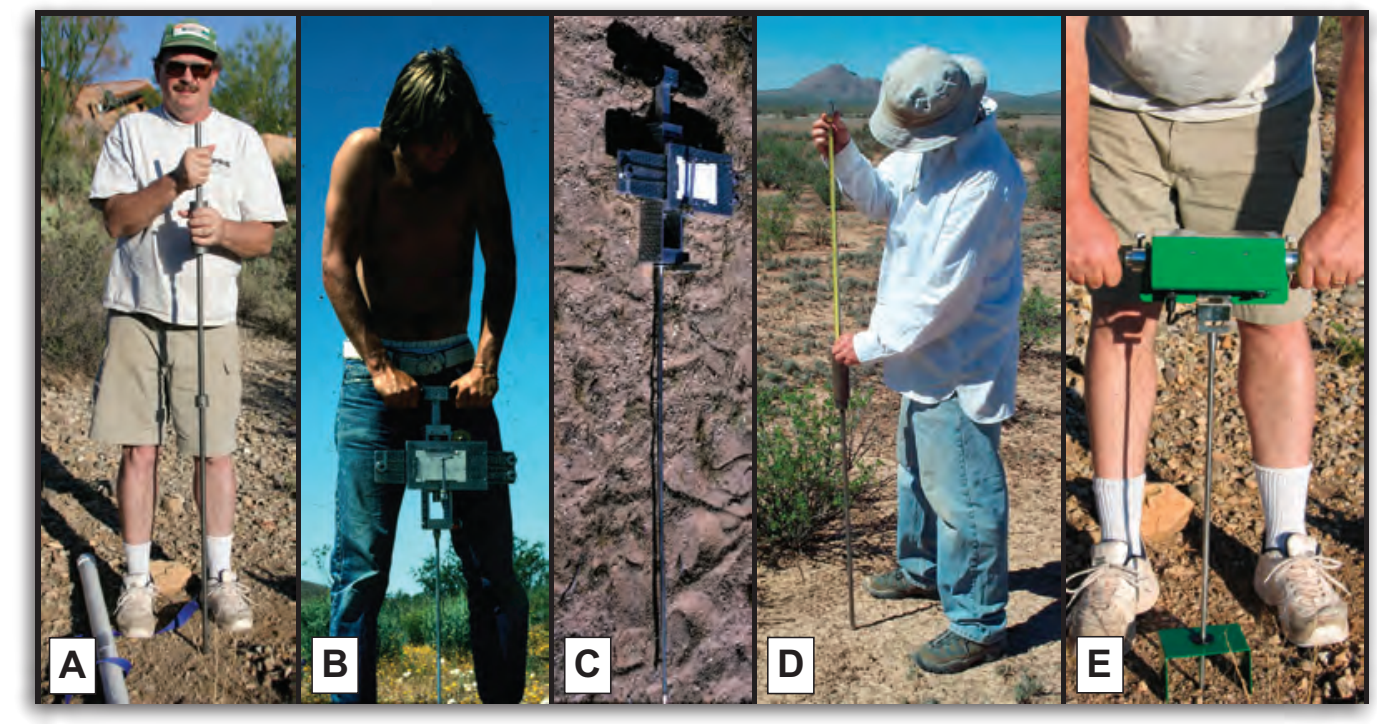

Figure 49. Soil cone penetrometers. A, The geostick, a device that measures cone penetration under the body weight of the operator. B, U.S. Army Corps of Engineers penetrometer, an analog device that has been linked to theoretical models of soil strength. C, Close-up of device shown in B. D, Dynamic-cone penetrometer. E, Automated recording penetrometer (U.S. Geological Survey photographs by Robert H. Webb). 
depth, either with analog springs (Carter, 1967) or load cells with distance sensors (Klute, 1986).

Our preferred tool is a dynamic-cone penetrometer (fig. 49D) that was recently developed for field monitoring of soil strength (Herrick and Jones, 2002). Unlike the other penetrometers, which require an operator to apply downward pressure, a weight is dropped a fixed number of times on the cone-bearing shaft, pounding the cone into the soil. This avoids many of the problems associated with those pushed into the soil by the operator. The results from the dynamic-cone penetrometer can be expressed either as the cumulative pressure (number of drops) required to penetrate a fixed distance, or as the depth penetrated with each drop or with a specific number of drops. As with the static cone penetrometers, we recommend a minimum of 25 repetitions of this technique to get an accurate mean value for penetration resistance, and because the measurement is sensitive to soil moisture, indexing or calibration is required.

Pocket penetrometers are used to measure the resistance of the soil surface. They have a small, blunt tip instead of a cone, and were designed for turf in golf courses. Use for measuring subsurface soil strength is not recommended, because its size and tip adds to the measurement variability. However, they can be very useful for measuring the strength of surface physical or biological soil crusts. Because most pocket penetrometers have very stiff springs designed for turf, they do not work in weak or thin soil crusts. For these crusts, one can use testers designed for fruit (fig. 50), which are available

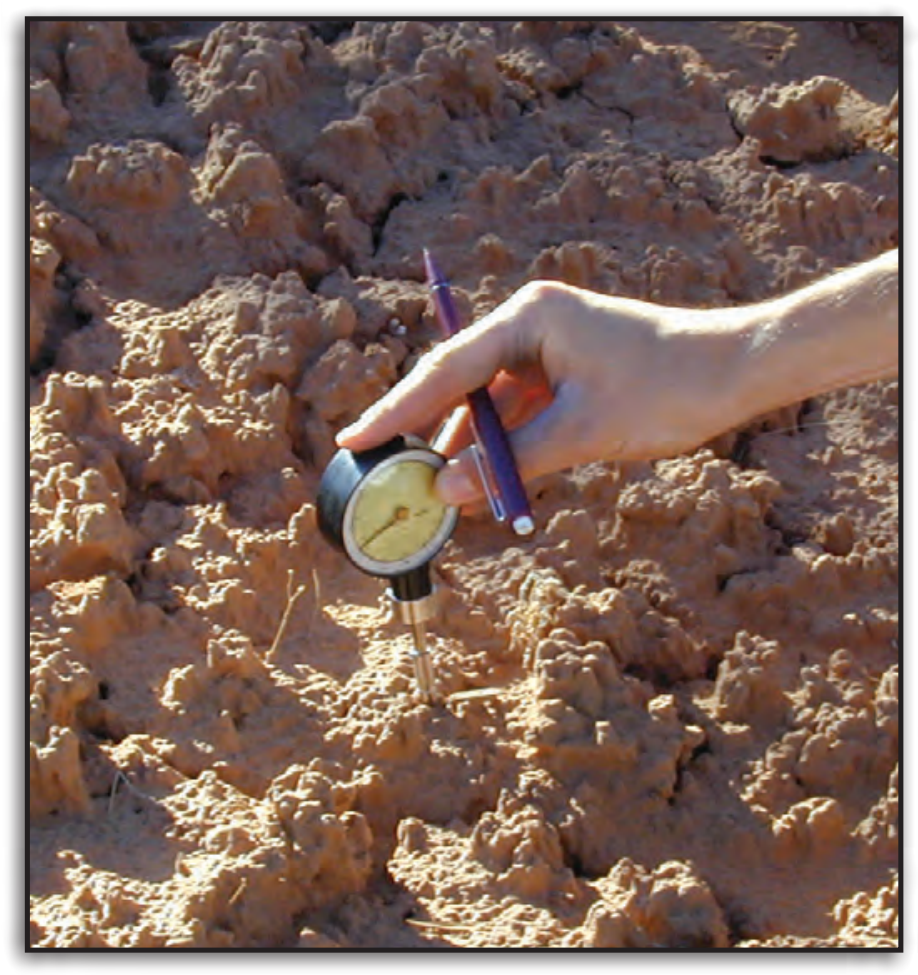

Figure 50. Fruit testers used to measure the strength of thin soil crusts (both physical and biological) (U.S. Geological Survey photograph by Jayne Belnap). across a range of forces (for example, grape, peach, apple). The strength of the crust will determine which fruit tester should be used.

Shear resistance is a soil property of high importance to trafficability (Karafiath and Nowatzki, 1978), and monitoring of shear resistance may provide important insights into changes that result from trampling. Shear resistance is perhaps more important in cohesive soils, because non-cohesive soils, particularly well-sorted sands, shear easily whether disturbed or undisturbed. Shear stress may be most useful in evaluating the impacts of physical soil crusts, which can develop following disturbance of soil with significant silt and clay content. Many devices are used to measure shear resistance, and all involve a spring-loaded device that has a disk with a variety of roughness elements that range from smooth metal to steel vanes (fig. 51). A constant normal stress is applied, followed by shear stress, until soil failure occurs. The torvane shear device is hand-held and has vanes that are inserted into the soil and twisted. Thus, the measure obtained is the force that causes the soil to fail at $0-2 \mathrm{~cm}$. One of the limitations of all these devices is that the surface being measured has to be broken in order to be measured. Thus, the true shear resistance of an intact surface is underestimated; instead, the shear resistance of the pieces of soil between the vanes is being measured. In addition, the spatial variability of shear properties appears to be larger than for penetration depth or resistance. Measurements with shear-stress devices should be made over a range of normal pressures.

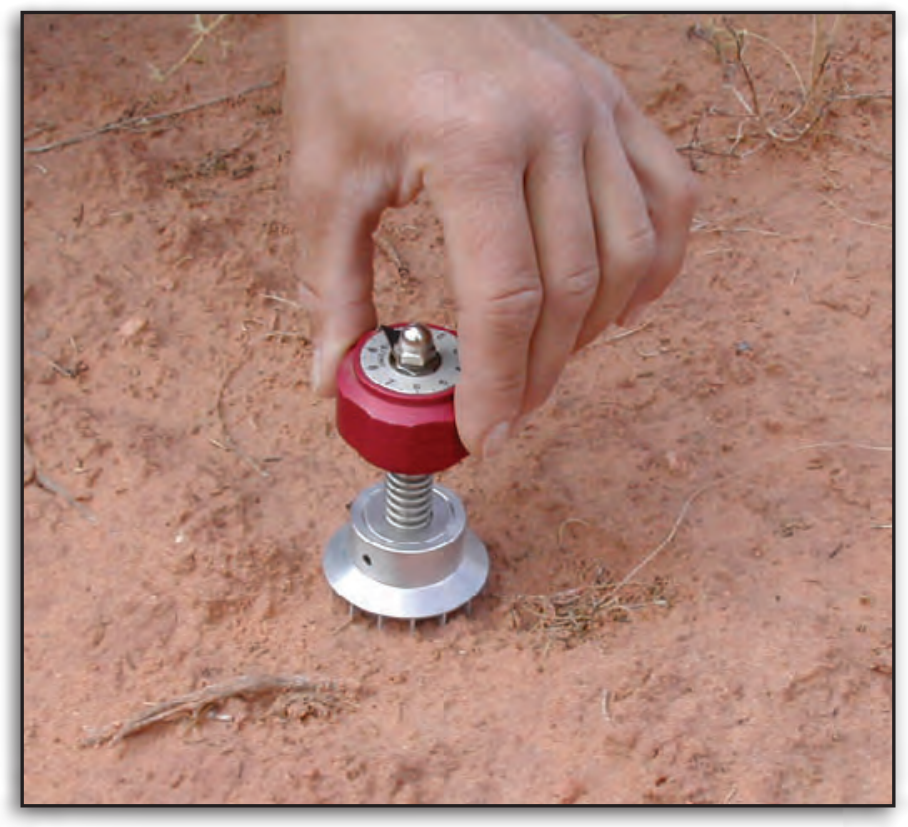

Figure 51. Hand-held torvane shear device measures shear stress of physical soil crust or subsurface soil horizons. Because of its small sampling area, repeated measures yield high variability (U.S. Geological Survey photograph by Jayne Belnap). 


\section{Soil Moisture}

Soil moisture is affected by a variety of physical and biological processes, creating a large number of possible measurement techniques. The choice of an appropriate technique for monitoring of soil moisture depends on whether moisture content is all that is needed, or whether rates of change in moisture content are required.

The simplest measurement of soil moisture is achieved by weighing samples of a set volume before and after drying. The standard method calls for drying in an oven at $100^{\circ} \mathrm{C}$ for 24 hours, but to minimize "baking" of clay minerals and a loss of structural water from clay minerals, we recommend drying at about $60^{\circ} \mathrm{C}$ for 48 hours. Soil moisture contents can be expressed either as gravimetric contents $\left(\mathrm{g} / \mathrm{cm}^{3}\right)$ or, if bulk density is known, as volumetric content $\left(\mathrm{cm}^{3} / \mathrm{cm}^{3}\right)$. Laboratory drying of samples is the only way to calibrate other soil moisture measurement devices.

As soil moisture decreases from saturation, the matric potential, or the pressure required to extract moisture from the soil, increases. Figure 52 shows the relation between moisture content and matric potential for a sandy loam, a typical desert soil. This relation, called the characteristic curve, is useful for several assessments of soil status, including pore size distributions, water-holding capacity, and infiltration rates. Characteristic curves can be measured several ways, but the most

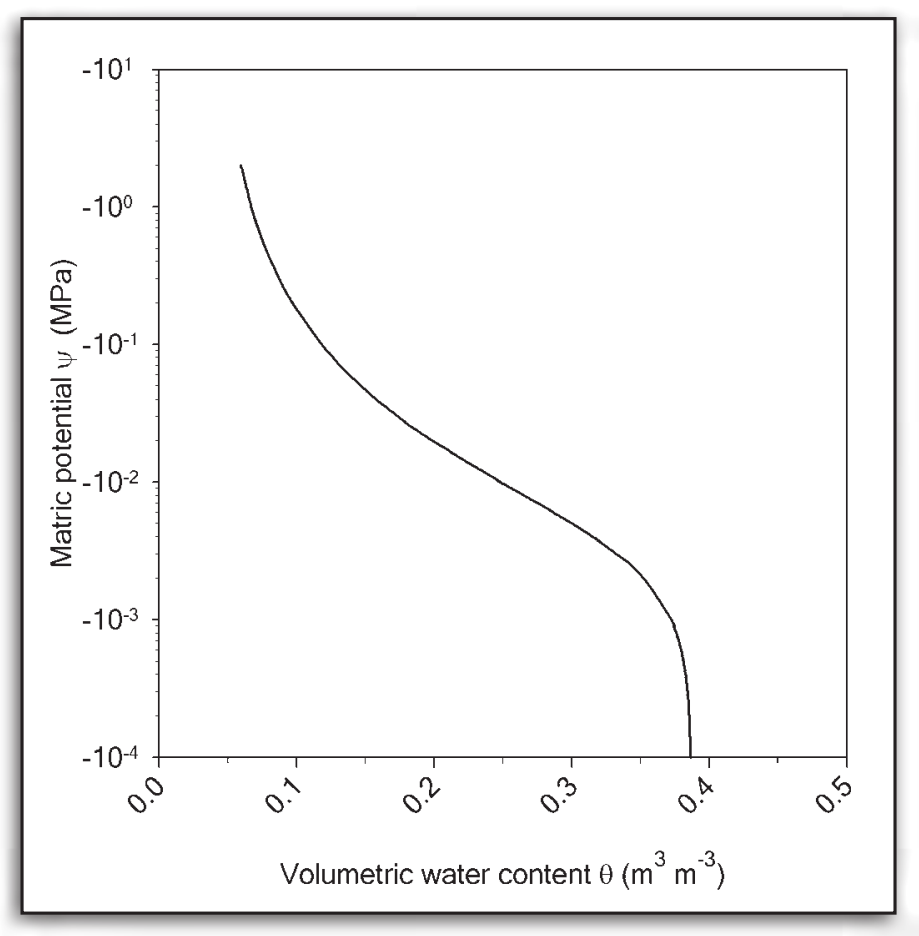

Figure 52. The relation between moisture content and matric potential for a sandy loam, a typical desert soil. This relation, called the characteristic curve, is useful for several assessments of soil status, including pore size distributions, water-holding capacity, and infiltration rates. Figure courtesy of M. Duniway, derived from the computer program ROSETTA (see Infiltration Rates; Schaap and others, 2001). common technique involves placement of soil samples-intact or disturbed —on a pressure-plate apparatus mounted in a pressure chamber. The pressure plate is a porous ceramic plate with drainage to the outside of the pressure chamber. As air pressure is increased within the chamber, water is forced from the soil through the pressure plate. After a sufficient period of equilibration has elapsed, the soil moisture content is measured for the specific applied pressure (matric potential).

In situ measurement of soil moisture involves either direct measurement of the matric potential, measurement of heat dissipation as affected by soil humidity, or direct measurement of humidity. Tensiometers use porous ceramic media to measure low matric potentials ( $>-1$ bar). Because these matric potentials are close to saturation, tensiometers seldom are useful for monitoring moisture contents of desert soils. They are useful for estimating wetting-front propagation during infiltration, but they cannot be deployed for significant time periods when desert soils are dry. Heat dissipation probes measure the ability of the soil to absorb heat generated in thin wires; this ability is related to the relative humidity of the gas within soil pores, which is related to soil moisture content.

Time-domain reflectometry (TDR) is a recently developed technique for using the dielectric properties of soils to measure moisture content (Klute, 1986). This technique covers the widest useful range in soil moisture content, from near-saturated to near-dry conditions. Because the TDR probe consists of parallel rods, it can be installed for long time periods and used for long-term monitoring, unlike other methods for measurement of soil moisture. However, data from times of very low soil moisture are much less accurate than at other soil moisture levels. Thermocouple psychrometers (Klute, 1986) remain a useful device for in situ measurement of very high matric potentials ( $>-15$ bars). All of these devices can be used for real-time soil moisture monitoring, but all share two critical problems: (1) they must be deployed through destructive manipulation of the soil, and (2) all are too expensive to effectively capture spatial variability in soil moisture.

Ground-penetrating radar (GPR) used to estimate soil moisture can partially overcome these two problems. When used in a borehole setting (Rucker and Ferré, 2003), GPR can detect the vertical water-content profile of a soil column. This method can determine the average moisture content over a relatively large area, but it has the disadvantage that manual operation is required, and thus continuous measures through time cannot be made. Other methods still in use for estimating soil-moisture properties include those that use gamma-ray radiation sources, neutron probes, and electrical conductance (Klute, 1986). Because of its ability to measure a wide range of soil moisture contents, as well as its ability to continuously measure for long time periods, we recommend TDR for monitoring of soil moisture in the Mojave Desert, while recognizing that the other techniques have greater usefulness for specific applications. 
Infiltration Rates

Infiltration rates can be measured using a wide variety of field and laboratory techniques (Klute,1986). Infiltration rate is defined as the rate of water movement into a soil surface, and soil hydraulic conductivities - both saturated and unsaturated-control these rates. Hydraulic conductivities strongly relate to soil texture and bulk density (pore space), as well as to the distribution of pore sizes, soil cracks, and voids left by animal burrows and roots. The presence of large amounts of gravel pose a particular problem to measurement of hydraulic conductivity, and laboratory measurements of infiltration rates typically are made on the soil fractions larger than $2 \mathrm{~mm}$. The "available water content" of soils may be greatly overestimated if gravel content is not considered (Cousin and others, 2003). Saturated conductivities decrease with increases in the volume of large rock fragments, and methods have been developed for correction of conductivities measured on fractions less than $2 \mathrm{~mm}$ for rock volume (Mehuys and others, 1975; Dunn and Mehuys, 1984).

The most common method for measuring infiltration rates is the use of either single- or double-ring infiltrometers (Haise and others, 1956; fig. 53). Ring infiltrometers estimate saturated conductivity only, and installation of these devices in gravelly soil can introduce considerable disturbance, which affects infiltration rates. Double-ring devices, where the outer ring is not measured but helps to minimize lateral flow from the inner ring, is the preferred technique for fine-grained soils. Because saturated conductivity is more spatially variable than other soil properties (Webb, 1983), a minimum of 10-20 repetitions is recommended. Recently, construction of in situ basins, either lined with berms or concrete banks, have been

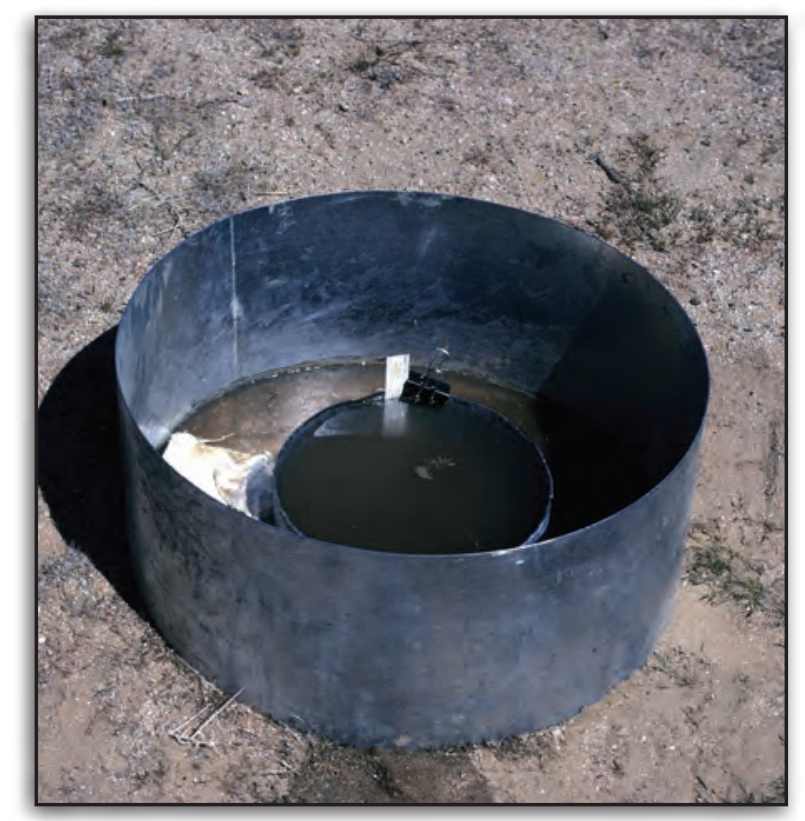

Figure 53. Double-ring infiltrometer being used in the western Mojave Desert (U.S. Geological Survey photograph by David M. Miller). used to measure infiltration rates over a larger area and with less disturbance than the ring-infiltrometer technique.

Tension infiltrometers (fig. 54) provide a less invasive technique for measurement of unsaturated hydraulic conductivities (Ankeny and others, 1988; Perroux and White, 1988). A porous disk (available in various sizes and tensions) of known hydraulic properties is attached to a water reservoir, and the disk is placed on the soil surface. A layer of wellsorted sand typically helps establish hydraulic contact between the disk and the surface of the soil. These devices can be used to measure hydraulic conductivity over a range of matric potentials to help define the unsaturated conductivity versus moisture content curve. This may be very useful for evaluating the hydrological effects of low levels of soil compaction where only the largest soil pores are affected, and where the effect on infiltration rates may be greatest at the lowest matric potentials. However, these instruments can measure only a very small surface area, and thus capturing the variability of a

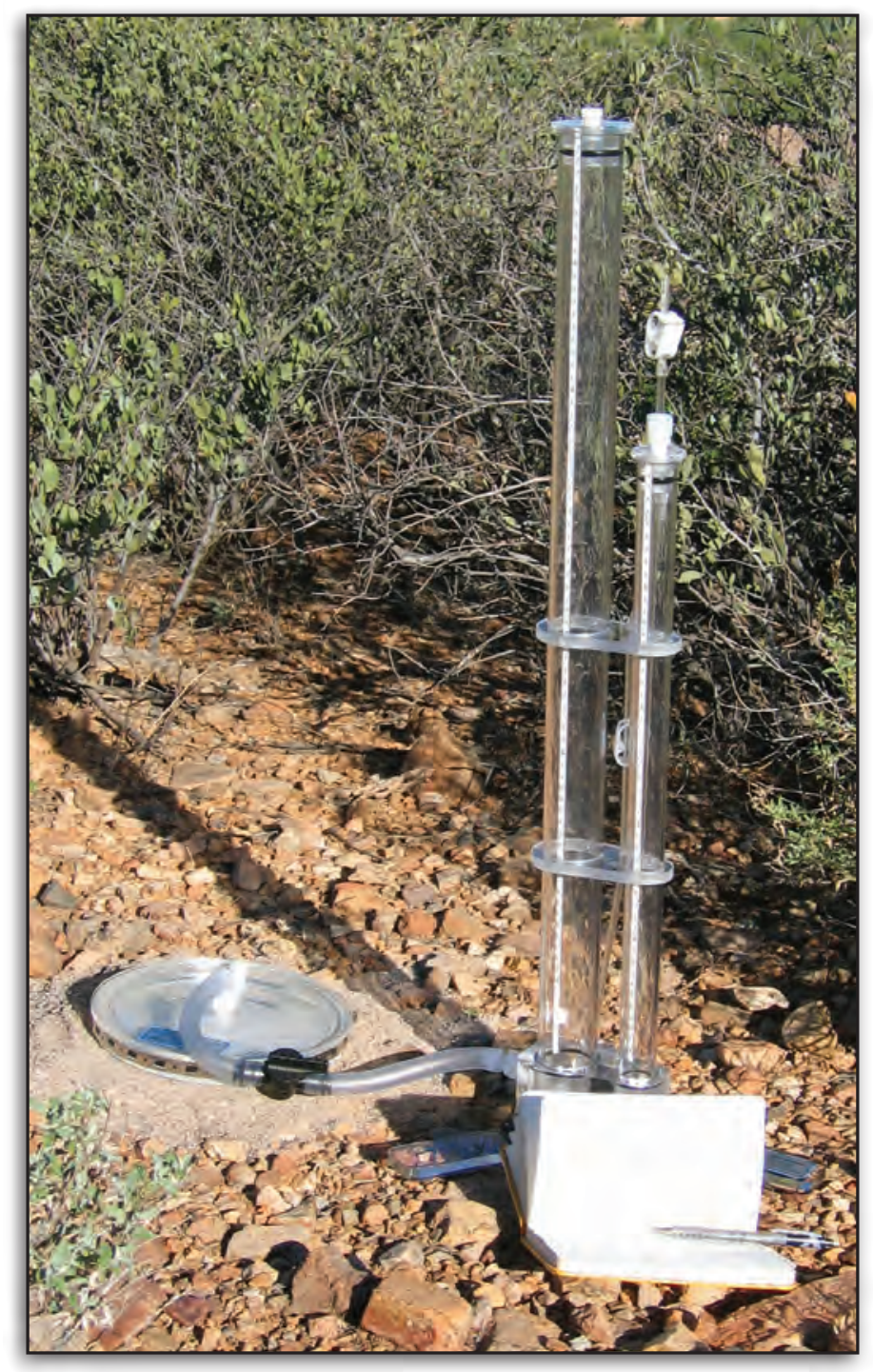

Figure 54. Tension infiltrometer in use in the Silurian Valley (U.S. Geological Survey photograph by David M. Miller). 
site is time consuming. In addition, the pore size of the soil must be closely matched with the tension of the instrument. These instruments can be automated with a datalogger so that other monitoring activities can take place while they run. However, as they only measure unsaturated conductivity, ring infiltrometers or other devices are required for measures of saturated conductivity.

Rainfall simulators provide one of the best field techniques for estimating infiltration rates (Iverson, 1980), although this method is intensive and expensive. The advantage of rainfall simulation is that it does not disturb the soil, unlike ring infiltrometers, and infiltration is averaged over a large area (typically greater than $1 \mathrm{~m}^{2}$ ), unlike with a tension permeameter. Most rainfall simulators use a nozzle that is designed to simulate the variability of natural raindrops. Water is applied at a specified intensity to simulate the physical crusting that can occur in disturbed soils. If measurement of saturated hydraulic conductivity is the goal, the intensity must be higher, and can be adjusted with nozzle pressure. Rain is directed over a plot that is cordoned off with metal flashing to contain and direct runoff to a point of outflow where it can be measured. Collected water, and the sediment in the water, is measured. Carbon and nutrient contents of the runoff water and sediments can be measured as well. Like in situ basins, this measurement is made over a larger soil area, thereby minimizing some of the spatial variability in hydraulic properties.

Laboratory analyses of either disturbed or undisturbed samples also can be used to measure saturated and unsaturated hydraulic conductivities. Manual techniques can be as simple as using drainage between a soil column and a lower elevation water chamber, or as complicated as using a centrifuge to rapidly apply pressure to a sample for fast drainage. These techniques generally are expensive and only useful if soil moisture properties must be accurately measured for small samples. Alternatively, soil hydraulic properties have been determined for a wide variety of soils, and statistical relations have been developed that allow estimation of these properties from soil particle size distributions and bulk density (Van Genuchten, 1980). A computer program (Rosetta) that performs these calculations is available from the USDA Agricultural Research Service (http://www.ars.usda.gov/Services/ docs.htm?docid=8953; Schaap and others, 2001).

\section{Perennial Vegetation}

Perennial plants have been monitored in the desert Southwest for more than 100 years, and the techniques are well established in the scientific literature. Phytoecological measurements are an essential part of evaluation of ecosystem sustainability (de Soyza and others, 2000) and should be included in any significant monitoring program for the Mojave Desert. Readers are particularly referred to Mueller-Dombois and Ellenberg (1974), Bonham and others (1997), Elzinga and Evenden (1997), and Elzinga and others (1998) for more specific information on how to measure perennial vegetation.
Here, we focus on the many nuances of measuring perennial plants that may affect a monitoring strategy for the Mojave Desert.

\section{Perennial Vegetation Types in the Mojave Desert}

Definition of assemblage, association, or alliance type is the first step towards establishing monitoring of perennial vegetation in the Mojave Desert. We recommend use of the classification technique presented in appendix B of Thomas and others (2004) to determine the type of alliance that is present at a site where long-term monitoring will occur. In addition, the NatureServe Web site (http://www.natureserve.org/ explorer) can be used to determine vegetation alliances for the Mojave Desert. However, we recognize that assemblage-level definitions are also possible for Mojave Desert vegetation.

\section{Plot Types}

\section{Permanent Plots}

Establishment of permanent vegetation plots has been long used in the Mojave Desert to assess the factors that affect the distribution and long-term stability of perennial vegetation (Beatley, 1980; Cody, 2000; Webb and others, 2003, in press). The most difficult questions to be addressed concerning the establishment of new permanent plots is determining where on the landscape to place them, how many plots are required to adequately represent a patch of vegetation, and how often the plots are to be re-measured.

Beatley (1980) used the approach of multiple plots within a given vegetation assemblage, spread over the elevation range of the Nevada Test site, and established 68 permanent plots in 1963 to be re-measured every 10 years for woody perennial plants and every year for herbaceous perennials. In contrast, Cody (2000) reports results from only one plot that was intensively monitored for 15 years.

Once a monitoring strategy for a vegetation assemblage has been developed, permanent plots should be located using aerial photography or remote sensing. The geomorphic surface underlying the new plot should be reasonably homogeneous, as evaluated with photography, and no apparent trends in perennial vegetation should be present. Rills, gullies, and small washes can affect the pattern of perennial vegetation, and these geomorphic features should either be eliminated from the area of the plot or explicitly included as part of the sampling design (that is, include monitoring plots with, and others without, these geomorphic features to evaluate their impacts). Considerable variation in plot area and shape is possible and depends on whether just the plot is marked or whether the plot is part of a larger exclosure. We prefer marking permanent plots with fence posts at corners or edges, and marking transects with rebar placed a minimum of $0.3 \mathrm{~m}$ into the ground to allow long-term repeated measurements. 


\section{Random Plots}

Establishment of permanent vegetation plots forces a statistical design of repeated measures, which may or may not be a desirable strategy, depending upon the goal of monitoring. Random monitoring of unmarked plots is a useful technique for one-time comparisons of status or recovery and can provide useful data in conjunction with measurement of permanent plots. By placing plant transects randomly, one can employ a different set of statistical techniques to evaluate change, although these techniques are less robust than repeated measures of one plot. As with establishment of permanent plots, use of aerial photography to locate random plots is an important component of site selection, both to avoid areas with problematic variability and to precisely locate measurement sites in the assemblage type of interest.

Point relevés have long been used observationally to quickly collect large amounts of data on species composition of perennial vegetation, and can be permanent or random plots. The primary data supporting two vegetation maps of the Mojave Desert relied on a combination of point relevés and other plant observations as the primary data for statistical extrapolation (Ostler and others, 2000; Thomas and others, 2004). Relevés are most useful for rapid acquisition of large amounts of data for mapping or other site characterization work. As applied by Thomas and others (2004), a circular plot of $1,000 \mathrm{~m}^{2}$ was established by placing two tapes perpendicular over a center point; each area measured was $35.6 \mathrm{~m}$ diameter. Visual estimates of the cover of each species within the circular plot were then made. Readers are directed to Mueller-Dombois and Ellenberg (1974) for more information on relevés.

McAuliffe (1990) proposed the log-series survey method for quickly estimating cover and density of desert vegetation. Circular plots of areas ranging between 250 and $1,000 \mathrm{~m}^{2}$ are established, and individuals of each species are assigned to

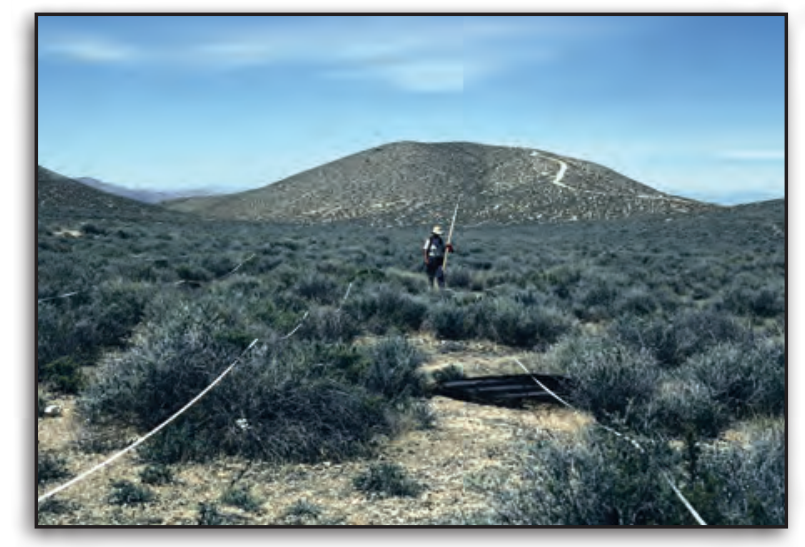

Figure 55. Belt transects at Skidoo townsite, Death Valley National Park. The number of plants between the lines, which are $2 \mathrm{~m}$ apart, is counted to obtain density, and the transect lines are used for line intercepts. Alternatively, two diameters and a height can be measured for all plants with bases between the lines, allowing calculation of density, cover, and biomass using regression equations (U.S. Geological Survey photograph by Jayne Belnap). classes of density and cover based on a logarithm of base- 2 scale. This method, which bridges the gaps between relevés, quadrats, and line-sampling techniques, is particularly well suited to rapid measurement of density and cover on a onetime basis.

If a general survey for a large area is desired, a step pointintercept transect (modified from Evans and Love, 1957) is often the most cost-effective method. A compass point or focal point on the horizon is identified. The observer walks in a straight line towards the point, without looking at the ground. Points are located after a predetermined number of steps (generally 2 to 4 ) are taken, at which point a walking stick, rod, or pin flag is touched to the ground (without looking at the ground) to mark the point. To characterize an area, at least 300 points are measured.

\section{Sampling Techniques within Plots}

\section{Line Sampling}

There are many types of line sampling techniques that can be used. The point-quarter method of Cottam and Curtis (1956) has been used to assess grazing impacts (Webb and Stielstra, 1979) and recovery from disturbance (Wells, 1961). This method consists of stretching a single line (or parallel lines) for a predetermined distance and establishing either a regular sampling interval (for example, every $10 \mathrm{~m}$ ) or random sampling locations. At each sampling location, an imaginary line perpendicular to the sampling line creates four quadrants. The distance to the nearest plant in each quadrant is measured, and each plant is measured for two diameters (maximum and minimum) and height. The results of the point-quarter method can be used to estimate density, cover, and biomass of perennial vegetation, but usually insufficient numbers of plants are measured, because the method is inefficient in terms of use of available sampling space. A more common use of this method is for the random selection of individual plants for measurements other than density and cover (for example, random selection for isotopic analyses).

The line intercept and belt transect methods-alone or in combination - have long been used to measure density and cover of perennial vegetation (fig. 55). The line intercept method measures cover and species composition based on coverage by a one-dimensional intercept method. A line is stretched tightly parallel to the soil surface, and the starting and ending points of the perennial canopies intercepted are recorded for each species encountered. The total length of the line that overlaps perennial canopy is divided by the total transect line and multiplied by 100 percent to obtain percent canopy cover. Cover may be absolute-in which only the individual with the tallest parts are measured (Webb and others, 1988) — or relative—in which cover of all overlapping canopies are measured (Beatley, 1980). The length of line required to adequately measure cover depends, in part, on whether the cover of uncommon species at the site is required. Usually, $200-400 \mathrm{~m}$ of line intercepts are used (usually as multiple 
lines). A one-dimensional map of the plot can also be made if the transect ends are marked and intercepts are recorded. Beatley (1980) used line intercepts combined with maximum height measurements (using the average height of the plant) in her 68 permanent plots on the Nevada Test Site.

Belt transects are more commonly used for shrub and seedling measurements, because both density and cover can be obtained, and a wider area is sampled along a given line (Vasek and others, 1975a, 1975b; Webb and others, 1988). A belt consisting of two parallel transect tapes is placed on the landscape a fixed distance apart. Although a separation of 2 $\mathrm{m}$ is convenient for most Mojave Desert shrub assemblages, wider separations are sometimes used if accurate data on uncommon species is desired, or if tree species are measured. All plants within a fixed polygon (for example, $2 \times 2 \mathrm{~m}$ ) are counted, and the presence of the basal stem between the tapes is the criterion for whether an individual is in or out of the transect. Definition of an individual can be a problem with many species in the Mojave Desert, especially Coleogyne ramosissima (blackbrush) and Ephedra nevadensis (Mormon tea). Cover can be obtained either by using the bounding tapes as line intercepts or by measuring one or two diameters of each shrub that is encountered. The latter measurements are typically made with a height measurement in order to estimate biomass (see Biomass Estimation: Direct and Indirect).

Hunter (1994) developed a hybrid belt transect method that serves as the basis for permanent plots on the Nevada Test Site. He stretched a line transect between marked fence posts and established a 2-m wide belt transect, $1 \mathrm{~m}$ on each side of the primary line. For each shrub within the 2-m width, he recorded the position along the main tape and the distance from the tape (negative to the left, positive to the right). After establishing the position in this reproducible way, he measured two diameter measurements (at the widest diameter and at a $90^{\circ}$ angle from ground to plant at the widest diameter) and the maximum height to estimate biomass. This method is perhaps the best way of measuring a permanent plot, because it yields more information than the line intercept method of Beatley (1980), but is less intensive than full mapping of plant diameters.

\section{Quadrat Sampling Techniques}

Quadrat sampling techniques are less commonly used in the Mojave Desert, but are extremely useful in high-density shrubs, which are encountered in certain blackbrush or big sagebrush assemblages, and to measure ground cover (see Measurement Techniques for Ground Cover). For areas with large shrubs, quadrat frames are generally at least $1 \mathrm{~m}^{2}$ in area. Carpenter and others (1986) used a 4- $\mathrm{m}^{2}$ quadrat in areas with low-density perennial vegetation. For grasslands or smaller shrubs, $1 / 4-\mathrm{m}^{2}$ quadrats are commonly used. One problem with the larger quadrats is that sampling requires trampling within the plot, which will impact ground covers, especially biological soil crusts, with repeated visits. In this situation, personnel should be required to stay on designated trails. Placement of the quadrats can be determined in many ways. The three most common ways include: (1) Establishing a line transect in the area to be measured and developing a grid from this line. Random numbers are created to describe the distance along the line and from the line for placement of the quadrat frame. Density and cover are then estimated as in a belt transect as described above, or visually estimated. (2) Placing the quadrat at random points along the line. (3) Placing the quadrat at regular intervals along the line.

Some species (for example, Yucca brevifolia [Joshua tree]) are poorly measured with most line, belt, or quadrat techniques. One means of estimating density and cover of these species is to establish plots up to 1 ha in size around the smaller-area plots designed for more common shrubs. Comanor and Clark (2000) used a circular area 1,000 $\mathrm{m}^{2}$ for their permanent plots to study Y. brevifolia growth. For columnar species like $Y$. brevifolia and Carnegiea gigantean (saguaro), heights are measured using a telescoping rod-usually a converted stadia rod-with a horizontal bar on the top. The bar is lowered onto the highest point to obtain the heights of the plants, which are then averaged. This type of approach is particularly suited to cacti or other species that occur on the landscape in low densities. Trails to the target plants need to be designated to reduce trampling of ground covers.

\section{Mapping Techniques}

The oldest plots for measurement of desert vegetation in the United States, at the Desert Laboratory in Tucson, Arizona, are irregularly shaped mapped plots of varying size (Goldberg and Turner, 1986; Bowers, 2005b). The typical plot at the Desert Laboratory is $100 \mathrm{~m}^{2}$, similar to the Beatley (1980) plots on the Nevada Test Site, but much larger plots $\left(800 \mathrm{~m}^{2}\right)$ are also present at the Desert Laboratory, including nested plots for studies of Carnegiea gigantean (saguaro). Initial mapping used a grid of strings stretched over the plot; more recently, surveying instruments were used to outline shrub canopies. Cody (2000) used the grid technique to map perennial vegetation on his plot in the Mojave Desert. Mapping perennial vegetation can be extremely labor-intensive, but can be the optimal way to answer some questions (for example, determining the distance from wash channels on plant distribution and productivity, documenting the spatial relationship among different plant species). In addition, GIS software is required to depict and analyze vegetation characteristics on these plots. The use of modern surveying equipment (total stations) has greatly reduced the time required for mapping vegetation.

\section{Monitoring of Invasive Plants}

Monitoring for new invaders can be made more effective through the use of predictive models linking landscape features with likely pathways of invasion; however the data on the presence/absence of species necessary to develop these models are rarely available (Brooks and Klinger, in press). 
If species lists are available, search areas can be prioritized based on the life history characteristics of the species present. In most cases, species occurrence data or comprehensive lists are not available, and monitoring plans need to be based solely on general invasion theory (Brooks and Klinger, in press). The basic guidelines suggest that invasions are most likely to occur near propagule sources and/or where resources for plant growth are most readily available (Brooks, 2007). In desert regions, these invasion pathways include roadsides, railroads, and utility rights-of-way (Brooks and Pyke, 2001; Brooks and Berry, 2006). They also include focused areas of disturbance to which invaders may disperse over long distances, such as livestock corrals or watering sites, mines, camping areas, off-road vehicle and military staging areas, and old townsites (Brooks and Pyke, 2001). Because these areas are extensive, monitoring should also be extensive, necessitating rapid assessment techniques, such as visual surveys of a given area (for example, between mile markers along a roadside) for a given amount of time (for example, a constrained-time search). Because the vast majority of invaders in the Mojave Desert are annual species (Kemp and Brooks, 1998; Brooks and Esque, 2002), surveys must be conducted during the active growing and flowering season (typically March-April for winter annuals and June-September for summer annuals). A common way of measuring the extent of an invasion from a known point source (for example, the edge of a road) is to evaluate the cover and/or density of the invasive plant at the edge of the heavily invaded area, and then at distances that double each preceding distance interval (for example, $1 \mathrm{~m}, 2 \mathrm{~m}, 4 \mathrm{~m}, 8 \mathrm{~m}$, $16 \mathrm{~m}$, and so on). This can be done either along a line transect or using a quadrat frame. When testing the hypothesis that the expected vector of spread is, in fact, facilitating spread, then one or more additional sampling transects should be established in random directions to serve as controls for hypothesis testing. Monitoring to determine the ecological effects of invaders can be done concurrently by measuring additional ecological variables within each sampling plot. For example, native annual plant community abundance and diversity can be measured in response to increased abundance of the invader as it spreads into new areas (for example, caused by competition; Brooks, 2000).

\section{Spatial and Temporal Variability and Sampling Intervals}

Proper sampling design for monitoring of perennial vegetation requires a plan for coverage of both spatial and temporal variability. Tests of statistical inference require replicate sampling, which would suggest that a minimum of three permanent plots should be established for each vegetation unit that is monitored. However, no previous permanent plot design in the Mojave Desert has used a replicate-sampling approach; although Beatley (1980) established 68 permanent plots, they were not explicitly established as replicates and instead are essentially 68 sites that represent independent vegetation assemblages. Cody (2000) used only one site but applied a repeated-measure statistical design.

The frequency of monitoring requires a tradeoff between maximum data acquisition and minimum site disturbance. Although proper evaluation of annual changes-particularly primary production - would require annual or seasonal visitation, trampling associated with monitoring access could affect soil compaction, disrupt seedbanks, damage biological soil crusts, and have inadvertent negative effects on perennial vegetation. Cody (2000) re-measured his single plot annually for 15 years with unknown sampler-access effects. The Beatley plots were re-measured for perennial vegetation only three times between 1963 and 2002 (Webb and others, 2003), but herbaceous perennials and other ecosystem attributes were sampled at least annually from 1963 through 1970 with uncertain consequences.

One possible solution would be to develop multiple replicate plots that are measured on an alternating basis, but for which at least one plot is measured annually. This sampling strategy would involve a high initial investment in time to create the array of plots but could ensure long-term viability of the monitoring program by minimizing sampler impacts. Even with this design, care would need to be taken during sampling to not disrupt ground covers. In addition, the sampling array would have to be carefully designed to avoid confounding effects that could arise from a variety of factors, including variation in geomorphic surface, soil subsurface properties, and land-use history.

\section{Measurement Techniques for Perennial Vegetation}

\section{Phytoecological Measures}

Numerous possible phytoecological measures have been used to evaluate ecosystem status, sustainability, and stability. Ranging from largely qualitative information on species composition to quantitative measurements of plant physiology, these measures can be easily acquired or can require an extensive research commitment. Our focus here is on discussing phytoecological measures that are appropriate for monitoring of the Mojave Desert ecosystem. While we briefly discuss isotopic and physiological techniques that have application to plant vigor, we will concentrate on measures that can reasonably be accomplished by a competent staff with limited monitoring resources. Readers are urged to consult Rundel and Gibson (1996) and Whitford (2002) for more information on the ecological processes that affect perennial vegetation in the North American deserts.

\section{Biomass Estimation: Direct and Indirect}

Biomass-whether above-ground, below-ground, or total-is one of the most important measures of the status and vigor of perennial plants. Biomass is usually expressed in dry mass per unit area. Direct estimation of biomass is accom- 
plished by harvesting the plants, drying the plant parts, and weighing them. Typically, above-ground biomass, also known as standing crop biomass, is measured, because obtaining sufficient quantities of roots of perennial plants for measurement is extremely difficult and time consuming. Because of its deleterious effects on plant assemblages, direct estimation of biomass cannot be used in permanent plots.

An indirect measure of biomass uses measurements of plant volume to determine a regression equation between plant volume and biomass, which is then used to estimate biomass in plots (appendix C). Several regression equations for indirectly estimating plant biomass are available for the Mojave Desert (Romney and others, 1973; Bureau of Land Management, 1980). Development of these equations is based on an assumption concerning the geometric shape of shrubs-some shrubs, such as Ambrosia dumosa (white bursage), are assumed to be hemispherical, whereas others, such as Larrea tridentata (creosote bush) are assumed to be inverted cones, truncated at the base or intact. Before indirect volume estimates are made, the shape of the species being measured should be determined from the regression equations. The extant regression equations relating biomass to shrub shape and volume are mostly unpublished and are given in appendix $\mathrm{C}$.

\section{Primary Production}

Primary production is an extremely important but difficult-to-measure attribute of perennial plant assemblages in the Mojave Desert. Because water availability controls the flow of energy through this type of ecosystem (Noy-Meir, 1973), primary productivity is intimately linked to precipitation and temperature monitoring. Webb and others $(1978,1983)$ define above-ground net primary production (ANPP) and its relation to water-use efficiency in a variety of biomes, including the Mojave Desert. Lane and Stone (1983) and Lane and others (1984) present a quantitative model linking soil moisture and ANPP, using data from the Nevada Test Site as an example. Turner and Randall (1989) discuss ANPP for the Nevada Test Site and report a precipitation threshold of $26 \mathrm{~mm}$ for annual plants and $21 \mathrm{~mm}$ for perennial plants (roughly in agreement with Beatley, 1974). Hamerlynck and others (2002) showed that gross production is related to geomorphic surface characteristics that control available soil moisture.

Measurements of ANPP generally involve destructive sampling of new-growth twigs and leaves (Turner and Randall, 1989). ANPP can also be calculated using biomass regression equations applied to old-growth volumes versus new-growth volumes; however, this technique involves considerable uncertainty and requires numerous assumptions about allometric growth relations among years. In a hybridization of destructive sampling and allometry, DeFalco and others (2007) marked two culms per perennial grass and four terminal twigs per shrub and followed the growth over time. Parallel measures were collected on other plants, but these were harvested, dried and weighed to develop the culm- and twig-level regression equations for calculating changes in productivity through time. Use of season-long leaf area index (LAI) measurements may be another way to non-destructively estimate ANPP. Lane and others (1984) provide a rudimentary water-balance model for estimating ANPP from precipitation and soil characteristics.

\section{Plant Vigor}

A large variety of techniques are available for measurement of plant vigor. The definition varies, but generally plant vigor is measured at the end of a growing season and represents the cumulative growth in a manner similar to ANPP. Vigor measurements can reflect both environmental variability and site-specific conditions and are usually conducted as a comparison of management treatment versus a control. For example, for Coleogyne ramosissima (blackbrush), twig growth essentially doubled as precipitation doubled, and twig growth was 1.9 times larger on deep soils than shallow soils under the same amount of precipitation (Provenza and others, 1983). Critical ratios of essential elements in plant tissuesuch as nitrogen and phosphorus - are another useful metric of plant vigor that have been tested in many ecosystems, including arid systems (Drenovsky and Richards, 2004), although not specifically in the Mojave Desert. Carbon isotopes in plant tissue can be used to determine water stress in $\mathrm{C}_{3}$ plants (Ehleringer and Cooper, 1988), but should be compared to a control plant of the same species from soils with the same texture. Nitrogen isotopic ratios can also be used to determine the status of nitrogen cycles in the soil: a lower number indicates that plants are growing in soils where nitrogen inputs exceed nitrogen losses.

\section{Phenology and Seed Production}

Phenology, or observations of the dates of leaf-growth start, flowering, and fruiting, is an important measure of plant productivity and vigor (Beatley, 1976; McGinnies, 1980; Turner and Randall, 1987). In light of current trends toward an increase in growing season length, which is also starting sooner, attributable to overall climatic warming in the Southwest, annual collection of phenological observations should be an integral part of a monitoring program in the Mojave Desert. Desert annuals and perennials are highly responsive to either winter or summer rains (Ackerman and Bamberg, 1974), and differential species response could be used to assess the effects of future shifts in the relative amounts of winter and summer precipitation as predicted in some general circulation models. Beatley (1974) presented an elaborate model of rainfall and phenology for the northeastern Mojave Desert, which could be used to integrate climatic and phenological observations.

Seed production, an extension of the more typical set of phenological observations, is extremely difficult to quantify and is labor intensive. However, seed production may also be sensitive to climatic change because, as spring temperatures rise, the possibility exists that the period during which flowering and fruiting can occur may be telescoped down to a narrower time period. For shrubs and some perennial grasses, 
small, fine-mesh bags can be secured to flowering branches or culms, and the mature seed collected and counted when it falls from the plant. Seed production should be expressed as a proportion of productivity (called reproductive effort; Harper and Ogden, 1970) and as indicated in the Primary Production section above (see DeFalco and others, 2007). Net seed production - the amount of viable seed produced minus the amount taken by seed predators - can also be roughly approximated with seedbank measurements (see Seedbank section).

\section{Seedbank}

Seedbanks are typically sampled after seeds have matured and fallen to the ground from the parent plant, but not before an after-ripening period, which is generally the period of prolonged high temperatures in July-August. For desert annuals, plants generally senesce with the onset of high spring and summer temperatures, which causes resources to be focused toward seed maturation and abscission from the plant. Seeds of some desert species require after-ripening so that physiological and physical changes in the seed embryo and seed coat can prepare it for the dormant phase and subsequent germination when conditions become favorable again. Perennial species typically have at least a magnitude lower seed densities and greater spatial variability than annual species and are therefore more challenging to sample. Care also needs to be taken when quantifying seedbanks in the Mojave Desert so that soils are sampled before significant late-fall/early-winter rainfall stimulates germination.

The distribution of seeds across the landscape is tremendously variable in the Mojave Desert, and the sampling design must account for this variability, as well as detect low abundances of rare species. Seed distributions in soil tend to be related to microtopography (Price and Reichman, 1987), thus seed collection locations are often stratified by canopy cover, irrespective of species (that is, beneath shrub canopy versus in the open spaces between shrubs; Esque, 2004). Other conditions that may contribute to spatial variability and that should be considered for stratification include shrub hummocks versus washes, and sites of varying soil ages or textures.

Sampling for annual species begins by collecting surface soil using a tin canister or soil tin pressed firmly into the ground, usually within the top $30 \mathrm{~mm}$, where seeds are found (Nelson and Chew, 1977; Ferrandis and others, 2001), and sliding a metal plaster knife underneath. Size of soil tins and the number of tins collected from one sampling point vary, but care should be taken to account for the variability of arid shrubland systems. For example, in a study examining the role of granivores, wildfire, and precipitation on the annual plant seedbank, Esque (2004) selected sampling points beneath both randomly selected shrubs and adjacent bare soil areas; then, at each point, four sampling tins were collected and pooled to obtain a single representative sample for each sample point. In the pooled samples, soil aggregations were crushed, litter and rocks ( $>1 \mathrm{~cm}$ diameter) were removed, and the remaining soil was thoroughly mixed. A soil volume of $120 \mathrm{~cm}^{3}$ (measured to a depth of $3 \mathrm{~mm}$ ) was used for each germination trial for a rough estimate of $40 \mathrm{~cm}^{2}$ of surface area. This can be multiplied by 250 to provide an estimate of the number of seeds $/ \mathrm{m}^{2}$.

Because perennial seed densities in the soil are typically much lower than annual seed densities, sampling with small soil tins may not capture the rare occurrence of perennials. A metal frame ranging in size from $10 \times 10 \mathrm{~cm}$ to $25 \times 25$ $\mathrm{cm}$ may be pressed in the ground to a depth of $3 \mathrm{~cm}$ and the soil collected within the frame to ensure perennial seeds are sampled more appropriately. However, consideration should be taken when developing more complex designs, as the larger volume of soil will require more space in the greenhouse (and a heavy duty truck to carry tons of soil!) if a grow-out method is used (see below). An alternative method for sampling perennial seeds is vacuuming the surface soil to a depth of $2 \mathrm{~cm}$ using a modified leaf blower (DeFalco and others, 2005: $2 \times 2$ $\mathrm{m}$ quadrats were vacuumed and grown out in the greenhouse successfully, and quadrats of this size captured many of the perennial species present at the site).

Soil seedbank is determined by subjecting soils to four phases of moisture and chemical wetting in a greenhouse. These phases include two wetting phases with tap water, a third wetting phase with the addition of a $0.01 \mathrm{M}$ solution of potassium nitrate $\left(\mathrm{KNO}_{3}\right.$; Mayer and Poljakoff-Mayber, 1982), and a fourth wetting phase with the addition of a $6.5 \times 10^{-4}$ $\mathrm{M}$ solution of gibberellic acid (T.C. Esque and others, unpub. data). The addition of these chemicals is known to trigger the germination of some types of seeds (Mayer and PoljakoffMayber, 1982; Baskin and Baskin, 1998). The treatments include $50 \mathrm{ml}$ of the solutions per treatment pot. Soil samples are kept damp with additional tap water, but not to the point of soil moisture draining off. Seedlings that germinate from each wetting cycle are identified, counted, and removed from pots. Pots are dried between each wetting treatment (approximately 3 to 4 weeks) to simulate the annual dry seasons, and thus break down seed dormancy agents so that all seeds will germinate. Seedlings are identified based on cotyledon shape, size, and surface characteristics (T.C. Esque and others, unpub. data, for photographic reference of Mojave Desert species).

This seedbank assay methodology is not foolproof, and can fail to detect some seeds, possibly due to their stringent germination requirements. A random subsample of assays from multiple sites in the Mojave Desert and adjacent ecoregions indicates that assays conducted during any given year detect an average of 87 to 91 percent of seeds present in the samples (Draper and Brooks, unpub. data, 2002-2004). Samples run back through the assay process a second and a third consecutive year detect an additional 7 to 8 percent and 2 to 4 percent, respectively, of the seeds present in the samples.

\section{Measurement Techniques for Desert Annuals}

\section{Density and Production}

Annual plant abundance is often characterized as number of individuals per unit area (density) or shoot biomass per 
unit area (production). Density and production are typically sampled when annual production peaks (April-May); however, phenologies of winter annuals vary by up to four weeks, so multiple sampling times may be necessary to capture differences in peak abundance by species. Quadrats are typically placed completely at random within a study area, stratified between disparate habitats (for example, beneath shrub canopy versus in the interspace), or placed at intervals along a randomly placed perennial line intercept or belt transect (see Perennial Vegetation). The efficiency of sampling, using different quadrat sizes (for example, $0.10 \mathrm{~m}^{2}$ versus $1 \mathrm{~m}^{2}$ ) and quadrat number, should be determined in pilot sampling before much investment is made. Quadrat size should be based on: (1) objective of study; (2) travel, set-up, and measuring time; (3) spatial distribution of plants; (4) edge effects; and (5) sampling impacts to the study (Elzinga and Evenden, 1997; Elzinga and others, 1998). While small quadrats allow for numerous replicates that can be rapidly sampled, a larger quadrat size may be necessary to capture small, widely spaced or rare annuals in years of low rainfall. After an initial number of randomly placed quadrats are sampled, and the mean and standard deviation calculated, a calculation can be made to determine if further sampling is necessary based on the adequacy of sampling techniques (that is, when a sufficient quadrat number is determined and when variances between plot numbers become stable; Bowers and others, 1995; Zar, 1997). Those seeking additional detail about appropriate sampling units and sampling design should consult Elzinga and others (1998).

\section{Species Composition}

The number of species present within a quadrat and the frequency of quadrats occupied by each species can provide valuable information on species dominance, competitive interactions, and local species extinctions. The number of species can vary considerably among different sized quadrats and does not scale linearly (for example, species-area curves). Therefore, quadrat size should be determined in pilot sampling and kept constant among the study areas that are being compared. Species richness (number of species) and species evenness (frequency of occurrence) are used to calculate species diversity. Discussion about the calculation of species diversity indices, and their uses and pitfalls, can be found in Bowers and others (1995).

\section{Cover}

Annual plant cover can be estimated directly or indirectly at the same time density and species composition are assessed on quadrats. Cover is often related to production, and so cover and production are measured simultaneously only for establishing the correlation between the two; once established, cover takes less time than collecting, drying and weighing plants for production. Cover is directly measured as the number of grid demarcations on a quadrat that contain annual plants, or, similarly, by counting the number of $1 \mathrm{~cm}^{2}$ grid squares with annual plants on a transparency held above the plant canopy. Indirect, ocular estimations of cover, using percent-cover classes, are less precise but allow rapid assessment for numerous quadrats. However, if multiple observers conduct the estimates, it is important to standardize ocular estimations of plant cover and validate the estimates against the actual cover measurements from a suitable number of plots.

\section{Measurement Techniques for Ground Cover (Including Biological Soil Crusts)}

Ground cover includes rocks, plant litter, live plant bases, animal feces, bare ground, and physical and biological soil crusts. These factors can be assessed in as many ways as vegetation is measured. In the Mojave Desert, where lichens and mosses tend to occur in widely spaced patches, there are two common ways to assess ground cover. Regardless of the measurement method chosen, one of the first decisions to be made is how ground cover will be defined: will only the top layer of ground cover be recorded, or will all layers of ground cover be recorded? For instance, a thin layer of plant litter may be on top of a moss, and one needs to decide if one or both will be recorded. At each point, whatever ground cover the rod hits is recorded in predefined categories described below. Whether or not the ground cover point is under the canopy of a shrub or is in the interspace can be recorded as well. This provides information both on vascular plant cover, as well as the distribution patterns in relationship to plants for the different ground covers.

Ground cover is often measured using a point-hit frame. The frame is small (fig. 56) and is gridded off with wires to form cells $5 \times 5 \mathrm{~cm}$, creating cross points. The size and shape of the frame depends on the questions being asked by the monitoring program. Percent cover is calculated by dividing the sum of hits for each category by the total number of hits and then multiplying by 100 . Quadrat frames can also be used, with crust cover estimated by cover classes or absolute cover. We find this technique only works with highly trained personnel.

The frames can be used in several ways to characterize ground cover at a site: (1) Stops are made every 1 to $5 \mathrm{~m}$ along three 50 to $100 \mathrm{~m}$ transect lines, depending on the variability in cover types. (If vascular plants are being measured, the length of line is generally determined by the vascular plant requirements, although the stops for ground cover variables may be more frequent, depending on the patchiness of the site.) At each cross of the wires, a pin flag is lowered to the ground surface, and whatever ground cover the pin flag encounters is recorded. Whether or not the quadrat is under the canopy of a vascular plant, in the interspace, or in both is recorded. (2) Interspaces and areas under plant canopies (often by plant species) are sampled separately. The results from the frames are multiplied by the proportion of interspace and plant canopy (usually obtained by a step-point intercept) to obtain values for the site. This combination of techniques is often the fastest way to characterize a site. (3) For specific studies on 
the community dynamics of soil crust organisms, a line-intercept transect is employed. The technique used is the same as that for vascular plants, but lines are generally much shorter, as this method is very time-consuming. The advantage to this method is that information is collected on the spatial distribution of ground covers.

\section{Lichens and Mosses}

Lichens and mosses should be recorded by species if possible, as the more detailed the information that is collected, the more can be determined about trends at the site. If the species is not known, there are several choices: (1) Record each different lichen and moss as a unique number, take a voucher from outside the plot, and have the species identified by an expert. (2) Record hits as either lichen or moss (mosses can be easily distinguished from lichens by moistening them: mosses will immediately turn green or brown, whereas lichens will not change color). This approach will give you information on nitrogen inputs (the black gelatinous lichens fix nitrogen) and carbon fixation (mosses fix more carbon per unit surface area than lichens). (3) Classify lichens into two classes: a) black gelatinous lichens that swell upon wetting, and b) plate lichens (black, brown, or colored, that don't swell with wetting); and classify mosses in two classes: a) short mosses or b) tall mosses (Eldridge and Rosentreter, 1999). This gives you information about nitrogen and carbon fixation, as well as effects on seed germination (tall mosses can prevent seed germination). If this latter option is chosen, these categories need to be carefully and clearly defined before the monitoring is started.

\section{Cyanobacteria and Physical Crusts}

Cyanobacterial crusts are divided into two classes, light and dark, which reflects the biomass of organisms in the surface soils. Soils with very low cyanobacterial biomass can be difficult to distinguish from soils with no cyanobacteria. If

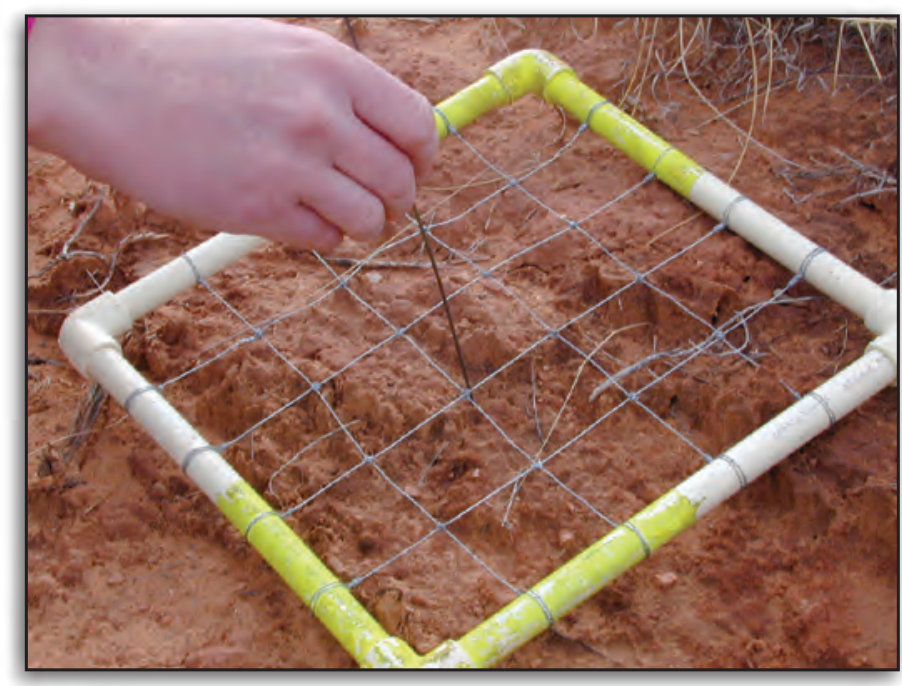

Figure 56. Removable frame for sampling cover of biological soil crusts (U.S. Geological Survey photograph by Jayne Belnap). the soil surface looks bare, tap it lightly with a pin flag. If you do not penetrate the soil surface, or if the pin flag goes through the surface leaving a distinct hole, you have either a physical or biological soil crust. Pick up a small piece of surface soil and look for hanging fibers (fig. 57). If you do not see them, record this hit as a physical crust. If you see them, record this hit as light cyanobacteria. If you do not see them, you can either (1) record the hit as bare ground or physical crust or (2) collect the soil and analyze it for chlorophyll (see Measurement of Cyanobacterial Biomass and UV-protective Pigments). Dark cyanobacterial hits are recorded if the soil surface is darker than underlying soils and the soil is slightly roughened but no lichens or mosses are visible. If desired, the amount of cyanobacteria present can be determined by chlorophyll analysis.

Translucent rocks embedded in the soil surface almost always have hypolithic cyanobacteria and green algae living underneath them, unless the rock protrudes more than $3-5 \mathrm{~cm}$ into the soil. The presence of these organisms is indicated by a bright green band around the edge or along the bottom of the rock. These can be recorded as a separate cyanobacterial class if they are of interest.

\section{Bare Soil}

Bare soil is any loose soil not covered with any other identifiable ground covers. (This does not include soil that has a few loose sand grains on the surface, as other ground covers are generally present as well). Bare soil can also be subdivided into soils that have been disturbed by animals (bioturbation) and those that have been disturbed by other factors (for example, water). Soil that has been previously disturbed by an animal but is crusted together with cyanobacteria can also be recorded as bioturbation/cyanobacteria. It should be remembered that there is very little bare soil in the desert, except in washes that run frequently or in recently disturbed areas.

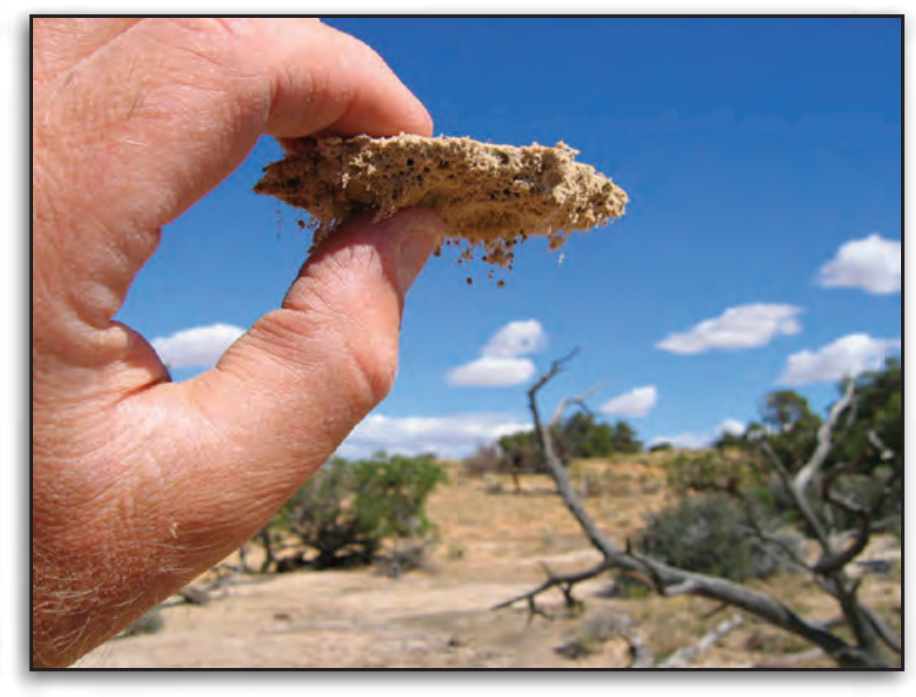

Figure 57. Cyanobacterial filaments hanging down from a piece of surface soil (U.S. Geological Survey photograph by Jayne Belnap). 


\section{Rocks}

It is useful to classify rocks into size classes to provide information on their resistance to movement by wind and water. Small (1-5 $\mathrm{mm}$ at their largest diameter) are moveable by wind; medium $(5-50 \mathrm{~mm})$ and small rocks are moveable by water; and large (greater than $50 \mathrm{~mm}$ ) are unlikely to be moved by physical forces other than debris flows. If interested in true cyanobacterial cover at a site, translucent rocks should be recorded as a separate category from other rocks.

\section{Attached and Unattached}

LitterThis category includes dead organic material (plant and animal) that is unattached to the soil surface, and thus easily moved by wind or water, and litter that is attached to the surface of the soil, such that no crust organisms live beneath it nor is it easily moved. Depending on the monitoring objectives, it is often best to distinguish between these two litter types.

\section{Live Plant Base}

Live plant bases are recorded whenever the pin flag hits where a live plant stem penetrates the soil surface, as they constitute ground cover.

\section{Measurement of Cyanobacterial Biomass and UV-protective Pigments}

Cyanobacterial biomass cannot be assessed in the field, but requires an estimate of chlorophyll $a$ in the lab. To collect samples for this analysis, it is essential that all living or recently deceased plant material is avoided, as it often contains chlorophyll as well. Therefore, after carefully brushing away all plant litter, the top $5 \mathrm{~mm}$ of soil is collected using a paint scraper modified by bending the edges up so they are 5 $\mathrm{mm}$ high, or test tubes marked to indicate the proper insertion depth. Keeping the depth of collection constant is critical so that results can be expressed on a surface area basis and because some analyses (that is, high pressure liquid chromatography, or HPLC) are based on sample volume. Samples are taken randomly by throwing a small object in the general area to determine where the sample will be taken, or along a line transect at predesignated intervals. At each stop, the soil is carefully scooped up, again making certain to hold the depth constant. At least 25 subsamples should be taken to characterize a $50-\mathrm{m}$ line. These can be composited to reduce variability and the number of samples needed. If composites are made, collect at least five subsamples into a single container and mix them thoroughly for consistency. One gram is needed for the chlorophyll analysis. Analysis is done using either a fluorimeter or HPLC after extraction with acetone (Karsten and Garcia-Pichel, 1996).

The advantage of HPLC analysis is that one also obtains measures of accessory pigments in the cyanobacteria, lichens and/or mosses. These UV-protective pigments are an excel- lent way to assess the physiological state of these organisms, as pigment production requires high amounts of water, carbon and sometimes nitrogen. When an organism is stressed, it must first allocate carbon and/or nitrogen to repair and maintain the structures needed for carbon and/or nitrogen fixation. Therefore, production of UV-protective pigments only occurs once these basic needs are met. However, these pigments are necessary to prevent damage and/or death, as UV exposure can quickly lead to severe damage or death (Bowker and others, 2002). Thus, higher pigment levels indicate favorable conditions (for example, wet cool conditions, fertilization by atmospheric nitrogen deposition). When lower UV pigments are detected, it indicates that the organism is under stress (for example, summers with long periods between rainfall; small, frequent rainfall events, disturbance). Typically, scytonemin, myxoxanthophyll, canthoxanthin, echinenone, and carotene are analyzed. Because pigment concentrations are sensitive to climate, a reference site must be used, unless it is the impact of climate change that is being monitored.

Other measures can also be made of soil crusts. These include nitrogen fixation and carbon fixation. Measuring nitrogen fixation requires expensive equipment and extensive expertise (see Nitrogen section). The same is true when measuring photosynthesis, respiration and/or the "health" of the photosynthetic machinery. These require a gas-exchange system, which measures changes in carbon dioxide concentrations in small specialized chambers, or a portable fluorimeter. For any of these measures, it needs to be decided whether to measure the potential of the organisms (done under optimal conditions in the lab) or actual levels of fixation in the field. Field measures need to be done repeatedly, as photosynthetic and nitrogen fixation rates vary widely with environmental conditions experienced by the organisms before and during the analyses.

\section{Subsurface Soil Bacteria, Fungi, Protozoa, and Fauna}

The analysis of soil biota is expensive. In addition, environmental conditions must be carefully controlled, unless a reference area is being used. If funds are limited but the monitoring of subsurface organisms is desired, previous studies have indicated that nematodes may be the most responsive to disturbance in deserts (Freckman and others, 1975; Mankau and others, 1973; Freckman and Mankau, 1986; J. Belnap, unpub. data).

If possible, it is best to collect samples for soil biota analysis at the same time as soils are collected for chemistry, and in the same way. Splits of the same soil can be sent for both types of analyses so that you also have data on soil nutrients as well as soil biota. In contrast to soil elemental analyses, however, soil food-web samples need to be bagged immediately in plastic to preserve the soil moisture, kept cool, and shipped overnight above ice (so they are cold, but not frozen). Identification of these organisms requires specialized 
microscopes and expertise, and thus is generally done by a professional lab. Samples should be approximately 100 to 200 $\mathrm{g}$ ( 2 cups in volume) to analyze for active and total bacteria and fungi, protozoa, and nematodes.

Soil microarthropods are larger than other soil biota, and collecting them with a small soil corer will result in many organisms being damaged. Therefore, soil microarthropods are best collected with a trowel and with minimal soil disturbance or stirring. Samples are much larger than for other soil biota (about $1 \mathrm{~kg}$ ), although 30 subsamples are still recommended per sample, with three to five samples per site. These samples, unlike those for microbial analysis, can be stored and shipped at room temperature, although they still need to be bagged to preserve soil moisture and shipped immediately. As with the smaller food web organisms, identification of these organisms is difficult and requires expertise (Moldenke, 1994). Invertebrates are generally identified to the family, genera or functional group level, as identification to species is extremely difficult.

\section{Enyzmes}

There are many enzymes secreted by soil biota that can be assayed in soils, with the most common being seven glycosidases, nine aminopeptidases and three aminohydrolases, as well as alkaline phosphatase, sulfatase, acetyl esterase, phenol oxidase, and peroxidase. These enzymes break down lignin, cellulose, and proteins. Therefore, which enzymes are assayed for depends on the monitoring question, and an expert in this field should be consulted. Aminopeptidase, aminohydrolase and peroxidase levels are high in desert soils, and thus are often measured. Potential enzyme activity should be assayed at the ambient soil $\mathrm{pH}$, and rates calculated per gram of soil organic matter or per gram of soil. While soils are easily collected by resource staff, extractions and analyses need to be done by qualified personnel, using a spectrophotometer and fluorimeter in the laboratory.

\section{Decomposition}

\section{Above-ground Decomposition}

In deserts, the main drivers of above-ground decomposition are abiotic (UV, wind), and thus are generally outside the control of land managers. This, combined with the difficulty of measuring this variable, has meant that above-ground decomposition rates are seldom included in a monitoring program. However, if this measure is desired, native plant material should be placed on top of the ground (either a known weight or complete coverage of a known surface area) in a bag that has a wide-gap mesh on top (for example, plastic bird netting) and a smaller mesh $(<5 \mathrm{~mm})$ on the bottom. The top mesh layer prevents material from being lost through wind or water, and the bottom layer facilitates picking up the litter for reweighing, and the large gaps do not prevent animal access. Disappearance of above-ground litter can be a good measure of termite, beetle, or ant activity, all of which can be disrupted by human-related disturbance. To prevent loss by UV, which can account for up to 85 percent of above-ground decomposition in deserts (Whitford, 2002), the plant material also should be shaded, unless loss by UV is to be measured. Loss rates can then be assessed annually by reweighing.

\section{Below-ground Decomposition}

In contrast to above-ground decomposition, belowground decomposition is biotically controlled and can be easily disrupted by disturbance. In addition, it is much more straightforward to measure. There are three main methods: decomposition cloths, wooden strips, or litter bags. Decomposition cloths (fig. 58) are cotton cloths of a standard thread/in ${ }^{2}$ construction. These $\sim 100 \mathrm{~mm}$-wide strips have been used to measure relative decomposition rates in ecosystems around the world (Harrison and others, 1988). Generally, three replicate strips are carefully inserted into the ground, making certain to keep them unwrinkled, to the desired depth (generally 20-30 $\mathrm{cm})$. Cloths are replaced monthly or bimonthly, depending on loss rates. After collection, cloths are cut into pieces spanning the soil depths of interest (such as $0-5 \mathrm{~cm}, 5-10 \mathrm{~cm}, 10-15$ $\mathrm{cm}, 15-20 \mathrm{~cm}$ ). These are then placed in a tensiometer that measures the strength of the cloth, as greater decomposition results in lower cloth strength. Tensiometers can be found in universities with textile departments. Similarly, wood strips (tongue depressors, toothpicks, balsa wood strips) are weighed, inserted into the ground and reweighed after a specified amount of time. These are best used in very rocky soils where decomposition cloths cannot be used. All these methods have the advantages of not restricting access by any soil fauna. However, as with any such method, they represent a concentration of resources not otherwise found in desert soils. Thus, they may attract a higher concentration of organisms than is generally found in these soils, and lead to an over estimation of decomposition rates. They are excellent in establishing the time of year when decomposition is most active. This information can be used to design sampling protocols if soil food webs are going to be measured. In addition, the cotton or wood strips can be placed in bags with mesh sizes to restrict or allow access by different types of organisms (for example, microbes versus small soil fauna [mites] versus large fauna [termites]). In this way, one can determine the degree to which the different types of organisms influence decomposition rates. Fumigated cloths can also be used to restrict microbial populations.

Litter bags are mesh bags filled with litter and/or plant roots collected on-site (Wardle and Lavelle, 1997). Green plant material is collected, dried, weighed, and placed in the bags. As with the cotton strips, different mesh sizes can be used to exclude or allow access by organisms of interest to determine levels of consumption by the different functional groups. Five to ten bags are buried at each of the desired depths (for example, 5 and $15 \mathrm{~cm}$ ) under a plant canopy or in the plant interspaces. Bags are weighed and replaced every 6 to 12 months, depending on loss rates. Litter bags can be problem- 
atic in deserts, as they increase the time litter is moist, thus causing overestimation of decomposition rates. They require disturbance to insert, and can also restrict access by soil fauna in undesirable ways, thus causing underestimation of decomposition rates.

\section{Arthropods}

Entomologists first implemented the use of pitfall trapping of animals in an attempt to secure samples of insects (Greenslade, 1964). Pitfall traps can be constructed using any cans; at the Nevada Test site, "cement test cans" with a steel insert were used. A 1-cm lip made sample removal easy, as did removable bottoms. The can is buried in the soil to the rim and covered with a lid when inactive. When the trap is set, the lid can just be removed, or set up on legs to create shade and thus attract the arthropods (Turner and Medica, 1977). The cans are placed in a grid within replicated study plots (for example, four 8.5-ha study plots with 400 pitfall traps in a 15 -m grid pattern each). Pitfall traps can also capture a sizable number of lizards and small snakes, who may eat some of the captured invertebrates. Thus, the traps need to be actively emptied.

A set of standardized protocols is being used on a global basis to inventory and analyze ant communities. This set is called the Ants of the Leaf Litter (ALL) protocol (Agosti and Alonso, 2000; Alonso and Agosti, 2000). The ALL protocol uses three methods: (1) pitfall trap arrays, (2) leaf litter sampling on standardized plots, and (3) general collecting throughout sampling sites. The pitfall traps are similar to those described above: cans, buried in the ground, in a grid pattern. The part of the protocol using leaf litter has limited applicability in the Mojave Desert, as leaf litter is fairly rare in many vegetation communities. Therefore, we suggest using the relevant portions of this protocol in habitats with significant leaf litter and adding bait stations to the protocol for the remainder of the desert. The results of standardized protocols can be used in comparison with data from other sites where the ALL protocol is used. In addition to the ALL protocol, we suggest using bait stations to provide additional information on the dominance of ant species at sampling sites.

\section{Reptiles}

\section{Techniques for Monitoring Reptiles}

Monitoring of Mojave Desert populations of reptiles is of significant importance to both the Federal and state land management agencies, as well as state wildlife agencies. The U.S. Fish and Wildlife Service is mandated to monitor the status of the Mojave Desert population of the desert tortoise (Gopherus agassizii), the largest reptile that inhabits the Mojave Desert, as it is listed as threatened north and west of the Colorado River (U.S. Fish and Wildlife Service, 1994; Tracy and others, 2003). Some reptilian species are short lived (1-2 years for side-blotched lizard [Uta stansburiana]; Turner and others, 1970), and their population fluctuations mirror short-term environmental changes. Other species, such as leopard lizards (Gambelii wislizenii) and horned lizards (Phrynosoma platyrhinos), can live 8 to $10 \mathrm{yrs}$ (Medica and Turner, 1984), and their behavior and population dynamics vary greatly from year to year in both activity and reproductive potential. Reptiles have demonstrated potential as indicators of environmental stress and disturbance (Medica, 1992; Medica and others, 1994), and may play an important role in future habitat monitoring as indicators of environmental health.

Monitoring Mojave Desert populations of reptiles can be accomplished through a number of sampling techniques, varying from measures of relative abundance to detailed population enumeration using mark-recapture methods. The type of information desired defines the intensity of the methodology required and the stringency with which the data is collected. Abundances of lizards and snakes can vary dramatically by year, season, month, week, or even day, depending upon the climatic conditions that exist at the time of sampling. Such variation needs to be accounted for in the planning and design of a sampling program.

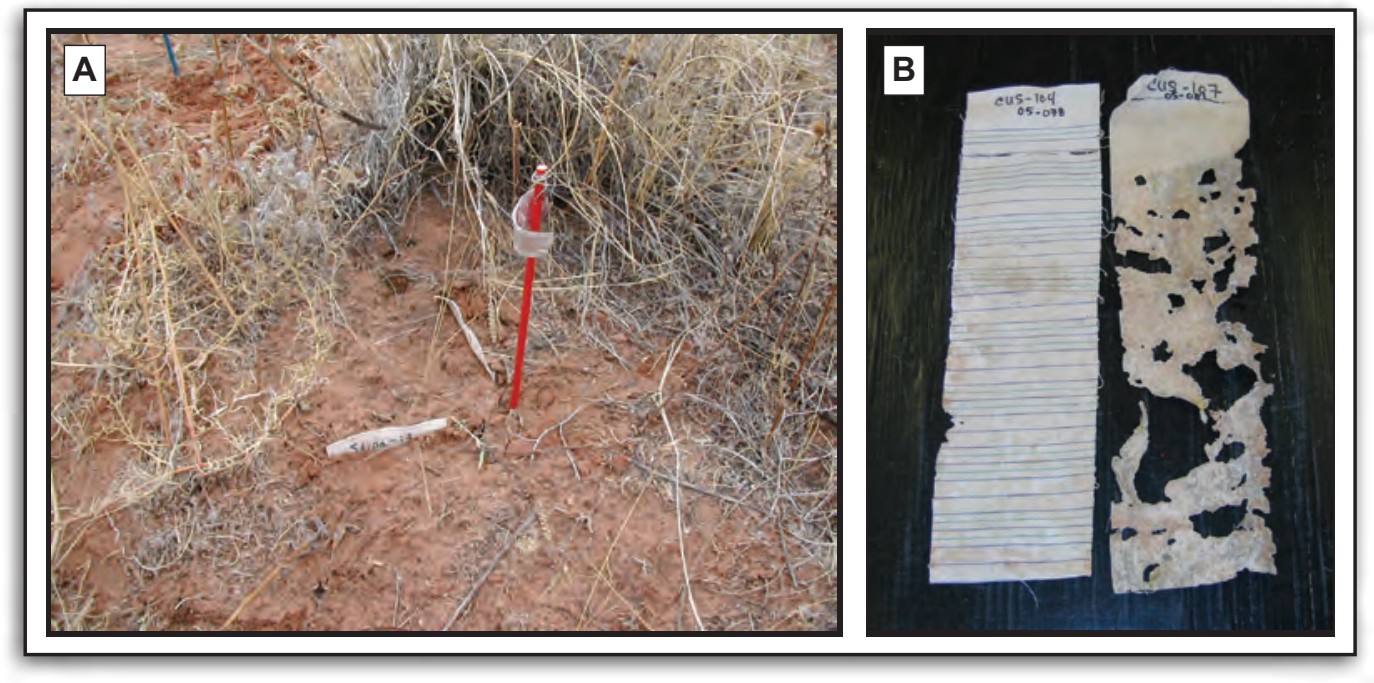

Figure 58. Decomposition cloths for measuring decomposition rates. $A$, Installation of a decomposition cloth. B, Examples of extracted decomposition cloth. The cloth on the left has had little decomposition compared to the one on the right (U.S. Geological Survey photographs by Jayne Belnap). 
Much of the methodology for assessing populations of reptiles comes from extensive studies in Rock Valley reported by Turner (1977), and elsewhere on the Nevada Test Site (Medica, 1992; Medica and others, 1994; Woodward, 1995). Reptilian sampling can be divided into several sampling methodologies, which can vary by taxa. The following discussion describes the various trapping methods and sampling techniques that have been used successfully within the Mojave Desert. All have occurred within permanent 9-ha fenced plots that have been gridded so that animal locations can be mapped. When more than simple indices of relative abundance or species richness are attempted using transect data, adequate tests using the line-distance sampling technique need to be tested. It is necessary to use known densities of lizards in enclosed populations to evaluate and calibrate the technique, and to determine the ability to inventory all observed specimens in order to estimate density.

\section{Night-driving Surveys}

Sampling snake populations by driving at night on paved roads for a specified distance in the arid southwest habitats was popularized by Klauber (1939). Night-driving surveys continue to be a viable methodology for determining species distribution, occurrence, and relative abundance in various habitats. Mendelson and Jennings (1992) used night-driving techniques to evaluate changes in relative abundance in a desert grassland community over a 30-year period. Little else has been done to evaluate snake species composition changes using this technique. Seasonal variation in snake abundance following rainfall periods has been documented by Reynolds (1982). Night driving has proven to be a successful technique for conducting mark-recapture studies of the nocturnal western banded gecko (Coleonyx vigilis), and the desert night lizard, (Xantusia vigilis; B.D. Hardenbrook and P.A. Medica, pers. observation).

\section{Pitfall Traps and Drift Fences}

In the early 1950s, Fitch (1982) sampled populations of amphibians and reptiles using pitfall traps at the Kansas Natural History Reserve. In the early 1960s, several research projects were initiated at the Nevada Test Site using arrays of pitfall traps — one by Brigham Young University and the University of California Laboratory of Nuclear Medicine and Radiation Biology (UCLA/LNRB) in conjunction with the Federal Government's nuclear testing program "Sedan" (Allred and others, 1963). An additional research project was initiated in Rock Valley between 1962 and 1964 by UCLA/ LNRB to evaluate the effects of gamma irradiation on natural populations of plants and animals (French, 1964). Using these techniques, pitfall traps are placed in a grid pattern within replicated permanent plots (in Rock Valley, the same traps for arthropods were also used for reptiles). Traps should be run daily to insure that no mortality occurs. Larger snakes and lizards might easily escape these traps, although occasionally can be found in the traps (for example, gopher snake [Pituophis melanoleucus], sidewinder [Crotalus cerastes] and long-nosed leopard lizard [Gambelia wislizenii]). The nocturnal lizard desert banded gecko (Coleonyx variegatus) can also be caught using pitfall traps; however, efforts to recapture marked individuals has proven to be difficult.

Drift fences, in combination with pitfall traps, have become increasingly more successful in capturing reptiles in more mesic habitats, as was proven in Kansas (Fitch, 1982). More recently, this method has proven to be highly successful in coastal southern California (R. Fisher, oral commun.) and has been used with a moderate degree of success in the Mojave Desert at Fort Irwin (Morafka, 1993) and Twentynine Palms (Hirsch and others, 2002). The physical characterization of pitfall trapping and drift fence arrays are numerous and well illustrated for assessing: (1) amphibians (Corn, 1994); (2) lizards, snakes, and small mammals (Hirsch and others, 2002); (3) lizards and small snakes (Medica and others, 1971); and (4) amphibians and reptiles (Campbell and Christman, 1982; Vogt and Hine, 1982; Corn and Bury, 1990). The pitfall-trap/ drift-fence technique is an excellent way to document species diversity from one place to another or one habitat type to another. This method can provide evidence of rare or relatively uncommon species, which may possibly be more numerous than cursory sampling might indicate. In order to understand patterns in trapping success, species richness, and relative abundance, environmental conditions during the sampling should be recorded, as these conditions can cause species and numbers to vary greatly. During a drought year (1970) drift fence trapping for snakes in Rock Valley was unsuccessful (P.A. Medica, pers. observation). Relative abundance provided by pitfall trap/drift fence sampling should not be construed as density. Population densities are more accurately estimated by mark-recapture sampling techniques.

\section{Mark-recapture}

An excellent summary of population estimation techniques was given by White and others (1982), who stated that "interest in estimating the size of populations has had a long history. The crudest methods date back at least at the $17^{\text {th }}$ century and probably long before that." The basic premise to all mark-recapture sampling techniques is based upon the initial assumption that there are no births, deaths, immigration, or emigration, and thus there exists a "closed population." For the most part this basic premise is violated by most researchers' experimental design, which results in high variance when statistical rigor is applied to the data.

The most efficacious method for capturing lizards in mark-recapture studies is by noosing species in the genera Uta, Urosaurus, Uma, Aspidoscelis (= Cnemidophorus), Callisaurus, Dipsosaurus, Sceloperus, Gambelia, and Crotaphytus. Horned lizards (Phrynosoma) are easily captured by hand, and geckos (Coleonyx) and night lizards (Xantusia) either by evening road collecting or pitfall traps. A cautionary note about Coleonyx - the ability to recapture individuals using pitfall traps without drift fences can be very low (P.A. Medica, pers. observation). 
In the Mojave Desert, the classical study of desert tortoises conducted by Woodbury and Hardy (1948) on the Beaver Dam Slope of southern Utah used branding techniques to permanently mark individuals. Notching of marginal scutes, the placement of epoxied numbers written on card stock attached to depressions in costal scutes, painted numbers or dots to signify individual animals, and the use of PIT tags (Passive Integrated Transponders) all have been used to identify desert tortoises. Additional marking techniques for other reptiles include: toe clipping; painting patterns or numbers on the body or base of the tail of lizards; clipping the ventral caudal or abdominal scutes on snakes; and placement of a PIT tag under the skin, into muscle or into the abdominal cavity of all reptiles. If individual recognition is necessary, individually distinct numbers or patterns have been used in order to expedite sampling after the initial permanent marking phase is completed.

When considering studying Mojave Desert saurian populations, the mark-recapture technique works well. The standard technique has been toe-clipping. Numbering front foot toes left to right in the order of $1,9,4,7$, and 2 provides the capability of numbering every numeral in between by clipping toes that are never adjacent to each other, and no more than two toes per foot (fig. 59). The long toe on each hind foot was specifically given the number 900 or 9,000 ; we normally avoided clipping these long toes (Medica and others, 1971; Hunter and Medica, 1989). The numbering system designated

Left front
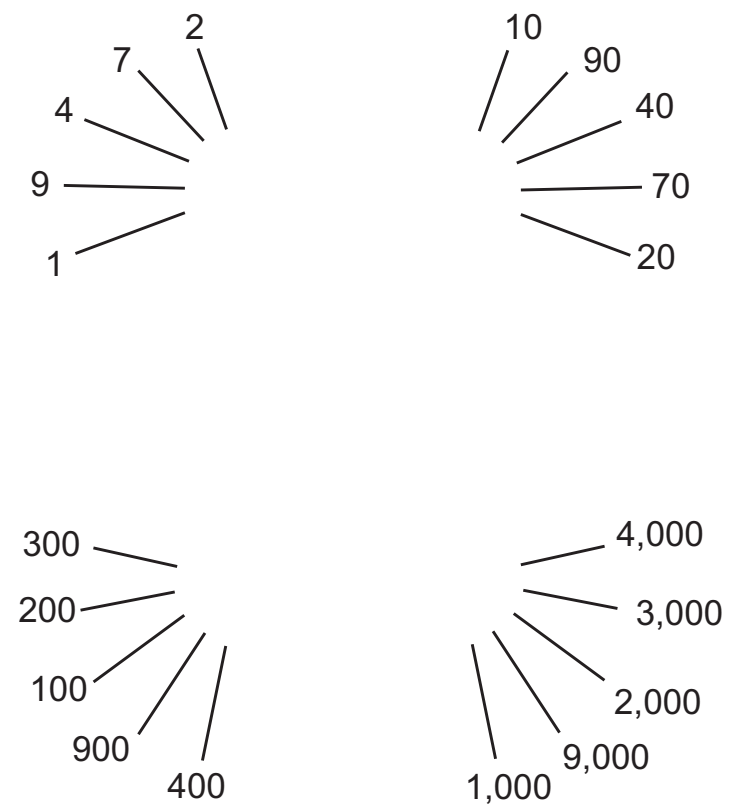

Figure 59. Lizard toe numbering system (Medica and others, 1971). the right rear foot in the thousands, the left rear foot in the hundreds, the right front foot in the tens, and the left front foot in ones.

\section{Considerations for Specific Species}

\section{Side-blotched Lizards}

Side-blotched lizards (Uta stansburiana) have been sampled in a manner similar to that described by Tinkle (1967). Two to four people walk back and forth systematically within a defined study area. When a lizard is observed, a numbered marker is dropped at the location and the lizard is noosed (over 95 percent of adult side-blotched lizards are successfully noosed). After capture, the lizards are placed in numbered plastic vials. The location, vial number, and marker number are recorded so that the lizard can later be returned to the spot where it was captured. Then the vial with the lizard inside is placed upside down in a sack containing 20 such vials. Empty vials are placed with the lid facing upward. Sampling continues until the entire plot has been searched. All sideblotched lizards are weighed to the nearest $0.01 \mathrm{~g}$, measured to the nearest $\mathrm{mm}$, palpated to determine reproductive status (whether they possess eggs or yolk follicles and the size and number), toe-clipped if not already marked, and painted with a distinctive paint pattern for easy recognition in subsequent sampling periods. After all of the lizards have been processed they are released at the point of capture and the numbered markers retrieved.

Sampling should be done for one week during each of the months of March and April. The spring density (as of March 1) is taken as the total roster of all different individuals registered. Densities of side-blotched lizards can also be effectively estimated indirectly by capture-recapture analysis, assuming that a chain of four or five consecutive samples is utilized (Turner and others, 1970).

As would be expected, the percentage of the total population enumerated over a period of time increases rapidly at first, and then declines as more individuals are registered. With stable weather conditions and uniform sampling effort, the percentage of the side-blotched lizard population $(P)$ can be approximated by the following equation:

$$
P=1-e^{-\beta t},
$$

where $t$ is the number of samples and $\beta$ an exponent depending on the number of workers involved and the local environment. When four people were working four 1.44-ha plots in Rock Valley in 1970, $\beta$ was estimated at about 0.65 . The majority of Uta in Nevada rarely survive beyond three years with approximately 70 percent of the population replaced annually (Turner and others, 1970). The maximal life span of side-blotched lizards in Rock Valley is about 58 months (Medica and Turner, 1984).

Juvenile lizards should be inventoried and marked during the months of July and August, using pitfall traps in combi- 
nation with noosing. Each week, the hatchlings captured are painted with a different colored tail dot. If a painted hatchling is seen, the location is recorded. The goal is to enumerate as many hatchlings as possible so that survivorship can be determined the following spring. Survivorship has been estimated simply as the fraction of the total number of juveniles marked in July and August recovered during the ensuing spring. In Rock Valley, juvenile survival was estimated as 0.24 from 1966 through 1967, whereas from 1967 through 1968 survival was 0.192 (Turner and others, 1970).

\section{Whiptail Lizards}

Density of whiptail lizards (Cnemidophorus $=$ Aspidoscelis tigris) can be estimated using mark-recapture techniques. The period of above-ground activity of adult whiptail lizards is generally compressed into about four months (late April to early August; Turner and others, 1969b). Not all animals are active throughout this period. Females generally become active a few weeks later in the season than males, there is a dilution effect as the season advances, and not all of the population is active at any one time (Tanner and Jorgensen, 1963). Therefore, most estimation work for this species should take place during May and June, although records should be accumulated throughout the summer as opportunities arise. In general, whiptail lizards are distributed fairly evenly, and thus the best survey technique is to have people walking grid lines from 7.5 to $15 \mathrm{~m}$ apart. When a whiptail is seen, all searchers converge on the animal and the lizard is noosed. Processing the animals is similar to that of side-blotched lizards, except that larger plastic vials are used to hold the animals in the field. The paint patterns are also different-whiptail lizards are painted with rings at the base of the tail instead of dorsal body patterns. The rings are painted on the dorsal and lateral sides of the tail and are visible from the side. Rings are painted in sets of three colors. The most proximal ring indicates sex; males are either white or blue, females are either pink or yellow. Using the above four colors, plus green, there are 25 possible combinations, totaling 100 possible patterns. Green is used as the proximal color when all of the 100 other patterns have been used, and can denote either sex. The more distal rings may be any combination of colors, which will distinguish individuals. Lizards painted in this manner are generally recognizable for 3 to 4 weeks.

Spring densities have been most successfully estimated by capture-recapture analysis (Turner and others, 1969b). The most reliable approach for density estimations is to consider any animals registered in a given year (except the young-ofthe-year marked in August and September) as a single cohort. All individuals registered in the ensuing year (except for oneyear-olds and young-of-the-year) constitute the second sample $(n)$, and recaptures $(r)$ are simply those animals originally registered the previous year. Each pair of consecutive years is analyzed separately, and the capture-recapture history of each individual assessed independently of events in any but the two years in question. This procedure may seem cumbersome, but it is more reliable than capture analyses based on short-term samples.

Spring densities can also be done by direct enumeration when the area being censused is fenced and the registry for a given year is predicated on data available from that year as well as several subsequent years. Such minimum registries have always been less than the corresponding capture-recapture estimates. In the absence of these conditions, capturerecapture analyses of the sort described above would be more reliable.

Simple counts, or counts along line transects (Degenhardt, 1966; Pianka 1970) are inadequate measures of true density. In fact, because of day-to-day variations in success, such counts are probably not safe estimators of relative abundance. In Rock Valley, four people, walking at an interval of $7.5 \mathrm{~m}$ within a fenced 9-ha plot, detected only about $1 / 3$ of the marked whiptail lizard population (Medica and others, 1971). There can be 5- to 10-fold differences in success at different times, even though the observers are following essentially the same procedures.

\section{Leopard and Horned Lizards}

Collections of leopard lizards (Gambelia wislizenii) and horned lizards (Phrynosoma platyrhinos) are made at all times of the spring and summer as opportunities arise. Paint patterns used are similar to those used with side-blotched lizards, whereas all other procedures are similar to those employed with whiptail lizards. Minimal spring densities of leopard lizards and horned lizards have been determined by direct enumeration, in a manner similar to that employed with whiptails (Turner and others, 1969b; Medica and others, 1973).

\section{Desert Tortoise}

Desert tortoises are generally marked by notching the shell with a three-cornered file, and populations followed using mark-recapture. When conducted on a long-term basis, trends in density of desert tortoise can be documented, although determining the cause of population fluctuations over long periods of time becomes problematic. With study plots that are unfenced, the statistical analysis of the traditional 30-day initial marking period with a 30-day recapture period within $1-\mathrm{mi}^{2}$ plots results in a large error. Attempts have been made to reduce the variance in population estimation by making plots smaller (for example, $1 \mathrm{~km}^{2}$ or $1 \mathrm{ha}^{2}$ ) as was recommended by the U.S. Fish and Wildlife Service recovery plan (1994), thus increasing the ability to sample plots in a shorter period of time. Reducing the interval between the marking phase and the recapture phase when sampling desert tortoises also greatly reduces the possibility of immigration and emigration, and also achieves closer to 100 percent coverage of the plot. Subsequently, researchers have experimented with combinations of line-distance transects and 1-ha ${ }^{2}$ plots in an attempt to develop methodology for range-wide desert tortoise monitoring (P.S. Corn and P.A. Medica, unpub. data). 
In 2001, the U.S. Fish and Wildlife Service initiated range-wide monitoring using the line-distance sampling technique developed by Buckland and others (1993) and field tested in Nevada by Anderson and others (2001). With this technique, individuals walk a line of known distance and observe tortoises along that line. When a tortoise is observed, the perpendicular distance from the line to the object is measured. The technique requires that all tortoises intersected by the line are observed and counted. With desert tortoises, it is also important to get an estimate of those individuals that are not above ground. This sampling methodology shall hopefully enable researchers to monitor the population trends over time by developing baseline population density estimates and reducing the variance error in sampling. Subsequently, monitoring desert tortoise populations may occur at 3- to 5-year intervals, once the baseline has been determined. Definitive techniques used in desert tortoise line-distance sampling evolved between 2001 and 2003 and appear in a final report that summarizes the range-wide sampling conducted throughout the Mojave Desert by the U.S. Fish and Wildlife Service (2006).

\section{Small Mammals}

Techniques for monitoring small-mammal populations within desert habitat have evolved greatly over the course of the past century. Early studies in southwestern North America on kangaroo rats (Dipodomys spp.; Vorhies and Taylor, 1922) and pack rats (Neotoma spp.; Vorhies and Taylor, 1940) pertained to the economic impacts of rodents upon food reserves and grazing. Collections for voucher specimens normally were conducted using snap traps and the traplines run early in the morning to retrieve specimens (Grinnell, 1937; Hall, 1946, 1962). Since that time, many sampling techniques, with variations in trapping arrays to account for species distributions, movements, population dynamics, and habitat preferences, have been developed. The objectives of small-mammal monitoring need to be well defined before deciding upon a sampling technique (Wilson and others, 1996). Choosing the proper trapping array, as well as the type of trap, needed for each species of rodent can be very important. For example, trapping whitetail antelope squirrels (Ammospermophilus leucurus) during mid-day requires open mesh traps with shaded covers to minimize temperature stress. Based upon sampling conducted in southern Nevada, the best time to sample for small mammals is generally spring and early summer (late April-early June), if the goal is to obtain the greatest number of species and the spring density of adult animals. The season in which sampling occurs is important, based upon the ecology of the species being sampled (for example, if trapping is conducted too early in the spring when nighttime temperatures are low, few little pocket mice [Perognathus longimembris] will be captured). Likewise, in some portions of southern Nevada, Ord kangaroo rats (Dipodomys ordii) appear to be more susceptible to trapping in fall rather than in spring and summer-whether this characteristic is more than a localized occurrence is not well documented. If much variation in elevation enters into the sampling scheme, then lower elevation sites should be trapped first. Many of the specific details with illustrations for marking and monitoring small mammal populations are described in great detail in Wilson and others (1996). Additionally, the American Society of Mammalogists (Gannon and others, 2007) has revised their guidelines for the use of wild mammals in research.

\section{Snap Traps}

Snap traps are often best for studies of species composition and richness, as well as knowledge of species distribution (Sedivec and Whidden, 2007). Use of these traps is particularly important when closer examination of the mammal is required, such as in studies of food habits where stomach contents are analyzed or studies of the age structure of a population as determined by examining the curvature of the eye lens. If destructive collection is necessary and voucher museum specimens are to be preserved, tissues from internal organs can be frozen (for example, liver, heart or kidney for DNA analysis; Riddle and Honeycutt, 1990; Yates, 1996). If collection of internal tissue is unnecessary, live-trapping methods are preferred. Genetic samples can be collected from ear and/or toe clippings (Dubach, 1986) and/or blood samples from the suborbital sinus (Mech and Hallett, 2001).

\section{Live Traps for Nocturnal Small Mammals}

Live trapping techniques vary widely, depending on the questions being asked and the number of traps and personnel available. Trapping needs to occur for a minimum of three consecutive nights (French and others, 1974). French (1964) estimated that 81 percent of the small-mammal population is captured on the first night, 13 percent more on the second night, and 5 percent on the third night. No more than 2 percent remained untrapped after three consecutive nights of trapping, although this can vary among sites.

Sherman live traps $(7.6 \times 8.9 \times 30.5 \mathrm{~cm})$ are used for the capture of small mammals. Trap stations are placed either in a grid (for example, a $12 \times 12$-m grid at 15 -m intervals with two traps per station is standard) or along a line, again with two traps per station (O'Farrell and others, 1977). Traps are typically baited in late afternoon with a combination of rolled oats and bird seed, and remain baited until shortly after sunrise on the succeeding morning. Traps are typically oriented northsouth and placed under a sheet metal (half-round) trap cover to prevent overheating by direct sunlight, or placed on the west side of shrubs when set in the late afternoon if trap covers are not used. The trap covers can prolong the time allowed to service the traps in the early morning by an hour or more in the event that a large number of animals are captured.

Many variations in the standard grid design have subsequently been developed in order to refine the ability to 
estimate density or to recapture all animals known or believed to occur on a designated plot. For example, the monitoring of small mammals in adjacent burned and unburned areas has been done using a $6 \times 6$-m staked grid with trap stations at 15-m intervals (total area sampled $0.56 \mathrm{ha}^{2}$ ). Two live traps with trap covers were placed at each staked location. A second method was also tried: four transect lines, spaced $15 \mathrm{~m}$ apart, extended $225 \mathrm{~m}$ into both the burned and unburned habitats. The total area sampled, using live trapping, was $1.44 \mathrm{ha}^{2}$. Two live traps and trap covers were placed at each of 32 stations per line (16 stations in each of the burned and unburned habitats). A comprehensive comparison and analysis of sampling procedures was published by White and others (1982) and Kendall and Pollock (2001).

\section{Handling and Marking Small Mammals}

Many small mammals are capable of inflicting a painful bite. Depending upon the experience of the handler, emptying traps can become problematic. Thus, wearing cloth gardening gloves is recommended, as they give the handler an ability to grasp animals gently while still affording adequate control and protection. Some mammalogists prefer to use a plastic bag to empty the trap into and subsequently capture the animal, while others do not. Some biologists simply insert 3 to 4 fingers into the trap and force the rodent into the palm of their hand and then grab it and pull it out of the trap in one smooth motion.

For monitoring individuals, such as in mark-recapture studies, each mammal is permanently marked using either numbered ear tags, clipped toes, or PIT tags that can be inserted subcutaneously. However, because ear tags may fall out or be torn from the ears, marking by toe clipping or PIT tagging are the preferred methods. No more than one toe should be clipped per foot. If the study is short-term (that is, 3 to 4 days in duration), marking a longitudinal stripe on the belly hair using indelible markers with different colors each day has worked well (P.A. Medica and T.C. Esque, pers. observation). After capture and marking, sex, reproductive condition, and grid location are recorded. Each animal is then weighed to the nearest gram using a Pesola spring scale, which weighs to $300 \mathrm{~g}$. Scales with the capacity to weigh animals in the 5 to $10 \mathrm{~kg}$ range should be kept handy in the event that mammals, such as squirrels, chipmunks, rabbits, or weasels, are captured. Densities are estimated using the formula developed by Seber (1973).

\section{Special Considerations for Diurnal Species}

\section{Ground Squirrels and Antelope Squirrels}

Ground squirrels occur in most major habitats in the Mojave Desert. At the lower elevations, the whitetail antelope squirrel (Ammospermophilus leucurus) and the roundtail ground squirrel (Spermophilus tereticaudus) are locally abundant. At higher elevations, the rock squirrel (Spermophilus variegatus) and the cliff chipmunk (Eutamias dorsalis) are present. Squirrel trapping on permanent plots should be conducted at least once a year (preferably in the spring) to determine the size and age distribution of the population. The "Tomahawk" live trap \#102 $(12.7 \times 12.7 \times 40.6 \mathrm{~cm})$, constructed of wire fabric with a single door at one end, is the most effective. Traps should be opened in early morning (about 8:00 AM) and should remain open until late afternoon (about 4:00 PM), or possibly later, depending upon the activity of the species being sought. Traps should be checked at one- or two-hour intervals throughout the day and closed after 4:00 PM, or at the end of the sampling period, until the next morning. Trap shades constructed of $30.48 \times 30.38 \times 0.48$ $\mathrm{cm}$ masonite should be used to block the sun and positioned appropriately, as the position of the sun changes throughout the day. This will insure that animals do not perish from exposure to direct sunlight, especially at mid-day.

Squirrels can be toe-clipped, as described for nocturnal small mammals, or PIT tagged (Schooley and others, 1993). Captured animals should be sexed, aged, and weighed, and released at the point of capture. Density estimates can be analyzed using the same methods described above and densities with statistical limits determined.

\section{Jackrabbits and Desert Cottontail Sampling}

Numerous methods have been used to estimate the density of jackrabbits (Lepus californicus) and cottontails (Sylvilagus audubonii). Pellet group counts, using quadrats, is not an effective method (W.H. Conley, oral commun.). Hunter (1987) has shown that jackrabbits make special use of disturbed sites in dry weather and might repopulate larger areas during favorable (for example, wetter) seasons. In late summer or early fall, transect lines walked by one or two observers are effective for surveying rabbits. As described by Whitford (1973), observers walk a predetermined distance; when a rabbit is noted, the distance and direction of the rabbit from the observers is estimated and recorded.

\section{Landscape and Regional Scale Monitoring}

Ground measurement of permanent vegetation plots surpasses any type of imaging in accuracy, but necessarily has limited spatial scope. Therefore, many monitoring programs utilize some type of imagery to document changes at the landscape or regional scale. Repeat photography has been used worldwide to document and analyze changes in landscapes (Rodgers and others, 1984). More than 500 studies show repeat photography is an excellent means of documenting many aspects of long-term ecological and landscape change and complements other techniques (fig. 60). Aerial photography has been used to study landscape changes since it first became available in the late 1920s. However, it does not cover earlier times when many of the changes began, and its resolution generally does not allow assessment of changes in species composition. High altitude airplanes can provide imagery with high spectral resolution but low spatial resolution. Multi- 
spectral satellite imagery is an excellent way to monitor and evaluate ecosystem change, as it provides widespread spatial coverage and collects visible and non-visible spectral data. However, it can provide only limited information on changes in species composition and is only available after 1974.

\section{Repeat Ground-based Oblique Photography}

\section{Methods and Equipment Used for Repeat Photography}

Proper interpretation and analysis of repeat photography requires an understanding of the equipment and film that the original photographers used and then employing comparable equipment to take the photo match. During and since the period encompassed by the original photography used in many studies, both cameras and film have radically evolved. Pioneer photographers invariably used large-format cameras $(100 \times$ $125 \mathrm{~mm}$ images or larger), some capable of taking images as large as $180 \times 356 \mathrm{~mm}$ on glass plates designed for stereographic images on $203 \times 254 \mathrm{~mm}$ media. Before about the turn of the $20^{\text {th }}$ century, lenses did not have shutters; to expose the negative, the lens cap was removed and then replaced after a timed period. Later photographers used medium-format cameras $(60 \times 70 \mathrm{~mm}$, or slightly larger images $)$ equipped with flexible roll film. Cameras using the $35-\mathrm{mm}$ film format gradually gained favor with photographers in the middle of the $20^{\text {th }}$ century. The result is a large variation in the resolution of the original images, as well as differences in the captured visible spectrum.

The first useful images of the southwestern United States were on glass-plate negatives. This medium, which was unwieldy and fragile, nonetheless created images with high detail and minimal distortion. Flexible, translucent roll film was developed in 1889 to lower the weight of negatives as well as to provide a medium for creating enlargements. Whether glass plates or roll film was used, the photographic media was orthochromatic, and these blue-sensitive emulsions, when properly exposed for typical landscapes, severely over-exposed the sky. As a result, the images look significantly different from modern panchromatic black-and-white films.

By the early $20^{\text {th }}$ century, cameras became smaller as films gained resolution and reliability. Most photographers from this time period used medium- and large-format cameras, usually with a film size of no larger than $100 \times 125 \mathrm{~mm}$. The earliest films were cellulose-nitrate based, a flammable substance that created a fire hazard for tightly rolled films. Photographic manufacturers started to replace nitrate film with cellulose acetate film in the 1920s. Color film was introduced in the 1920s, although the first color films were unstable and faded; development of Kodachrome films in the mid- $20^{\text {th }}$ century provided a stable and archival color film, if stored properly. Polyester-based films, introduced in the 1960s, are the predominant type in use today.

To replicate historical views, we recommend the use of medium-format $(60 \times 90 \mathrm{~mm})$ and large-format $(100 \times 125$ $\mathrm{mm}$, aka $4 \times 5$ ) cameras, equipped with a variety of lenses.
These formats provide higher film resolution than typical 35-mm camera systems and are more comparable with historical cameras. Most medium-format cameras use roll film, which makes them very convenient, whereas large format cameras use $100 \times 125 \mathrm{~mm}$ sheet film. We suggest that each replicated view be documented with black-and-white negative, color positive, and color negative films. Filters, typically Wratten Yellow 8, may be used with black-and-white film as a haze filter to increase contrast and bring out background scenery. Color film, not used by most of the original photographers, primarily adds current information for future interpretation of changes. Film should be stored in acid-free media in an environment with controlled temperature and humidity.

At present, digital cameras may be a potential replacement for film cameras. Digital photography offers several advantages, including no cost for film, immediate evaluation of composition and lighting, and the potential for immediate printing of the match view for in-field analysis. On the other hand, digital photography cannot be considered to be archival at the present time, owing to lack of archival digital mediaCDs may only have a reasonable life-expectancy of decadesand the likelihood of technology transfer to a different medium in the future. High-quality digital cameras currently equal the resolution of a good 35-mm camera, and will undoubtedly soon equal the quality of a medium- and large-format film camera. Large format digital cameras are currently expensive and not a reasonable alternative to film, but digital camera technology is rapidly evolving and will likely become a viable option in the future.

Repeat photography offers some technical difficulties in closely occupying the original camera position, making an acceptable match, and then assessing changes (Rodgers and others, 1984). In the field, it is essential to relocate the original camera position as accurately as possible. Sometimes this is difficult owing to landscape changes, obstruction of the view by vegetation growth, lack of background features, or loss of the original camera station due to road or other construction. When possible, duplication of lighting, shadows, and condition of perennial vegetation as depicted in the original photograph is desirable; however, logistics of repeat photography for many sites are not amenable to even duplication of the original seasons for many photographs, although this usually is not a major limitation. Camera stations are documented using hand-held global-positioning-system devices (latitude, longitude, elevation, and estimated position error), the geometry of the view (camera height, azimuth, and tilt), the camera settings (shutter speed, f-stop, and film type; Hall, 2002a, $2002 \mathrm{~b}$ ), and date and time. It is also useful to record general atmospheric conditions (hazy, cloudy, etc.).

\section{Sources of Historical Photography}

Historical photographs can be obtained from many archives and private individuals. The following archives are particularly good sources of historical photographs of the Mojave Desert: the Bancroft Library, University of California 
at Berkeley; the Arizona Historical Society, Tucson; Special Collections and the Homer Shantz Collection, University of Arizona, Tucson; Cline Library, Special Collections and Archives, Northern Arizona University, Flagstaff; the Museum of Vertebrate Ecology, University of California at Berkeley; the National Geographic Society, Washington, D.C.; the Southwest Museum in Los Angeles; the Marriott Library, University of Utah, Salt Lake City; the Huntington Library, San Marino. Table 4 lists Web sites and archives where historical photography of the Mojave Desert can be obtained.

Several Federal government archives have extensive photographic archives. These include the U.S. Geological Survey (USGS) Photographic Library in Denver, Colorado; the National Archives and Records Administration in College Park, Maryland; the Bureau of Land Management; and the National Park Service Historic Graphic Collection, Harpers Ferry Center, Harpers Ferry, West Virginia.

\section{Image Analysis}

Repeat photography has been used to extract qualitative and quantitative data on landscape changes. The most powerful uses involve large numbers of photographs with extraction of simple qualitative or quantitative data on either presence-absence of features or count statistics of readily interpretable features. Examples of applications include estimating mortality and recruitment rates of perennial vegetation (Bowers and others, 1995), documenting the occurrence of debris flows (Webb and others, 1999), calculating the probability of debris-flow occurrence (Griffiths and others, 2004), and documenting large-scale changes in landscapes (Turner and others, 2003; Webb and others, 2004). Use of repeat photography in association with permanent plots is particularly useful for qualitatively verifying plot data and extending change detection over the larger landscape (Webb and others, 2003).

The oblique ground images generally used for repeat photography present a challenge to using computers for change analysis. If digital analysis is desired, the best imagery would have little information in the foreground and most of the information on slopes facing the camera. Although rubber-sheet rectification has been applied to downward-looking repeat photography (Webb and others, 1999), the most appropriate analysis would appear to be relative change between images.

Table 4. Archives and Web sites from which historical photography of the Mojave Desert can be obtained.

\begin{tabular}{|c|c|}
\hline Archive or repository & URL for web access \\
\hline Arizona Historical Foundation & None \\
\hline Bancroft Library & http://sunsite.berkeley.edu/CalHeritage/ \\
\hline Death Valley National Park & None \\
\hline Desert Laboratory Repeat Photography & http://geography.wr.usgs.gov/mojave/time-series/ \\
\hline Harold Wright Collection & none \\
\hline National Archives and Record Service & http://www.archives.gov/research_room/arc/ \\
\hline Nevada Historical Society & http://dmla.clan.lib.nv.us/docs/museums/reno/his-soc.htm \\
\hline Nevada State Historical Society & http://dmla.clan.lib.nv.us/docs/museums/lv/vegas.htm \\
\hline Northern Arizona University Cline Library & http://www.nau.edu/library/speccoll/index.html \\
\hline Shantz Collection (University of Arizona Herbarium) & None \\
\hline Southwest Museum/Autry National Center & http://www.autrynationalcenter.org/collections/ \\
\hline University of Wisconsin: Golda Meier Library & http://www.uwm.edu/Libraries/special/ \\
\hline U.S. Geological Survey Photographic Library & http://libraryphoto.cr.usgs.gov/ \\
\hline Smithsonian Institution & http://www.siris.si.edu/ \\
\hline Denver Public Library & http://photoswest.org/presearch.html \\
\hline Online Archive of California (searches multiple archives) & http://www.oac.cdlib.org/ \\
\hline Bureau of Land Management & http://www.photos.blm.gov/his_imsearch.html \\
\hline Harpers Ferry Center, National Park Service & http://data2.itc.nps.gov/hafe/hfc/npsphoto2.cfm \\
\hline Arizona Archives Online (searches multiple archives) & http://aao.lib.asu.edu/index.html \\
\hline $\begin{array}{l}\text { Library of Congress American Memory Project (searches } \\
\text { multiple archives) }\end{array}$ & http://lcweb2.loc.gov/ammem/browse/ \\
\hline
\end{tabular}



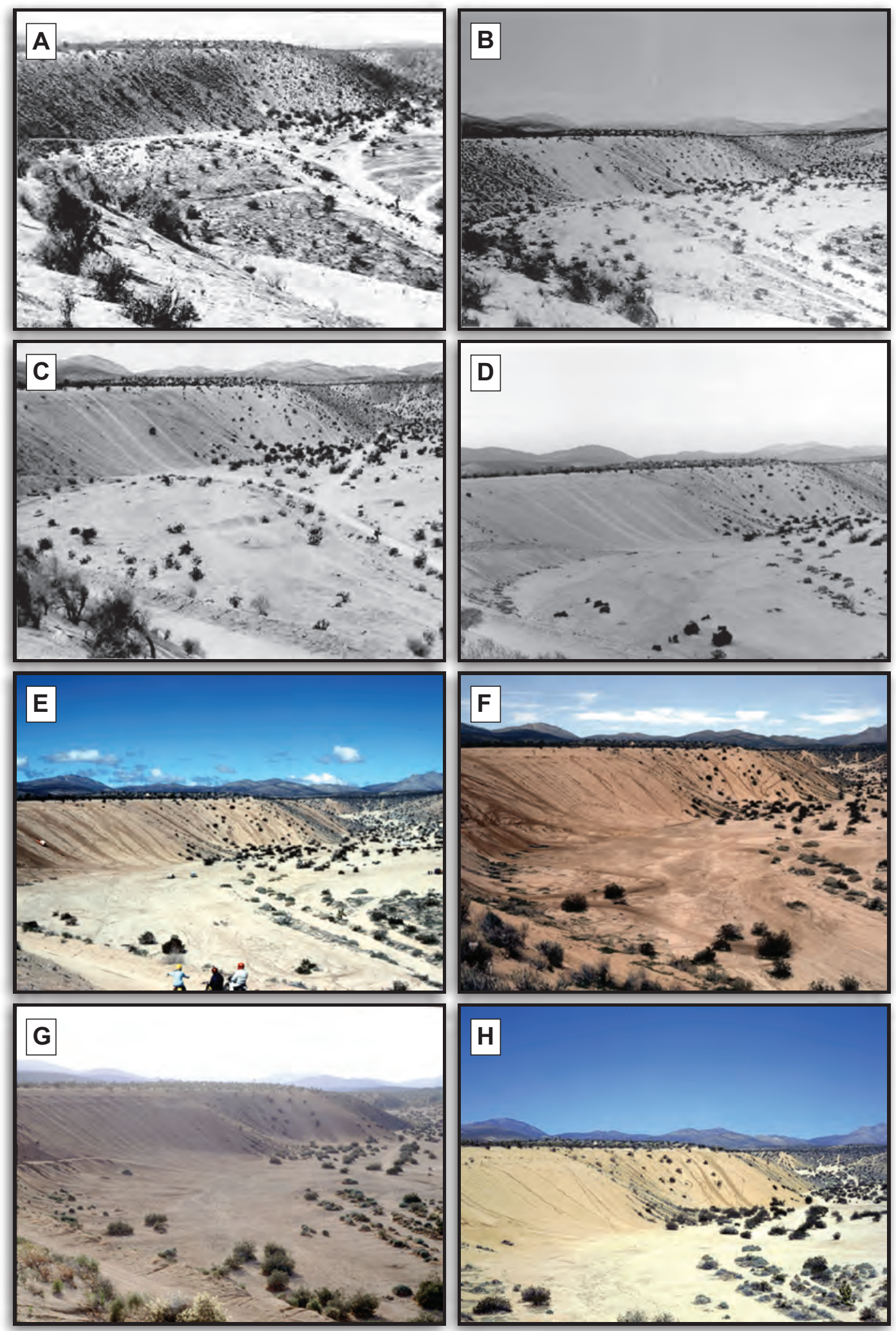

Figure 60. An example of repeat photography in the Mojave Desert. A, In 1968, Dove Spring Canyon, in the western Mojave Desert, had limited off-road vehicle use in the general location of the Los Angeles Aqueduct corridor (Bureau of Land Management photograph). This photograph shows hillslopes relatively undisturbed but with initial hillclimbs. Changes in the landscape are documented in subsequent photographs: B, 1970 (Bureau of Land Management photograph); C, 1972 (Bureau of Land Management photograph); D, 1976 (U.S. Geological Survey photograph by R. Webb); E, 1978 (U.S. Geological Survey photograph by R. Webb); F, 1983 (U.S. Geological Survey photograph by R. Webb); G, 1992 (photograph by H.W. Wilshire); H, 1999 (U.S. Geological Survey photograph by R. Webb). 
Because percentage change is strongly affected by the distance of an object into the view, repeat photography with a large foreground component cannot be easily analyzed using digital image processing, but requires manual evaluation.

\section{Airborne Remote Sensing}

\section{Aerial Mapping Photography}

Aerial photography is used to assess a variety of landscape elements and changes and is the standard tool for geologic, soil, and vegetation mappers. This data is extremely useful for change detection (fig. 61) and particularly to document recovery from disturbance or other long-term changes, such as channel narrowing in washes (Hereford and others, 2006). From its humble beginnings during the early $20^{\text {th }}$ century with oblique aerial images, vertical aerial mapping photography of high quality became commonly available over large areas in the 1930s. Commissioned by the Soil Conservation Service (now the Natural Resources Conservation Service), early black-and-white photographs generally were taken over either agricultural areas or high-value rangelands, and the imagery is stored at the National Archives and Records Service in College Park, Maryland.

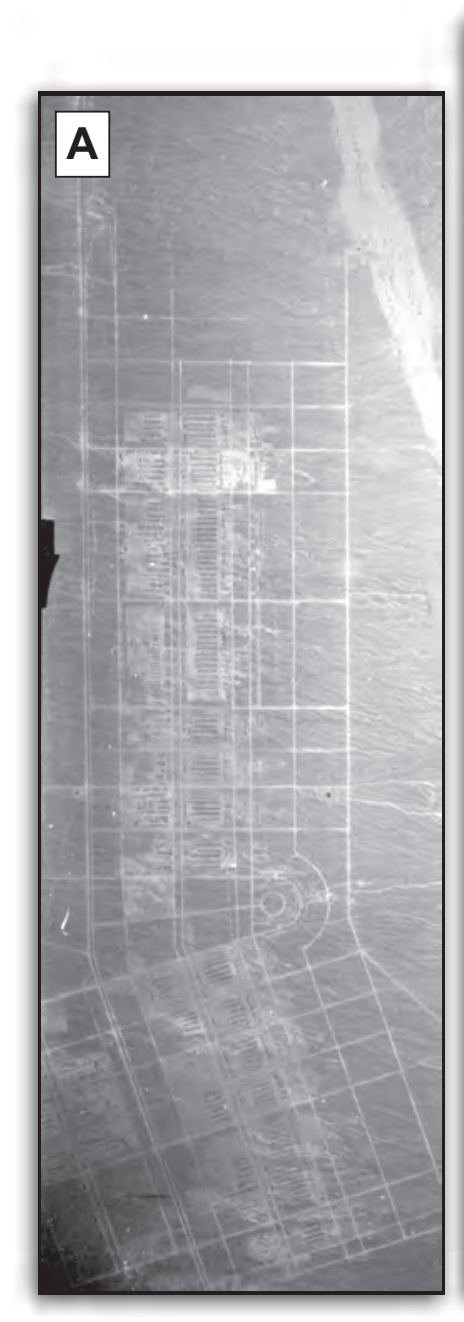

Depending upon location, aerial photography may be available for every decade of the $20^{\text {th }}$ century after 1940 . These aerial photographs are available in color, black-and-white, and color infrared formats from a wide variety of Federal government agencies or private archives. The USGS has developed the National Aerial Photography Program (NAPP), which supplies aerial photography taken by a consortium of agencies. The program, which began in 1987, provides cloud-free photography for the entire United States at a scale of 1:40,000 per $229 \times 229 \mathrm{~mm}$ image taken on a period of 5 to 7 year cycles. Larger and smaller scale imagery is also available from the Earth Resources Observation and Science (EROS) data center of the USGS, although the images are currently only available as digital scans, not as photographic prints. The Bureau of Land Management and National Forest Service are better sources for photographic prints that are superior for stereoscopic analysis.

Digital orthophoto quarter quadrangles (DOQQs) are aerial photographs that have been scanned and rectified to eliminate distortions and sized to one quarter of a standard USGS 7.5 minute quadrangle map. DOQQs interact with other data sets, such as topographic maps, and are extremely useful for digitizing of field data that are needed in a spatially referenced framework, as for GIS applications. For the southwestern United States, the aerial photography used to create the 1:24,000 DOQQs was taken between 1993 and 1995 and provides a baseline of 1-m resolution imagery for monitoring purposes. Large shrubs, such as Larrea tridentata (creosote bush), can typically be resolved in these images. Of the private archives holding aerial photography, the Fairchild Aerial Photography collection at Whittier College in Whittier, California, is one of the largest, containing 500,000 images taken between

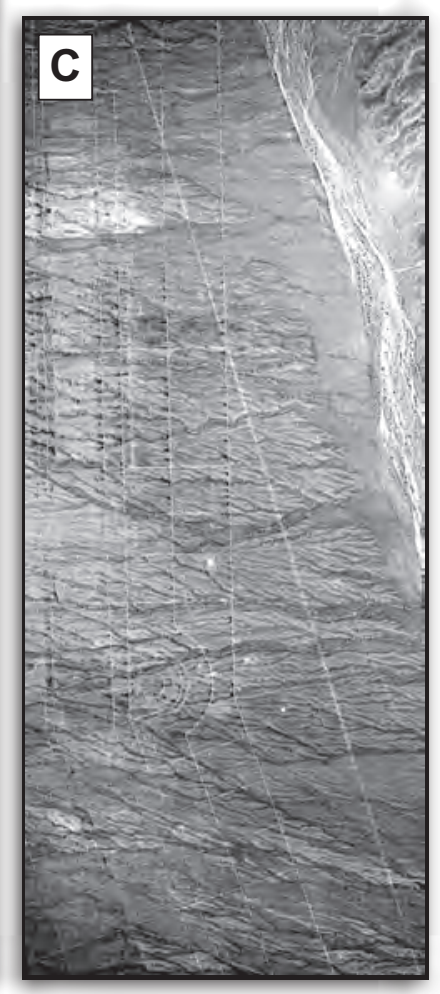
edu/fairchild/home.html). Finally, private companies frequently operate in regions of the United States, flying contract aerial imagery for government agencies or commercial companies.

Aerial photographs can be used directly to qualitatively assess changes or used

Figure 61. Aerial photographs of Camp Ibis, a World War II training camp northwest of Needles, California. A, April 1943 , shortly before the camp was abandoned (U.S. Army Map Service photograph); B, April 1953 (U.S. Geological Survey photograph); C, April 1982 (U.S. Geological Survey photograph). 
quantitatively to map features of interest. These photographs contain considerable distortion, particularly on their edges, and photogrammetric techniques are necessary to remove this distortion and to make aerial photography directly compatible with maps. Several image-processing software packages provide the capability of the simplest form of rectification, informally called "rubber sheeting." Control points are identified on an image, and computer software is used to digitally stretch the image to a best fit of the control points. More sophisticated rectification, as used on DOQQs, involves careful calculations using data on the camera focal length and other characteristics, the photograph's fiducial marks on all four sides, and control points within the image to rectify the view. Alternatively, features mapped on aerial photographs can be readily digitized by "heads up" methods on DOQQs to remove distortion. The most sophisticated software can create digital elevation models (DEMs) from overlapping aerial photography, allowing extraction of quantitative data from the imagery.

Use of aerial photography should be an integral part of a monitoring program in the Mojave Desert, but use of photography requires careful planning. Low-level photography flights or balloon (fig. 62) and kite photography may be necessary to get sufficient resolution for desert plants, and use of groundsurveyed targets typically is required to perform high-quality rectifications. Careful planning for data acquisition should focus on the expected use and accuracy of the data acquired from aerial photographs, particularly if historical imagery taken with cameras of unknown characteristics are compared with recently obtained imagery.

\section{Aircraft-borne Multispectral Scanners}

NASA has developed several imagers that are flown on specialized aircraft, including color infrared, MASTER thermal infrared, and multispectral scanners. Of these, the most useful is the Airborne Visible Infrared Imaging Spectrometer (AVIRIS) developed in 1987. AVIRIS uses 224 continuous spectrum channels, making it the spectral sensor with the largest detection range. This device has an 18-m pixel and is particularly useful for identifying soil major cation chemistry, clay mineralogy, and vegetation. AVIRIS has also been used to evaluate vegetation change and the effects of grazing (for example, Harris and others, 2003). Although AVIRIS is a useful tool for site-specific studies where substrate characterization, in particular, is a necessary component of a monitoring program, it is extremely expensive.

\section{Satellite-based Remote Sensing}

For regional information, data obtained from remote sensing provides consistent information over large areas and provides valuable temporal and geospatial perspectives on ecosystem changes. In particular, remote sensing provides retrospective data that can be used to study past effects of land use or climatic variation, validate long-term site conditions of potential permanent monitoring points, and improve the ability to scale up plot information to larger areas.

The rapid increase in the number of different types of remote-sensing platforms and sensors in the last few decades

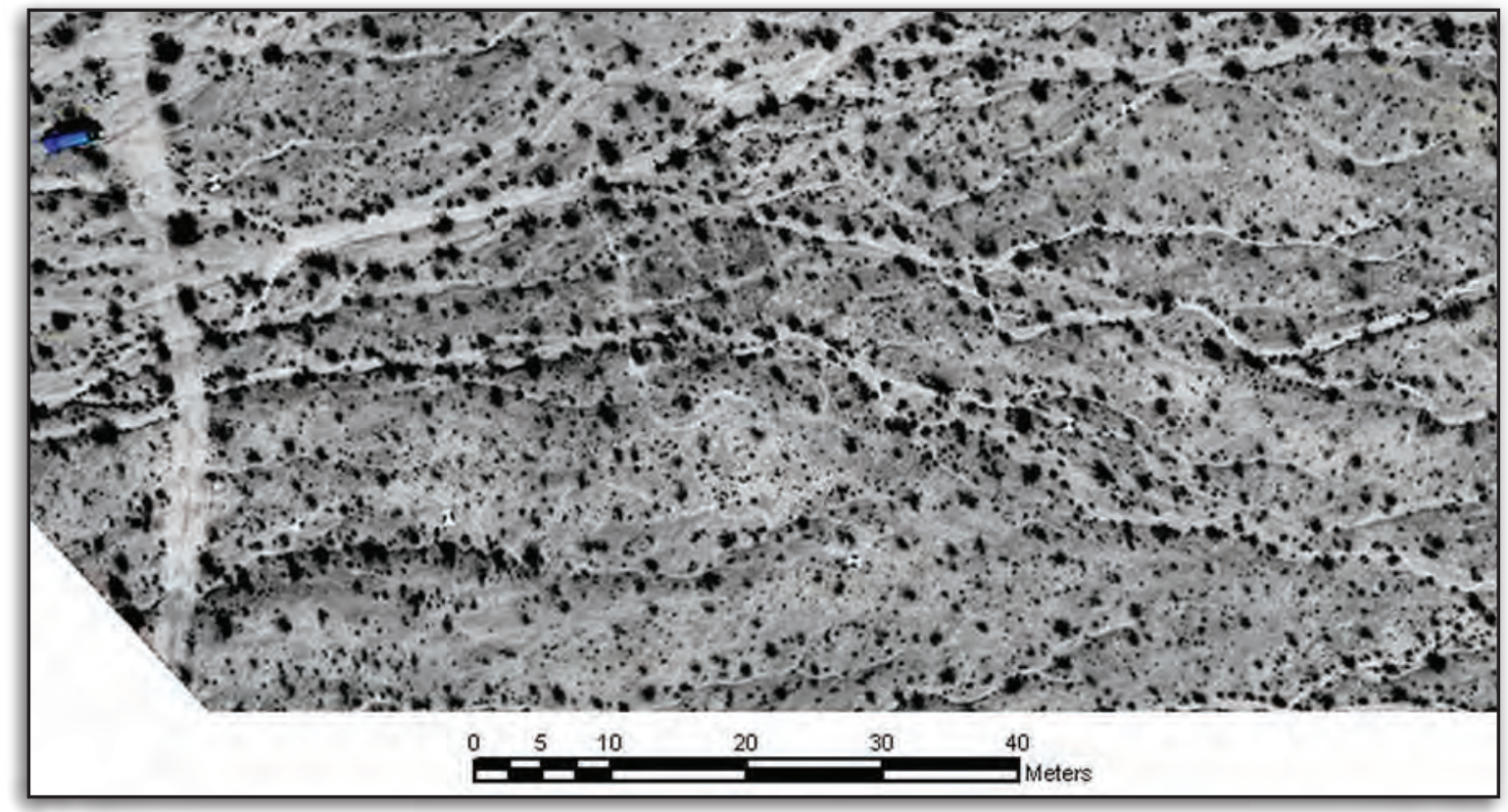

Figure 62. Piedmont photo-mosaic (taken by balloon, Mojave National Preserve) depicting soil and plant patterns. Bright green plants are Larrea tridentata (creosote bush); pale and smaller plants are Ambrosia dumosa (white bursage). Pale lines running right to left are stream channels (downhill to left); broad pale line is a dirt road with blue vehicle parked next to it. Note the larger L. tridentata adjacent to channels. Detailed plot studies have demonstrated that plant pattern varies with age of deposit and associated soils (S. Robinson, U.S. Geological Survey, unpub. data). 
makes any review of remote sensing beyond the scope of this report. Here, we focus on the types of remotely sensed data that are most likely to be used to monitor long-term ecosystem quality and change over the continental United States. This imagery either is visual (color or black and white) or multispectral. We do not discuss radar platforms, although these clearly have significant applications for topographic mapping or change detection, or imagery from spy satellites, which may be declassified and available for certain regions. The information presented in this section is gleaned from Web pages for the National Aeronautics and Space Administration (NASA) (http://www.nasa.gov), the Jet Propulsion Laboratory (http:// www.jpl.nasa.gov), the USGS (http://www.usgs.gov), or the National Oceanic and Atmospheric Administration (http:// www.noaa.gov).

Although photographs were taken by TIROS-1 in 1960 and during the Apollo missions of the 1960s and early 1970s, satellite remote sensing began with the launch of the Landsat-1 satellite in 1972 (fig. 63). Landsat-1 had a multispectral scanner capable of recording four spectral frequencies at an 80-m resolution and one panchromatic band at 40-m resolution. With the launch of Landsat-4 in 1982, the Thematic Mapper (TM), a multispectral scanning radiometer, was introduced with seven spectral bands and a 30-m resolution. Currently,

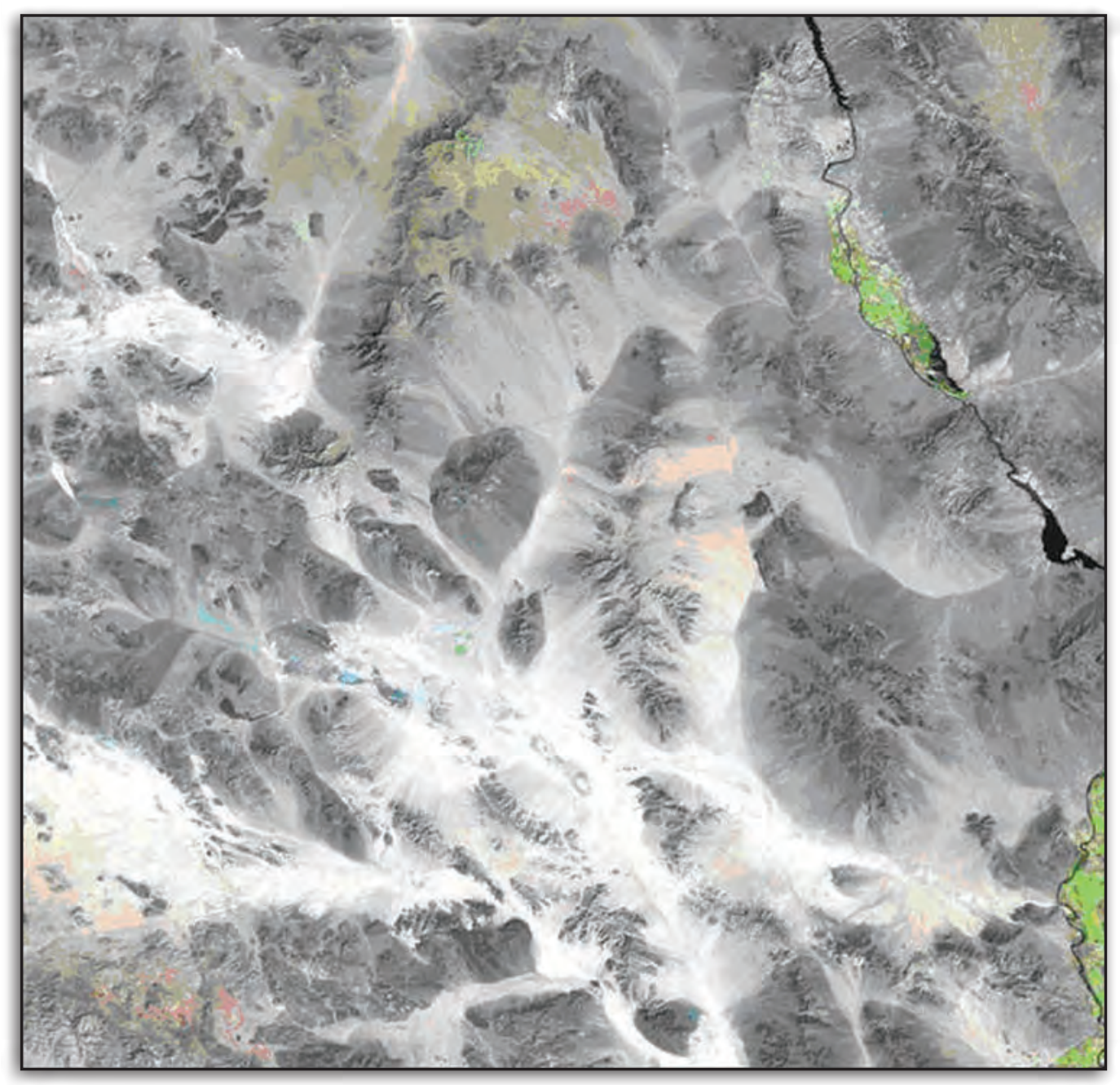

Landsat-7, launched in 1999, is the most advanced satellite in this series of remote-sensing platforms, with the Enhanced Thematic Mapper Plus (ETM+) multispectral scanner with a highest resolution of $15 \mathrm{~m}$ (panchromatic) and $30 \mathrm{~m}$ (most spectral bands) over a $185-\mathrm{km}$ swath width.

The North American Land Classification (NALC) imagery is a standardized set of Landsat imagery that is used for change detection or long-term assessment of site conditions (U.S. Environmental Protection Agency, 1993). This data, when used with more recent data (such as Landsat TM data), can be used to assess time-series of changes on a watershed or larger scale at 60-m resolution (Jones and others, 2001; Kepner and others, 2002). In the late 1990s, Landsat TM data were analyzed to produce the National Land Cover Data (NLCD), which provides 21 classes of land cover as determined consistently throughout the United States (http://landcover.usgs. gov). Although many land-classification types have been extracted for more humid regions, application to the Mojave Desert may be problematic, owing to the low vegetation cover. This method seems to be particularly well suited to identifying severely disturbed areas in the landscape (W.H. Kepner, U.S. Environmental Protection Agency, oral commun.).

Privately owned satellites provide very detailed, if very expensive, satellite imagery. Satellite Pour l'Observation de la Terre (SPOT), a satellite owned by France, began in 1978. SPOT data has $10-\mathrm{m}$ resolution panchromatic and 30-m multispectral imagery. Several privately owned satellites with high resolution have been launched in the last decade. IKONOS 1, launched in September, 1999, has a 1 -m resolution with its panchromatic camera and 4-m resolution with its 4-channel multispectral scanner. Quickbird, launched in 2001 (http:// www.digitalglobe.com), has a resolution of about $0.60 \mathrm{~m}$ for panchromatic imagery and

Figure 63. Landsat Thematic Mapper (TM) image of part of the Mojave Desert ecoregion taken in 1997. The Colorado River appears on the right; Lake Mohave is at the top, and the Palo Verde Valley near Blythe, California, is at lower right. The Colorado River Aqueduct is shown crossing the center of the view from right to left (U.S. Geological Survey photograph). 
$2.4 \mathrm{~m}$ for multispectral imagery. This platform, in particular, has the desirable characteristics of sub-meter resolution, quick response, and large frame imagery, and is being increasingly used for large-scale monitoring efforts.

Two other satellite platforms provide lower resolution data that are extremely useful for monitoring of vegetation status. In 1999, NASA launched the Earth Observing System (EOS) satellite named Terra; a second satellite called EOSAqua was launched in 2002. These satellites have Moderate Resolution Imaging Spectroradiometers (MODIS) as primary instruments designed to monitor vegetation (fig. 64). When both satellites operate in concert, daily imagery is obtained, and the principal products are 16-day averages at a resolution of $250 \mathrm{~m}$. The Advanced Very High Resolution Radiometer (AVHRR) is a satellite-based platform for relatively low resolution (1.1 km² per pixel) launched in 1978. AVHRR data are especially well suited for large-scale analyses of vegetation change (Zhou and others, 2001) but may have little ability to resolve changes in regions like the Mojave Desert, where vegetation biomass is low. Advanced Spaceborne Thermal Emission Radiometer (ASTER) imagery (http://asterweb.jpl.nasa.gov/) is free and presents several bands in the thermal infrared spectrum at 90-m resolution; it is useful for identifying broad vegetation patterns and largescale geomorphic change.
Satellite imagery is useful for several applications related to monitoring of the Mojave Desert. While sensing of perennial and annual vegetation cover remains difficult, new approaches are yielding positive results. Perennial plant cover may be successfully modeled with a combination of MODIS and TM data (Wallace and others, 2008), and annual plant production during good rainfall years can be detected with TM, yielding information on spatial variability of rainfall ( $\mathrm{P}$. Chavez, USGS, pers. commun.) and plant response. Change detection has been used to document the expansion of development in Clark County of southern Nevada (W.H. Kepner, U.S. Environmental Protection Agency, written commun.). Ikonos imagery has been used in the vicinity of Palm Springs, California to map eolian sand distributions where endangered species may live (C. Barrows, oral commun.). As the highresolution commercial data become more readily available, satellite-based remotely sensed data will increasingly be used to scale plot information to regional scales, and therefore play a large role in monitoring of change in the Mojave Desert.

\section{Comparison of Landscape-scale Monitoring Techniques}

The four landscape-scale monitoring techniques discussed in this section-land-based repeat photography, aircraft-based aerial photography, aircraft-based remote sensing, and satellite-based remote sensing - offer significantly different options. Satellite-based remote sensing provides a consistent data set for large landscape areas, making it the best value for regional monitoring. Satellite-based remote sensing has significant limitations,

Figure 64. Moderate Resolution Imaging Spectroradiometers (MODIS) image showing the Enhanced Vegetation Index (EVI), a multispectral representation that reflects vegetation cover (Wallace and others, unpub. data), composited over the period of May 25 to June 9, 2001, for the Mojave National Preserve. High EVI values indicate greater vegetation cover of annuals and perennials (from Wallace and others, 2008). 
including a relatively short (30-year) record that precludes significant retrospective analysis, general lack of ability for species-specific monitoring except for large plants or monospecific stands, and an ever-evolving technology that is not necessarily backward compatible. Future changes in remotesensing technology will undoubtedly improve this monitoring technique and increase its relevance to site-specific monitoring. Aircraft-based remote sensing tends to be the most expensive, but this platform can provide extremely valuable one-time data, whether it is AVIRIS data for detailed, sitespecific study or Lidar (Light Detection and Ranging; http:// www.csc.noaa.gov/products/sccoasts/html/tutlid.htm) data for high-resolution topography.

Aerial mapping photography is particularly useful when registered or rectified to remove distortion and provide a uniform scale. This readily available form of imagery should be considered an important first step in establishing plot-level monitoring, because aerial photography, particularly when used to develop time series, can identify past disturbances or other factors that may enhance or diminish the relevance of a specific site to a monitoring program. Likewise, repeat photography is very useful when historical photography is available. Although this technique is superior to the others for documenting species-specific changes-particularly subtle ones-over long time periods, the limited amount of historical photography makes this technique less useful in many areas. However, a search for historical photography might be a useful starting point when planning a monitoring program. The Quickbird satellite-based imagery platform may eventually replace aerial photography, particularly if its resolution continues to improve.

The ideal monitoring program would utilize most, if not all, of these techniques for maximum effectiveness. Because repeat photography is superior at documenting antecedent conditions and long-term change, this technique is invaluable for establishing monitoring locations, as well as setting an agenda for those attributes and processes that would be more likely to change in the future. Aerial mapping photography is invaluable for delineating geomorphic surfaces, mapping vegetation, validating sites for large-scale land-use effects, and for determining representation of a site to the broader landscape. Finally, the various remotely sensed ecosystem characteristics, whether through aircraft- or satellite-borne sensors, should be an integral part of most monitoring programs in the Mojave Desert.

\section{Acknowledgments}

The authors thank the many individuals who have helped with ongoing monitoring and research in the Mojave Desert. These individuals include Diane Boyer, Sara Scoles, Sue Phillips, Peter Griffiths, Dustin Haines, Marilyn Murov, David Bedford, Kevin Schmidt, Sara Robinson, and Elizabeth Deliso. Raymond Turner helped start widespread repeat photography in the Mojave Desert, and Dominic Oldershaw has helped to perfect the technique, particularly as it is applied to the Mojave Desert. John Steiger helped with our discussion of the legal basis for land management in the Mojave Desert. Katie Coulson and Tina Kister helped to prepare the manuscript. We thank numerous people for critically reviewing this manuscript. This work was funded by the Research on the DOI Landscape (in the Western Region) and the Priority Ecosystem Science's Recovery and Vulnerability of Desert Ecosystems program of the USGS.

\section{References}

Abrahams, A.D., and Parsons, A.J., 1994, Hydraulics of interrill overland flow on stone-covered desert surfaces: Catena, v. 23 , no. $1-2$, p. 111-140.

Ackerman, T.L., and Bamberg, S.A., 1974, Phenological studies in the Mojave Desert at Rock Valley (Nevada Test Site), in Lieth, H., ed., Phenology and seasonality modeling: New York, Springer-Verlag, p. 215-226.

Adams, J.A., Stolzy, L.H., Endo, A.S., Rowlands, P.G., and Johnson, H.B., 1982, Desert soil compaction reduces annual plant cover: California Agriculture, v. 36, p. 6-7.

Agosti, D., and Alonso, L.E., 2000, The ALL protocol: A standard method for collection of ground-dwelling ants, in Agosti, D., Majer, J.D., Alonso, L.E., and Schultz, T.R., eds., Ants: Standard methods for measuring and monitoring biodiversity: Washington, D.C., Smithsonian Institution Press, p. 204-214.

Aguiar, M.R., and Sala, O.E., 1999, Patch structure, dynamics and implications for the functioning of arid ecosystems: Trends in Ecology and Evolution, v. 14, no. 7, p. 273-277.

Akram, M., and Kemper, W.D., 1979, Infiltration of soils as affected by the pressure and water content at the time of compaction: Soil Science Society of America Journal, v. 43, p. 1080-1086.

Allen, C.D., and Breshears, D.D., 1998, Drought-induced shift of a forest-woodland ecotone: Rapid landscape response to climate variation: Proceedings of the National Academy of Science, v. 95, no. 25, p. 14839-14842.

Allen, E.B., Rao, L.E., Steers, R.J., Bytnerowicz, A., and Fenn, M.E., in press, Impacts of atmospheric nitrogen deposition on vegetation and soils at Joshua Tree National Park, in Webb, R.H., Fenstermaker, L.F., Heaton, J.S., Hughson, D.L., McDonald, E.V., and Miller, D.M., eds., The Mojave Desert: Ecosystem processes and sustainability: Reno, Nevada, University of Nevada Press. 
Allen, L.H., Jr., Drake, B.G., Rogers, H.H., and Shinn, J.H., 1992, Field techniques for exposure of plants and ecosystems to elevated $\mathrm{CO}_{2}$ and other trace gases: Critical Reviews in Plant Sciences, v. 11, no. 2-3, p. 85-119.

Allison, L.E., and Moodie, C.D., 1965, Carbonate, in Black, C.A., ed., Methods of soil analysis, part 2-Chemical and microbiological properties: Madison, Wis., American Society of Agronomy, p. 1379-1396.

Alloway, B.J., and Tills, A.R., 1984, Copper deficiency in world crops: Outlook on Agriculture, v. 13, no. 1, p. 32-34.

Allred, D.M., Beck, D.E., and Jorgensen, C.D., 1963, Biotic communities of the Nevada Test Site: Brigham Young University Bulletin, Biology Series, v. 2, no. 2, p. 1-52.

Alonso, L.E., and Agosti, D., 2000, Biodiversity studies, monitoring, and ants-An overview, in Agosti, D., Majer, J.D., Alonso, L.E., and Schultz, T.R., eds., Ants-Standard methods for measuring and monitoring biodiversity: Washington, D.C., Smithsonian Institution Press, p. 1-9.

Alward, R.D., Detling, J.K., and Milchunas, D.G., 1999, Grassland vegetation changes and nocturnal global warming: Science, v. 283 , no. 5399 , p. 229-231.

Andersen, A.N., and Majer, J.D., 2004, Ants show the way Down Under: Invertebrates as bioindicators in land management: Frontiers in Ecology and Environment, v. 2, no. 6, p. 291-298.

Anderson, D.R., Burnham, K.P., Lubow, B.C., Thomas, L., Corn, P.S., Medica, P.A., and Marlow, P.W., 2001, Field trials of line transect methods applied to estimation of desert tortoise abundance: Journal of Wildlife Management, v. 65, no. 3 , p. 583-597.

Angerer, J., Ostler, W.K., Gabbert, W.D., and Schultz, B.W., 1994, Secondary plant succession on disturbed sites at Yucca Mountain, Nevada. Technical Report EGG-112651118: Springfield, Va., National Technical Information Service, $74 \mathrm{p}$.

Ankeny, M.D., Kaspar, T.C., and Horton, R., 1988, Design for an automated tension infiltrometer: Soil Science Society of America Journal, v. 52, p. 893-896.

Archer, S., and Stokes, C., 2000, Stress, disturbance and change in rangeland ecosystems, in Arnalds, O., and Archer, S., eds., Rangeland desertification: Dordrecht, The Netherlands, Kluwer Academic Publishers, p. 17-38.

Asner, G.P., Seastedt, T.R., and Townsend , A.R., 1997, The decoupling of terrestrial carbon and nitrogen cycles: BioScience, v. 47, no. 4, p. 226-234.
Austin, A.T., Yahkjian, M.L., Stark, J.M., Belnap, J., Porporato, A., Norton, U., Ravetta, D., and Shaeffer, S.M., 2004, Water pulses and biogeochemical cycles in arid and semiarid ecosystems: Oecologia, v. 141, no. 2, p. 221-235.

Avery, H.W., 1998, Nutritional ecology of the desert tortoise (Gopherus agassizii) in relation to cattle grazing in the Mojave Desert: Los Angeles, Calif., University of California, Ph.D. dissertation, $158 \mathrm{p}$.

Barber, S.A., 1995, Soil nutrient bioavailability (2nd ed.): New York, John Wiley and Sons, 434 p.

Barger, N.N., Herrick, J.E., Van Zee, J., and Belnap, J., 2006, Impacts of biological soil crust disturbance and composition on $\mathrm{C}$ and $\mathrm{N}$ loss from water erosion: Biogeochemistry, v. 77 , no. 2, p. 247-263.

Barrow, J.R., and Osuna, P., 2002, Phosphorus solubilization and uptake by dark septate fungi in fourwing saltbush, Atriplex canescens (Pursh) Nutt: Journal of Arid Environments, v. 51 , no. 3 , p. $449-459$.

Baskin, C.C., and Baskin, J.M., 1998, Seeds: Ecology, biogeography, and evolution of dormancy and germination: New York, Academic Press, 666 p.

Beatley, J.C., 1966, Ecological status of introduced brome grasses (Bromus spp.) in desert vegetation of southern Nevada: Ecology, v. 47, no. 4, p. 548-554.

Beatley, J.C., 1967, Survival of winter annuals in the northern Mojave Desert: Ecology, v. 48, no. 5, p. 745-750.

Beatley, J.C., 1969, Dependence of desert rodents on winter annuals and precipitation: Ecology, v. 50, no. 4, p. 721-724.

Beatley, J.C., 1974, Phenological events and their environmental triggers in Mojave Desert ecosystems: Ecology, v. 55, no. 4, p. 856-863.

Beatley, J.C., 1976, Vascular plants of the Nevada Test Site and central-southern Nevada: Ecologic and geographic distributions: Springfield, Va., National Technical Information Service, TID-26881, $308 \mathrm{p}$.

Beatley, J.C., 1980, Fluctuations and stability in climax shrub and woodland vegetation of the Mojave, Great Basin and transition deserts of southern Nevada: Israel Journal of Botany, v. 28, p. 149-168.

Bedford, D.R., 2003, Surficial and bedrock geologic map database of the Kelso 7.5 minute quadrangle, San Bernardino County, California, scale 1:24,000: U.S. Geoogical Survey Open-File Report [http://geopubs.wr.usgs.gov/open-file/ of03-501/]. 
Bedford, D.R., Miller, D.M., and Phelps, G.A., 2006, Preliminary surficial geologic map database of the Amboy $30 \times 60$ minute quadrangle, California: U.S. Geoogical Survey Open-File Report 2006-1165 [http://pubs.usgs.gov/ of/2006/1165/].

Bedford, D.R., Miller, D.M., Schmidt, K.M., and Phelps, G.A., in press, Landscape-scale relationships between surficial geology, soil texture, topography, and creosote bush size and density in the eastern Mojave Desert of California, in Webb, R.H., Fenstermaker, L.F., Heaton, J.S., Hughson, D.L., McDonald, E.V., and Miller, D.M., eds., The Mojave Desert: Ecosystem processes and sustainability: Reno, Nev., University of Nevada Press.

Bell, K.L., Hiatt, H.D., and Niles, W.E., 1979, Seasonal changes in biomass allocation in eight winter annuals of the Mojave Desert: Journal of Ecology, v. 67, no. 3, p. 781-787.

Belnap, J., 1997, Cryptobiotic soils-Holding the place in place; U.S. Global Change Research Program, Impact of Climate Change and Land Use in the Southwestern United States, a Web-based Workshop: [http://geochange.er.usgs. gov/sw/impacts/biology/crypto/].

Belnap, J., 2002, Nitrogen fixation in biological soil crusts from southeast Utah, USA-Biology and Fertility of Soils, v. 35 , no. 2 , p. $128-135$.

Belnap, J., 2003a, Comparative structure of physical and biological soil crusts, in Belnap, J., and Lange, O.L., eds., Biological soil crusts-Structure, function, and management (2nd ed.): Berlin, Springer-Verlag, Ecological Studies Series 150, p. 177-191.

Belnap, J., 2003b, Microbes and microfauna associated with biological soil crusts, in Belnap, J., and Lange, O.L., eds., Biological soil crusts-Structure, function, and management (2nd ed.): Berlin, Springer-Verlag, Ecological Studies Series 150, p. 167-174.

Belnap, J., 2003c, Factors influencing nitrogen fixation and nitrogen release in biological soil crusts, in Belnap, J., and Lange, O.L., eds., Biological soil crusts-Structure, function, and management (2nd ed.): Berlin, Springer-Verlag, Ecological Studies Series 150, p. 241-261.

Belnap, J., and Eldridge, D., 2003, Disturbance and recovery of biological soil crusts, in Belnap, J., and Lange, O.L., eds., Biological soil crusts-Structure, function, and management (2nd ed.): Berlin, Springer-Verlag, Ecological Studies Series 150, p. 363-383.

Belnap, J., and Lange, O.L., eds., 2003, Biological soil crusts-Structure, function, and management (2nd ed.): Berlin, Springer-Verlag, Ecological Studies Series 150, 503 p.
Belnap, J., and Phillips, S.L., 2001, Soil biota in an ungrazed grassland-Response to annual grass (Bromus tectorum) invasion: Ecological Applications, v. 11, no. 5, p. 12611275 .

Belnap, J., Phillips, S.L., and Smith, S., 2007, Dynamics of cover, UV-protective pigments, and quantum yield in biological soil crust communities of an undisturbed Mojave Desert shrubland: Flora, v. 202, no. 8, p. 674-686.

Belnap, J., Phillips, S.L., and Troxler, T., 2006, Soil lichen and moss cover and species richness can be highly dynamicThe effects of invasion by the annual exotic grass Bromus tectorum and the effects of climate on biological soil crusts: Applied Soil Ecology, v. 32, no. 1, p. 63-76.

Belnap, J., and Warren, S.D., 2002, Patton's tracks in the Mojave Desert, USA: An ecological legacy: Arid Land Research and Management, v. 16, no. 3, p. 245-258.

Belnap, J., Welter, J.R., Grimm, N.B., Barger, N.N., and Ludwig, J.A., 2005, Linkages between microbial and hydrologic processes in arid and semi-arid watersheds: Ecology, v. 86, no. 2, p. 298-307.

Bernstein, R.A., 1974, Seasonal food abundance and foraging activity in some desert ants: American Naturalist, v. 108, no. 962, p. 490-498.

Berry, K.H., Bailey, T.Y., and Anderson, K.M., 2006, Attributes of desert tortoise populations at the National Training Center, Central Mojave Desert, California, USA: Journal of Arid Environments, v. 67, supplement 1, p. 165-191.

Berry, K.H., and Turner, F.B., 1984, Notes on the behavior and habitat preferences of juvenile desert tortoises (Gopherus agassizii), Proceedings of the Eighth Annual Desert Tortoise Council Symposium, Lake Havasu City, Arizona: Las Vegas, Nev., Desert Tortoise Council, p. 111-130.

Bestelmeyer, B.T., Brown, J.R., Havstad, K.M., Alexander, R., Chavez, G., and Herrick, J.E., 2003, Development and use of state-and-transition models for rangelands: Journal of Range Management, v. 56, no. 2, p. 114-126.

Bhark, E.W., and Small, E.E., 2003, Association between plant canopies and the spatial patterns of infiltration in shrubland and grassland of the Chihuahuan Desert, New Mexico: Ecosystems, v. 6, no. 2, p. 185-196.

Billings, W.D., 1990, Bromus tectorum, a biotic cause of ecosystem impoverishment in the Great Basin, in Woodwell, G.M., ed., The Earth in transition: Patterns and processes of biotic impoverishment: Cambridge, Mass., Cambridge University Press, p. 301-322.

Birkeland, P.W., 1984, Soils and geomorphology (1st ed.): New York, Oxford University Press, 372 p. 
Bischoff, M.C., 2000, The Desert Training Center/CaliforniaArizona Maneuver Area, 1942-1944-Historical and archaeological contexts: Tucson, Ariz., University of Arizona Press, $145 \mathrm{p}$.

Blair, T.C., and McPherson, J.G., 1994, Alluvial fans and their natural distinction from rivers based on morphology, hydraulic processes, sedimentary processes, and facies assemblages: Journal of Sedimentary Research, v. 64, no. 3a, p. 450-489.

Blank, R.R., Allen, F., and Young, J.A., 1994, Growth and elemental content of several sagebrush-steppe species in unburned and post-wildfire soil and plant effects on soil attributes: Plant and Soil, v. 164, no. 1, p. 35-41.

Blake, G.R., Nelson, W.W., and Allmaras, R.R., 1976, Persistence of subsoil compaction in a mollisol: Soil Science Society of America Journal, v. 40, p. 943-948.

Boarman, W.I., Sazaki, M., and Jennings, W.B., 1997, The effect of roads, barrier fences, and culverts on desert tortoise populations in California, USA, in van Abbema, J., ed., Proceedings: Conservation, restoration, and management of tortoises and turtles; An international conference, July 11-16, 1993, State University of New York, Purchase, New York: Orange, N.J., New York Turtle and Tortoise Society, p. 54-58.

Bolling, J.D., and Walker, L.R., 2000, Plant and soil recovery along a series of abandoned desert roads: Journal of Arid Environments, v. 46, no. 1, p. 1-24.

Bolling, J.D., and Walker, L.R., 2002, Fertile island development around perennial shrubs across a Mojave desert chronosequence: Western North American Naturalist, v. 62, no. 1, p. $88-100$.

Bolton, H., Jr., Smith, J.L., and Link, S.O., 1993, Soil microbial biomass and activity of a disturbed and undisturbed shrub-steppe ecosystem: Soil Biology and Biochemistry, v. 25 , no. 5 , p. 545-552.

Bonham, C.D., Brady, W.W., and Bousquin, S.G., 1997, Ecological monitoring in Lake Mead National Recreation Area-Vegetation change and ecological risk; Report to the National Park Service: Fort Collins, Colo., Colorado State University, Rangeland Ecosystem Science Department, Report LAME-R94-0446, 31 p.

Bowers, J.E., 2005a, El Niño and displays of spring-flowering annuals in the Mojave and Sonoran deserts: Journal of the Torrey Botanical Society, v. 132, no. 1, p. 38-49.

Bowers, J.E., 2005b, Effects of drought on shrub survival and longevity in the northern Sonoran Desert: Journal of the Torrey Botanical Society, v. 132, p. 421-431.
Bowers, J.E., Webb, R.H., and Rondeau, R.J., 1995, Longevity, recruitment and mortality of desert plants in Grand Canyon, Arizona, USA: Journal of Vegetation Science, v. 6, no. 4, p. 551-564.

Bowers, M.A., 1987, Precipitation and the relative abundances of desert winter annuals-A 6-year study in the northern Mohave desert: Journal of Arid Environments, v. 12, p. 141-149.

Bowker, M.A., Belnap, J., Davidson, D.W., and Goldstein, H., 2006, Correlates of biological soil crust abundance across a continuum of spatial scales-Support for a hierarchical conceptual model: Journal of Applied Ecology, v. 43, no. 1, p. $152-163$.

Bowker, M.A., Belnap, J., Davidson, D.W., and Phillips, S.L., 2005, Evidence for micronutrient limitation of biological soil crusts: Importance to arid-lands restoration: Ecological Applications, v. 15, no. 6, p. 1941-1951.

Bowker, M.A., Reed, S.C., Belnap, J., and Phillips, S.L., 2002, Temporal variation in community composition, pigmentation, and $F_{v} / F_{m}$ of desert cyanobacterial soil crusts: Microbial Ecology, v. 43, no. 1, p. 13-25.

Brady, N.C., and Weil, R.R., 1996, The nature and properties of soils (11th ed.): Upper Saddle River, NJ, Prentice Hall, $740 \mathrm{p}$.

Bremner, J.M., 1960, Determination of nitrogen in soil by the Kjeldahl method: Journal of Agricultural Science, v. 55, p. 11-33.

Breshears, D.D., and Barnes, F.J., 1999, Interrelationships between plant functional types and soil moisture heterogeneity for semiarid landscapes within the grassland/forest continuum-A unified conceptual model: Landscape Ecology, v. 14, p. 465-478.

Breshears, D.D., Nyhan, J.W., Heil, C.E., and Wilcox, B.P., 1998, Effects of woody plants on microclimate in a semiarid woodland: Soil temperature and evaporation in canopy and intercanopy patches: International Journal of Plant Sciences, v. 159 , no. 6 , p. $1010-1017$.

Breshears, D.D., Whicker, J.J., Johansen, M.P., and Pinder III, J.E., 2003, Wind and water erosion and transport in semiarid shrubland, grassland and forest ecosystems-Quantifying dominance of horizontal wind-driven transport: Earth Surface Processes and Landforms, v. 28, p. 1189-1209.

Brian, M.V., ed., 1978, Production ecology of ants and termites: International Biological Programme 13: Cambridge, Mass., Cambridge University Press, 409 p.

Brisson, J., and Reynolds, J.F., 1994, The effect of neighbors on root distribution in a creosotebush (Larrea tridentata) population: Ecology, v. 75, no. 6, p. 1693-1702. 
Brittingham, S., and Walker, L.R., 2000, Facilitation of Yucca brevifolia recruitment by Mojave Desert shrubs: Western North American Naturalist, v. 60, no. 4, p. 374-383.

Brooks, M.L., 1999a, Habitat invasibility and dominance by alien annual plants in the western Mojave Desert: Biological Invasions, v. 1, no. 4, p. 325-337.

Brooks, M.L., 1999b, Alien annual grasses and fire in the Mojave Desert: Madroño, v. 46, no. 1, p. 13-19.

Brooks, M.L., 1999c, Effects of protective fencing on birds, lizards, and black-tailed hares in the western Mojave Desert: Environmental Management, v. 23, no. 3, p. 387-400.

Brooks, M.L., 2000, Competition between alien annual grasses and native annual plants in the Mojave Desert: American Midland Naturalist, v. 144, no. 1, p. 92-108.

Brooks, M.L., 2002, Peak fire temperatures and effects on annual plants in the Mojave Desert: Ecological Applications, v. 12, no. 4, p. 1088-1102.

Brooks, M.L., 2003, Effects of increased soil nitrogen on the dominance of alien annual plants in the Mojave Desert: Journal of Applied Ecology, v. 40, no. 2, p. 344-353.

Brooks, M.L., 2007, Effects of land management practices on plant invasions in wildland areas, in Nentwig, W., ed., Biological Invasions, Ecological Studies Series 193: Heidelberg, Germany, Springer, p. 147-162.

Brooks, M.L., in press, Spatial and temporal distribution of non-native plants in upland areas the Mojave Desert, in Webb, R.H., Fenstermaker, L.F., Heaton, J.S., Hughson, D.L., McDonald, E.V., and Miller, D.M., eds., The Mojave Desert-Ecosystem processes and sustainability: Reno, Nev., University of Nevada Press.

Brooks, M.L., and Berry, K.H., 2006, Dominance and environmental correlates of alien annual plants in the Mojave Desert, USA: Journal of Arid Environments, v. 67, supplement 1 , p. 100-124.

Brooks, M.L., D’Antonio, C.M., Richardson, D.M., Grace, J.B., Keeley, J.E., DiTomaso, J.M., Hobbs, R.J., Pellant, M., and Pyke, D., 2004, Effects of invasive alien plants on fire regimes: BioScience, v. 54, no. 7, p. 677-688.

Brooks, M.L., and Esque, T.C., 2002, Alien plants and fire in desert tortoise (Gopherus agassizii) habitat of the Mojave and Colorado Deserts: Chelonian Conservation and Biology, v. 4 , no. 2 , p. 330-340.

Brooks, M.L., and Klinger, R., in press, Practical considerations for detecting and monitoring plant invasions, in Inderjit, ed., Management of non-native invasive plant species: Heidelberg, Germany, Springer.
Brooks, M.L., and Lair, B., in press, Ecological effects of vehicular routes in a desert ecosystem, in Webb, R.H., Fenstermaker, L.F., Heaton, J.S., Hughson, D.L., McDonald, E.V., and Miller, D.M., eds., The Mojave Desert-Ecosystem processes and sustainability: Reno, Nev., University of Nevada Press.

Brooks, M.L., and Matchett, J.R., 2006, Spatial and temporal patterns of wildfires in the Mojave Desert, 1980-2004: Journal of Arid Environments, v. 67, supplement 1, p. 148-164.

Brooks, M.L., Matchett, J.R., and Berry, K.H., 2006, Effects of livestock watering sites on alien and native plants in the Mojave Desert, USA: Journal of Arid Environments, v. 67, no. Supplement 1, p. 125-147.

Brooks, M.L., and Minnich, R.A., 2006, Southeastern deserts bioregion, in Sugihara, N.G., van Wagtendonk, J.W., Fites-Kaufman, J., Shaffer, K.E., and Thode, A.E., eds., Fire in California ecosystems: Berkeley, Calif., University of California Press, p. 391-414.

Brooks, M.L., and Pyke, D.A., 2001, Invasive plants and fire in the deserts of North America, in Galley, K.E.M., and Wilson, T.P., eds., Invasive Species Workshop_-The role of fire in the control and spread of invasive species; Fire Conference 2000, the First National Congress on Fire Ecology, Prevention, and Management, Nov 27-Dec 1, 2000, San Diego, California: Tallahassee, Fla., Tall Timbers Research Station, Miscellaneous Publication 11, p. 1-14. v

Brown, D.E., and Minnich, R.A., 1986, Fire and creosote bush scrub of the western Sonoran Desert, California: American Midland Naturalist, v. 116, p. 411-422.

Brown, J.H., Grover, J., Davidson, D.W., and Lieberman, G.A., 1975, A preliminary study of seed predation in desert and montane habitats: Ecology v. 56, no. 4, p. 987-992.

Brown, J.H., and Heske, E.J., 1990, Control of a desert-grassland transition by a keystone rodent guild: Science, v. 250, no. 4988, p. 1705-1707.

Brown, J.H., Reichman, O.J., and Davidson, D.W., 1979, Granivory in desert ecosystems: Annual Review of Ecology and Systematics, v. 10, p. 201-227.

Buckland, S.T., Anderson, D.R., Burnham, K.P., and Laake, J.L., 1993, Distance sampling-Estimating abundance of biological populations: London, Chapman and Hall, 446 p.

Bureau of Land Management, 1980, Final environmental impact statement and proposed plan; appendix XIII, volume F-Livestock grazing: Riverside, Calif., Bureau of Land Management, 15-120 p. 
Burke, I.C., Lauenroth, W.K., Riggle, R., Brannen, P., Madigan, B., and Beard, S., 1999, Spatial variability of soil properties in the shortgrass steppe-The relative importance of topography, grazing, microsite, and plant species in controlling spatial patterns: Ecosystems, v. 2, no. 5, p. 422-438.

Bury, R.B., Esque, T.C., DeFalco, L.A., and Medica, P.A., 1994, Distribution, habitat use, and protection of the desert tortoise in the eastern Mojave Desert, in R.B., and Germano, D.J., eds., Biology of North American Tortoises: Washington, D.C., Technical Report 13, National Biological Survey, p. 57-72.

Bytnerowicz, A., Arbaugh, M.J., and Alonso, R., eds., 2003, Ozone air pollution in the Sierra Nevada-Distribution and effects on forests: Boston, Mass., Elsevier, 388 p.

Bytnerowicz, A., Olszyk, D.M., Fox, C.A., Dawson, P.J., Kats, G., Morrison, C.L., and Wolf, J., 1988, Responses of desert annual plants to ozone and water stress in an in situ experiment: Journal of the Air Pollution Control Association, v. 38, no. 9, p. 1145-1151.

Campbell, C.E., 1972, Some environmental effects of rural subdividing in an arid area: A case study in Arizona: Journal of Geography, v. 7, p. 147-154.

Campbell, H.W., and Christman, S.P., 1982, Field techniques for herpetofaunal community analysis, in Scott, N.J., ed., Herpetological communities: Washington, D.C., U.S. Fish and Wildlife Service, Wildlife Research Report 13, p. 193-200.

Carpenter, D.E., 1983, Old field succession in Mojave Desert scrub: Davis, Calif., University of California, M.S. thesis $112 \mathrm{p}$.

Carpenter, D.E., Barbour, M.G., and Bahre, C.J., 1986, Old field succession in Mojave Desert scrub: Madroño, v. 33, no. 2, p. 111-122.

Carroll, C.R., and Janzen, D.H., 1973, Ecology of foraging by ants: Annual Review of Ecology and Systematics, v. 4, p. 231-257.

Carter, L.M., 1967, Portable recording penetration measures soil strength profiles: Agricultural Engineering, v. 48, p. 348-349.

Cartwright, B., and Hallsworth, E.G., 1970, Effects of copper deficiency on root nodules of subterranean clover: Plant and Soil, v. 33, p. 685-698.

Chapin III, F.S., Torn, M.S., and Tateno, M., 1996, Principles of ecosystem sustainability: The American Naturalist, v. 148, no. 6, p. 1016-1037.

Charley, J.L., and West, N.E., 1975, Plant-induced soil chemical patterns in some shrub-dominated semi-desert ecosystems of Utah: Journal of Ecology, v. 63, p. 945-964.
Chesson, P., Gebauer, R.L., Schwinning, S., Huntly, N., Wiegand, K., Ernest, M.S.K., Sher, A.A., Novoplansky, A., and Weltzin, J.F., 2004, Resource pulses, species interactions, and diversity maintenance in arid and semi-arid environments: Oecologia, v. 141, no. 2, p. 236-253.

Chew, R.M., and Butterworth, B.B., 1964, Ecology of rodents in Indian Cove (Mojave Desert), Joshua Tree National Monument, California: Journal of Mammalogy, v. 45, p. 203-225.

Chew, R.M., and Chew, A.E., 1970, Energy relationships of the mammals of a desert shrub (Larrea tridentata) community: Ecological Monographs, v. 40, no. 1, p. 1-21.

Christensen, J.H., Hewitson, B., Busuioc, A., Chen, A., Gao, X., Held, I., Jones, R., Kolli, R.K., Kwon, W.-T., Laprise, R., Magaña Rueda, V., Mearns, L., Menéndez, C.G., Räisänen, J., Rinke, A., Sarr, A., and Whetton, P., 2007, Regional climate projections, in Solomon, S., Qin, D., Manning, M., Chen, Z., Marquis, M., Averyt, K.B., Tignor, M., and Miller, H.L., eds., Climate change 2007-The physical science basis; Contribution of Working Group I to the Fourth Assessment Report of the Intergovernmental Panel on Climate Change, February 2007, Paris: Cambridge, Mass., Cambridge University Press, p. 848-940.

Christensen, N.L., Bartuska, A.M., Brown, J.H., Carpenter, S., D’Antonio, C., Francis, R., Franklin, J.F., MacMahon, J.A., Noss, R.F., Parsons, D.J., Peterson, C.H., Turner, M.G., and Woodmansee, R.G., 1996, The report of the Ecological Society of America committee on the scientific basis for ecosystem management: Ecological Applications, v. 6, no. 3, p. 665-693.

Cody, M.L., 2000, Slow-motion population dynamics in Mojave Desert perennial plants: Journal of Vegetation Science, v. 11 , no. 3 , p. 351-358.

Cohen, D., 1966, Optimizing reproduction in a randomly varying environment: Journal of Theoretical Biology, v. 12, no. 1, p. 119-129.

Cole, J.E., Overpeck, J.T., and Cook, E.R., 2002, Multiyear La Niña events and persistent drought in the contiguous United States: Geophysical Research Letters, v. 29, no. 13, p. 1647.

Coleman, D.C., and Crossley Jr., D.A., 1996, Fundamentals of soil ecology: San Diego, Calif., Academic Press, Inc., 205 p.

Comanor, P.L., and Clark, W.H., 2000, Preliminary growth rates and a proposed age-form classification for the Joshua tree, Yucca brevifolia (Agavaceae): Haseltonia, v. 7, p. 37-46.

Comstock, J.P., and Ehleringer, J.R., 1992, Plant adaptation in the Great Basin and Colorado Plateau: Great Basin Naturalist, v. 52, no. 3, p. 195-215. 
Corn, P.S., 1994, Straight-line drift fences and pitfall traps, in Heyer, W.R., Donnelly, M.A., McDiarmid, R.W., C., H.L.-A., and Foster, M.S., eds., Measuring and monitoring biological diversity standard methods for amphibians: Washington, D.C., Smithsonian Institution Press, p. 109-117.

Corn, P.S., and Bury, R.B., 1990, Sampling methods for terrestrial amphibians and reptiles: Portland, Oreg., USDA Forest Service, Pacific Northwest Research Station, General Technical Report PNW-GTR-256. 34 p.

Costanza, R., Mageau, M., Norton, B., and Patten, B.C., 1998, What is sustainability?, in Rapport, D.J., Costanza, R., Epstein, P.R., Gaudet, C., and Levins, R., eds., Ecosystem health: Malden, Mass., Blackwell Science, p. 231-239.

Cottam, G., and Curtis, J.T., 1956, The use of distance measurements in phytosociological sampling: Ecology, v. 37, p. $451-460$.

Cousin, I., Nicoullaud, B., and Coutadeur, C., 2003, Influence of rock fragments on the water retention and water percolation in a calcareous soil: Catena, v. 53, p. 97-114.

Cowles, R.B., 1977, Desert journal-A naturalist reflects on arid California: Berkeley, Calif., University of California Press, 263 p.

Cramer, G.R., and Nowak, R.S., 1992, Supplemental manganese improves the relative growth, net assimilation and photosynthetic rates of salt-stressed barley: Physiologia Plantarum, v. 84, p. 600-605.

Crawford, C.S., 1988, Surface-active arthropods in a desert landscape: Influences of microclimate, vegetation and soil texture on assemblage structure: Pedobiologia, v. 32, p. 373-385.

Crist, T.O., and MacMahon, J.A., 1992, Harvester ant foraging and shrub-steppe seeds: Interactions of seed resources and seed use: Ecology, v. 73, no. 5, p. 1768-1779.

Cross, A.F., and Schlesinger, W.H., 1999, Plant regulation of soil nutrient distribution in the northern Chihuahuan Desert: Plant Ecology, v. 145, no. 1, p. 11-25.

Dale, V.H., Brown, S., Haeuber, R.A., Hobbs, N.T., Huntly, N., Naiman, R.J., Riebsame, W.E., Turner, M.G., and Valone, T.J., 2000, Ecological principles and guidelines for managing the use of land: Ecological Applications, v. 10, no. 3, p. 639-670.

D’Antonio, C.M., and Vitousek, P.M., 1992, Biological invasions by exotic grasses, the grass/fire cycle, and global change: Annual Review of Ecology and Systematics, v. 23, p. $63-87$.
Davidson, D.W., 1980, Some consequences of diffuse competition in a desert ant community: American Naturalist, v. 116, p. 92-105.

Davidson, E., and Fox, M., 1974, Effects of off-road motorcycle activity on Mojave desert vegetation and soil: Madroño, v. 22 , no. 8 , p. $381-412$.

Davidson, E.A., Matson, P.A., Vitousek, P.M., Riley, R., Dunkin, K., Garcia-Mendez, G., and Maass, J.M., 1993, Processes regulating soil emissions of $\mathrm{NO}$ and $\mathrm{N}_{2} \mathrm{O}$ in a seasonally dry tropical forest: Ecology, v. 74, no. 1, p. 130-139.

Day, A.D., and Ludeke, K.L., 1993, Plant nutrients in desert environments: Berlin, Springer-Verlag, 127 p.

de Soyza, A.G., Van Zee, J.W., Whitford, W.G., Nealè, A., Tallent-Hallsel, N., Herrick, J.E., and Havstad, K.M., 2000, Indicators of Great Basin rangeland health: Journal of Arid Environments, v. 45, no. 4, p. 289-304.

de Soyza, A.G., Whitford, W.G., Herrick, J.E., Van Zee, J.W., and Havstad, K.M., 1998, Early warning indicators of desertification: Examples of tests in the Chihuahuan Desert: Journal of Arid Environments, v. 39, no. 2, p. 101-112.

DeBano, L.F., Neary, D.G., and Ffolliot, P.F., 1998, Fire's effects on ecosystems: New York, John Wiley and Sons, Inc., $333 \mathrm{p}$.

DeFalco, L.A., 1995, Influence of cryptobiotic crusts on winter annuals and foraging movements of the desert tortoise Fort Collins, Colo., Colorado State University, M.S. thesis, $48 \mathrm{p}$.

DeFalco, L.A., 2003, Physiological ecology of the invasive annual grass, Bromus madritensis ssp. rubens, and its interaction with native Mojave Desert species: Reno, Nev., University of Nevada Reno, Ph.D dissertation, 131 p.

DeFalco, L.A., Bryla, D.R., Smith-Longozo, V.L., and Nowak, R.S., 2003, Are Mojave Desert annual species equal? Resource acquisition and allocation for the invasive grass Bromus madritensis subsp. rubens (Poaceae) and two native species: American Journal of Botany, v. 90, no. 7, p. 1045-1053.

DeFalco, L.A., Detling, J.K., Tracy, C.R., and Warren, S.D., 2001, Physiological variation among native and exotic winter annual plants associated with microbiotic crusts in the Mojave Desert: Plant and Soil, v. 234, no. 1, p. 1-14.

DeFalco, L.A., Fernandez, G.C.J., and Nowak, R.S., 2007, Variation in the establishment of a non-native annual grass influences competitive interactions with Mojave Desert perennials: Biological Invasions, v. 9, no. 3, p. 293-307. 
DeFalco, L.A., Kane, J., Nicklas, M., and Esque, T., 2005, Assessment of seed banks associated with disturbances at Fort Irwin National Training Center, California; Final report delivered to Department of Army, Integrated Training Area Management: U.S. Geological Survey, 23 p.

Degenhardt, W.G., 1966, A method of counting some diurnal ground lizards of the genera Holbrookia and Cnemidophorus with results from the Big Bend National Park: American Midland Naturalist, v. 75, p. 61-100.

Díaz, S., and Cabido, M., 2001, Vive la différence—Plant functional diversity matters to ecosystem processes: Trends in Ecology and Evolution, v. 16, p. 646-655.

Dreimanis, A., 1962, Quantitative gasometric determination of calcite and dolomite by using Chittick apparatus: Journal of Sedimentary Petrology, v. 32, p. 520-529.

Drenovsky, R.E., and Richards, J.H., 2004, Critical N:P values: Predicting nutrient deficiencies in desert shrublands: Plant and Soil, v. 259, no. 1-2, p. 59-69.

Dubach, J., 1986, Pinna tissue, a source of allozymic information: Southwestern Naturalist, v. 31, p. 419-420.

Dukes, J.S., and Mooney, H.A., 1999, Does global change increase the success of invaders?: Trends in Ecology and Evolution, v. 14, p. 135-139.

Dunkerley, D., 2000, Hydrologic effects of dryland shrubsDefining the spatial extent of modified soil water uptake rates at an Australian desert site: Journal of Arid Environments, v. 45, no. 2, p. 159-172.

Dunn, A.J., and Mehuys, G.R., 1984, Relationship between gravel content of soils and saturated hydraulic conductivity in laboratory tests, in Nichols, J.D., Brown, P.L., and Grant, W.J., eds., Erosion and productivity of soils containing rock fragments: Madison, Wis., Soil Science Society of America, Special Publication 13, p. 55-63.

Ehleringer, J.R., and Cooper, T.A., 1988, Correlations between carbon isotope ratio and microhabitat in desert plants: Oecologia, v. 76 , no. 4 , p. 562-566.

Ehleringer, J.R., Schwinning, S., and Gebauer, R., 2000, Water use in arid land ecosystems, in M.C., Scholes, J.D., and Barker, M.G., eds., Physiological plant ecology: Boston, Blackwell Science, p. 347-365.

Eldridge, D.J., and Rosentreter, R., 1999, Morphological groups: A framework for monitoring microphytic crusts in arid landscapes: Journal of Arid Environments, v. 41, p. $11-25$.

Elzinga, C.L., and Evenden, A.G., 1997 Vegetation monitoring-An annotated bibliography: Ogden, Utah, General Technical Report INT-GTR-352, USDA Forest Service, Intermountain Research Station.
Elzinga, C.L., Salzer, D.W., and Willoughby, J.W., 1998, Measuring and monitoring plant populations: Denver, Colo., Bureau of Land Management, Technical Report BLM/RS/ ST-98/005+1730, $477 \mathrm{p}$.

Ernst, C.H., and Ernst, E.M., 2003, Snakes of the United States and Canada: Washington, D.C., Smithsonian Institution Press, 668 p.

Esque, T.C., 1994, Diet and diet selection of the desert tortoise (Gopherus agassizii) in the northeast Mojave Desert: Fort Collins, Colo., Colorado State University, M.S. thesis, 243 p.

Esque, T.C., 2004, The role of fire, rodents and ants in changing plant communities in the Mojave Desert: Reno, Nev., University of Nevada Reno, Ph.D. dissertation, 168 p.

Esque, T.C., Schwalbe, C.R., DeFalco, L.A., Duncan, R.B., and Hughes, T.J., 2003, Effects of desert wildfires on desert tortoise (Gopherus agassizii) and other small invertebrates: The Southwestern Naturalist, v. 48, no. 1, p. 103-111.

Evans, R.A., and Love, R.M., 1957, The step-point method of sampling-A practical tool in range research: Journal of Range Management, v. 10, no. 5, p. 208-212.

Evans, R.D., and Ehleringer, J.R., 1993, A break in the nitrogen cycle in arid lands? Evidence from $\delta^{15} \mathrm{~N}$ of soils: Oecologia, v. 94, p. 314-317.

Evans, R.D., and Lange, O.L., 2003, Biological soil crusts and ecosystem nitrogen and carbon dynamics, in Belnap, J., and Lange, O., eds., Biological soil crusts: Structure, function, and management (2nd ed.): Ecological Studies Series 150: Berlin, Springer-Verlag, p. 263-279.

Facelli, J.M., and Pickett, S.T.A., 1991, Plant litter: Light interception and effects on an old-field plant community: Ecology, v. 72, no. 3, p. 1024-1031.

Fenn, M.E., Baron, J.S., Allen, E.B., Rueth, H.M., Nydick, K.R., Geiser, L., Bowman, W.D., Sickman, J.O., Meixner, T., Johnson, D.W., and Neitlich, P., 2003, Ecological effects of nitrogen deposition in the Western United States: BioScience, v. 53, no. 4 , p. 404-420.

Ferner, J.W., 2007, A review of marking and individual recognition techniques for amphibians and reptiles. Herpetological Circular 35, Society for the Study of Amphibians and Reptiles, $72 \mathrm{p}$.

Ferrandis, P., De las Heras, J., Martinez-Sanchez, J., and Herranz, J., 2001, Influence of a low-intensity fire on a Pinus halepensis Mill. forest seed bank and its consequences on the early stages of plant succession: Israel Journal of Plant Sciences, v. 49, p. 105-114. 
Fisher, F.M., and Whitford, W.G., 1995, Field simulation of wet and dry years in the Chihuahuan desert: Soil moisture, $\mathrm{N}$ mineralization and ion-exchange resin bags: Biology and Fertility of Soils, v. 20, no. 2, p. 137-146.

Fitch, H.S., 1982, Resources of a snake community in prairiewoodland habitat of northeastern Kansas, in Scott, N.J., ed., Herpetological communities: Washington, D.C., U.S. Fish and Wildlife Service, Wildlife Research Report 13, p. 83-97.

Fleischner, T.L., 1994, Ecological costs of livestock grazing in western North America: Conservation Biology, v. 8, no. 3, p. 629-644.

Flint, A.L., and Davies, W.J., 1997, Meteorological data for water years, 1988-94 from five weather stations at Yucca Mountain, Nevada: U.S. Geological Survey Open-File Report 96-462, 10 p.

Freckman, D.W., and Mankau, R., 1986, Abundance, distribution, biomass and energetics of soil nematodes in northern Mojave Desert Ecosystem: Pedobiologia, v. 29, p. 129-142.

Freckman, D.W., Mankau, R., and Ferris, H., 1975, Nematode community structure in desert soils: nematode recovery: Journal of Nematology, v. 7, no. 4, p. 343-346.

Freitag, D.R., 1971, Methods of measuring soil compaction, in Barnes, K.K., Carleton, W.M., Taylor, H.M., Throckmorton, R.I., and Vanden Berg, G.E., eds., Compaction of agricultural soils: St. Joseph, Mich., American Society of Agricultural Engineers, p. 47-103.

French, A.R., 1993, Physiological ecology of the Heteromyidae-Economics of energy and water utilization, in Genoways, H.H., and Brown, J.H., eds., Biology of the Heteromyidae: American Society of Mammalogists, Special Publication 10, p. 509-538.

French, N.R., 1964, Description of a study of ecological effects on a desert area from chronic exposure to low level ionizing radiation: Los Angeles, Calif., University of California, Laboratory of Radiation Biology, U.S. Atomic Energy Commission Report UCLA 12-532.

French, N.R., Maza, B.G., Hill, H.O., and Aschwanden, A.P., 1974, A population study of irradiated desert rodents: Ecological Monographs v. 44, no. 1, p. 45-72.

Frenkel, R.E., 1970, Ruderal vegetation along some California roadsides: Berkeley, Calif., University of California Press, $163 \mathrm{p}$.

Fryrear, D.W., 1995, Soil losses by wind erosion: Soil Science Society of America Journal, v. 59, no. 3, p. 668-672.

Galindo, C., 1986, Do desert rodent populations increase when ants are removed?: Ecology, v. 67, no. 5, p. 1422-1423.
Gallardo, A., and Schlesinger, W.H., 1992, Carbon and nitrogen limitations of soil microbial biomass in desert ecosystems: Biogeochemistry, v. 18, no. 1, p. 1-17.

Galloway, J.N., Aber, J.D., Erisman, J.W., Seitzinger, S.P., Howarth, R.W., Cowling, E.B., and Cosby, B.J., 2003, The nitrogen cascade: BioScience, v. 53, no. 4, p. 341-356.

Gannon, W.L., Sikes, R.S., and the Animal Care and Use Committee of the American Society of Mammalogists, 2007, Guidelines of the American Society of Mammalogists for the use of wild mammals in research: Journal of Mammalogy, v. 88, no. 3, p. 809-823.

Garcia-Moya, E., and McKell, C.M., 1970, Contribution of shrubs to the nitrogen economy of a desert-wash plant community: Ecology, v. 51, no. 1, p. 81-88.

Garland, T., and Bradley, W.G., 1984, Effects of a highway on Mojave Desert rodent populations: American Midland Naturalist, v. 111, no. 1, p. 47-56.

Gelbard, J.L., and Belnap, J., 2003, Roads as conduits for exotic plant invasions in a semiarid landscape: Conservation Biology, v. 17, no. 2, p. 420-432.

George, D.B., Roundy, B.A., St. Clair, L.L., Johansen, J.R., Schaalje, G.B., and Webb, B.L., 2003, The effects of microbiotic soil crusts on soil water loss: Arid Land Research and Management, v. 17, no. 2, p. 113-125.

Germano, D.J., Williams, D.F., and Tordoff, W., III, 1994, Effect of drought on blunt-nosed leopard lizards (Gambelia sila): Northwestern Naturalist, v. 75, p. 11-19.

Gilewitch, D., 2004 The effect of military operations on desert pavement-A case study from Butler Pass, AZ (USA), in Caldwell, D.R., Ehlen, J., and Harmon, R.S., eds., Studies in military geography and geology: Dordrecht, The Netherlands, Kluwer Academic Publishers, p. 243-258.

Giorgi, F., Whetton, P., Jones, R., Christenson, J.H., Mearns, L.O., Hewitson, B., von Storch, H., Francisco, R., and Jack, C., 2001, Emerging patterns of simulated regional climatic changes for the 21 st century due to anthropogenic forcing: Geophysical Research Letters, v. 28, no. 17, p. 3317-3321.

Goldberg, D.E., and Turner, R.M., 1986, Vegetation change and plant demography in permanent plots in the Sonoran desert: Ecology, v. 67, no. 3, p. 695-712.

Gonzalez-Coloma, A., Wisdom, C.S., and Rundel., P.W., 1988, Ozone impact on the antioxidant nordihydroguaiaretic acid content in the external leaf resin of Larrea tridentata: Biochemical Systematics and Ecology, v. 16, p. 59-64. 
Gordon, M.S., 1982, Water and solute metabolism, in Gordon, M.S., Bartholomew, G.A., Grinnell, A.D., Jorgensen, C.B., and White, F.N., eds., Animal physiology_Principles and adaptations (4th ed.): New York, Macmillan Publishing Company, p. 272-332.

Grayson, D.K., 1994, The extinct late Pleistocene mammals of the Great Basin, in Harper, K.T., St. Clair, L.L., Thome, K.H., and Hess, W.M., eds., Natural history of the Colorado Plateau and Great Basin: Niwot, Colo., University Press of Colorado, p. 55-85.

Greacen, E.L., 1960, Water content and soil strength: Journal of Soil Science, v. 11, no. 2, p. 313-333.

Greenslade, P.J.M., 1964, Pitfall trapping as a method for studying Caribidae (Coleoptera): Journal of Animal Ecology, v. 33, p. 301-310.

Griffiths, P.G., Webb, R.H., and Melis, T.S., 2004, Initiation and frequency of debris flows in Grand Canyon, Arizona: Journal of Geophysical Research, Surface Processes, v. 109, F04002, doi:10.1029/2003JF000077, 14 p.

Grimm, V., and Wissel, C., 1997, Babel, or the ecological stability discussions: An inventory and analysis of terminology and a guide for avoiding confusion: Oecologia, v. 109, p. 323-334.

Grinnell, J., 1937, Mammals of Death Valley: Proceedings of the California Academy of Sciences, v. 23, no. 9, p. $115-169$.

Guo, Q.F., 1998, Microhabitat differentiation in Chihuahuan Desert plant communities: Plant Ecology, v. 139, p. 71-80.

Guo, Q., Rundel, P.W., and Goodall, D.W., 1998, Horizontal and vertical distribution of desert seed banks: patterns, causes, and implications: Journal of Arid Environments, v. 38 , no. 3 , p. $465-478$.

Guo, Q., Rundel, P.W., and Goodall, D.W., 1999, Structure of desert seed banks: comparisons across four North American desert sites: Journal of Arid Environments, v. 42, no. 1, p. $1-14$.

Hacisalihoglu, G., and Kochian, L.V., 2003, How do some plants tolerate low levels of soil zinc? Mechanisms of zinc deficiency in crop plants: New Phytologist, v. 159, no. 2, p. 341-350.

Hafner, M.S., 1977, Density and diversity in the Mojave Desert rodent and shrub communities: Journal of Animal Ecology, v. 46, p. 925-938.
Haise, H.R., Donnan, W.W., Phelan, J.T., Lawhon, L.F., and Shockley, D.G., 1956, The use of cylinder infiltrometers to determine the intake characteristics of irrigated soils. Publication ARS 41-7: Washington, D.C., U.S. Department of Agriculture, Agricultural Research Service and Soil Conservation Service, 10 p.

Hall, E.R., 1946, Mammals of Nevada: Berkeley, Calif., University of California Press, 720 p.

Hall, E.R., 1962, Collecting and preparing study skins of vertebrates: Lawrence, Kans., University of Kansas, Museum of Natural History, Miscellaneous Publication 30, 46 p.

Hall, F.C., 2002a, Photo point monitoring handbook, part A-field procedures: Portland, Oreg., USDA Forest Service, Pacific Northwest Research Station, General Technical Report PNW-GTR-526, p. 1-48.

Hall, F.C., 2002b, Photo point monitoring handbook, part B-concepts and analysis: Portland, Oreg., USDA Forest Service, Pacific Northwest Research Station, General Technical Report PNW-GTR-526, p. 49-134.

Halvorson, W.T., and Patten, D.T., 1975, Productivity and flowering of winter ephemerals in relation to Sonoran Desert shrubs: American Midland Naturalist, v. 93, no. 2, p. 311-319.

Hamerlynck, E.P., McAuliffe, J.R., McDonald, E.V., and Smith, S.D., 2002, Ecological responses of two Mojave Desert shrubs to soil horizon development and soil water dynamics: Ecology, v. 83, no. 3, p. 768-779.

Haney, R.L., Franzluebbers, A.J., Porter, E.B., Hons, F.M., and Zuberer, D.A., 2004, Soil carbon and nitrogen mineralization: Influence of drying temperature: Soil Science Society of America Journal, v. 68, p. 489-492.

Harper, J.L., and Ogden, J., 1970, The reproductive strategy of higher plants, I-The concept of strategy with special reference to Senecio vulgaris L.: Journal of Ecology, v. 58, no. 3, p. $681-698$.

Harper, K.T., and Belnap, J., 2001, The influence of biological soil crusts on mineral uptake by associated vascular plants: Journal of Arid Environments, v. 47, no. 3, p. 347-357.

Harris, A.T., Asner, G.P., and Miller, M.E., 2003, Changes in vegetation structure after long-term grazing in pinyon-juniper ecosystems-Integrating imaging spectroscopy and field studies: Ecosystems, v. 6, no. 4, p. 368-383.

Harrison, A.F., Latter, P.M., and Walton, D.W.H., eds., 1988, Cotton strip assay-An index of decomposition in soils: Grange-Over-Sands, U.K., Institute of Terrestrial Ecology. 
Harwell, M.A., V., M., Young, T., Bartuska, A., Gassman, N., Gentile, J.H., C.C., H., Appelbaum, S., Barko, J., Causey, B., Johnson, C., McLean, A., Smola, R., Templet, P., and Tosini, S., 1999, A framework for an ecosystem integrity report card: BioSicence, v. 49, no. 7, p. 543-556.

Havstad, K.M., Herrick, J.E., and Schlesinger, W.H., 2000, Desert rangelands, degradation and nutrients, in Arnalds, O., and Archer, S., eds., Rangeland desertification: Dordrecht, The Netherlands, Kluwer Academic Publishers, p. 77-86.

Hereford, R., in press, Alluviation and visual removal of landscape disturbances, Camp Ibis-Piute Wash, Eastern Mojave Desert, in Webb, R.H., Fenstermaker, L.F., Heaton, J.S., Hughson, D.L., McDonald, E.V., and Miller, D.M., eds., The Mojave Desert-Ecosystem processes and sustainability: Reno, Nev., University of Nevada Press.

Hereford, R., Webb, R.H., and Longpre, C.I., 2004, Precipitation history of the Mojave Desert region, 1893-2001: U.S. Geological Survey Fact Sheet 117-03, 4 p.

Hereford, R., Webb, R.H., and Longpré, C.I., 2006, Precipitation history and ecosystem response to multidecadal precipitation variability in the Mojave Desert region, 1893-2001: Journal of Arid Environments, v. 67, no. Supplement 1, p. $13-34$.

Herrick, J.E., and Jones, T.L., 2002, A dynamic cone penetrometer for measuring soil penetration resistance: Soil Science Society of America Journal, v. 66, p. 1320-1324.

Herrick, J.E., and Whitford, W.G., 1995, Assessing the quality of rangeland soils: Challenges and opportunities: Journal of Soil and Water Conservation, v. 50, no. 3, p. 237-242.

Herrick, J.E., Whitford, W.G., De Soyza, A.G., Van Zee, J.W., Havstad, K.M., Seybold , C.A., and Walton, M., 2001, Field soil aggregate stability kit for soil quality and rangeland health evaluations: Catena, v. 44, no. 1, p. 27-35.

Heyer, W.R., Donnelly, M.A., McDiarmid, R.W., Hayek, L., and Foster, M.S., 1993, Measuring and monitoring biological diversity - Standard methods for amphibians: Washington, D.C., Smithsonian Institution Press, 364 p.

HilleRisLambers, R., Rietkerk, M., van den Bosch, F., Prins, H.H.T., and de Kroon, H., 2001, Vegetation pattern formation in semi-arid grazing systems: Ecology, v. 82, no. 1, p. 50-61.

Hirsch, R., Hathaway, S., and Fisher, F., 2002, Herpetofauna and small mammal surveys on the Marine Corps Air Ground Combat Center, Twentynine Palms, CA, March, 1999-October, 2001: U.S. Geological Survey, 29 p.

Hölldobler, B., and Wilson, E.O., 1994, Journey to the ants: A story of scientific exploration: Cambridge, Mass., Belknap Press of Harvard University Press, 240 p.
Holling, C.S., 1996, Surprise for science, resilience for ecosystems, and incentives for people: Ecological Applications, v. 6 , no. 3, p. 733-735.

Hooper, D.U., and Johnson, L.C., 1999, Nitrogen limitation in dryland ecosystems - Responses to geographical and temporal variation in precipitation: Biogeochemistry, v. 46, no. $1-3$, p. 247-293.

Houghton, J.T., Ding, Y., Griggs, D.J., Noguer, M., van der Linden, P.J., and Xiaosu, D., eds., 2001, Climate change 2001-The scientific basis: Contributions of Working Group I to the Third Assessment Report of the Intergovernmental Panel on Climate Change: Cambridge, Mass., Cambridge University Press, 881 p.

Howard, G.W., 1985, The Desert Training Center/CaliforniaArizona maneuver area: Journal of Arizona History, v. 26, no. 3, p. 273-294.

Howard, J.L., 2006, Nonnative annual grass fuels and fire in the Mojave Desert, Fire effects information system: Fort Collins, Colo., USDA Forest Service, Rocky Mountain Research Station, Fire Sciences Laboratory [http://www. fs.fed.us/database/feis/].

Humphrey, R.R., 1974, Fire in the deserts and desert grassland of North America, in Kozlowski, T.T., and Ahlgrren, C.E., eds., Fire and ecosystems: New York, Academic Press, Inc., p. $365-400$.

Hunter, R., 1987, Jackrabbit-shrub interactions in the Mojave Desert, in Provenza, D., Flinders, J.T., and McArthur, E.D., eds., Proceedings: Symposium on plant-herbivore interactions: Ogden, Utah, USDA Forest Service, Intermountain Research Station, General Technical Report INT-222, p. 88-92.

Hunter, R., 1991, Bromus invasions on the Nevada Test Site: Present status of $B$. rubens and B. tectorum with notes on their relationship to disturbance and altitude: Great Basin Naturalist, v. 5, no. 12, p. 176-182.

Hunter, R.B., 1994, Trends in perennial plant populations on the Nevada Test site, 1989-1991, in Hunter, R.B., ed., Status of the flora and fauna on the Nevada Test Site, 1989-91: Las Vegas, Nev., Reynolds Electrical and Engineering Co., Inc., DOE/NV/11432-57, p. 236-333.

Hunter, R.B., 1995, Status of the flora and fauna on the Nevada Test Site, 1994: Las Vegas, Nev., Reynolds Electrical and Engineering Co., Inc., . DOE/NV11432-195, 363 p.

Hunter, R.B., and Medica, P.A., 1989, Status of the flora and fauna on the Nevada Test Site-Results of continuing basic environmental research January through December, 1987: Las Vegas, Nev., U.S. Department of Energy, Report DOE/V/10630-2, 103 p. 
Hunter, R.B., Wallace, A., and Romney, E.M., 1980, Field studies of mineral nutrition of Larrea tridentata: Importance of N, pH, and Fe: Great Basin Naturalist Memoirs, v. 4, p. 162-167.

Inouye, R.S., 1980, Density-dependent germination response by seeds of desert annuals: Oecologia, v. 46, p. 235-238.

Inouye, R.S., 1991, Population biology of desert annual plants, in Polis, G., ed., The ecology of desert communities: Tucson, Ariz., University of Arizona Press, p. 27-54.

Inouye, R.S., Huntley, N., and Wasley, G.A., 1997, Effects of pocket gophers (Geomys bursarius) on microtopographic variation: Journal of Mammalogy, v. 78, p. 1144-1148.

Iverson, R.M., 1980, Processes of accelerated pluvial erosion on desert hillslopes modified by vehicular traffic: Earth Surface Processes and Landforms, v. 5, p. 369-388.

Iverson, R.M., Hinckley, B.S., and Webb, R.H., 1981, Physical effects of vehicular disturbances on arid landscapes: Science, v. 212, no. 4497, p. 915-917.

Jackson, L.E., 1985, Ecological origins of California's Mediterranean grasses: Journal of Biogeography, v. 12, p. 349-361.

Jackson, R.B., and Caldwell, M.M., 1993, Geostatistical patterns of soil heterogeneity around individual perennial plants: The Journal of Ecology, v. 81, no. 4, p. 683-692.

Jarrell, W.M., and Virginia, R.A., 1989, Micronutrient metals in mesquite dominated Chihuahuan Desert ecosystems: Bulletin of the Ecological Society of America, v. 70, p. 155.

Jaurequi, M.A., and Reisenauer, H.M., 1982, Dissolution of oxides of manganese and iron by root exudate components: Soil Science Society of America Journal, v. 46, p. 314-317.

Jeffries, D.L., Link, S.O., and Klopatek, J.M., 1993, $\mathrm{CO}_{2}$ fluxes of cryptogamic crusts, I-Response to resaturation: The New Phytologist, v. 125, no. 1, p. 163-173.

Jennings, W.B., 2001, Comparative flowering phenology of plants in the western Mojave Desert: Madroño, v. 48, no. 3, p. $162-171$.

Jenny, H., 1941, Factors of soil formation: A system of quantitative pedology: New York, McGraw-Hill Book Company, Inc., $281 \mathrm{p}$.

Jenny, H., 1980, The soil resource: Origin and behavior Ecological Studies Series 37: New York, Springer-Verlag, 377 p.

Johansen, M.P., Hakonson, T.E., and Breshears, D.D., 2001, Post-fire runoff and erosion from rainfall simulation-Contrasting forests with shrublands and grasslands: Hydrological Processes, v. 15, no. 15, p. 2953-2965.
Johnson, A.W., and Sallberg, J.R., 1960, Factors that influence field compaction of soils: Washington, D.C., Department of Transportation, Highway Research Board Bulletin 272, 206 p.

Johnson, H.B., 1976, Vegetation and plant communities of southern California deserts-a functional view, in Latting, J.L., ed., Plant communities of southern California: Sacramento, Calif., California Native Plant Society, . Special Publication 2, p. 125-164.

Johnson, H.B., Vasek, F.C., and Yonkers, T., 1975, Productivity, diversity and stability relationships in Mojave Desert roadside vegetation: Bulletin of the Torrey Botanical Club, v. 102 , no. 3 , p. 106-115.

Jones, K.B., Neale, A.C., Ade, T.G., Wickham, J.D., Cross, C.L., Edmonds, C.M., Loveland, T.R., Nash, M.S., Riiters, K.H., and Smith, E.R., 2001, The consequences of landscape change on ecological resources-An assessment of the United States Mid-Atlantic Region, 1973-1993: Ecosystem Health, v. 7, no. 4, p. 229-242.

Juhren, M., Went, F.W., and Phillips, E., 1956, Ecology of desert plants IV-Combined field and laboratory work on germination of annuals in the Joshua Tree National Monument, California: Ecology, v. 37, no. 2, p. 318-330.

Kade, A., and Warren, S.D., 2002, Soil and plant recovery after historic military disturbances in the Sonoran Desert, USA: Arid Land Research and Management, v. 16, no. 3, p. 231-243.

Karafiath, L.L., and Nowatzki, E.A., 1978, Soil mechanics for off-road vehicle engineering: Clausthal, Germany, Trans Tech Publications, $515 \mathrm{p}$.

Karsten, U., and Garcia-Pichel, F., 1996, Carotenoids and mycosporine-like amino acid compounds in members of the genus Microcoleus (Cyanobacteria) - a chemosystematic study: Systematic and Applied Microbiology, v. 19, p. 285-294.

Kay, F.R., Sobhy, H.M., and Whitford, W.G., 1999, Soil microarthropods as indicators of exposure to environmental stress in Chihuahuan Desert rangelands: Biology and Fertility of Soils, v. 28, no. 2, p. 121-128.

Kellerhals, R., and Bray, D.I., 1971a, Sampling procedures for coarse fluvial sediments: American Society of Civil Engineers, Journal of the Hydraulics Division, v. 97, p. $1165-1180$.

Kellerhals, R., and Bray, D.I., 1971b, Comments on 'An improved method for size distribution of stream bed gravel' by Luna B. Leopold: Water Resources Research, v. 7, p. 1045-1047. 
Kelrick, M.I., and MacMahon, J.A., 1985, Nutritional and physical attributes of seeds of some common sagebrushsteppe plants-Some implications for ecological theory and management: Journal of Range Management, v. 38, no. 1, p. 65-69.

Kelrick, M.I., MacMahon, J.A., Parmenter, R.R., and Sisson, D.V., 1986, Native seed preferences of shrub-steppe rodents, birds and ants - The relationships of seed attributes and seed use: Oecologia v. 68, no. 3, p. 327-337.

Kemp, P., and Brooks, M.L., 1998, Exotic species of California deserts: Fremontia, v. 26, no. 4, p. 30-34.

Kendall, W.L., and Pollock, K.H., 2001, The robust design in capture-recapture studies-A review and evaluation by Monte Carlo simulation, in McCullough, D.R., and Barrett, R.H., eds., Wildlife 2001: Populations: London, Elsevier Applied Science, p. 31-43.

Kepner, W.G., Edmonds, C.M., and Watts, C.J., 2002, Remote sensing and geographic information systems for decision analysis in public resource administration-A case study of 25 years of landscape change in a Southwestern watershed: Las Vegas, Nev., Environmental Protection Agency, Report EPA/600/R-02/039, 23 p.

Kerley, G.I.H., and Erasmus, T., 1991, What do mice select for in seeds?: Oecologia, v. 86, no. 2, p. 261-267.

Kerley, G.I.H., Whitford, W.G., and Kay, F.R., 1997, Mechanisms for the keystone status of kangaroo rats: Graminivory rather than granivory?: Oecologia, v. 111, no. 3, p. 422-428.

Kieft, T.L., Soroker, E., and Firestone, M.K., 1987, Microbial biomass response to a rapid increase in water potential when dry soil is wetted: Soil Biology and Biochemistry, v. 19, no. 2, p. 119-126.

Kieft, T.L., White, C.S., Loftin, S.R., Aguilar, R., Craig, J.A., and Skaar, D.A., 1998, Temporal dynamics in soil carbon and nitrogen resources at a grassland-shrubland ecotone: Ecology, v. 79, no. 2, p. 671-683.

Killingbeck, K.T., 1989, Inefficient nitrogen resorption in a population of ocotillo (Fouquieria splendens Engelm.): A paradox caused by zinc deficiency?: Bulletin of the Ecological Society of America, v. 70, p. 168.

Klauber, L.M., 1939, Studies of reptile life in the arid Southwest. I. Night collecting on the desert with ecological statistics: Bulletin of the Zoological Society of San Diego, v. 14 , p. 100.

Klute, A., 1986, Methods of soil analysis. Part 1. Physical and mineralogical methods: Madison, Wis., American Society of Agronomy, Monograph Number 9, 1188 p.
Knapp, P.A., 1992, Soil loosening processes following the abandonment of two arid western Nevada townsites: Great Basin Naturalist, v. 52, no. 2, p. 149-154.

Knight, W.G., Allen, M.F., Jurinak, J.J., and Dudley, L.M., 1989, Elevated carbon dioxide and solution phosphorus in soil with vesicular-arbuscular mycorrhizal western wheatgrass: Soil Science Society of America Journal, v. 53, p. 1075-1082.

Krauskopf, K.B., and Bird, D.K., 1995, Introduction to geochemistry: Boston, Mass., McGraw-Hill, 721 p.

Krogh, S.N., Zeissetw, M.S., Jackson, E., and Whitford, W.G., 2002, Presence/absence of a keystone species as an indicator of rangeland health: Journal of Arid Environments, v. 50, no. 3, p. 513-519.

Lajtha, K., and Bloomer, S.H., 1988, Factors affecting phosphate sorption and phosphate retention in a desert ecosystem: Soil Science, v. 146, no. 3, p. 160-167.

Lajtha, K., and Harrison, A.F., 1995, Strategies of phosphorus acquisition and conservation by plant species and communities, in Tiessen, H., ed., Phosphorus in the global environment-Transfers, cycles and management: Chichester, John Wiley and Sons, p. 139-147.

Lajtha, K., and Schlesinger, W.H., 1988, The biogeochemistry of phosphorus cycling and phosphorus availability along a desert soil chronosequence: Ecology, v. 69, no. 1, p. 24-39.

Landsberg, J., and Crowley, G., 2004, Monitoring rangeland biodiversity-Plants as indicators: Australian Ecology, v. 29, no. 1, p. 59-77.

Lane, L.J., Romney, E.M., and Hakonson, T.E., 1984, Water balance calculations and net production of perennial vegetation in the northern Mojave Desert: Journal of Range Management, v. 37, no. 1, p. 12-18.

Lane, L.J., and Stone, J.J., 1983, Water balance calculations, water use efficiency, and aboveground net production: Hydrology and water research in Arizona and the Southwest, v. 13, p. 27-34.

Lange, O.L., 2003, Photosynthesis of soil-crust biota as dependent on environmental factors, in Belnap, J., and Lange, O.L., eds., Biological soil crusts-Structure, function, and management (2nd ed.): Ecological Studies Series 150: Berlin, Springer-Verlag, p. 217-240.

Larson, W.E., and Allmaras, R.R., 1971, Management factors and natural forces as related to compaction, in Barnes, K.K., Carleton, W.M., Taylor, H.M., Throckmorton, R.I., and VandenBerg, G.E., eds., Compaction of agricultural soils: St. Joseph, Mich., American Society of Agricultural Engineers, p. $367-427$. 
Lathrop, E.W., 1983, Recovery of perennial vegetation in military maneuver areas, in Webb, R.H., and Wilshire, H.G., eds., Environmental effects of off-road vehicles: Impacts and management in arid regions: New York, Springer-Verlag, p. 265-277.

Lathrop, W.E., and Rowlands, P.G., 1983, Plant ecology in deserts: An overview, in Webb, R.H., and Wilshire, H.G., eds., Environmental effects of off-road vehicles: Impacts and management in arid regions: New York, Springer-Verlag, p. 113-152.

Leatherman, D.A., and Kondratieff, B.C., 2003, Insects associated with the piñon-juniper woodlands of Mesa Verde country, in Floyd, M.L., ed., Ancient piñon-juniper woodlands: Boulder, Colo.., University Press of Colorado, p. 167-180.

Lei, S.A., 1999, Postfire woody vegetation recovery and soil properties in blackbrush (Coleogyne ramosissima Torr.) shrubland ecotones: Journal of the Arizona-Nevada Academy of Science, v. 32, no. 2, p. 105-116.

Lei, S.A., 2004, Soil compaction from human trampling, biking, and off-road motor vehicle activity in a blackbrush (Coleogyne ramosissima) shrubland: Western North American Naturalist, v. 64, no. 1, p. 125-130.

Leita, L., De Nobili, M., Mondini, C., Muhlbachova, G., Marchiol, L., Bragato, G., and Contin, M. 1999, Influence of inorganic and organic fertilization on soil microbial biomass, metabolic quotient and heavy metal bioavailability: Biology and Fertility of Soils, v. 28, p. 371-376.

Leung, L., Qian, Y., Bian, X., Washington, W., Han, J., and Roads, J., 2004, Mid-century ensemble regional climate change scenarios for the western United States: Climate Change, v. 62, no. 1-3, p. 75-113.

Lichvar, R.W., Spencer, W.E., and Campbell, J.E., 1998, Distribution of winter annual vegetation across environmental gradients within a Mojave Desert playa: Madroño, v. 45, no. 3, p. 231-238.

Lightfoot, D.C., and Whitford, W.G., 1991, Productivity of creosote foliage and associated canopy arthropods along a desert roadside: American Midland Naturalist, v. 125, no. 2, p. 310-322.

Likens, G., 1992, An ecosystem approach-Its use and abuse Excellence in ecology, Book 3: Oldendorf/Luhe, Germany, International Ecology Institute.

Logan, J.A., Regniere, J., and Powell, J.A., 2003, Assessing the impacts of global warming on forest pest dynamics: Frontiers in Ecology and the Environment, v. 1, no. 3, p. 130-137.
Longland, W.S., Jenkins, S.H., Vander Wall, S.B., Veech, J.A., and Pyare, S., 2001, Seedling recruitment in Oryzopsis hymenoides - Are desert granivores mutualists or predators?: Ecology, v. 82, no. 11, p. 3131-3148.

Longshore, K.M., Jaeger, J.R., and Sappington, J.M., 2003, Desert tortoise (Gopherus agassizii) survival at two eastern Mojave Desert sites—Death by short-term drought?: Journal of Herpetology, v. 37, no. 1, p. 169-177.

Lovich, J.E., and Bainbridge, D., 1999, Anthropogenic degradation of the southern California desert ecosystem and prospects for natural recovery and restoration: Environmental Management, v. 24, no. 3, p. 309-326.

Ludwig, J., Tongway, D., Freudenberger, D., Noble, J., and Hodgkinson, K., eds., 1997, Landscape ecology: Function and management. Principles from Australia's rangelands: Collinwood, Australia, CSIRO Publishing, 158 p.

Ludwig, J.A., Wilcox, B.P., Breshears, D.D., Tongway, D.J., and Imeson, A.C., 2005, Vegetation patches and runofferosion as interacting ecohydrological processes in semiarid landscapes: Ecology, v. 86, no. 2, p. 288-297.

Mack, R.N., 1986, Alien plant invasion into the Intermountain west: A case history, in Mooney, H.A., and Drake, J.A., eds., Ecology of biological invasions of North America and Hawaii: New York, Springer-Verlag, p. 191-213.

Mack, R.N., and Thompson, J.N., 1982, Evolution in steppe with few large, hooved mammals: The American Naturalist, v. 119 , no. 6 , p. $757-773$.

MacKay, W.P., Loring, S.J., Zak, J.C., Silva, S.I., Fisher, F.M., and Whitford, W.G., 1994, Factors affecting loss in mass of creosotebush leaf-litter on the soil surface in the northern Chihuahuan Desert: The Southwestern Naturalist, v. 39, no. 1, p. $78-82$.

MacMahon, J.A., Mull, J.F., and Crist, T.O., 2000, Harvester ants (Pogonomyrmex spp.) - Their community and ecosystem influences: Annual Review of Ecology and Systematics, v. 31, p. 265-291.

MacMillan, R.E., and Hinds, D.S., 1983, Water regulatory efficiency in heteromyid rodents-A model and its application: Ecology, v. 64, no. 1, p. 152-164.

Mankau, R., Sher, S.A., and Freckman, D.W., 1973, Biology of nematodes in desert ecosystems: 1971 Progress Report. Research Memorandum No. 73-7: Riverside, Calif., University of California, v. 2.

Mares, M.A., and Rosenzweig, M.L., 1978, Granivory in North and South American deserts-Rodents, birds, and ants: Ecology, v. 59, no. 2, p. 235-241.

Marschner, H., 1995, Mineral nutrition of higher plants (2nd ed.): San Diego, Calif., Academic Press, 889 p. 
Marticorena, B., Bergametti, G., Gillette, D., and Belnap, J., 1997, Factors controlling threshold friction velocity in semiarid and arid areas of the United States: Journal of Geophysical Research, v. 102, no. D19, p. 23277-23287.

Marumoto, T., Anderson, J.P.E., and Domsch, K.H., 1982, Mineralization of nutrients from soil microbial biomass: Soil Biology and Biochemistry, v. 14, p. 469-475.

Matchett, J. R., L. Gass, M. L. Brooks, A. M. Mathie, R. D. Vitales, M. W. Campagna, D. M. Miller, and J. F. Weigand. 2004. Spatial and temporal patterns of off-highway vehicle use at the Dove Springs OHV Open Area, California: Report prepared for the Bureau of Land Management, California State Office, Sacramento, Calif.

Mayer, A.M., and Poljakoff-Mayber, 1982, The germination of seeds (3rd ed.): New York, Pergamon Press, 270 p.

McAdoo, J.K., Evans, C.C., Roundy, B.A., Young, A.J., and Evans, R.A., 1983, Influence of heteromyid rodents on Oryzopsis hymenoides germination: Journal of Range Management, v. 36, no. 1, p. 61-64.

McAuliffe, J.R., 1990, A rapid survey method for the estimation of density and cover in desert plant communities: Journal of Vegetation Science, v. 1, no. 5, p. 653-656.

McAuliffe, J.R., 1994, Landscape evolution, soil formation, and ecological patterns and processes in Sonoran desert bajadas: Ecological Monographs, v. 64, no. 2, p. 111-148.

McAuliffe, J.R., 2003, The interface between precipitation and vegetation-The importance of soils in arid and semi-arid environments, in Weltzin, J.F., and McPherson, G.R., eds., Changing precipitation regimes and terrestrial ecosystemsA North American perspective: Tucson, Ariz., University of Arizona Press, p. 9-27.

McDonald, E.V., McFadden, L.D., and Wells, S.G., 1995, The relative influence of climate change, desert dust, and lithologic control on soil-geomorphic processes on alluvial fans, Mojave Desert, California-Summary of results: San Bernardino County Museum Association Quarterly, v. 42, no. 3, p. 35-42.

McFadden, L.D., and Knuepfer, P.L.K., 1990, Soil geomorphology-The linkage of pedology and surficial processes: Geomorphology, v. 3, p. 197-205.

McFadden, L.D., Ritter, J.B., and Wells, S.G., 1987, Use of multiparameter relative-age methods for age estimation and correlation of alluvial fan surfaces on a desert piedmont, eastern Mojave Desert, California: Quaternary Research, v. 32 , p. 276-290.

McGinnies, W.G., 1980, Native desert plant flowering seasons, Tucson vicinity: Tucson, Ariz., University of Arizona, Office of Arid Lands Studies, 6 p.
McLaughlin, S.P., and Bowers, J.E., 1981, Effects of fire on a Sonoran Desert plant community: Ecology, v. 63, p. 246-248.

Mech, S.G., and Hallett, J.G., 2001, Evaluating the effectiveness of corridors-A genetic approach: Conservation Biology, v. 15 , no. 2 , p. $467-474$.

Medica, P.A., 1992, Status of reptiles in 1988, in Hunter, R.B., ed., Status of the flora and fauna of the Nevada Test Site, 1988: Las Vegas, Nev., Reynolds Electrical and Engineering Co., Inc., Report DOE/NV/10630-29, p. 59-95.

Medica, P.A., Hoddenbach, G.A., and Lannom Jr., J.R., 1971, Lizard sampling techniques: Los Angeles, Calif., University of California, Laboratory of Radiation Biology, Rock Valley Miscellaneous Publications No. 1, 55 p.

Medica, P.A., Saethre, M.B., Hunter, R.B., and Drumm, J.D., 1994, Trends in reptile populations on the Nevada Test Site, in Hunter, R.B., ed., Status of the flora and fauna on the Nevada Test Site, 1988-91: Las Vegas, Nev., Reynolds Electrical and Engineering Co., Inc., Report DOE/ NV/11432-57, p. 1-49.

Medica, P.A., and Turner, F.B., 1984, Natural longevity of lizards in southern Nevada: Herpetological Review, v. 15, no. 2 , p. 34-35.

Medica, P.A., Turner, F.B., and Smith, D.D., 1973, Effects of radiation on a fenced population of horned lizards (Phrynosoma platyrhinos) in southern Nevada: Journal of Herpetology, v. 7, no. 2, p. 79-85.

Meehl, G.A., and Tebaldi, C., 2004, More intense, more frequent, and longer lasting heat waves in the $21^{\text {st }}$ century: Science, v. 305, no. 5686, p. 994-997.

Mehuys, G.R., Stolzy, L.H., Letey, J., and Weeks, L.V., 1975, Effects of stones on the hydraulic conductivity of relatively dry desert soils: Soil Science Society of America Proceedings, v. 39, p. 37-41.

Mendelson, J.R., and Jennings, W.B., 1992, Shifts in the relative abundance of snakes in a desert grassland: Journal of Herpetology, v. 26, no. 1, p. 38-45.

Menges, C.M., Taylor, E.M., Slate, J.L., and Dohrenwend, J.C., 1999, Strategy for mapping quaternary surficial deposits in support of the Death Valley Regional Flow Model in California and Nevada, in Slate, J.L., ed., Proceedings of the Conference on Status of Geologic Research and Mapping in Death Valley National Park, April 9-11, 1999, Las Vegas, Nevada: U.S. Geological Survey Open-File Report 99-153, p. $81-82$. 
Menges, C.M., Taylor, E.M., Workman, J.B., and Jayko, A.S., 2001, Regional surficial-deposit mapping in the Death Valley area of California and Nevada in support of groundwater modeling, in Machette, M.N., Johnson, M.L., and Slate, J.L., eds., Quaternary and late Pleistocene geology of the Death Valley region-Recent observations on tectonics, stratigraphy, and lake cycles (Guidebook for the 2001 Pacific Cell-Friends of the Pleistocene fieldtrip, February 17-19, 2001: U.S. Geological Survey Open-File Report 01-51, p. H151-H166.

Mielke, H.W., 1977, Mound building by pocket gophers (Geomyidae)_-Their impact on soils and vegetation in North America: Journal of Biogeography, v. 4, no. 2, p. 171-180.

Miller, M., Belnap, J., Beatty, S., and Webb, B., 2001, Components of spatial and temporal soil variation at Canyonlands National Park-Implications for P dynamics and cheatgrass (Bromus tectorum) performance, in McArthur, E.D., and Fairbanks, D.J., eds., 11th Wildland Shrub Symposium: Shrubland Ecosystem Genetics and Biodiversity, June 13-15, 2000, Provo, Utah, Proceedings: Fort Collins, Colo., USDA Forest Service, Rocky Mountain Research Station, RMRS-P-21, p. 154-162.

Miller, M.E., 2005, The structure and functioning of dryland ecosystems - conceptual models to inform long-term ecological monitoring: U.S. Geological Survey Scientific Investigations Report 2005-5197 [http://pubs.usgs.gov/ $\operatorname{sir} / 2005 / 5197 /]$.

Miller, M.E., Belnap, J., Beatty, S., and Reynolds, R.L., 2006, Performance of Bromus tectorum L. in relation to soil properties, water additions, and chemical amendments in calcareous soils of southeastern Utah, USA: Plant and Soil, v. 288 , no. $1-2$, p. 1-18.

Miller, D.M., Bedford, D.R., Hughson, D.L., McDonald, E.V., Robinson, S.E., and Schmidt, K.M., in press, Mapping Mojave Desert ecosystem properties with surficial geology, in Webb, R.H., Fenstermaker, L.F., Heaton, J.S., Hughson, D.L., McDonald, E.V., and Miller, D.M., eds., The Mojave Desert-Ecosystem processes and sustainability: Reno, Nev., University of Nevada Press.

Miriti, M.N., Howe, H.F., and Wright, S.J., 1998, Spatial patterns of mortality in a Colorado desert plant community: Plant Ecology, v. 136, no. 1, p. 41-51.

Moldenke, A.R., 1994, Arthropods, in Weaver, R.W., Angle, S., and Bottomley, P., eds., Methods of soil analysis, Part 2-Microbiological and biochemical properties: Madison, Wis., Soil Science Society of America, p. 517-542.

Mooney, H.A., J., E., and Berry, J.A., 1976, High photosynthetic capacity of a winter annual in Death Valley: Science, v. 194 , no. 4262 , p. 322-324.
Moorhead, D.L., and Callaghan, T., 1994, Effects of increasing ultraviolet $\mathrm{B}$ radiation on decomposition and soil organic matter dynamics-A synthesis and modeling study: Biology and Fertility of Soils, v. 18, p. 19-26.

Moorhead, D.L., and Reynolds, J.F., 1989, The contribution of abiotic processes to buried litter decomposition in the northern Chihuahuan Desert: Oecologia, v. 79, no. 1, p. 133-135.

Morafka, D.J., 1993, Amphibian and reptile study of 20 sites at National Training Center, Ft. Irwin, CA: Carson, Calif., California State University, Dominguez Hills.

Mueller-Dombois, D., and Ellenberg, H., 1974, Aims and methods of vegetation ecology: New York, John Wiley and Sons, $547 \mathrm{p}$.

Mummey, D.L., Smithe, J.L., and Bolton Jr., H., 1997, Smallscale spatial and temporal variability of $\mathrm{N}_{2} \mathrm{O}$ flux from a shrub-steppe ecosystem: Soil Biology and Biochemistry, v. 29, no. 11-12, p. 1699-1706.

Mun, H.-T., and Whitford, W.G., 1998, Changes in mass and chemistry of plant roots during long-term decomposition on a Chihuahuan Desert watershed: Biology and Fertility of Soils, v. 26, no. 1, p. 16-22.

Nagy, K.A., and Medica, P.A., 1986, Physiological ecology of desert tortoises in southern Nevada: Herpetologica, v. 42, no. 1, p. 73-92.

Nash, M.S., Bradford, D.F., Franson, S.E., Neale, A.C., Whitford, W.G., and Heggem, D.T., 2004, Livestock grazing effects on ant communities in the eastern Mojave Desert, USA: Ecological Indicators, v. 4, no. 3, p. 199-213.

National Research Council, 1995, Review of EPA's Environmental Monitoring and Assessment Program: Overall Evaluation: Washington, D.C., Committee to Review the EPA's Environmental Monitoring and Assessment Programs, National Research Council, National Academy Press, 178 p.

Neff, J.C., Reynolds, R., Belnap, J., and Lamothe, P., 2005, Multi-decadal impacts of grazing on soil physical and biogeochemical properties in southeast Utah: Ecological Applications, v. 15, no. 1, p. 87-95.

Nelson, J.F., and Chew, R.M., 1977, Factors affecting seed reserves in the soil of a Mojave Desert ecosystem, Rock Valley, Nye County, Nevada: American Midland Naturalist, v. 97 , no. 2, p. 300-320.

Nichols, K.K., and Bierman, P.R., 2001, Fifty-four years of ephemeral channel response to two years of intense World War II military activity, Camp Iron Mountain, Mojave Desert, California, in Ehlen, J., and Harmon, R.S., eds., The environmental legacy of military operations: Boulder, Colo., Geological Society of America, Reviews in engineering geology, v. XIV, p. 123-136. 
Nicholson, L., 1978 The effects of roads on desert tortoise populations, in Trotter, M., ed., Proceedings of the Third annual Desert Tortoise Council Symposium, Las Vegas, Nevada: Las Vegas, Nev., Desert Tortoise Council, p. $127-129$.

Niering, W.A., Lowe, C.H., and Whittaker, R.H., 1963, The saguaro-A population in relation to environment: Science, v. 142 , no. 3588 , p. $15-23$.

Noon, B.R., 2003, Conceptual issues in monitoring ecological systems, in Busch, D.E., and Trexler, J.C., eds., Monitoring ecosystems-Interdisciplinary approaches for evaluating ecoregional initiatives: Washington, D.C., Island Press, p. $27-71$.

Noy-Meir, I., 1973, Desert ecosystems: Environment and producers: Annual Review of Ecology and Systematics, v. 4, p. 25-51.

O’Farrell, M.J., Kaufman, D.W., and Lundahl, D.W., 1977, Use of live-trapping with the assessment line method for density estimation: Journal of Mammalogy, v. 58, no. 4, p. 575-582.

Oliver, I., and Beattie, A.J., 1996, Designing a cost-effective invertebrate survey-A test of methods for rapid assessment of biodiversity: Ecological Applications, v. 6, no. 2, p. 594-607.

Olsen, S.R., Cole, C.V., Watanabe, F.S., and Dean, L.A., 1954, Estimation of available phosphorus in soils by extraction with sodium bicarbonate: Washington, D.C, U.S. Department of Agriculture, Circular 939.

Olszyk, D.M., Bytnerowicz, A., Fox, C.A., Kats, G., Dawson, P.J., and Wolf, J., 1987, Injury and physiological responses of Larrea tridentata (DC) Coville exposed in situ to sulphur dioxide: Environmental Pollution, v. 48, p. 197-211.

Orr, H.K., 1975, Recovery from soil compaction on bluegrass range in the Black Hills: Transactions of the American Society of Agricultural Engineering, v. 18, no. 6, p. 1076-1081.

Ostler, W.K., Hansen, D.J., Anderson, D.C., and Hall, D.B., 2000, Classification of vegetation on the Nevada Test Site: Las Vegas, Nev., Bechtel Nevada, DOE/NV/11718-477, 556 p.

Parker, J.T.C., 2000, A field guide for the assessment of erosion, sediment transport, and deposition in incised channels of the southwestern United States: U.S. Geological Survey Water Resources Investigations Report 99-4227, 34 p.

Pavich, M.J., and Chadwick, O.A., 2003, Soils and the Quaternary climate system, in Gillespie, A.R., Porter, S.C., and Atwater, B.F., eds., The Quaternary period in the United States: Amsterdam, Elsevier, p. 311-330.
Pellant, M., Shaver, P., Pyke, D.A., and Herrick, J.E., 2000, Interpreting indicators of rangeland health, Version 3: Denver, Colo., Bureau of Land Management, National Science and Technology Center, Technical Reference TR-1734-6, $130 \mathrm{p}$.

Pendleton, R.L., Pendleton, B.K., and Harper, K.T., 1989, Breeding systems of woody plant species in Utah, in McArthur, E.D., Wallace, A., and Haferkamp, M.R., eds., Proceedings_-Symposium on shrub ecophysiology and biotechnology, June 30-July 2, 1987, Logan, Utah: Ogden, Utah, USDA Forest Service, Intermountain Research Station, General Technical Report INT-256, p. 5-22.

Perroux, K.M., and White, I., 1988, Designs for disc permeameters: Soil Science Society of America Journal, v. 52, p. 1205-1215.

Peters, D.P.C., and Havstad, K.M., 2006, Nonlinear dynamics in arid and semi-arid systems: Interactions among drivers and processes across scales: Journal of Arid Environments, v. 65 , no. 2, p. 196-206.

Peterson, F.F., 1981, Landforms of the Basin and Range province defined for soil survey: Reno, Nev., University of Nevada, Nevada Agricultural Experiment Station, Technical Bulletin 28, 52 p.

Pianka, E.R., 1970, Comparative autecology of the lizard Cnemidophorus tigris in different parts of its geographic range: Ecology, v. 51, no. 4, p. 703-720.

Price, M.V., and Jenkins, S.H., 1986, Rodents as seed consumers and dispersers, in Murray, D.R., ed., Seed dispersal: Sydney, Academic Press, p. 191-235.

Price, M.V., and Joyner, J.W., 1997, What resources are available to desert granivores: Seed rain or soil seed bank?: Ecology, v. 78, no. 3, p. 764-773.

Price, M.V., and Reichman, O.J., 1987, Distribution of seeds in Sonoran Desert soils: Implications for heteromyid rodent foraging: Ecology, v. 68, no. 6, p. 1797-1811.

Price, M.V., Waser, N.M., and McDonald, S.A., 2000, Elevational distributions of kangaroo rats (genus Dipodomys): Long-term trends at a Mojave Desert site: American Midland Naturalist, v. 144, no. 2, p. 352-361.

Prichard, D., Anderson, J., Correll, C., Fogg, J., Gebhardt, K., Krapf, R., Leonard, S., Mitchell, B., and Staats, J., 1998, Riparian area management-A user guide to assessing proper functioning condition and the supporting science for lotic areas. Technical Reference 1737-15: Denver, Colo., Bureau of Land Management, National Science and Technology Center, 126 p.

Prose, D.V., 1985, Persisting effects of armored military maneuvers on some soils of the Mojave Desert: Environmental Geology and Water Science, v. 7, no. 3, p. 163-170. 
Prose, D.V., and Metzger, S.K., 1985, Recovery of soils and vegetation in World War II military base camps, Mojave Desert: U.S. Geological Survey Open-File Report 85-234, $115 \mathrm{p}$.

Prose, D.V., Metzger, S.K., and Wilshire, H.G., 1987, Effects of substrate disturbance on secondary plant succession: Mojave Desert California: Journal of Applied Ecology, v. 24 , no. 1, p. 305-313.

Prose, D.V., and Wilshire, H.G., 2000, The lasting effects of tank maneuvers on desert soils and intershrub flora: U.S. Geological Survey Open-File Report 00-512, : Menlo Park, $22 \mathrm{p}$.

Provenza, F.D., Malechek, J.C., Urness, P.J., and Bowns, J.E., 1983, Some factors affecting twig growth in blackbrush: Journal of Range Management, v. 35, no. 4, p. 518-520.

Puigdefábregas, J., 2005, The role of vegetation patterns in structuring runoff and sediment fluxes in drylands: Earth Surface Processes and Landforms, v. 30, no. 2, p. 133-147.

Puigdefabregas, J., and Sanchez, G., 1996, Geomorphological implications of vegetation patchiness on semi-arid slopes, in Anderson, M.G., and Brooks, S.M., eds., Advances in hillslope processes, Volume 2: Chichester, John Wiley and Sons, p. 1027-1060.

Puigdefabregas, J., Sole, A., Gutierrez, L., del Barrio, G., and Boer, M., 1999, Scales and processes of water and sediment redistribution in drylands-Results from the Rambla Honda field site in Southeast Spain: Earth-Science Reviews, v. 48, no. 1-2, p. 39-70.

Pulliam, H.R., and Brand, M.R., 1975, The production and utilization of seeds in plains grassland of southeastern Arizona: Ecology, v. 56, no. 5, p. 1158-1166.

Raison, R.J., 1979, Modification of the soil environment by vegetation fires, with particular reference to nitrogen transformations-A review: Plant and Soil, v. 51, no. 1, p. 73-108.

Rapport, D.J., 1998, Defining ecosystem health, in Rapport, D.J., Costanza, R., Epstein, P.R., Gaudet, C., and Levins, R., eds., Ecosystem health: Malden, Mass., Blackwell Science, p. 18-33.

Reheis, M.C., Harden, J.W., McFadden, L.D., and Shroba, R.R., 1989, Development rates of late Quaternary soils, Silver Lake Playa, California: Soil Science Society of America Journal, v. 53, no. 4, p. 1127-1140.

Reheis, M.C., 1999, Dust deposition and its effect on soils: A progress report, in Breed, C.S., and Reheis, M.C., eds., Desert winds-Monitoring wind-related surface processes in Arizona, New Mexico, and California: U.S. Geological Survey Professional Paper 1598, p. 123-131.
Reichman, O.J., 1975, Relation of desert rodent diets to available resources: Journal of Mammalogy, v. 56, no. 4, p. $731-751$.

Reichman, O.J., 1976, Seed distribution and the effect of rodents on germination of desert annuals: Logan, Utah, Utah State University, U.S. International Biological Program, Desert Biome Research Memorandum 76.

Reichman, O.J., 1984, Spatial and temporal variation of seed distributions in Sonoran Desert soils: Journal of Biogeography, v. 11, no. 1, p. 1-11.

Reichman, O.J., and Oberstein, D., 1977, Selection of seed distribution types by Dipodomys merriami and Perognathus amplus: Ecology, v. 58, no. 3, p. 636-643.

Reichman, O.J., and Seabloom, E.W., 2002, The role of pocket gophers as subterranean ecosystem engineers: Trends in Ecology and Evolution, v. 17, no. 1, p. 44-49.

Reid, K.D., Wilcox, B.P., Breshears, D.D., and MacDonald, L., 1999, Runoff and erosion in a piñon-juniper woodland: Influence of vegetation patches: Soil Science Society of America Journal, v. 63, no. 6, p. 1869-1879.

Reynolds, J.F., and Glendening, G.E., 1949, Merriam kangaroo rat-A factor in mesquite propagation on southern Arizona range lands: Journal of Range Management, v. 2, no. 4, p. 193-197.

Reynolds, R., Belnap, J., Reheis, M., Lamothe, P., and Luiszer, F., 2001, Aeolian dust in Colorado Plateau soils: Nutrient inputs and recent change in source: Proceedings of the National Academy of Sciences, v. 98, no. 13, p. 7123-7127.

Reynolds, R.E., Reheis, M., Hinkley, T., Tigges, R., Clow, G.D., Lamothe, P., Yount, J.C., Meeker, G., Chavez Jr., P.S., Mackinnon, D.J., Velasco, M.G., Sides, S.C., Soltesz, D.L., Lancaster, N., Miller, M.E., Fulton, R., and Belnap, J., 2003, Dust emission and deposition in southwestern United States-Integrated field, remote sensing, and modeling studies to evaluate response to climatic variability and land use, in Alsharhan, A.S., Wood, W.W., Goudie, A.S., Fowler, A., and Abdellatif, E.M., eds., Desertification in the Third Millennium, Proceedings of an international conference, February 12-16, 2000, Dubai, United Arab Emerites: Lisse, The Netherlands, Swets and Zeitlinger, p. 271-282.

Reynolds, R.P., 1982, Seasonal incidence of snakes in northeastern Chihuahua, Mexico: Southwestern Naturalist, v. 27, no. 2, p. 161-166.

Rice, S., and Church, M., 1996, Sampling surficial fluvial gravels - The precision of size distribution percentile estimates: Journal of Sedimentary Research, v. 66, no. 3, p. 654-665.

Ricklefs, R.E., 1990, Ecology (3 ed.): New York, Freeman, 896 p. 
Riddle, B.R., and Honeycutt, R.L., 1990, Historical biogeography in North American arid regions-An approach using mitochondrial-DNA phylogeny in grasshopper mice (Genus Onychomys): Evolution, v. 44, no. 1, p. 1-15.

Robichaud, P.R., and Brown, R.E., 2002, Silt fences: An economical technique for measuring hillslope soil erosion: Fort Collins, Colo., USDA Forest Service, Rocky Mountain Research Station, . General Technical Report RMRSGTR-94, 24 p.

Rodgers, G.F., Malde, H.E., and Turner, R.M., 1984, Bibliography of repeat photography for evaluating landscape change: Salt Lake City, Utah, University of Utah Press, 179 p.

Romney, E.M., Hale, V.Q., Wallace, A., Lunt, O.R., Alexander, G.V., Kinnear, J.E., and Ackerman, T.L., 1973, Some characteristics of soil and perennial vegetation in northern Mojave Desert areas of the Nevada Test site: Springfield, Va., National Technical Information Service, Report UCLA 12-916, $340 \mathrm{p}$.

Rowlands, P.G., 1995, Regional bioclimatology of the California desert, in Latting, J.L., and Rowlands, P.G., eds., The California Desert-An introduction to natural resources and man's impact: Riverside, Calif., June Latting Books, p. 95-134.

Rowlands, P.G., Johnson, H., Ritter, E., and Endo, A., 1982, The Mojave Desert, in Vender, G.L., ed., Reference handbook on the deserts of North America: Westport, Conn., Greenwood Press, p. 103-145.

Rucker, D.F., and Ferré, T.P.A., 2003, Near-surface water content estimation with borehole ground penetrating radar using critically refracted waves: Vadose Zone Journal, v. 2, no. 2, p. 247-252.

Rundel, P.W., and Gibson, A.C., 1996, Ecological communities and processes in a Mojave Desert ecosystem, Rock Valley, Nevada: Cambridge, Mass., Cambridge University Press, 369 p.

Ryel, R.J., Caldwell, M.M., Leffler, A.J., and Yoder, C.K., 2003, Rapid soil moisture recharge to depth by roots in a stand of Artemisia tridentata: Ecology, v. 84, no. 3, p. 757-764.

Sala, O.E., and Lauenroth, W.K., 1982, Small rainfall events: An ecological role in semiarid regions: Oecologia, v. 53, no. 3, p. 301-304.

Samson, D.A., 1986, Community ecology of Mojave Desert winter annuals: Salt Lake City, Utah, University of Utah, Ph.D. dissertation, $270 \mathrm{p}$.
Samson, D.A., Philippi, T.E., and Davidson, D.W., 1992, Granivory and competition as determinants of annual plant diversity in the Chihuahuan Desert: Oikos, v. 65, no. 1, p. 61-80.

Sanborn, S.R., 1972, Food habits of Sauromalus obesus obesus on the Nevada Test Site: Journal of Herpetology, v. 6, no. 2, p. 142-144.

Sanchez, G., and Puigdefabregas, J., 1994, Interactions of plant growth and sediment movement on slopes in semi-arid environment: Geomorphology, v. 9, p. 243-260.

Sawyer, J.O., and Keeler-Wolf, T., 1995, A manual of California vegetation: Sacramento, Calif., California Native Plant Society $471 \mathrm{p}$.

Schaap, M.G., Leij, F.J., and van Genuchten, M.T., 2001, ROSETTA - A computer program for estimating soil hydraulic parameters with hierarchical pedotransfer functions: Journal of Hydrology, v. 251, no. 3, p. 163-176.

Scheffer, M., Carpenter, S., Foley, J.A., Folke, C., and Walker, B., 2001, Catastrophic shifts in ecosystems: Nature, v. 413, no. 11, p. 591-596.

Schenk, H.J., and Mahall, B.E., 2002, Positive and negative plant interactions contribute to a north-south-patterned association between two desert shrub species: Oecologia, v. 132, no. 3, p. 402-410.

Schiffman, P.M., 1994, Promotion of exotic weed establishment by endangered giant kangaroo rats (Dipodomys ingens) in a California grassland: Biodiversity and Conservation, v. 3 , no. 6 , p. 524-537.

Schiffman, P.M., 1997, Animal-mediated dispersal and disturbance: Driving forces behind alien plant naturalization, in Luken, J.O., and Thieret, J.W., eds., Assessment and management of plant invasions: New York, Springer-Verlag, Springer Series on Environmental Management, p. 87-99.

Schlesinger, W.H., Fonteyn, P.J., and Reiners, W.A., 1989, Effects of overland flow on plant water relations, erosion, and soil water percolation on a Mojave Desert landscape: Soil Science Society of America Journal, v. 53, no. 5, p. 1567-1572.

Schlesinger, W.H., and Pilmanis, A.M., 1998, Plant-soil interactions in deserts: Biogeochemistry, v. 42, no. 1-2, p. 169-187.

Schlesinger, W.H., Raikes, J.A., Hartley, A.E., and Cross, A.F., 1996, On the spatial pattern of soil nutrients in desert ecosystems: Ecology, v. 77, no. 2, p. 364-374.

Schlesinger, W.H., Reynolds, J.F., Cunningham, G.L., Huenneke, L.F., Jarrell, W.M., Virginia, R.A., and Whitford, W.G., 1990, Biological feedbacks in global desertification: Science, v. 247, no. 4946, p. 1043-1048. 
Schmidt, K.M., and McMackin, M., 2002, Preliminary surficial geologic map database and material properties for the Mesquite Lake quadrangle, California and Nevada, U.S. Geological Survey Open-File Report 2006-1035, scale 1:100,000 [http://pubs.usgs.gov/of/2006/1035/].

Schmidt, K.M., and Webb, R.H., 2001, Researchers consider U.S. Southwest's response to warmer, drier conditions: EOS, v. 82, no. 41, p. 475-478.

Schmidt-Nielsen, K., 1964, Desert animals: Physiological problems of heat and water: Oxford, Clarendon Press, 277 p.

Schoenau, J.J., and Karamonos, R.E., 1993, Sodium bicarbonate extractable $\mathrm{P}, \mathrm{K}$, and $\mathrm{N}$, in Carter, M.R., ed., Soil sampling and methods of analysis: Ottawa, Ontario, Canada, Canadian Society of Soil Science, p. 51-58.

Schooley, R.L., Van Horne, B., and Burnham, K.P., 1993, Passive integrated transponders for marking free-ranging Townsend's ground squirrels: Journal of Mammalogy, v. 74, no. 2 , p. $480-484$.

Schwinning, S., and Sala, O.E., 2004, Hierarchy of responses to resource pulses in arid and semi-arid ecosystems: Oecologia, v. 141, no. 2, p. 211-220.

Seager, R., Ting, M., Held, I., Kushnir, Y., Lu, J., Vecchi, G., Huang, H.-P., Harnik, N., Leetmaa, A., Lau, N.-C., Li., C., Velez, J., and Naik, N., 2007, Model projections of an imminent transition to a more arid climate in southwestern North America: Science v. 316, no. 5828, p. 1181-1184.

Seber, G.A.F., 1973, The estimation of animal abundance and related parameters: London, Griffin, 506 p.

Sedivec, S.A., and Whidden, H.P., 2007, Importance of trap type for the detection and conservation of small mammals: Park Science, v. 24, no. 2, p. 67-71.

Seybold, C.A., Herrick, J.E., and Brejda, J.J., 1999, Soil resilience: A fundamental component of soil quality: Soil Science, v. 164, no. 4, p. 224-234.

Sharifi, M.R., Gibson, A.C., and Rundel, P.W., 1997, Surface dust impacts on gas exchange in Mojave desert shrubs: Journal of Applied Ecology, v. 34, no. 4, p. 837-846.

Sharifi, M.R., Gibson, A.C., and Rundel, P.W., 1999, Phenological and physiological responses of heavily dusted creosote bush (Larrea tridentata) to summer irrigation in the Mojave Desert: Flora, v. 194, p. 369-378.

Shreve, F., 1917, The establishment of desert perennials: Journal of Ecology, v. 5, no. 3-4, p. 210-216.
Sinsabaugh, R.L., Carreiro, M.M., and Alvarez, S., 2002, Enzyme and microbial dynamics of litter decomposition, in Burns, R.G., and Dick, R.P., eds., Enzymes in the environment: Activity, ecology and applications: New York, Marcel Dekker, Inc., p. 249-265.

Slate, J.L., and Berry, M.E., 1999, Preliminary surficial geologic map of the Beatty $30 \times 60$-minute quadrangle, Nevada-California, in Slate, J.L., ed., Proceedings of the Conference on Status of Geologic Research and Mapping in Death Valley National Park, April 9-11, 1999, Las Vegas, Nevada: U.S. Geological Survey Open-File Report 99-153, p. $78-80$.

Smith, S.D., Herr, C.A., Leary, K.L., and Piorkowski, J.M., 1995, Soil-plant water relations in a Mojave Desert mixed shrub community-A comparison of three geomorphic surfaces: Journal of Arid Environments, v. 29, no. 3, p. 339-351.

Smith, S.D., Huxman, T.E., Zitzer, S.F., Charlet, T.N., Housman, D.C., Coleman, J.S., Fenstermaker, L.K., Seemann, J.R., and Nowak, R.S., 2000, Elevated $\mathrm{CO}_{2}$ increases productivity and invasive species success in an arid ecosystem: Nature, v. 408 , no. 6808 , p. $79-82$.

Smith, W., 1986, The effects of eastern North Pacific tropical cyclones on the southwestern United States: Salt Lake City, Utah, National Oceanic and Atmospheric Administration, Technical Memorandum NWS WR-197, 229 p.

Society for Range Management, 1999, A glossary of terms used in range management: Denver, Colo., Society for Range Management, $20 \mathrm{p}$.

Soholt, L.F., 1973, Consumption of primary production by a population of kangaroo rats (Dipodomys merriami) in the Mojave desert: Ecological Monographs, v. 43, no. 3, p. 357-376.

Soil Science Society of America, 1997, Glossary of soil science terms: Madison, Wis., Soil Science Society of America [https://www.soils.org/sssagloss/].

Sparks, D.L., Page, A.L., Helmke, P.A., Loeppert, R.H., Soltanpour, P.N., Tabatabai, M.A., Johnston, C.T., and Sumner, M.E., eds., 1996, Methods of soil analysis, Part 3-Chemical methods: Madison, Wis., Soil Science Society of America, $1390 \mathrm{p}$.

Starr, M.J., 2002, The effects of roads on perennial shrubs in the Mojave Desert, California: Papers and Proceedings of the Applied Geography Conference, v. 25, p. 85-92.

Stebbins, R.C., 2003, Field guide to western reptiles and amphibians: New York, Houghton Mifflin Company, 533 p. 
Steiger, J.W., and Webb, R.H., 2000, Recovery of perennial vegetation in military target sites in the eastern Mojave Desert, Arizona: U.S. Geological Survey Open-File Report 00-355 [http://geopubs.wr.usgs.gov/open-file/of00-355/].

Storey, T.G., 1969, Tree weights and fuel size distribution of pinyon pine and Utah juniper, Project Flambeau-An investigation of mass fire (1964-1967), Volume 2: Berkeley, Calif., USDA Forest Service, Pacific Southwest Forest and Range Experiment Station, p. 15-32.

Stradling, D.J., 1978, Food and feeding habits of ants, in Brian, M.V., ed., Production ecology of ants and termites: Cambridge, Mass., Cambridge University Press, p. 81-106.

Stringham, T.K., Krueger, W.C., and Shaver, P.L., 2003, State and transition modeling-An ecological process approach: Journal of Range Management, v. 56, no. 2, p. 106-113.

Sumner, M.E., and Stewart, B.A., eds., 1992, Soil crusting: Chemical and physical processes: Advances in soil science: Boca Raton, FL, Lewis Publishers, 372 p.

Suter, G.W., 1993, A critique of ecosystem health concepts and indexes: Environmental Toxicology and Chemistry, v. 12, no. 9, p. 1533-1539.

Swantek, P.J., Halvorson, W.L., and Schwalbe, C.R., 1999, GIS database development to analyze fire history in southern Arizona and beyond-an example from Saguaro National Park: Tucson, Ariz., Cooperative Park Studies Unit, University of Arizona, Technical Report Number 61.

Swetnam, T.W., and Betancourt, J.L., 1998, Mesoscale disturbance and ecological response to decadal climatic variability in the American southwest: Journal of Climate, v. 11, no. 12, p. 3128-3147.

Tanner, W.W., and Jorgensen, C.D., 1963, Reptiles of the Nevada Test Site: Brigham Young University Bulletin, Biology Series, v. 3, no. 3, p. 1-31.

Temple, P.J., 1989, Oxidant air pollution effects on plants of Joshua Tree National Monument, California, USA: Environmental Pollution, v. 57, no. 1, p. 35-48.

Thomas, K.A., Keeler-Wolf, T., Franklin, J., and Stine, P., 2004, Mojave Desert Ecosystem Program-Central Mojave vegetation database: U.S. Geological Survey, 251 p. [http:// www.dfg.ca.gov/biogeodata/vegcamp/pdfs/VegMappingRpt_ Central_Mojave_Vegetation_Database.pdf].

Thompson, C.R., Olszyk, D.M., Kats, G., Bytnerowicz, A., Dawson, P.J., and Wolf, J., 1984, Effects of ozone or sulphur dioxide on annual plants of the Mojave Desert: Journal of the Air Pollution Control Association, v. 34, p. 1017-1022.
Thompson, R.S., Hostetler, S.W., Bartlein, P.J., and Anderson, K.H., 1998, A strategy for assessing potential future changes in climate, hydrology, and vegetation in the western United States: U.S. Geological Survey Circular 1153:[http:// pubs.usgs.gov/circ/1998/c1153/].

Tinkle, D.W., 1967, The life and demography of the sideblotched lizard, Uta stansburiana: Ann Arbor, Mich., University of Michigan Museum of Zoology, Miscellaneous Publication 132.

Titus, J.H., Nowak, R.S., and Smith, S.D., 2002, Soil resource heterogeneity in the Mojave Desert: Journal of Arid Environments, v. 52, no. 3, p. 269-292.

Tongway, D.J., and Ludwig, J.A., 1994, Small-scale resource heterogeneity in semi-arid landscapes: Pacific Conservation Biology, v. 1, p. 201-208.

Tongway, D.J., and Ludwig, J.A., 1997, The conservation of water and nutrients within landscapes, in Ludwig, J., Tongway, D., Freudenberger, D., Noble, J., and Hodgkinson, K., eds., Landscape ecology-Function and management. Principles from Australia's rangelands: Collingwood, Australia, CSIRO Publishing, p. 13-22.

Tracy, C.R., R. Averill-Murray, R., Boarman, W.I., Delehanty, D., Heaton, J., McCoy, E., Morafka, D., Nussear, K., Hagerty, B., and Medica, P.A., 2003, Desert tortoise recovery plan assessment: Reno, Nev., University of Nevada, 254 p. [http://www.fws.gov/nevada/desert_tortoise/documents/ dtrpac/dtrpac_report.pdf].

Troeh, F.R., and Thompson, L.M., 2005, Soils and soil fertility (6th ed.): New York, Oxford University Press, 489 p.

Truett, J., 1996, Bison and elk in the American Southwest: In search of the pristine: Environmental Management, v. 20, no. 2, p. 195-206.

Turner, F.B., 1973, Rock Valley validation site report: Logan, Utah, Utah State University, U.S. International Biological Program, Desert Biome Research Memorandum 73-2.

Turner, F.B., 1977, The dynamics of populations of squamates, crocodilians and Rhynchocephalians, in Gans, C., and Tinkle, D.W., eds., Biology of the Reptilia. Volume 7: London, Academic Press, p. 157-264.

Turner, F.B., Hoddenbach, G.A., Medica, P.A., and Lannom, J.R., 1970, The demography of the lizard, Uta stansburiana Baird and Girard, in southern Nevada: Journal of Animal Ecology, v. 39, no. 2, p. 505-519.

Turner, F.B., and Medica, P.A., 1977, Sterility among female lizards (Uta stansburiana) exposed to continuous gamma irradiation: Radiation Research, v. 70, no. 1, p. 154-163. 
Turner, F.B., Medica, P.A., Bridges, K.W., and Jennrich, R.I., 1982, A population model of the lizard Uta stansburiana in southern Nevada: Ecological Monographs, v. 52, no. 3, p. 243-259.

Turner, F.B., Medica, P.A., Lannom Jr., J.R., and Hoddenbach, G.A., 1969b, A demographic analysis of fenced populations of the whiptail lizard, Cnemidophorus tigris, in southern Nevada: Southwestern Naturalist, v. 14, no. 2, p. 189-202.

Turner, F.B., Medica, P.A., and Smith, D.D., 1974, Reproduction and survivorship of the lizard Uta stansburiana and the effects of winter rainfall, density and predation on these processes: Logan, Utah, Utah State University, U.S. International Biological Program, Desert Biome Research Memorandum 74-26.

Turner, F.B., and Randall, D.C., 1987, The phenology of desert shrubs in southern Nevada: Journal of Arid Environments, v. 13 , p. $119-128$.

Turner, F.B., and Randall, D.C., 1989, Net production by shrubs and winter annuals in southern Nevada: Journal of Arid Environments, v. 17, p. 23-36.

Turner, R.M., Webb, R.H., Bowers, J.E., and Hasting, J.R., 2003, The changing mile revisited-An ecological study of vegetation change with time in the lower mile of an arid and semiarid region: Tucson, Ariz., University of Arizona Press, $334 \mathrm{p}$.

U.S. Environmental Protection Agency, 1993, North American Landscape Characterization (NALC) research brief: Washington, D.C., U.S. Environmental Protection Agency, EOA/600/S-93/0005.

U.S. Fish and Wildlife Service, 1994, Desert tortoise (Mojave population) recovery plan: Portland, Oreg., U.S. Fish and Wildlife Service, 73 p.

U.S. Fish and Wildlife Service, 2006, Range-wide monitoring of the Mojave population of the desert tortoise, 2001-2005. Summary Report: Reno, Nev., U.S. Fish and Wildlife Service, Desert Tortoise Recovery Office, 96 p.

van Donk, S.J., Huang, X., Skidmore, E.L., Andersen, A.B., Gebhart, D.L., Prehoda, V.E., and Kellogg, E.M., 2003, Wind erosion from military training lands in the Mojave Desert, California, U.S.A.: Journal of Arid Environments, v. 54, no. 4, p. 687-703.

van Genuchten, M.T., 1980, A closed-form equation for predicting the hydraulic conductivity of unsaturated soils: Soil Science Society of America Journal, v. 44, p. 892-898.

van Ouwerkerk, C., 1968, Two model experiments on the durability of subsoil compaction: Netherlands Journal of Agricultural Science, v. 16, p. 204-210.
Vander Wall, S.B., 1990, Food hoarding in animals: Chicago, University of Chicago Press, 445 p.

Vander Wall, S.B., 1997, Dispersal of singleleaf piñon pine (Pinus monophylla) by seed-caching rodents: Journal of Mammalogy, v. 78, no. 1, p. 181-191.

Vasek, F.C., 1980, Early successional stages in Mojave desert scrub vegetation: Israel Journal of Botany, v. 28, p. 133148 .

Vasek, F.C., Johnson, H.B., and Brum, G.D., 1975a, Effects of power transmission lines on vegetation of the Mojave Desert: Madroño, v. 23, no. 3, p. 114-130.

Vasek, F.C., Johnson, H.B., and Eslinger, D.H., 1975b, Effects of pipeline construction on creosote bush scrub vegetation of the Mojave Desert: Madroño, v. 23, no. 1, p. 1-64.

Veblen, T.T., Hadley, K.S., Reid, M.S., and Rebertus, A.J., 1991, The response of subalpine forests to spruce beetle outbreak in Colorado: Ecology v. 72, no. 1, p. 213-231.

Verrecchia, E., Yair, A., Kidron, G.J., and Verrecchia, K., 1995, Physical properties of the psammophile cryptogamic crust and their consequences to the water regime of sandy soils, north-western Negev Desert, Israel: Journal of Arid Environments, v. 29, no. 4, p. 427-437.

Vincent, K.R., and Chadwick, O.A., 1994, Synthesizing bulk density for soils with abundant rock fragments: Soil Science Society of America Journal, v. 58, no. 2, p. 455-464.

Virginia, R.A., Jarrell, W.M., and Franco-Vizcaino, E., 1982, Direct measurement of denitrification in a Prosopis (Mesquite) dominated Sonoran Desert ecosystem: Oecologia, v. 53, p. $120-122$.

Vogel, J., and Hughson, D.L., in press, Historical patterns of road networks in Mojave National Preserve, The Mojave Desert:-Ecosystem processes and sustainability: Reno, Nev., University of Nevada Press.

Vogt, R.C., and Hine, R.L., 1982, Evaluation of techniques for assessment of amphibian and reptile populations in Wisconsin., in Scott, N.J., ed., Herpetological communities. Wildlife Research Report 13: Washington, D.C., U.S. Fish and Wildlife Service, p. 201-217.

Wagner, D., and Jones, J.B., 2006, The impact of harvester ants on decomposition, $\mathrm{N}$ mineralization, litter quality, and the availability of $\mathrm{N}$ to plants in the Mojave Desert: Soil Biology and Biochemistry, v. 38, no. 9, p. 2593-2601.

Wagner, D., Jones, J.B., and Gordon, D.M., 2004, Development of harvester ant colonies alters soil chemistry: Soil Biology and Biochemistry, v. 36, no. 5, p. 797-804. 
Wallace, A., 1989, Comparative growth of four shrub species in a native desert soil and an amended non-calcareous soil and some unsolved problems in mineral nutrition of desert shrubs, in McArthur, E.D., Wallace, A., and Haferkamp, M.R., eds., Proceedings: Symposium on shrub ecophysiology and biotechnology, June 30-July 2, 1987, Logan, Utah: Ogden, Utah, USDA Forest Service, Intermountain Research Station, General Technical Report INT-256, p. 169-172.

Wallace, A., and Romney, E.M., 1972, Radioecology and ecophysiology of desert plants at the Nevada Test Site: Springfield, Va., National Technical Information Service, TID-25954, 283 p.

Wallace, A., Romney, E.M., and Hunter, R.B., 1980, The challenge of a desert-Revegetation of disturbed desert lands: Great Basin Naturalist Memoirs, v. 4, p. 216-225.

Wallace, C.S.A., Webb, R.H., and Thomas, K.A., 2008, Estimation of perennial vegetation cover distribution in the Mojave Desert using MODIS-EVI data: GIScience \& Remote Sensing, v. 45, no. 2, p. 167-187.

Walvoord, M.A., Phillips, F.M., Stonestrom, D.A., Evans, R.D., Hartsough, P.C., Newman, B.D., and Striegl, R.G., 2003, A reservoir of nitrate beneath desert soils: Science, v. 302, no. 5647, p. 1021-1024.

Wardle, D.A., 2002, Communities and ecosystems-Linking the aboveground and belowground components: Princeton, N.J., Princeton University Press, Monographs in population biology 34, $400 \mathrm{p}$.

Wardle, D.A., and Lavelle, P., 1997, Linkages between soil biota, plant litter quality and decomposition, in Cadisch, G., and Giller, K.E., eds., Driven by nature-Plant litter quality and decomposition: Oxon, U.K., CAB International/Oxford University Press, p. 107-124.

Webb, R.H., 1982, Off-road motorcycle effects on a desert soil: Environmental Conservation, v. 9, no. 3, p. 197-208.

Webb, R.H., 1983, Compaction of desert soils by off-road vehicles, in Webb, H.G., and Wilshire, H.G., eds., Environmental effects of off-road vehicles-Impacts and management in arid regions: New York, Springer-Verlag, p. 51-79.

Webb, R.H., 2002, Recovery of severely compacted soils in the Mojave Desert, California, USA: Arid Land Research and Management, v. 16, no. 3, p. 291-305.

Webb, R.H., Belnap, J., and Thomas, K.A., in press, Natural recovery from severe disturbance in the Mojave Desert, in Webb, R.H., Fenstermaker, L.F., Heaton, J.S., Hughson, D.L., McDonald, E.V., and Miller D.M., eds., The Mojave Desert-Ecosystem processes and sustainability: Reno, Nev., University of Nevada Press.
Webb, R.H., Belnap, J., and Weisheit, J.S., 2004, Cataract Canyon: A human and environmental history of the rivers in Canyonlands: Salt Lake City, Utah, University of Utah Press, 268 p.

Webb, R.H., Esque, T.C., Medica, P.A., and DeFalco, L.A., 2001, Monitoring of ecosystem dynamics in the Mojave Desert-The Beatley permanent plots: U.S. Geological Survey Fact Sheet 040-01, 4 p.

Webb, R.H., Fenstermaker, L.F., Heaton, J.S., Hughson, D.L., McDonald, E.V., and Miller, D.M., in press, The Mojave Desert: Ecosystem processes and sustainability: Reno, Nev., University of Nevada Press.

Webb, R.H., Melis, T.S., Griffiths, P.G., Elliott, J.G., Cerling, T.E., Poreda, R.J., Wise, T.W., and Pizzuto, J.E., 1999, Lava Falls Rapid in Grand Canyon-Effects of late Holocene debris flows on the Colorado River: U.S. Geological Survey Professional Paper 1591, 90 p.

Webb, R.H., Murov, M.B., Esque, T.C., Boyer, D.E., DeFalco, L.A., Haines, D.F., Oldershaw, D., Scoles, S.J., Thomas, K.A., Blainey, J.B., and Medica, P.A., 2003, Perennial vegetation data from permanent plots on the Nevada Test Site, Nye County Nevada: U.S. Geological Survey Open-File Report 03-336, 251 p.

Webb, R.H., Steiger, J.W., and Newman, E.B., 1988, The response of vegetation to disturbance in Death Valley National Monument, California: U.S. Geological Survey, . Bulletin 1793, 103 p.

Webb, R.H., Steiger, J.W., and Wilshire, H.G., 1986, Recovery of compacted soils in Mojave Desert ghost towns: Soil Science Society of America Journal, v. 50, no. 5, p. 1341-1344.

Webb, R.H., and Stielstra, S.S., 1979, Sheep grazing effects on Mojave Desert vegetation and soils: Environmental Management, v. 3, no. 6, p. 517-529.

Webb, W., Szarek, S., Lauenroth, W., Kinerson, R., and Smith, M., 1978, Primary productivity and water use in native forest, grassland, and desert ecosystems: Ecology, v. 59, no. 6, p. 1239-1247.

Webb, R.H., and Thomas, K.A., 2003, Recoverability of severely disturbed soils and vegetation in the Mojave Desert, California, USA, in Alsharhan, A.S., Wood, W.W., Goudie, A., Fowler, A., and Abdellatif, E.M., eds., Desertification in the Third Millennium, Proceedings of an international conference, February 12-16, 2000, Dubai, United Arab Emerites: Lisse, The Netherlands, Swets and Zeitlinger, p. 283-289.

Webb, R.H., and Wilshire, H.G., 1980, Recovery of soils and vegetation in a Mojave Desert ghost town, Nevada, U.S.A.: Journal of Arid Environments, v. 3, no. 4, p. 291-303. 
Webb, R.H., and Wilshire, H.G., eds., 1983, Environmental effects of off-road vehicles-Impacts and management in arid regions: New York, Springer-Verlag, Springer Series on Environmental Management, 534 p.

Webb, R.H., Wilshire, H.G., and Henry, M.A., 1983, Natural recovery of soils and vegetation following human disturbance, in Webb, R.H., and Wilshire, H.G., eds., Environmental effects of off-road vehicles-Impacts and management in arid regions: New York, Springer-Verlag, $p$. 279-302.

Wells, P.V., 1961, Succession in desert vegetation on streets of a Nevada ghost town: Science, v. 134, no. 3480, p. 670-671.

Wells, S.G., McFadden, L.D., and Dohrenwend, J.C., 1987, Influence of late Quaternary climatic changes on geomorphic and pedogenic processes on a desert piedmont, eastern Mojave Desert: Quaternary Research, v. 27, p. 130-146.

Weltzin, J.F., Loik, M.E., Schwinning, S., Williams, D.G., Fay, P.A., Haddad, B.M., Harte, J., Huxman, T., Knap, A.K., Lin, G., Pockman, W.T., Shaw, M.R., Small, E.E., Smith, M.D., Smith, S.D., Tissue, D.T., and Zak, J., 2003, Assessing the response of terrestrial ecosystems to potential changes in precipitation: BioScience, v. 53, no. 10, p. 941-952.

Went, F.W., 1948, Ecology of desert plants. I. Observations on germination in the Joshua Tree National Monument, California: Ecology, v. 29, no. 3, p. 242-253.

Went, F.W., 1949, Ecology of desert plants. II. The effect of rain and temperature on germination and growth: Ecology, v. 30 , no. 1 , p. 1-13.

Went, F.W., and Westergaard, M., 1949, Ecology of desert plants. III. Development of plants in the Death Valley National Monument, California: Ecology, v. 30, no. 1, p. 26-38.

Whelan, R.J., 1995, The ecology of fire: New York, Cambridge University Press, $356 \mathrm{p}$.

Whicker, J.J., Breshears, D.D., Wasiolek, P.T., Kirchner, T.B., Tavani, R.A., Schoep, D.A., and Rodgers, J.C., 2002, Temporal and spatial variation of episodic wind erosion in unburned and burned semiarid shrubland: Journal of Environmental Quality, v. 31, no. 2, p. 599-612.

Whisenant, S.G., 1999, Repairing damaged wildlands: A process-oriented, landscape-scale approach to biological conservation, restoration, and sustainability: Cambridge, U.K., Cambridge University Press, 312 p.

White, G.C., Anderson, D.R., Burnham, K.P., and Otis., D.L., 1982, Capture-recapture and removal methods for sampling closed populations: Los Alamos, N. Mex., Los Alamos National Laboratory, Technical Report LA-8787NERP, 249 p.
White, P.S., and Pickett, S.T.A., 1985, Natural disturbance and patch dynamics-An introduction, in Pickett, S.T.A., and White, P.S., eds., The ecology of natural disturbance and patch dynamics: San Diego, Calif., Academic Press, p. 3-13.

Whitford, W.G., 1973, Jornada validation site report: Logan, Utah, Utah State University, U.S. International Biological Program, Desert Biome Research Memorandum, 73-4p. 135-167.

Whitford, W.G., 1978, La structure et l'activité saisonnière des sociétés de fourmis de la région désertique de Chihuahua (Structure and seasonal activity of Chihuahua Desert ant communities): Insectes Sociaux, v. 25, no. 1, p. 79-88.

Whitford, W.G., 1998, Validation of indicators, in Rapport, D.J., Costanza, R., Epstein, P.R., Gaudet, C., and Levins, R., eds., Ecosystem health: Malden, Mass., Blackwell Science, p. 205-209.

Whitford, W.G., 2002, Ecology of desert systems: San Diego, Calif., Academic Press, 343 p.

Whitford, W.G., Forbes, G.S., and Kerley, G.I., 1995, Diversity, spatial variability and functional roles of invertebrates in desert grassland ecosystems, in McClaran, M.P., and Van Devender, T.R., eds., The desert grassland: Tucson, Ariz., University of Arizona Press, p. 152-195.

Whitford, W.G., and Kay, F.R., 1999, Biopedturbation by mammals in deserts: A review: Journal of Arid Environments, v. 41, no. 2, p. 203-230.

Wilcox, B.P., Breshears, D.D., and Allen, C.D., 2003, Ecohydrology of a resource-conserving semiarid woodland: Effects of scale and disturbance: Ecological Monographs, v. 73, no. 2, p. 223-239.

Williams, J.D., Dobrowolski, J.P., and West, N.E., 1995a, Microphytic crust influence on interrill erosion and infiltration capacity: Transactions of the American Society of Agricultural Engineers, v. 38, no. 1, p. 139-146.

Williams, J.D., Dobrowolski, J.P., West, N.E., and Gillette, D.A., 1995b, Microphytic crust influence on wind erosion: Transactions of the American Society of Agricultural Engineers, v. 38, no. 1, p. 131-137.

Williams, R.B., and Bell, K.L., 1981, Nitrogen allocation in Mojave Desert winter annuals: Oecologia, v. 48, no. 2, p. 145-150.

Wills, C.A., and Ostler, W.K., 2001, Ecology of the Nevada Test Site-An annotated bibliography: Las Vegas, Nev., Bechtel Nevada, DOE/NV/11718-594, 386 p.

Wilshire, H.G., Howard, K.A., Wentworth, C.M., and Gibbons, H., 1996, Geologic processes at the land surface: U.S. Geological Survey Bulletin 2149, 41 p. 
Wilshire, H.G., and Nakata, J.K., 1976, Off-road vehicle effects on California's Mojave Desert: California Geology, v. 29 , p. $123-132$.

Wilson, D.E., Cole, F.R., Nichols, J.D., Rudran, R., and Foster, M.S., 1996, Measuring and monitoring biological diversity: Standard methods for mammals: Washington, D.C., Smithsonian Institution Press, 409 p.

Wolman, M.G., 1954, A method for sampling coarse river bed material: American Geophysical Union Transactions, v. 35, p. 951-956.

Woodbury, A.M., and Hardy, R., 1948, Studies of the desert tortoise, Gopherus agassizii: Ecological Monographs, v. 18, no. 2 , p. $145-200$.

Woodward, B., 1994, Reptile populations on the Nevada Test Site in 1993, in Hunter, R.B., ed., Status of the flora and fauna on the Nevada Test Site, 1993: Las Vegas, Nev., Reynolds Electrical and Engineering Co., Inc., Report DOE/ NV/11432-162, p. 1-35.

Wu, J., and Levin, S.A., 1994, A spatial patch dynamic modeling approach to pattern and process in an annual grassland: Ecological Monographs, v. 64, no. 4, p. 447-464.

Yates, T.L., 1996, Tissues, cell suspensions, and chromosomes, in Wilson, D.E., Cole, F.R., Nichols, J.D., Rudran, R., and Foster, M.S., eds., Measuring and monitoring biological diversity: Standard methods for mammals: Washington, D.C., Smithsonian Institution Press, p. 275-278.

Young, J.A., Evans, R.A., and Eckert Jr., R.E., 1969, Population dynamics of downy brome: Weed Science, v. 17, p. 20-26.

Zar, J.H., 1984, Biostatistical analysis (2nd ed.): Englewood Cliffs, N.J., Princeton Hall, 718 p.

Zhou, L., Tucker, C.J., Kaufmann, R.K., Slayback, D., Shabanov, N.V., and Myneni, R.B., 2001, Variations in northern vegetation activity inferred from satellite data of vegetation index during 1981 to 1999: Journal of Geophysical Research, v. 106, p. 20,069-20,083.

Zweifel, R.G., and Lowe, C.H., 1966, The ecology of a population of Xantusia vigilis, the desert night lizard: American Museum Novitiates, v. 2247, p. 1-57. 


\section{Appendix A: Trigger-Transfer-Reserve- Pulse}

The trigger-transfer-reserve-pulse (TTRP) framework (Ludwig and others, 1997) is a useful framework for understanding how resource patterning affects ecosystem processes and how these components and processes are connected in drylands (fig. A1). "Triggers" are events, such as rain, that elicit a response from the ecosystem. "Transfer" is the vertical or horizontal movement of materials (for example, water, nutrients, soil) across the landscape in response to the trigger. In deserts, this is generally done by wind and water. Transfer patterns vary naturally among different ecosystems (figs. A2 and A3). Transferred resources are either retained by the receiving patch (the reserve) or leave the system. The retained resources, when triggered by an event, respond with a resource pulse (for example, microbial activity, germination of vascular plants). This framework emphasizes that landscape components are connected by the transfer of materials and highlights feedback processes that regulate and maintain landscape function. Because of the integral connection between plants and soils, any changes in the distribution of one will affect the other. Understanding the distribution of ecosystem components and their connections is essential to the design and implementation of an effective monitoring program. Whereas the example below uses rainfall as the trigger, similar scenarios can be constructed for other triggers.

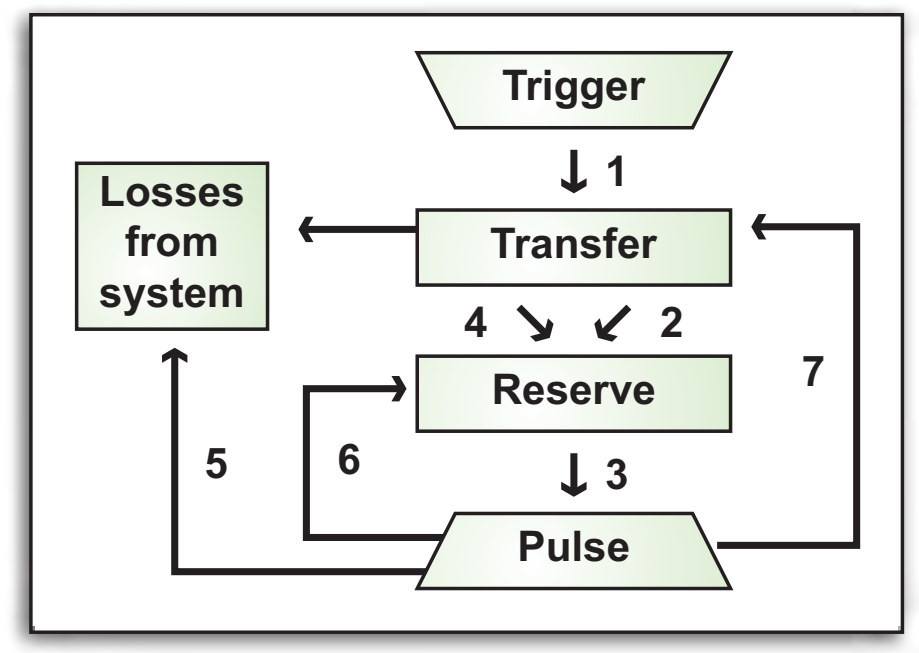

Figure A1. A conceptual framework representing sequences of landscape ecological and hydrological processes and feedback loops. Examples of processes are (1) rainstorm; (2) infiltration, capture, and retention or storage; (3) plant germination, nutrient mineralization, and uptake processes; (4) soil loss, runoff into streams, rill flow, and erosion; (5) herbivory, leaching, fire, harvesting, and deep drainage; (6) biomass increase, nutrient availability, and organic matter cycling; and (7) physical obstruction/absorption processes (adapted from Belnap and others, 2005).

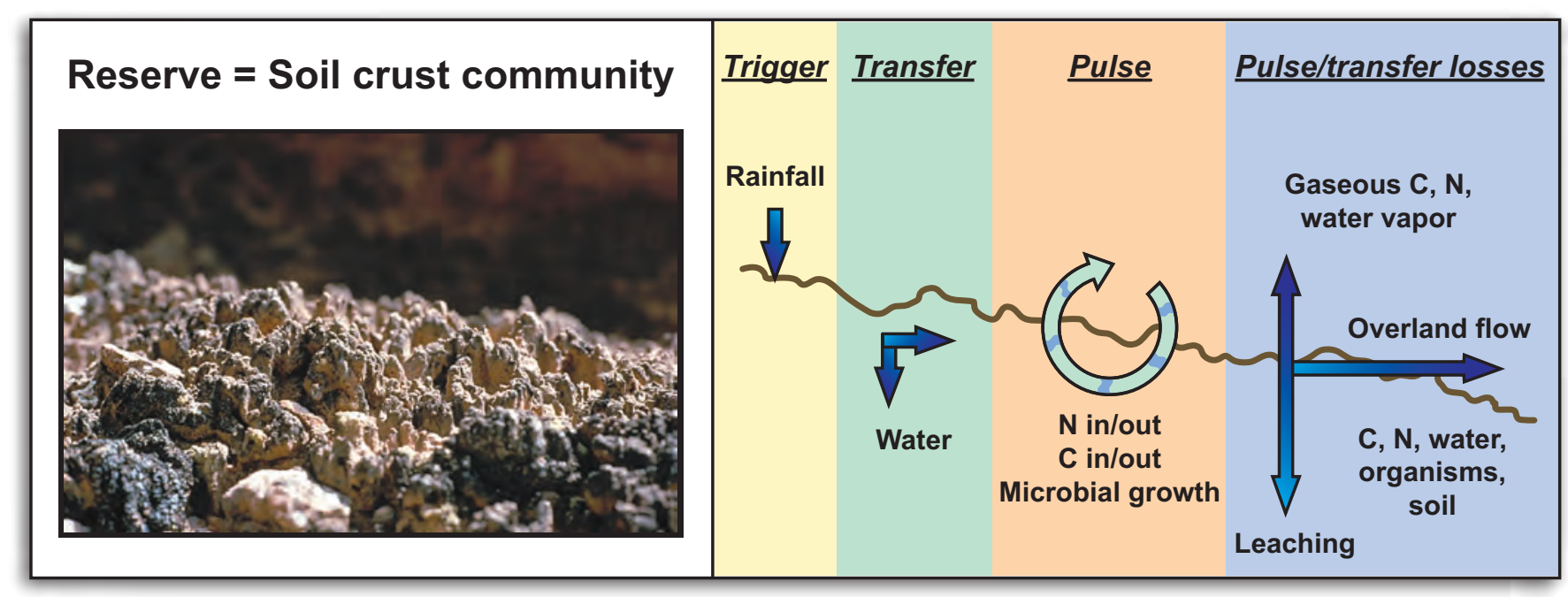

Figure A2. Trigger-transfer-reserve-pulse (TTRP) model applied to the plant interspace. The trigger is precipitation, and the reserve is the soil biotic community. Pulses discussed here include nitrogen (N) and carbon (C) dynamics. Transfer and losses include water, carbon, nitrogen, organisms, and soil (adapted from Belnap and others, 2005). 


\section{A Reserve $=$ hillslope patches}

\section{Transfer}

\section{$B$ Hillslope patch configurations}

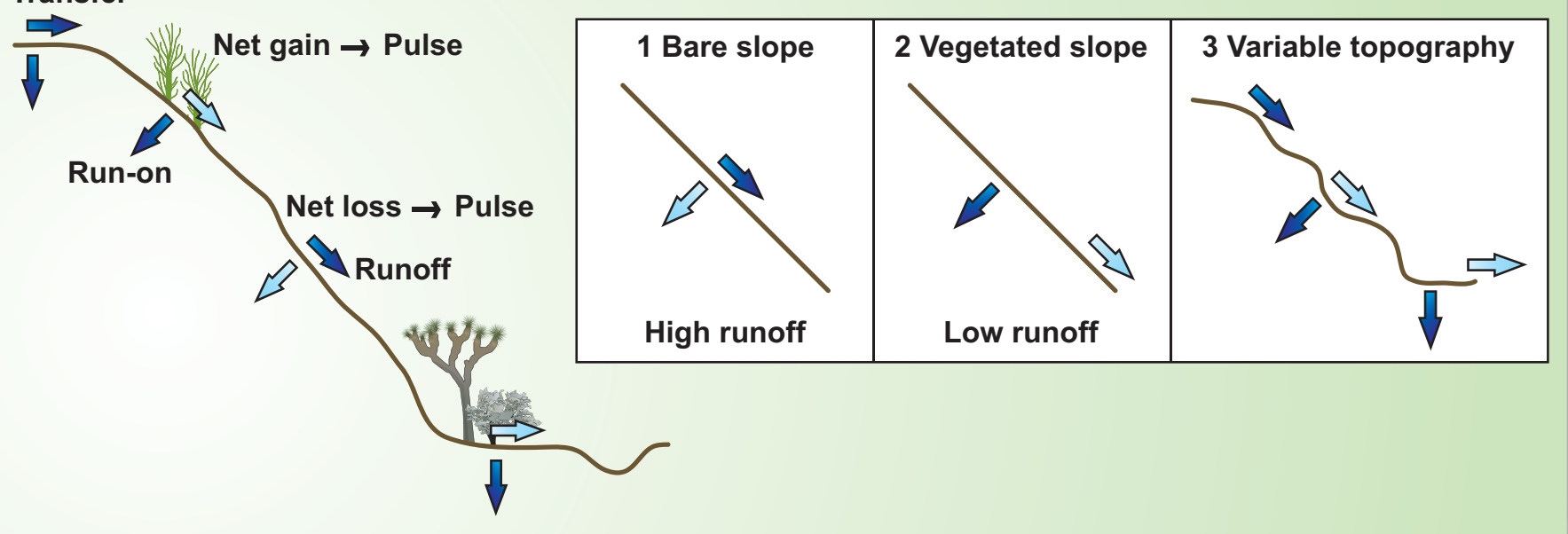

Figure A3. A, Stylized depiction of a desert hillslope including vegetated and non-vegetated patches arrayed along a topographical gradient from ridge top to valley bottom. Vegetated patches and topographic depressions have greater capacity to absorb rainfall, leading to greater pulses of microbial activity and less runoff when compared to plant interspaces. B, Hypothesized effect of hillslope patch configuration on hydrologic and material retention. Bare slopes have (1) little capacity to absorb water and nutrients in comparison with vegetated hillslopes (2), and those with variable topography (3), including topographic flats or depressions. Since topographic depressions and vegetated areas increase retention, hillslope patch configuration may influence overall retention. As runoff volume and material redistribution increase (with increasing storm intensity), the effects of patch configuration on hillslope retention may become more pronounced. Dark blue arrows indicate more water movement, while light blue arrows indicate less.

\section{Example of the Trigger-Transfer-Reserve-Pulse Model at the Local and Hillslope Scale, Using Rainfall as the Trigger}

\section{Example of Reserves: Plant Interspaces, Plant Islands, and Hillslopes}

Plant interspace patches are generally covered by biological soil crusts, which mediate most gas, nutrient and water inputs to, and losses from, desert soils. Other factors, such as rocks, plant litter, ant mounds and surface roughness, also influence processes in the interspace patch. In wet years, the interspace patch supports a significant cover of annual plants. Plant island patches in the Mojave Desert generally show increased water availability, infiltration, organic matter, soil biota, and faunal abundance when compared to the plant interspace soils (for example, Jackson and Caldwell, 1993; Smith and others, 1995; Breshears and others, 1998; Schlesinger and Pilmanis, 1998; Breshears and Barnes, 1999; Cross and Schlesinger, 1999; Dunkerley, 2000; Bolling and Walker, 2002; Bhark and Small, 2003). The pattern (spacing, density, composition) of plant patches in arid ecosystems has been linked to the mechanisms by which water is redistributed from the interspace to the plant island patches (for example, Sanchez and Puigdefabregas, 1994; Puigdefabregas and Sanchez, 1996; HilleRisLambers and others, 2001; Wilcox and others, 2003). At the hillslope scale, a given area can be envisioned as a series of plant and interspace patches. At this scale, more organic matter, nutrients, and microbial biomass occur in valley bottoms relative to ridge tops (Gallardo and Schlesinger, 1992).

\section{Example of Resource Transfer: Horizontal and Vertical Movement of Water, Sediments, and Nutrients}

The interplay between the intensity of the trigger (for example, wind or precipitation) and site characteristics (for example, the arrangement of plant interspaces and islands; topographic position; aspect and slope, soil hydraulic conductivity; and the presence, structure, and arrangement of ground surface cover) will determine whether materials are absorbed by the receiving patch or transferred downslope (Tongway and Ludwig, 1997; Puigdefabregas and others, 1999). The arrangement of plants can differentially affect water flow velocity and direction (fig. A3). Stems can deflect flow and soils under shrubs often have greater water and nutrient absorption than interspace soils (Abrahams and Parsons, 1994). During wet years, annual plants that occur in plant interspaces slow the transfer of water and sediment. When rainfall rates exceed interspace or plant island infiltration rates, the resultant overland flow horizontally redistributes water, sediment, and nutrients. Losses are determined by interspace characteristics. For 
example, smooth and thin cyanobacterial soil crusts will allow more nutrients, sediment, and water to be transferred from the interspace soils than rough and thick lichen soil crusts. Nutrients lost from a given patch can provide a resource subsidy for receiving patches or be lost to downslope intermittent washes. Retention is concentrated in "run-on" patches-generally mounds around plant bases and topographic depressions, depending on the scale being measured.

There are other avenues of water and nutrient loss. The dominant loss pathway for water is evaporation, and rates for a given area are influenced by the amount, arrangement and cover of plant patches, as well as ground cover of interspace patches. Evaporation is lower under lichen soil crusts than cyanobacterial soil crusts (George and others, 2003). Soils shaded by plants will dry more slowly than soils in full sun. In wetter years, both subsurface patch connectivity and vertical losses may be greater. Downward leaching of carbon and nitrogen is thought to be very low in deserts, but may be substantial in coarse-textured soils, especially after low-intensity synoptic storms accompanied by high infiltration rates (Walvoord and others, 2003). Soil erosion by wind can lead to substantial loss of soil fertility (Neff and others, 2005).

\section{Example of a Pulse Response to the Trigger: Carbon and Nitrogen Dynamics}

Because microbial activity can occur only when soils are sufficiently wet, local and hillslope patch structure interacts with incoming rainfall to create a mosaic of microbial activity. Microbial respiration begins immediately upon wetting and across a range of temperatures, whereas photosynthesis requires light and optimal temperatures (Lange, 2003). Thus, precipitation that occurs at night, in small events, and/or when soil temperatures are high, often results in carbon losses for

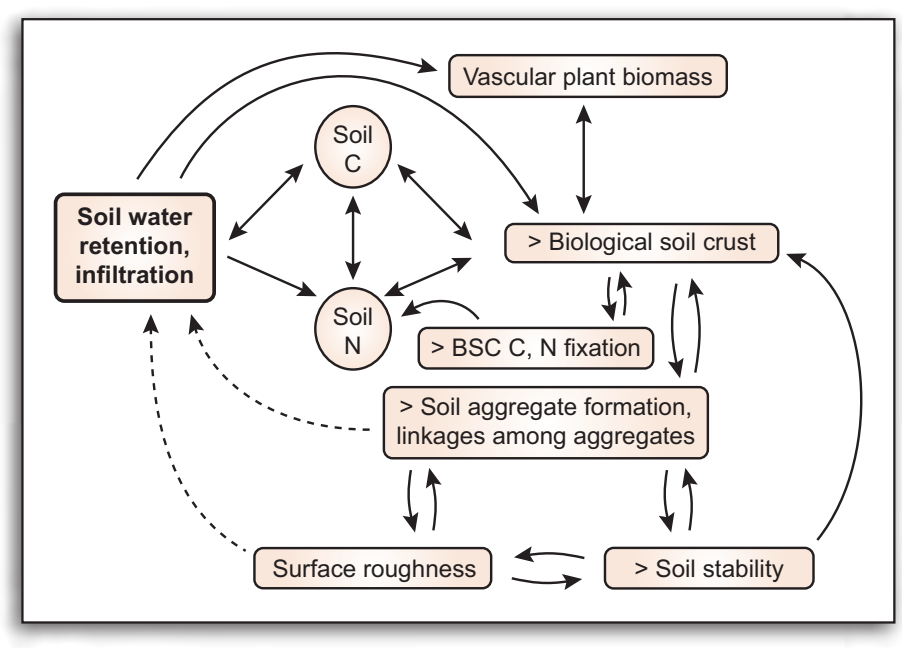

Figure A4. Many feedbacks that occur in deserts influence the effect of moisture pulses on multiple scales, including those of the plant interspace patch, plant patch, and hillslope patch. The solid lines represent linkages that have been explicitly studied; the dotted arrows represent connections that require further study. soil autotrophs (Jeffries and others, 1993). Wetting of dry soils also kills up to $1 / 2$ of the soil microbial biomass through osmolysis (Kieft and others, 1987), releasing microbial carbon and nitrogen that stimulates a pulse of microbial activity (for example, Marumoto and others, 1982). Rapid increases in microbial biomass (Kieft and others, 1987) and microbial process rate (for example, nitrogen mineralization, nitrification) occur with wetting (Davidson and others, 1993; Fisher and Whitford, 1995). Longer time periods between wetting events result in greater microbial activity once soils are wetted than when times between wetting events are shorter, because resource availability increases over time as organic matter photo-degrades (Moorhead and Callaghan, 1994), atmospheric deposition results in a buildup of nitrogen, phosphorus, and other nutrients on the soil surface (Verrecchia and others, 1995), and microbes die.

Potential carbon and nitrogen mineralization rates are generally higher in vegetated patch reserves than interspace patch reserves, given the higher soil organic matter found there (Kieft and others, 1998; Burke and others, 1999). Spatial variation in microbial processes at the hillslope and landscape scale is expected to be highest in summer due to differential evaporation rates among the patches; the variable influence of aspect, slope, vegetation; and the localized nature of short high-intensity rains. This will create greater disparity between gaining (positive carbon and nitrogen balance) and losing (negative carbon and nitrogen balance) patches in hot summer months compared to winter months. During wet years, increased water availability can create carbon and nitrogen limitations (Mummey and others, 1997).

Losses of carbon and nitrogen also vary according to season and patch type, as these processes are dependent on soil temperature and moisture. In all deserts, the rate of nitrogen loss peaks in the hot summer months. However, total losses during the three dry and hot summer months can be similar to total losses during the wetter nine-month fall-spring season. Vegetated and soil lichen patches have higher rates of denitrification and respiration than bare interspaces or those covered with cyanobacterial crust (Virginia and others, 1982; Bolton and others, 1993; Lange, 2003). Winter-rainfall-dominated regions of the Mojave likely have less overlap between the timing of maximal nitrogen inputs (fall, winter, spring) and losses (summer) than in summer-rainfall-dominated regions, where maximum inputs and losses may coincide in time and space (summer). Disturbance is also important, as it decreases the input and increases the loss of both carbon and nitrogen (Belnap and Eldridge, 2003).

\section{Example Feedbacks between Transfers, Reserves, and Pulses}

Many feedbacks determine how precipitation events influence processes on scales ranging from interspace to hillslope (fig. A4). For instance, the longer soil crusts are wet, the more carbon and nitrogen they fix. More carbon and nitro- 
gen results in more soil biota and plant biomass. Increased biomass increases soil aggregates, soil surface roughness, and soil stability, all of which increase retention of water and organic matter (Tongway and Ludwig, 1997). Greater retention of resources results in more microbial activity, and thus soil biota and plant biomass. There are also strong feedbacks between plant and interspace patches (Charley and West, 1975; Schlesinger and others, 1990, 1996). Because patches vary in their ability to intercept and retain water and provide nutrients, the strength of the feedback will vary among patches. Spatial configuration of patches will also influence water and nutrient retention on the hillslope, particularly as storm size and intensity increase (fig. A3). Plants influence the spatial and temporal distribution of soil resources through the capture of soil, water, organic matter, root exudates, litter deposition, shading of soils, concentration of soil biota, and nutrient uptake (for example, Noy-Meir, 1973; Tongway and Ludwig, 1994; Reid and others, 1999; Whitford, 2002; Ludwig and others, 2005; Puigdefabregas, 2005). Vegetation patterns, in turn, are driven by patterns of soil resource availability (Aguiar and Sala, 1999). Changes in the distribution of vegetation or soil resources at any scale can therefore determine the amount of resources that are retained or lost from an ecosystem at all scales.

\section{Intra-patch Dynamics}

There are also many dynamics that occur within a given patch that are important in ecosystem functioning. Competition and facilitation among biota can be important, because water and nutrients (or forage) are often limited in desert settings. Plants of similar functional types (for example, deeply rooted perennial shrubs) can compete for space and water (Brisson and Reynolds, 1994; Cody, 2000). Although data is generally lacking, it is assumed that dissimilar functional types (for example, shallow and deep rooting types) only compete for space, and that as long as water is partitioned into separate moisture pools, competition does not occur. Chesson and others (2004) suggest that climate variability, combined with differential plant phenology and competition, may drive species composition. When a preferred forage plant or habitat type is limited, animals can compete for resources within a patch as well (see sections on Ants and Termites and Small Mammals).

Facilitation may also be a common phenomenon within a plant patch. Exotic annual grasses preferentially grow under perennial shrubs. Many native plant seedlings use shrub canopies as "nurse" locations as well (Miriti and others, 1998; Brittingham and Walker, 2000; Schenk and Mahall, 2002), although these plants may eventually compete with each other. Facilitation can also occur among ecosystem components. For instance, biological soil crusts facilitate the development and maturity of subsurface soil biota (Belnap and Phillips, 2001; Austin and others, 2004; Schwinning and Sala, 2004). The conditions which determine whether relationships among ecosystem components are competitive or facilitating are not known. It is likely that competition and facilitation vary through time and space and are dependent on climate and resource variability (Chesson and others, 2004). 


\section{Appendix B: Mapping Surficial Geology}

Most geologic maps for the Mojave Desert made before about 1990 focused on bedrock geology and have sparse information on surficial deposits. Over about the past 15 years, new approaches have been developed to identify surficial deposits, interpret those surfaces in terms of the processes that created them, and place them in age categories based on soil development (McFadden and others, 1987; Wells and others, 1987; McDonald and others, 1995). The most reliable studies employ field investigations supplemented by stereoscopic analysis of aerial photography, which permits viewing of the three-dimensional landforms as well as tonal differences (Slate and Berry, 1999). Aids to evaluating surficial geology include satellite images, such as Landsat TM data (Menges and others, 1999, 2001) and MASTER and ASTER data (see pages 76-78). Scales used in preparing surficial geologic maps range from $1: 24,000$ to $1: 250,000$, representing very detailed surficial data to generalized information, respectively. For regional studies requiring a uniform presentation, a scale of 1:100,000 is the most useful and most widely available. Examples of these maps are Schmidt and McMackin (2002), Bedford (2003), and Bedford and others (2006).

Field work associated with surficial geologic mapping generally includes study of surface characteristics, such as desert pavements, which increase in density with age; desert varnish, which increases in darkness with age; bar-and-swale microtopography, the expression of which decreases with surface age; and surface roughness of particles, which dissolve and fracture with increasing age. By studying stream cuts and digging shallow pits, these surface characteristics are tied to deposit characteristics, such as the presence and thickness of the vesicular $\mathrm{A}(\mathrm{Av})$ horizon and the degree of development of soil horizons, indicated by such features as color changes in parent material (cambic horizon development); accumulation of clay (a process termed illuviation); and accumulation of pedogenic carbonate or gypsum into calcic or gypsic horizons, respectively. Ages of surficial deposits typically are assigned by correlation with surfaces of known age in the region, preferably a soil chronosequence (for example, Reheis and others, 1989). In order to be finalized, maps must pass a field inspection by experienced Quaternary geologists.

\section{Map Units Used to Describe Geomorphic Surfaces in the Mojave Desert}

In recent years, the U.S. Geological Survey has attempted to standardize map units used to depict Quaternary geomorphic surfaces. Correlation tables have been developed to compare past and present map units in the Mojave Desert (Menges and others, 2001). Slate and Berry (1999) presented a generalized table of the characteristics used in aerial photography interpretation to distinguish surficial deposits that span a wide range in ages. Menges and others (2001) give detailed descriptions of 11 surficial geology units used for mapping in the vicinity of Death Valley National Park in the northeastern Mojave Desert; for example, map units Qac, Qfy, Qfi, Qay, Qfo, and Qta depict alluvial deposits that range in age from recent (historic to several hundred years old) to the Tertiary (greater than two million years old). Map units used by the U.S. Geological Survey in the Mojave Desert of California for alluvial deposits are summarized in table B1.

Surficial map units can be used to interpret both the characteristics of perennial vegetation and some of the abiotic factors that could affect productivity and long-term stability (Miller and others, in press; Bedford and others, in press). Young geomorphic surfaces (for example, Qac, Qfy, Qfi) have little pedogenic modification or soil structure; typically, these are deep soils with relatively rapid infiltration rates and

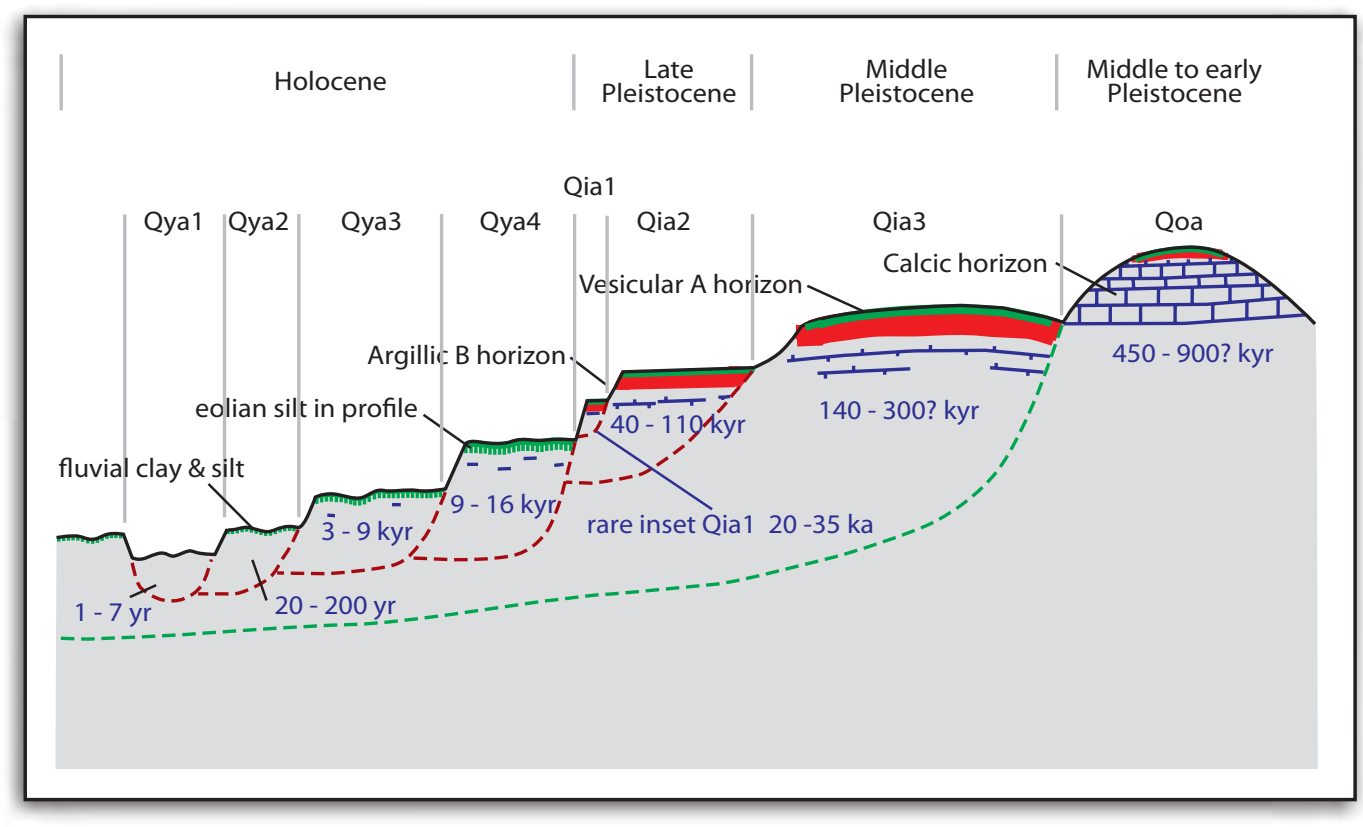

Figure B1. Schematic diagram showing units used in surficial geologic mapping in the Mojave Desert. All of the units are developed in alluvium or colluvium, as opposed to bedrock, and age generally increases from left to right. 
[Features in brown type are most diagnostic. Deposits are poorly dated, but as a general guideline, young (Qya) deposits are roughly younger than $15 \mathrm{ka}$ (ka $=$ kilo-annum, one thousand years), intermediate deposits (Qia) are about 30-250 ka, and old deposits (Qoa) are generally 500-800 ka. Bt = clay (argillic) horizon]

\begin{tabular}{|c|c|c|c|c|c|c|c|}
\hline \multicolumn{2}{|c|}{ Units on map } & \multirow{2}{*}{$\begin{array}{l}\text { Surface } \\
\text { topography or } \\
\text { processes }\end{array}$} & \multicolumn{5}{|c|}{ Characteristics } \\
\hline $\begin{array}{l}\text { Scale of } \\
1: 100,000\end{array}$ & $\begin{array}{l}\text { Scale of } \\
1: 24,000\end{array}$ & & Desert pavement & Desert varnish & Av (vesicular A) horizon & B (argillic) horizon & K (calcic) horizon \\
\hline Qaa & Qya1 & $\begin{array}{l}\text { Active wash or } \\
\text { fan }\end{array}$ & None & None & None & None & None \\
\hline \multirow{3}{*}{ Qya } & Qya2 & $\begin{array}{l}\text { Bars and } \\
\text { swales } \\
\text { prominent }\end{array}$ & None & None to very weak & $\begin{array}{l}\text { Generally no develop- } \\
\text { ment }\end{array}$ & None & None \\
\hline & Qya3 & $\begin{array}{l}\text { Remnant bar } \\
\text { and swale } \\
\text { topography, } \\
\text { somewhat } \\
\text { flattened } \\
\text { surface }\end{array}$ & Incipient (lag gravel) & Weak & $\begin{array}{l}\text { Weak, consisting of } \\
\text { sandy silt }\end{array}$ & $\begin{array}{l}\text { Weak development, } \\
\text { reddish (cambic) } \\
\text { development }\end{array}$ & $\begin{array}{l}\text { Stage I (rind under } \\
\text { pebbles) carbonate } \\
\text { development }\end{array}$ \\
\hline & Qya4 & $\begin{array}{l}\text { Weak remnant } \\
\text { bar and } \\
\text { swale topog- } \\
\text { raphy, fairly } \\
\text { flat surface }\end{array}$ & $\begin{array}{l}\text { Weak development with } \\
\text { some leveling of tops } \\
\text { of pebbles }\end{array}$ & $\begin{array}{l}\text { Weak to moderate on } \\
\text { desert pavement }\end{array}$ & $\begin{array}{l}\text { Weak, consisting of } \\
\text { loose sandy silt }\end{array}$ & Bt horizon development & $\begin{array}{l}\text { Stage I to II carbonate } \\
\text { development }\end{array}$ \\
\hline \multirow[t]{3}{*}{ Qia } & Qia1 & $\begin{array}{l}\text { Flat surface } \\
\text { with faint } \\
\text { bar and } \\
\text { swale }\end{array}$ & Weak to moderate & Moderate & $\begin{array}{l}\text { Structured silt, } 2-6 \mathrm{~cm} \\
\text { thick }\end{array}$ & $\begin{array}{l}\text { Strong red color (cam- } \\
\text { bic) development, } \\
\text { weak clay illuviation }\end{array}$ & Stage II (pebble rinds) \\
\hline & Qia2 & $\begin{array}{l}\text { Flat surface, } \\
\text { even pebble } \\
\text { size, pebble } \\
\text { tops level }\end{array}$ & Moderate to strong & Moderate to strong & $\begin{array}{l}\text { Structured silt, } 4-8 \mathrm{~cm} \\
\text { thick }\end{array}$ & $\begin{array}{l}\text { Bt horizon present with } \\
\text { moderate illuviated } \\
\text { clay }\end{array}$ & $\begin{array}{l}\text { Stage II to III carbonate } \\
\text { development }\end{array}$ \\
\hline & Qia3 & $\begin{array}{l}\text { Crowned } \\
\text { surface, } \\
\text { incipient } \\
\text { whaleback }\end{array}$ & $\begin{array}{l}\text { Strong to degraded; } \\
\text { exposed Av }\end{array}$ & $\begin{array}{l}\text { Strong with purplish } \\
\text { casts }\end{array}$ & $\begin{array}{l}\text { Structured silt, } 4-15 \mathrm{~cm} \\
\text { thick }\end{array}$ & $\begin{array}{l}\text { Bt present with high } \\
\text { clay content }\end{array}$ & $\begin{array}{l}\text { Stage III to IV (pores } \\
\text { filled) carbonate } \\
\text { development }\end{array}$ \\
\hline Qoa & Qoa & $\begin{array}{l}\text { Whaleback } \\
\text { (highly } \\
\text { crowned) } \\
\text { surface }\end{array}$ & $\begin{array}{l}\text { Calcic chips in pave- } \\
\text { ment }\end{array}$ & Secondary or none & Secondary or none & Secondary or none & $\begin{array}{l}\text { Stage IV — layered and } \\
\text { massive carbonate } \\
\text { development }\end{array}$ \\
\hline
\end{tabular}


relatively high cumulative biomass production. Vesicular A horizons restrict infiltration through the first soil horizon, and Av horizons increase in thickness and structure with age; desert pavements also develop, and surfaces smooth, reducing the potential for wind-transported seeds to lodge on the surface. Therefore, the potential for germination and establishment of certain perennial species may be diminished with increasing deposit age. Finally, eolian deposition over a pre-existing geomorphic surface may completely change its biotic characteristics, in effect making it more xerophytic than the original surface, despite no change in climate (D.M. Miller, oral commun.). As a result, the abiotic characteristics indicated

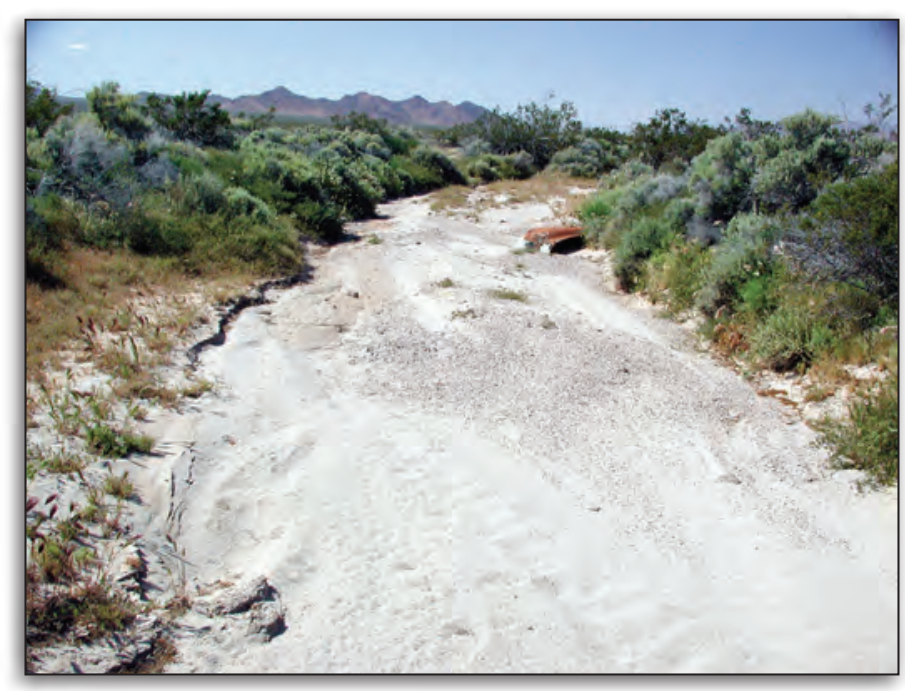

Figure B2. An active wash (Qya1 deposit) that recently flowed, spurring abundant growth of annual plants in bands along the sides of the wash. Perennial plants generally do not establish in active washes owing to periodic scour.

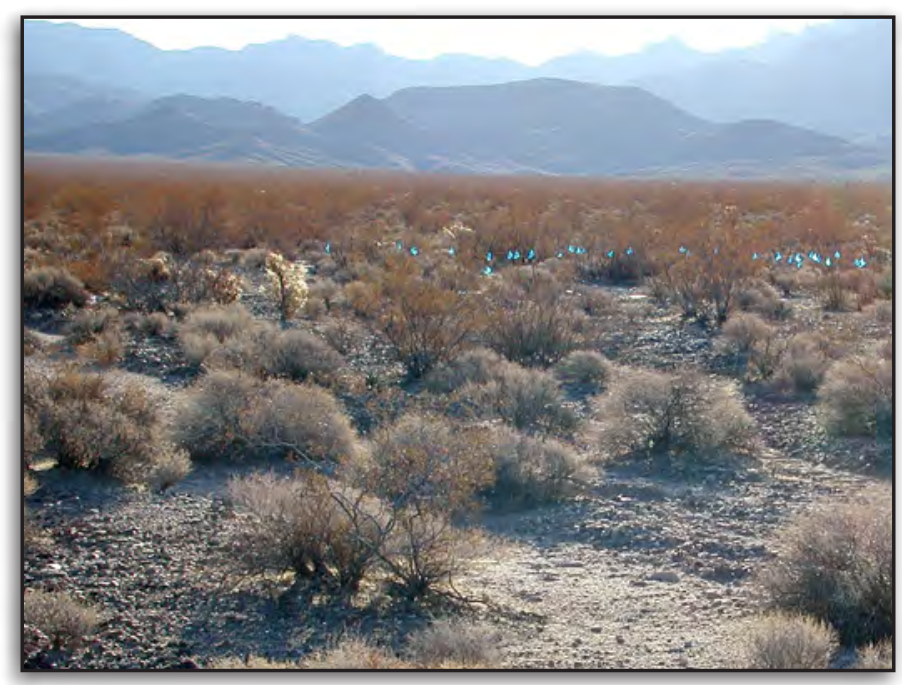

Figure B3. Ambrosia dumosa (white bursage) and Larrea tridentata (creosote bush) on an early Holocene piedmont (Oya4 surface) near Kelso, California. Opuntia echinocarpa (staghorn cholla) appears in the left midground, and the blue flags at center mark plants in a permanent plot. on surficial geologic maps may provide important regional information needed to properly design monitoring protocols to examine the range of natural variability, as well as potential effects of management actions.

Maps depicting geomorphic surfaces and surficial deposits of the Mojave Desert are available from the U.S. Geological Survey (http://geopubs.wr.usgs.gov), as well as the California Geological Survey, the Arizona Geological Survey, and the Nevada Bureau of Mines and Geology.

An understanding of landform types present in arid regions is important to a full appreciation of these maps. Readers can consult several publications for descriptions of common landforms in the Southwest, such as Peterson (1981). A description of alluvial channels is given by Parker (2000), and an online data source is the Mojave Desert Ecosystem Program (http://www.mojavedata.gov). Commonly used terms in soil science are given in Soil Science Society of America's Glossary of Soil Science Terms (1997), and a general application of soil sciences to surficial geology is presented by Birkeland (1984). Finally, Wilshire and others (1996) discuss geomorphic processes that affect the stability of geomorphic surfaces in the southwestern United States.

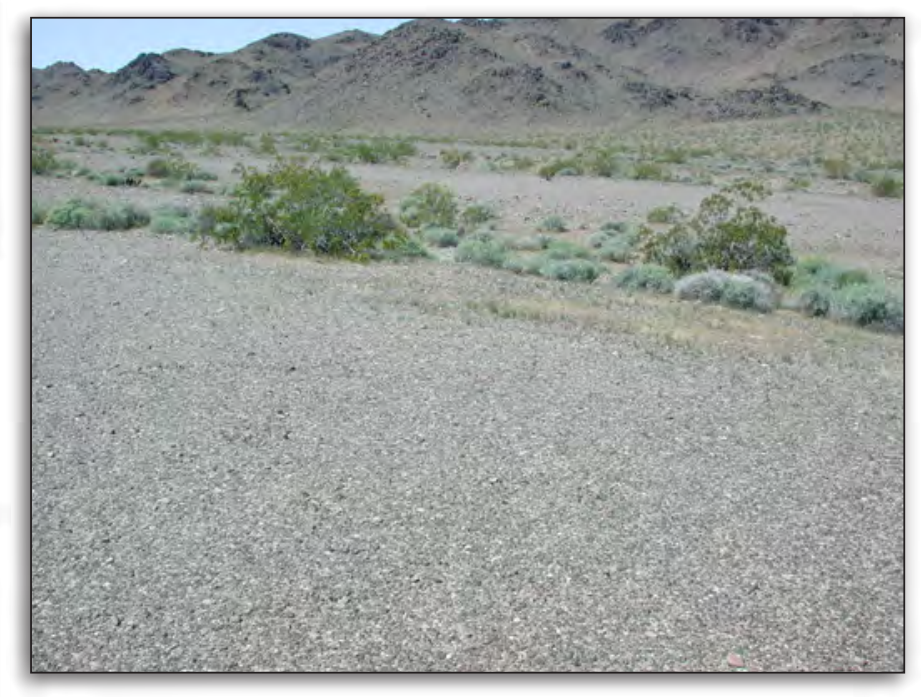

Figure B4. Desert pavement on a Qoa deposit with old soils devoid of perennial vegetation except in dissected gullies, where soil horizons are disrupted and Larrea tridentata (creosote bush) and Ambrosia dumosa (white bursage) are found. 


\section{Appendix C: Regression Relations For Perennial Plants}

Regression relations for indirect biomass calculations for common Mojave Desert perennial plants.

Table C1. Regression equation producing a dry-weight biomass (kg).

[ $V$ is the shrub volume, which is vaguely defined as a width and a height (adapted from Wallace and Romney, 1972, p. 252)]

\begin{tabular}{llrl}
\hline \multicolumn{1}{c}{ Species } & Regression equation & $\boldsymbol{n}$ & $\boldsymbol{R}^{2}$ \\
\hline Acamptopappus shockleyi & $2.36 V+0.004$ & 46 & 0.79 \\
Achnatherum hymenoides & $0.52 V+0.022$ & 6 & 0.59 \\
Ambrosia dumosa & $2.13 V+0.001$ & 67 & 0.79 \\
Ephedra funereal & $1.64 V-0.030$ & 16 & 0.86 \\
Grayia spinosa & $1.69 V+0.0433$ & 51 & 0.74 \\
Krameria parvifolia & $1.84 V-0.001$ & 34 & 0.74 \\
Krascheninnikovia lanata & $2.16 V-0.002$ & 51 & 0.76 \\
Larrea tridentata & $1.15 V+0.076$ & 33 & 0.83 \\
Lycium andersonii & $1.35 V+0.190$ & 52 & 0.77 \\
Machaeranthera tortifolia & $1.07 V-0.004$ & 13 & 0.98 \\
Sphaeralcea ambigua & $0.33 V+0.001$ & 16 & 0.77 \\
Yucca schidigera & $3.04 V+0.458$ & 13 & 0.59 \\
\hline
\end{tabular}


Table C2. Regression equation with no intercept that produces $K$, the dry-weight biomass $(\mathrm{kg})$.

$\left[V=\right.$ shrub volume $\left(\mathrm{m}^{3}\right)$, which is calculated as an elliptical tube using the equation $V=\underline{h \pi a b}$, where $h=$ height $(\mathrm{m})$ and $a$ and $b=$ diameters $(\mathrm{m} ; \mathrm{J} . \mathrm{E}$. Kinnear, University of California Los Angeles, written commun., 1979)] 4

\begin{tabular}{|c|c|c|}
\hline Species & $\begin{array}{c}\text { Volume-biomass } \\
\text { coefficient } K\end{array}$ & $\begin{array}{l}95 \% \text { confidence } \\
\text { limits }\end{array}$ \\
\hline Acamptopappus shockleyi & 3.1 & 0.3 \\
\hline Achnatherum hymenoides & 1.1 & 0.6 \\
\hline Achnatherum speciosum & 1. & 0.6 \\
\hline Ambrosia dumosa & 2.5 & 0.2 \\
\hline Artemisia spinescens & 4.1 & 0.4 \\
\hline Artemisia tridentata & 1.8 & 0.2 \\
\hline Atriplex canescens & 2.57 & 0.5 \\
\hline Atriplex confertifolia & 4.7 & 0.5 \\
\hline Atriplex polycarpa & 2.1 & 0.4 \\
\hline Coleogyne ramosissima & 5.2 & 0.5 \\
\hline Encelia virginensis & 1.1 & 0.1 \\
\hline Ephedra funereal & 2.3 & 0.4 \\
\hline Ephedra nevadensis & 1.4 & 0.3 \\
\hline Grayia spinosa & 2.3 & 0.2 \\
\hline Hymenoclea salsola & 3.2 & 0.4 \\
\hline Kochia americana & 3.1 & 0.3 \\
\hline Krameria parvifolia & 2.0 & 0.2 \\
\hline Krascheninnikovia lanata & 3.2 & 0.3 \\
\hline Larrea tridentata & 1.3 & 0.1 \\
\hline Lepidium fremontii & 3.2 & 0.4 \\
\hline Lycium andersonii & 2.2 & 0.2 \\
\hline Lycium pallidum & 1.2 & 0.1 \\
\hline Lycium shockleyi & 3.8 & 0.3 \\
\hline Machaeranthera tortifolia & 1.8 & 0.5 \\
\hline Menodora spinescens & 8.3 & 1.0 \\
\hline Pleuraphis rigida & 0.70 & 0.20 \\
\hline Psorothamnus fremontii & 2.5 & 0.5 \\
\hline Salsola iberica & 1.7 & 0.2 \\
\hline Salsola paulsenii & 2.1 & 0.2 \\
\hline Sitanian jubatum & 1.1 & 0.6 \\
\hline Sphaeralcea ambigua & 0.43 & 0.10 \\
\hline Tetradymia axillaries & 2.7 & 0.4 \\
\hline Tetradymia glabrata & 2.7 & 0.4 \\
\hline Thamnosma montana & 1.7 & 0.2 \\
\hline
\end{tabular}




\section{Monitoring Ecosystem Quality and Function in Arid Settings of the Mojave Desert}

Table C3. Regression equation with no intercept that produces $K$, the dry-weight biomass $(\mathrm{kg})$.

$[V=$ shrub volume (m3), which is calculated as an elliptical tube using the equation $V=\underline{h \pi a b}$, where $h=$ height $(\mathrm{m})$ and $a$ and $b=\operatorname{diameters}(\mathrm{m})$. Root $/ \mathrm{stem}$ ratio is live weight to live weight. n.d. = no data (Turner, 1973)]

\begin{tabular}{lccll}
\hline \multicolumn{1}{c}{ Species } & $\begin{array}{c}\text { Volume-biomass } \\
\text { coefficient } \boldsymbol{K}\end{array}$ & $\boldsymbol{n}$ & $\boldsymbol{R}^{2}$ & Root/stem ratio \\
\hline Acamptopappus shockleyi & 2.793 & 43 & 0.81 & 0.527 \\
Achnatherum hymenoides & 1.044 & 7 & 0.64 & n.d. \\
Ambrosia dumosa & 2.238 & 62 & 0.85 & 1.155 \\
Atriplex confertifolia & 4.864 & 28 & 0.96 & 0.427 \\
Coleogyne ramosissima & 5.232 & 16 & 0.96 & n.d. \\
Ephedra nevadensis & 1.492 & 7 & 0.85 & 0.835 \\
Grayia spinosa & 2.002 & 53 & 0.67 & 0.715 \\
Krameria parvifolia & 1.937 & 34 & 0.61 & 0.789 \\
Krascheninnikovia lanata & 3.046 & 56 & 0.83 & 0.900 \\
Larrea tridentata & 1.539 & 41 & 0.81 & 1.240 \\
Lycium andersonii & 1.975 & 56 & 0.69 & 0.835 \\
Lycium pallidum & 0.786 & 29 & 0.56 & 1.646 \\
Machaeranthera tortifolia & 1.615 & 11 & 0.62 & n.d. \\
\hline
\end{tabular}


Table C4. Regression equation with no intercept that produces $K$, the dry-weight biomass (kg).

$\left[V=\right.$ shrub volume $\left(\mathrm{m}^{3}\right)$, which is calculated as an elliptical tube using the equation $V=\underline{h \pi a b}$, where $h=$ height $(\mathrm{m})$ and $a$ and $b=$ diameters $(\mathrm{m}) . \mathrm{n} . \mathrm{d} .=$ no data, n.a. = not applicable. Sources: (1) California Desert Plan Staff, unpub. data, 1979.

(2) Garcia-Moya and McKell, 1970. (3) Storey, 1969. (4) Green and others, unpub. data, 1978]

\begin{tabular}{|c|c|c|c|c|}
\hline Species & $\begin{array}{c}\text { Volume-biomass } \\
\text { coefficient } K\end{array}$ & $n$ & $R^{2}$ & Source \\
\hline Acacia greggii & 0.8 & 20 & n.d. & 2 \\
\hline Acamptopappus sphaerocephalus & 10.65 & 7 & 0.90 & 1 \\
\hline Achnatherum hymenoides & 1.04 & 8 & 0.98 & 1 \\
\hline Achnatherum speciosum & 2.92 & 10 & 0.97 & 1 \\
\hline Ambrosia dumosa & 2.36 & 10 & 0.98 & 1 \\
\hline Artemisia spinescens & 4.01 & 10 & 0.94 & 1 \\
\hline Atriplex confertifolia & 6.39 & 10 & 0.99 & 1 \\
\hline Atriplex hymenelytra & 2.83 & 12 & 0.98 & 1 \\
\hline Atriplex polycarpa & 4.54 & 10 & 0.97 & 1 \\
\hline Chrysothamnus nauseosus & 3.49 & 10 & .84 & 1 \\
\hline Ceanothus greggii & 4.73 & 31 & 0.97 & 4 \\
\hline Cercidium floridum & 1.00 & 10 & 0.97 & 1 \\
\hline Coleogyne ramosissima & 4.80 & 10 & 0.94 & 1 \\
\hline Distichlis spicata & 1.82 & 9 & 0.89 & 1 \\
\hline Encelia farinosa & 0.91 & 10 & 0.89 & 1 \\
\hline Ephedra nevadensis & 4.29 & 10 & 0.94 & 1 \\
\hline Ephedra viridis & 5.47 & 5 & 0.99 & 1 \\
\hline Ericameria cooperi & 2.79 & 10 & 0.94 & 1 \\
\hline Ericameria linearifolia & 2.44 & 10 & 0.99 & 1 \\
\hline Eriogonum fasciculatum & 2.53 & 10 & 0.84 & 1 \\
\hline Erioneuron pulchellum & 1.46 & 7 & 0.92 & 1 \\
\hline Ferocactus cylindraceus & 107.29 & 6 & 0.98 & 1 \\
\hline Fouquieria splendens & 6.13 & 10 & 0.97 & 1 \\
\hline Grayia spinosa & 4.28 & 10 & 0.82 & 1 \\
\hline Gutierrezia microcephala & 2.11 & 5 & 0.93 & 1 \\
\hline Haplopappus gooddingii & 0.304 & 10 & 0.92 & 1 \\
\hline Hymenoclea salsola & 1.54 & 10 & 0.96 & 1 \\
\hline Juniperus osteosperma & 3.36 & 13 & 0.96 & 3 \\
\hline Krameria parvifolia & 0.98 & 10 & 0.96 & 1 \\
\hline Krameria grayii & 0.55 & 5 & n.d. & 2 \\
\hline Krascheninnikovia lanata & 3.90 & 7 & 0.83 & 1 \\
\hline Larrea tridentata & 2.14 & 10 & 0.86 & 1 \\
\hline Lycium brevipes & 12.98 & 10 & 0.95 & 1 \\
\hline Menodora spinescens & 8.36 & 5 & 0.89 & 1 \\
\hline Muhlenbergia porteri & 1.92 & 10 & 0.88 & 1 \\
\hline Olneya tesota & 0.91 & 10 & 0.91 & 1 \\
\hline Opuntia acanthocarpa & 1.098 & 16 & 0.98 & 1 \\
\hline Opuntia bigelovii & 10.2 & 2 & n.a. & 1 \\
\hline
\end{tabular}


Table C4. Regression equation with no intercept that produces $K$, the dry-weight biomass (kg).-Continued

$\left[V=\right.$ shrub volume $\left(\mathrm{m}^{3}\right)$, which is calculated as an elliptical tube using the equation $V=\underline{h \pi a b}$, where $h=$ height $(\mathrm{m})$ and $a$ and $b=$ diameters $(\mathrm{m}) . \mathrm{n} . \mathrm{d} .=\mathrm{no}$ data, n.a. = not applicable. Sources: (1) California Desert Plan Staff, unpub. data, 1979.

(2) Garcia-Moya and McKell, 1970. (3) Storey, 1969. (4) Green and others, unpub. data, 1978]

\begin{tabular}{lcccc}
\hline \multicolumn{1}{c}{ Species } & $\begin{array}{c}\text { Volume-biomass } \\
\text { coefficient } \boldsymbol{K}\end{array}$ & $\boldsymbol{n}$ & $\boldsymbol{R}^{\mathbf{2}}$ & Source \\
\hline Opuntia phaeacantha & 11.70 & 5 & 0.99 & 1 \\
Pinus monophylla & 2.47 & 26 & 0.98 & 3 \\
Pleuraphis jamesii & 5.21 & 10 & 0.88 & 1 \\
Pleuraphis rigida & 3.60 & 10 & 0.96 & 1 \\
Prosopis glandulosa & 0.81 & 10 & 0.86 & 1 \\
Prunus fasciculata & 3.45 & 5 & 0.98 & 1 \\
Psorothamnus polydenius & 4.00 & $\mathrm{n} . \mathrm{d}$. & $\mathrm{n} . \mathrm{d}$. & 1 \\
Psorothamnus spinosus & 0.63 & 10 & 0.91 & 1 \\
Salazaria mexicana & 0.9 & 50 & $\mathrm{n} . \mathrm{d}$. & 1 \\
Senna armata & 3.29 & 10 & 0.91 & 1 \\
Sporobolus airoides & 6.11 & 5 & 0.93 & 1 \\
Suaeda torreyana & 0.75 & 10 & 0.93 & 1 \\
Thamnosma montana & 2.99 & 5 & 0.97 & 1 \\
Tetradymia spinosa & 3.19 & 10 & 0.92 & 1 \\
Yucca baccata & 4.88 & 5 & 0.97 & 1 \\
Yucca brevifolia & 6.65 & 6.99 & 0.98 & 1 \\
Yucca schidigera & 16.94 & & & 1 \\
\hline
\end{tabular}


Table C5. This table includes estimates of volume density $(K)$ not included in tables C1-C4.

[ $e=$ estimated using an undocumented technique. See Table C4 for additional notes (Bureau of Land Management, 1980)]

\begin{tabular}{|c|c|c|c|}
\hline Species & $\begin{array}{c}\text { Volume density } \\
\quad(\mathrm{kg} / \mathrm{m} 3)\end{array}$ & Species & $\begin{array}{c}\text { Volume density } \\
(\mathrm{kg} / \mathrm{m} 3)\end{array}$ \\
\hline Agave deserti & $5.0 e$ & Muhlenbergia microsperma & $2.5 e$ \\
\hline Agave utahensis & $5.0 e$ & Nolina bigelovii & $17.0 e$ \\
\hline Allenrolfea occidentalis & $1.5 e$ & Opuntia basilaris & $11.7 e$ \\
\hline Aristida sp. & $2.9 e$ & Oputia echinocarpa & $1.1 e$ \\
\hline Artemisia nova & $1.8 e$ & Opuntia ramosissima & $1.1 e$ \\
\hline Atriplex lentiformis & $3.0 e$ & Petalonyx thurberi & $3.3 e$ \\
\hline Atriplex spinifera & $6.4 e$ & Peucephyllum schottii & $3.0 e$ \\
\hline Atriplex torreyi & $5.0 e$ & Poa scabrella & $1.1 e$ \\
\hline Bebbia juncea & $0.8 e$ & Prosopis pubescens & $0.8 e$ \\
\hline Beleperone californica & $3.0 e$ & Purshia glandulosa & $4.8 e$ \\
\hline Bouteloua curtipendula & $1.9 e$ & Quercus chrysolepis & $4.5 e$ \\
\hline Bouteloua eriopoda & $1.9 e$ & Quercus dumosa & $4.5 e$ \\
\hline Bouteloua gracilis & $1.9 e$ & Ribes velutinum & $1.0 e$ \\
\hline Brickellia arguta & $1.3 e$ & Salcornia utahensis & $1.5 e$ \\
\hline Cercocarpus intricatus & $4.0 e$ & Salix exigua & $1.0 e$ \\
\hline Cercocarpus ledifolius & $1.7 e$ & Salvia dorrii & $3.0 e$ \\
\hline Chilopsis linearis & $0.5 e$ & Salvia mohavensis & $3.0 e$ \\
\hline Chrysothamnus paniculatus & $3.5 e$ & Sarcobatus vermiculatus & $4.0 e$ \\
\hline Chrysothamnus teretifolius & $3.3 e$ & Sitanian hystrix & $1.1 \mathrm{e}$ \\
\hline Chrysothamnus viscidiflorus & $3.3 e$ & Stephanomeria pauciflora & $0.8 e$ \\
\hline Cowania mexicana & $4.8 e$ & Trixis californica & $1.0 e$ \\
\hline Psorothamnus polydenius & $3.0 e$ & Viguiera deltoidea $\mathrm{v}$. parishii & $1.0 e$ \\
\hline Echinocereus engelmanii & $10.0 e$ & & \\
\hline Encelia fructescens & $1.0 e$ & & \\
\hline Ephedra californica & $5.5 e$ & & \\
\hline Eriogonum wrightii & $3.0 e$ & & \\
\hline Fallugia paradoxa & $4.0 e$ & & \\
\hline Garrya flavescens & $4.7 e$ & & \\
\hline Gutierrezia californica & $2.1 e$ & & \\
\hline Hyptis emoryi & $1.3 e$ & & \\
\hline Isomeris arborea & $3.5 e$ & & \\
\hline Juniperus californica & $3.4 e$ & & \\
\hline Juniperus occidentalis & $3.4 e$ & & \\
\hline Lepidospartum squamatum & $3.0 e$ & & \\
\hline Lotus rigidus & $2.0 e$ & & \\
\hline Lycium cooperi & $2.0 e$ & & \\
\hline Mirabilis bigelovii & $0.4 e$ & & \\
\hline
\end{tabular}




\section{Appendix D: Additional Resources}

\section{Web Resources}

Bainbridge, D., MacAller, R., Fidelibus, M., Franson, R., Williams, A.C., and Lippit., L., 1995, A beginner's guide to desert restoration: Denver, Colo., Department of the Interior, National Park Service, Denver Service Center [http://www. westernecology.com/pdfs/bainbridgebook.pdf].

Desert Managers Group: Russel Scofield, DOI Coordinator, Phone: 760-365-0955, Cell: 760-900-5643, Fax: 760-3655526: http://www.dmg.gov/.

Bainbridge, D.A. Environmental restoration: http://www. ecocomposite.org/restoration/.

Thomas, K.A., Keeler-Wolf, T., Franklin, J., and Stine, P., 2004, Mojave Desert Ecosystem Program-Central Mojave vegetation database: U.S. Geological Survey, 251 p. [http:// www.dfg.ca.gov/biogeodata/vegcamp/pdfs/VegMappingRpt_ Central_Mojave_Vegetation_Database.pdf].

Mojave Desert Ecosystem Program: http://www.mojavedata. gov/.

Desert Research Institute: http://www.dri.edu/Aboutdri/.

Recoverability and Vulnerability of Desert Ecosystems: http:// mojave.usgs.gov/rvde/index.html.

Rangeland health-New methods to classify, inventory, and monitor rangelands: Committee on Rangeland Classification, Board on Agriculture National Research Council [http://books.nap.edu/openbook.php?record_ $\mathrm{id}=2212 \&$ page $=18]$.

Belnap, J., 2005, Biological soil crusts: http://www.soilcrust. org/

\section{Other Resources}

Bauder, E.T., and Larigauderie, A., 1991, Rehabilitation success and potential of Mojave and Colorado Desert sitesFinal Report to Department of Parks and Recreation, OffHighway Motor Vehicle Recreation Division: Sacramento, Calif., 77 p.

Several guides and decision-making tools have been developed at Joshua Tree National Park, 74485 National Park Drive, Twentynine Palms, CA 92277-3597. Phone: (760) 367-5500.

Bureau of Land Management Ridgecrest Field Office, $300 \mathrm{~S}$. Richmond Rd., Ridgecrest, CA, 93555, Phone: (760) 3845400, Fax: (760) 384-5499: http://www.blm.gov/ca/st/en/fo/ ridgecrest.html.

Soil Ecology and Restoration Group, San Diego State University: http://www.serg.sdsu.edu/SERG/index.html.

Racin (1988) published a report on revegetation of slopes along U.S. Highway 395 in Inyo and Mono Counties, California, with native plant seedlings: Racin, J.A., 1988, Revegetating desert cut slopes with containerized native shrubs: Sacramento, Calif., California Department of Transportation, FHWA/CA/TL-88.09 [http://www.dot.ca.gov/ newtech/researchreports/1981-1988/88-09.pdf].

Knute, A., and Faber, C., 1991, Plants of the east Mojave: Cima, Calif., Wide Horizons.

Lovich, J.E, and Bainbridge, D., 1999, Anthropogenic degradation of the southern California desert ecosystem and prospects for natural recovery and restoration: Environmental Management, v. 24, p. 309-326.

Rosentreter, R., Bowker, M., and Belnap, J., 2008, A field guide to biological soil crusts of western U.S. drylandsCommon lichens and bryophytes: Denver, Colo., U.S. Government Printing Office, 104 p. 


\section{Glossary}

Attributes are any living or nonliving features or processes of the environment that can be measured or estimated and that provide insights into the state of the ecosystem. The term indicator is reserved for a subset of attributes that is particularly information-rich, in the sense that their values are somehow indicative of the quality, health, or integrity of the larger ecological system to which they belong (Noon, 2003; science.nature.nps.gov/im/monitor/Glossary.cfm).

$\mathbf{C}_{\mathbf{3}}$ photosynthetic pathway: the most common biochemical pathway for plant photosynthesis, called $\mathrm{C}_{3}$, because $\mathrm{CO}_{2}$ is initially incorporated into a three-carbon compound. Because this pathway requires fewer enzymes and less specialized anatomy, and because stomata are open during the day, it is the most efficient in cooler, moister conditions.

$\mathbf{C}_{4}$ photosynthetic pathway: a photosynthetic pathway that is an adaptation to high light and arid conditions, in which $\mathrm{CO}_{2}$ is first incorporated into a four-carbon compound. Specialized anatomy and enzymes allow for rapid delivery of $\mathrm{CO}_{2}$ to the photosynthetic pathway, allowing stomata to be closed more than in $\mathrm{C}_{3}$ plants.

CAM photosynthetic pathway stands for Crassulacean Acid Metabolism; CAM is an adaptation to high light and aridity, because stomata are closed in the day and opened at night when evaporation rates are lower. The $\mathrm{CO}_{2}$ is stored in an acid at night and released inside the plant during the day to be broken down for photosynthesis. CAM plants are typically succulents like cactus and agave.

Degradation refers to an anthropogenically induced reduction in the capacity of a particular ecosystem or ecosystem component to perform desired ecosystem functions (for example, degraded capacity for conserving soil and water resources). Human actions may degrade desired ecosystem functions directly, or they may do so indirectly by damaging the capacity of ecosystem functions to resist or recover from natural disturbances and/or anthropogenic stressors (derived from the concepts of Herrick and others, 1995; Ludwig and others, 1997; Whisenant, 1999; Archer and Stokes, 2000; Whitford, 2002).

Disturbance is "...any relatively discrete event in time that disrupts ecosystem, community, or population structure and changes resources, substrate availability, or the physical environment" (White and Pickett, 1985, p. 7). In relation to monitoring, disturbances are considered to be ecological factors that are within the evolutionary history of the ecosystem (for example, drought). These are differentiated from anthropogenic factors (stressors, below) that are outside the range of disturbances naturally experienced by the ecosystem (Whitford, 2002).

Driver refers to a natural agent responsible for causing temporal changes or variability in quantitative measures of structural and functional attributes of ecosystems.

Ecological indicator is explained below. Please see indicator.

Ecological integrity refers to a concept that expresses the degree to which the physical, chemical, and biological components (including composition, structure, and process) of an ecosystem and their relations are present, functioning, and capable of self-renewal. Ecological integrity implies the presence of appropriate species, populations and communities and the occurrence of ecological processes at appropriate rates and scales as well as the environmental conditions that support these taxa and processes (science.nature.nps.gov/im/monitor/ Glossary.cfm).

Ecological site indicates a kind of land with specific physical characteristics, which differs from other kinds of land in its ability to produce distinctive types and amounts of vegetation and in its response to management (Society for Range Management Task Group on Unity in Concepts and Terminology, 1995, p. 279, http://www.rangelands.org/ram/ evaluating.shtml).

Ecological sustainability is the tendency of a system or process to be maintained or preserved over time without loss or decline (Dale and others, 2000, p. 642; see also sustainable ecosystem).

Ecosystem refers to a spatially explicit unit of the Earth that includes all of the organisms, along with all components of the abiotic environment within its boundaries (Likens, 1992, cited by Christensen and others, 1996, p. 670).

Ecosystem functioning refers to the flow of energy and materials through the arrangement of biotic and abiotic components of an ecosystem. It includes many ecosystem processes, such as primary production, trophic transfer from plants to animals, nutrient cycling, water dynamics, and heat transfer. In a broad sense, ecosystem functioning includes two components: ecosystem resource dynamics and ecosystem stability (Díaz and Cabido, 2001).

Ecosystem health is a metaphor pertaining to the assessment and monitoring of ecosystem structure, function, and resilience in relation to the notion of ecosystem "sustainability"

(following Rapport, 1998; Costanza and others, 1998). A healthy ecosystem is sustainable (see sustainable ecosystem). "Ecosystem sustainability" and "ecosystem quality" are preferable terms due to the confusion that "ecosystem health" conveys (Suter, 1993).

Ecosystem integrity is explained above. Please see ecological integrity.

Ecosystem management refers to the processes of land use decision making and land management practices that take into account the full suite of organisms and processes that characterize and comprise an ecosystem, and is based on the best understanding currently available as to how the ecosystem works. Ecosystem management includes a primary goal of sustainability of ecosystem structure and function, recognition that ecosystems are spatially and temporally dynamic, and acceptance of the dictum that ecosystem function depends on ecosystem structure and diversity (Dale and others, 2000, p. 642).

Ecosystem sustainability is explained below under Sustainable ecosystem.

Functional groups indicate groups of species that have similar effects on ecosystem processes (Chapin and others, 1996). This term is frequently applied interchangeably with functional types. 
Functional types are sets of organisms sharing similar responses to environmental factors, such as temperature, resource availability, and disturbance (= functional response types) or similar effects on ecosystem functions, such as productivity, nutrient cycling, flammability, and resistance/ resilience (= functional effect types; Díaz and Cabido, 2001).

Hydrologic function (upland systems) refers to the capacity of a site to capture, store, and safely release water from rainfall, run-on, and snowmelt, to resist a reduction in this capacity, and to recover this capacity following degradation (Pellant and others, 2000).

Hydrologic function (lotic and lentic systems) refers to the capacity of an area to dissipate energies associated with (1) high stream flow (lotic); or (2) wind action, wave action, and overland flow (lentic), thereby reducing erosion and improving water quality; to filter sediment, capture bedload, and aid floodplain development; to improve flood-water retention and groundwater recharge; to develop root masses that stabilize channel banks against cutting action; to develop diverse ponding and channel characteristics to provide the habitat and the water depth, duration, and temperature necessary for fish production, waterfowl breeding, and other uses; and to support greater biodiversity (from Prichard and others, 1998).

Indicator (general use of term) is a term reserved for a subset of environmental attributes that is particularly information rich, in the sense that their values are somehow indicative of the quality, health, or integrity of the larger ecological system to which they belong (Noon, 2003; http://science.nature.nps. gov/im/monitor/Glossary.cfm).

Indicators of ecosystem "health" (specific use of term) are measurable attributes of the environment (biotic or abiotic) that provide insights regarding (1) the functional status of one or more key ecosystem processes, (2) the status of ecosystem properties that are clearly related to these ecosystem processes, and/or (3) the capacity of ecosystem processes or properties to resist or recover from natural disturbances and/ or anthropogenic stressors (modified from Whitford, 1998). In the context of ecosystem health, key ecosystem processes and properties are those that are most closely associated with the capacity of the ecosystem to maintain its characteristic structural and functional attributes over time (including natural variability). See Suter (1993) for criticism of using the term "health".

Landscape refers to a spatially structured mosaic of different types of ecosystems interconnected by flows of materials (for example, water, sediments), energy, and organisms.

Major functional groups refers to organisms with similar effects on ecosystem functions, such as primary production, nutrient cycling, and soil stabilization, and functional response types-organisms with similar responses to environmental factors, such as climate, resource availability, natural disturbances, and land-use activities.

Measures refer to the specific variables used to quantify the condition or state of an Attribute or Indicator (or vital sign). These are specified in definitive sampling protocols. For example, stream acidity may be the indicator, while $\mathrm{pH}$ units are the measure (http://science.nature.nps.gov/im/monitor/ Glossary.cfm).
Rangeland indicates land on which the indigenous vegetation is predominantly grasses, grass-like plants, forbs, or shrubs, and is managed as a natural ecosystem. Rangelands include natural grasslands, savannas, shrublands, many deserts, tundra, alpine communities, marshes, and wet meadows (Society for Range Management, 1999). For purposes of this document, we further include pinyon-juniper woodlands and oak woodlands in this definition.

Resistance is the capacity of a particular ecological attribute or process to remain essentially unchanged from its reference state, despite exposure to a disturbance and/or stressor (adapted from Grimm and Wissel, 1997). Resistance is a dynamic property that varies in relation to environmental conditions (Scheffer and others, 2001).

Stability refers to the capacity of a site to limit redistribution and loss of soil resources (including nutrients and organic matter) by wind and water (Pellant and others, 2000).

State, as applied to state-and-transition models, is defined as "a recognizable, resistant and resilient complex of two components, the soil [or geomorphic] base and the vegetation structure" (Stringham and others, 2003, p. 109). These two ecosystem components interactively determine the functional status of the primary ecosystem processes of energy flow, nutrient cycling, and hydrology. States are dynamic and “... are distinguished from other states by relatively large differences in plant functional groups and ecosystem processes [including disturbance and hydrologic regimes] and, consequently, in vegetation structure, biodiversity, and management requirements" (Bestelmeyer and others, 2003, p. 116; also see threshold and transition.)

Stressor refers to any physical, chemical, or biological entity or process that can induce an adverse response (modified from the Environmental Monitoring and Assessment Program Master Glossary, http://www.epa.gov/emap/html/pubs/docs/ resdocs/mglossary.html). For purposes of monitoring, stressors are considered to be anthropogenic factors that are outside the range of disturbances naturally experienced by the ecosystem (Whitford, 2002). Compare stressor with disturbance, above.

Sustainable ecosystem indicates an ecosystem "...that, over the normal cycle of disturbance events, maintains its characteristic diversity of major functional groups, productivity, and rates of biogeochemical cycling" (Chapin and others, 1996, p. 1016).

Threshold, as applied to state-and-transition models, is a point "...in space and time at which one or more of the primary ecological processes responsible for maintaining the sustained [dynamic] equilibrium of the state degrades beyond the point of self-repair. These processes must be actively restored before the return to the previous state is possible. In the absence of active restoration, a new state ... is formed" (Stringham and others, 2003, p. 109). Thresholds are defined in terms of the functional status of key ecosystem processes and are crossed when capacities for resistance and resilience are exceeded. (Also see State and Transition.) 
Transition, as applied to state-and-transition models, is a trajectory of change that is precipitated by natural events and/ or management actions which degrade the integrity of one or more of the primary ecological processes responsible for maintaining the dynamic equilibrium of the state. Transitions are vectors of system change that will lead to a new state without abatement of the stressor(s) and/or disturbance(s) prior to exceeding the system's capacities for resistance and resilience (adapted from Stringham and others, 2003; also see state and threshold.)

Vital signs indicate a subset of physical, chemical, and biological elements and processes of ecosystems that are selected to represent the overall quality or condition of resources, known or hypothesized effects of stressors, or elements that have important human values. The elements and processes that are monitored are a subset of the total suite of natural resources that park managers are directed to preserve "unimpaired for future generations," including water, air, geological resources, plants and animals, and the various ecological, biological, and physical processes that act on those resources. Vital signs may occur at any level of organization, including landscape, community, population, or genetic level, and may be compositional (referring to the variety of elements in the system), structural (referring to the organization or pattern of the system), or functional (referring to ecological processes; http://science.nature.nps.gov/im/monitor/Glossary.cfm). 
This page intentionally left blank 
This page intentionally left blank 
골 흥

둥

舟

胥

$\sum_{0}$

कs

익

के

33

흥.

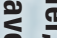

-

唡

3

$\overrightarrow{3}$

क क

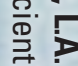

言

כ

格

क

ㅁ.
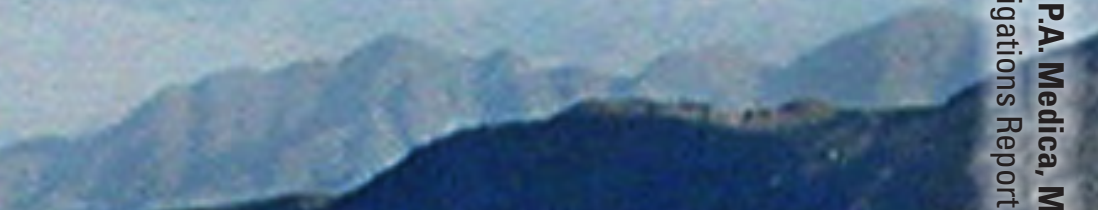

तु

3

N

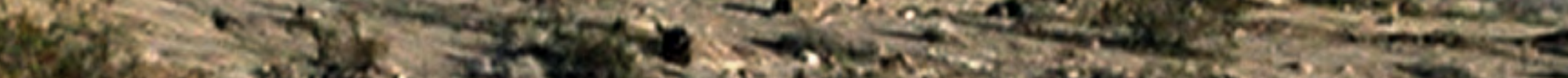

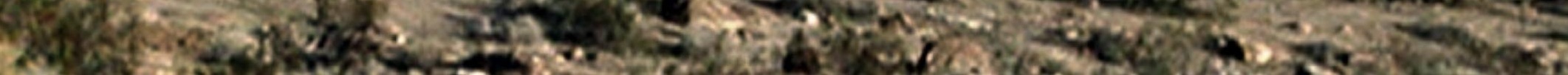

